\title{
SYNTHESIS AND CHARACTERIZATION OF FERROCENYL STANNANES AND POLYFERROCENYL STANNANES
}

\author{
by \\ Jonathan Ward \\ Bachelor of Science, Ryerson University, Toronto, Ontario, Canada, 2010 \\ A thesis \\ presented to Ryerson University \\ in partial fulfillment of the \\ requirements for the degree of \\ Masters of Science \\ in the program of \\ Molecular Science \\ Toronto, Ontario, Canada, 2013 \\ (O)(Jonathan Ward) 2013
}




\section{Author's Declaration}

I hereby declare that I am the sole author of this thesis.I authorize Ryerson University to lend this thesis to other insitutions of individuals for the purpose of scholarly research.

Name:

Signature:

I further authorize Ryerson University to reproduce this thesis by photocopying or by other means, in total or in part, at the request of other institutions or individuals for the purpose of scholarly research.

Name: Signature: 


\title{
SYNTHESIS AND CHARACTERIZATION OF FERROCENYL STANNANES AND POLYFERROCENYL STANNANES
}

\author{
Jonathan Ward \\ Masters of Science, Molecular Science, Ryerson University 2013
}

\begin{abstract}
A novel polymer polybis(dimethyl stannyl)ferrocene was synthesized through both metal catalyzed intermolecular dehydrogenative condensation and ring-opening polymerization. This polymer was the first evidence of a dibridged polyferrocenyl stannane, and was found to be of low to moderate molecular weight by gel permation chromatography and ${ }^{1} \mathrm{H}$ NMR spectroscopy. This polymer displayed extensive electronic communication observed previously synthesized monobridged ferrocenyl stannane polymers. The first tristanna-bridged [3.3]ferrocenophane was discovered through an amine coupling of a tin amine, and 1,1'bis(dimethyl stannyl) ferrocene. The [3.3]ferrocenophane displayed a strong interaction between connected ferrocenes despite the large distance, $(8.49 \AA$ A) between Fe centers. Finally, a new and improved synthesis of 1,1,2,2tetramethyldistanna-[2]ferrocenophane was found. This metal catalyzed intramolecular dehydrogenative coupling employs $\mathrm{Pd}_{2}(\mathrm{dba})_{3}$ as a catalyst and yields $90 \%$ product. All products were characterized where possible ${ }^{1} \mathrm{H},{ }^{13} \mathrm{C}$, and ${ }^{119} \mathrm{Sn}$ NMR and UV-Visible spectrocopy, as well as through cyclic voltammetry and DFT modeling.
\end{abstract}




\section{Acknowledgements}

Firstly, I would like to thank Dr. Daniel Foucher. His teaching and guidance for the past three years has been invaluable. It has been a pleasure being a part, and eventually a leader in his research group. As well, thank you to my committee members Dr Robert Gossage and Dr. Russell Viirre for their input throughout my research.

Next I would like to thank all the members of the Foucher research group, both past and present. Working with everyone has been challenging at times, although I have many fond memories of both working with, and distracting each other. Special thanks must be made to Damion Miles who helped train me, and Aman Khan who has been an excellent member of our group. I have worked with Aman for almost 5 years and have appreciated him as both a coworker and a friend.

Thanks must be made to all the undergraduate researchers that have helped in small parts to the ongoing project that I have been working on. Thanks to Patricia, Tamara, Katie and Shane. It has been a pleasure working with all of you, and I have found working with all of you both fun and entertaining.

Both Matthew Forbes and Timothy Burrow from the University of Toronto deserve both acknowledgement and thanks for their help with mass spectrometry and NMR spectroscopy. Thanks also to Dr. Brian Koivisto and Saif Al-Alul for the use of and support with cyclic voltammetry, as well as Shawn McFadden for this assistance with the equipment in the RUAC. Thank as well Dr. Russell Viirre for the continued upkeep and support of the NMR.

I must also thank all of my friends both in the research labs and abroad for their continued support and guidance throughout my graduate thesis. I would like to specially thank Robert Denning and Rama Sriharsha who have been friends through this ordeal.

Finally, thanks to the continued support of my parents, Martin and Gail Ward, my siblings, Bronwen and Matthew Ward. Thanks also to the three additions to our family, Alaura, my brother's beautiful wife, as well as Isabella and Skylynn, who were born during the making of this thesis. 


\section{Dedication}

This is dedicated to my parents Martin and Gail Ward, for their moral, emotional and (most importantly)

financial support 


\section{Table of Contents}

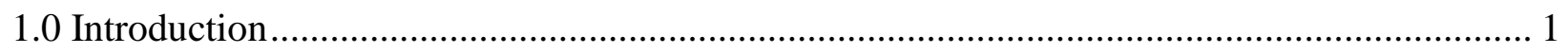

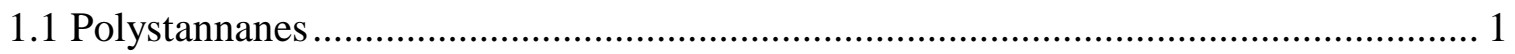

1.1.1 Synthesis........................................................................................ 2

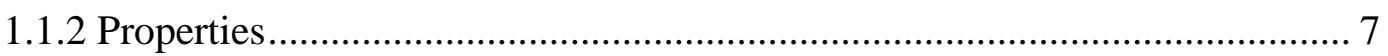

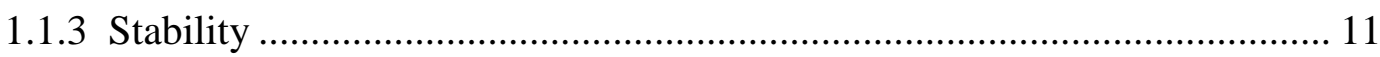

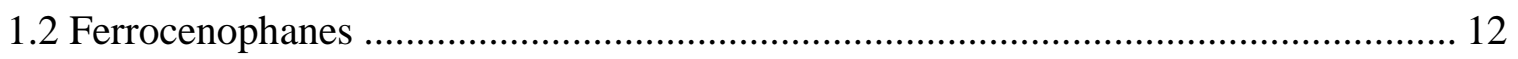

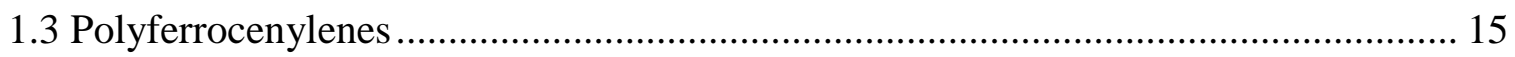

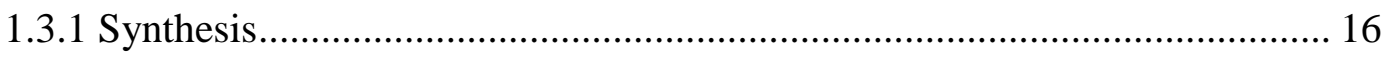

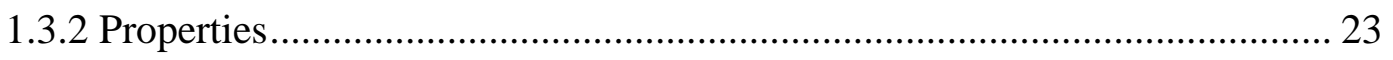

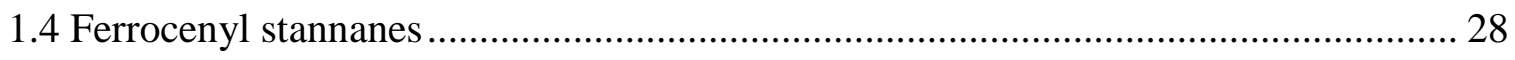

1.5 Polyferrocenyl stannanes .................................................................................. 33

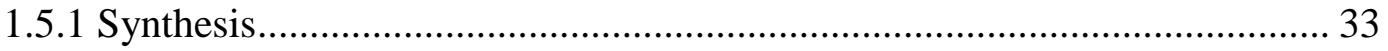

1.5.2 Properties.............................................................................................. 37

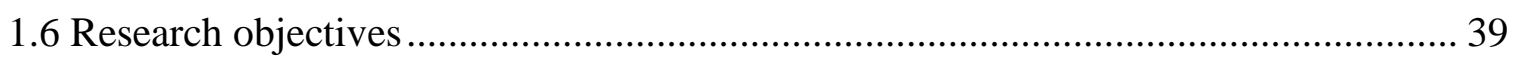

2.0 Polymerisation of Novel Polyferrocenyl Dimethyl Stannyl Polymers .................................... 40

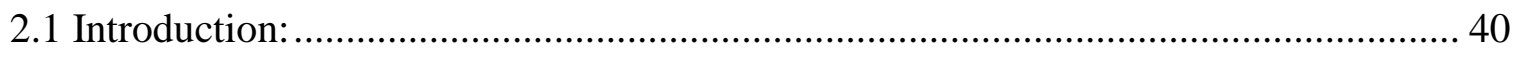

2.2 Results and discussion ................................................................................. 41

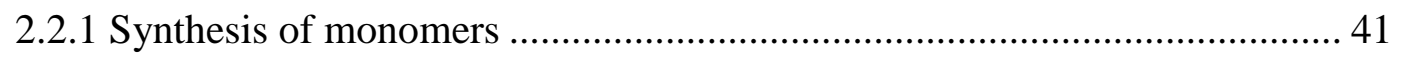




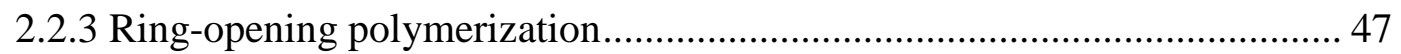

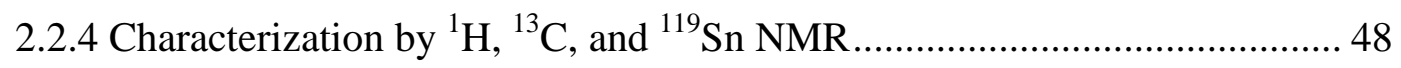

2.2.5 Molecular weight determination by GPC.............................................. 52

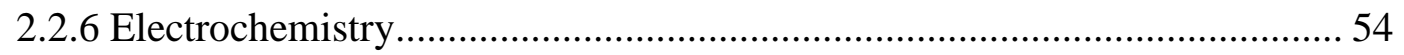

2.2.7 UV-Visible spectroscopy and DFT studies ........................................ 56

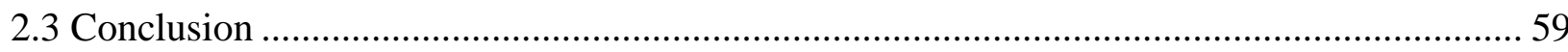

3.0 Synthesis and Spectral Electrochemical Properties of a Symmetrical Tristanna-Bridged

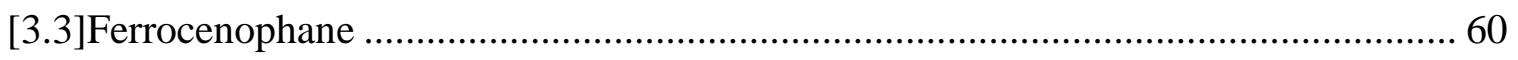

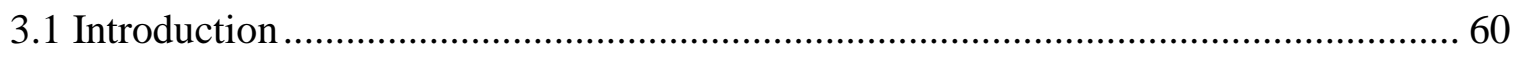

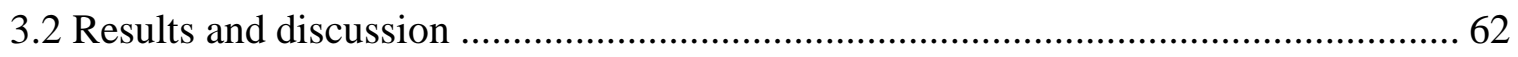

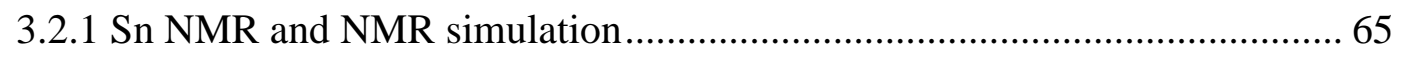

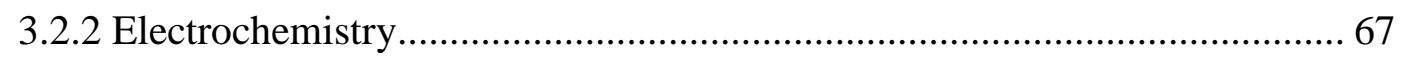

3.2.3 DFT modelling and UV-Vis spectroscopy ....................................... 70

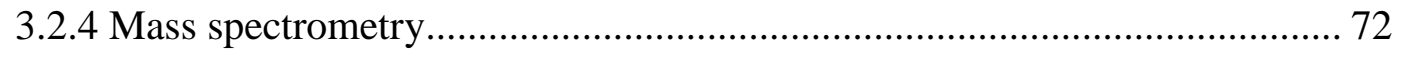

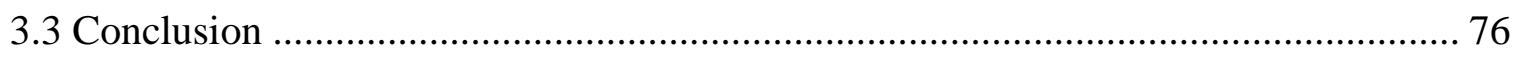

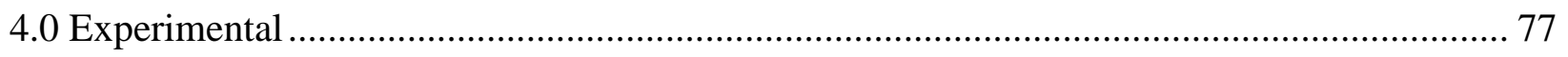

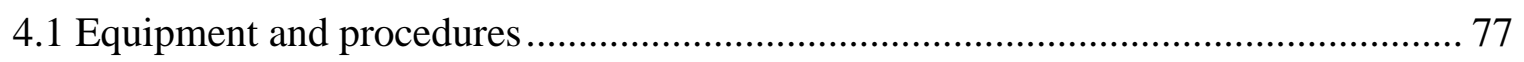

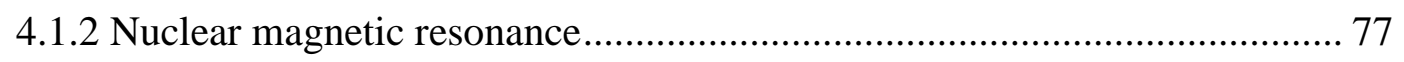

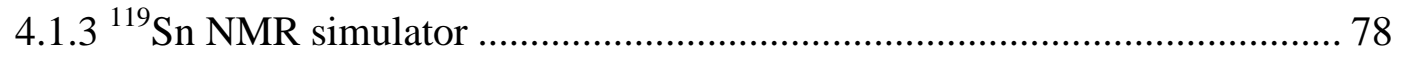


4.1.4 Cyclic voltammetry

4.1.5 Density functional theory calculations ................................................ 79

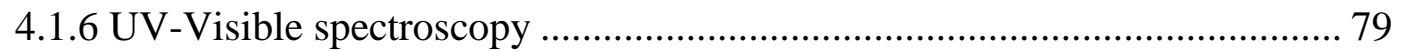

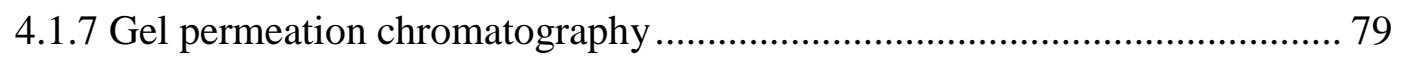

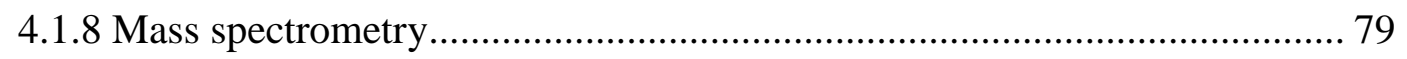

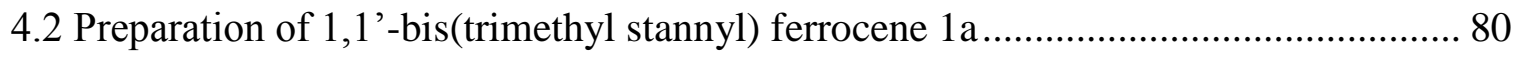

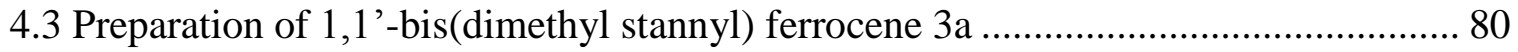

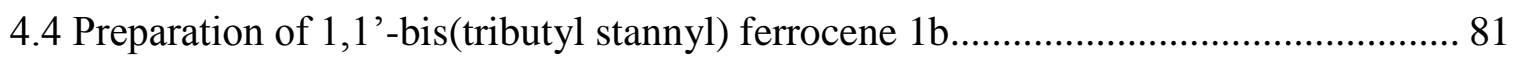

4.5 Attempted preparation of 1,1'-bis(chlorodi(n-butyl) stannyl) ferrocene $2 \mathrm{~b}$ through

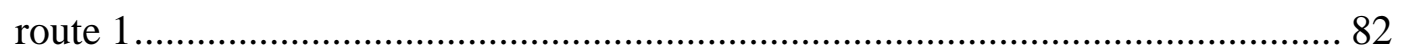

4.6 Attempted preparation of 1,1'-bis(chlorodi(n-butyl) stannyl) ferrocene $2 \mathrm{~b}$ through

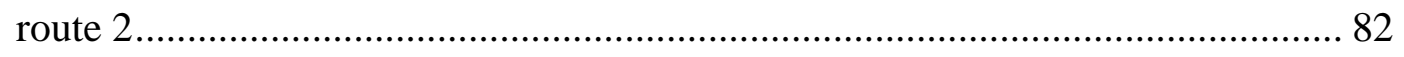

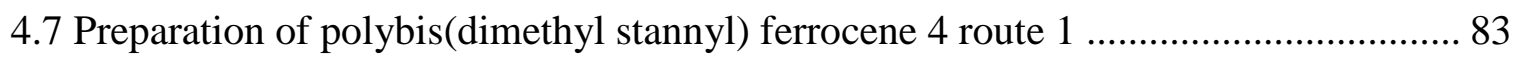

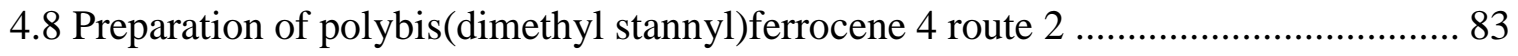

4.9 Ring-opening polymerization of 5a to form polybis(dimethyl stannyl) ferrocene 4 .. 84

4.10 Preparation of 1,1,2,2-tetramethyl-distannanediyl-[2]ferrocenophane 5a from the

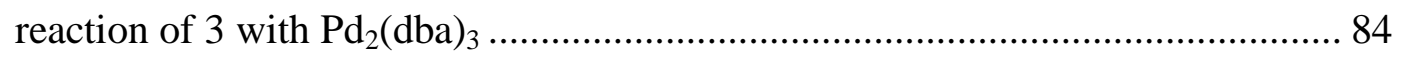

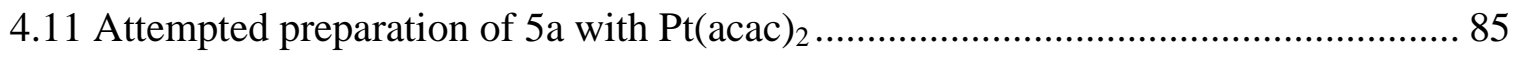

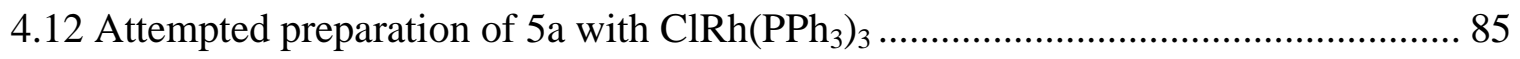

4.13 Preparation of 1,1,14,14-tetra-n-butyl-2,2,13,13,15,15,26,26-octamethyl1,2,13,14,15,26-hexastanna-[3.3]ferrocenophane 11 (low dilution) .................... 85 
4.14 Preparation of 1,1,14,14-tetra-n-butyl-2,2,13,13,15,15,26,26-octamethyl1,2,13,14,15,26-hexastanna-[3.3]ferrocenophane 11 (high dilution).................. 87

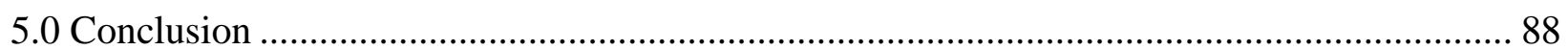

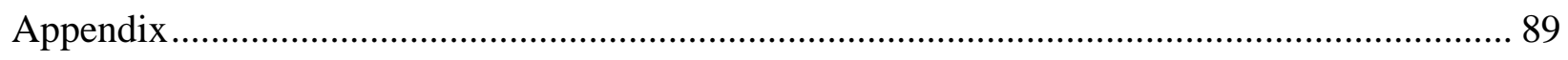

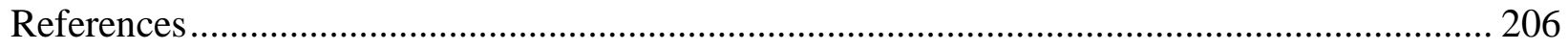

Glossary ...................................................................................Error! Bookmark not defined. 


\section{List of Tables}

$1.1 \quad$ UV-Vis of selected poly(diaryl)stannanes ....................................................... 4

$1.2 \quad$ UV-Vis of selected poly(diaryl)stannanes ...................................................... 8

1.3 Thermal transitions of alkyl Polystannanes ........................................................ 10

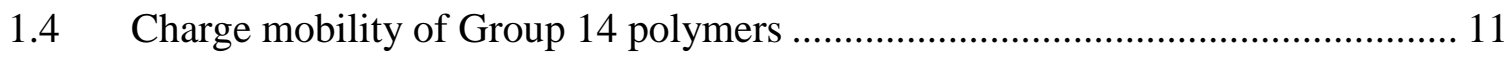

1.5 Structure, size and electrochemical data for bridged ferrocenylenes synthesised

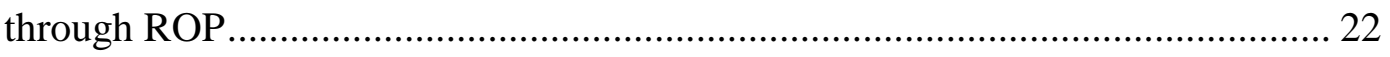

1.6 Glass transition temperature, $\lambda_{\max }$, and CV of various polyferrocenylenes......... 24

$1.7 \quad$ Refractive indices for various polyferrocenylenes .............................................. 26

$1.8 \quad$ Electronic properties of ferrocenyl stannanes ……………………………….... 38

2.1 Cyclic voltammetry of polyferrocenyl stannanes............................................. 55

3.1 Comparison of catalytic activity for main group and transition metalcatalysts in

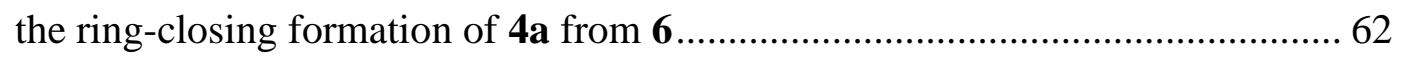

3.2 Half-potentials for bridged bisferrocenes and selected ferrocene polymers ......... 68

3.3 DART-TOF-MS relative abundance of mass fragments @ $200^{\circ} \mathrm{C}$ and $300^{\circ} \mathrm{C} . . . . . .75$ 


\section{List of Figures}

1.1 Three reaction routes for the synthesis of polystannanes..................................... 2

1.2 Tilley's catalysts evaluated for the dehydrogentative coupling of $(n-\mathrm{Bu})_{2} \mathrm{SnH}_{2} \ldots .5$

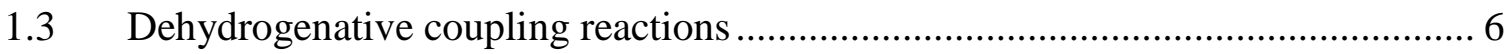

$1.4 \quad$ Basic structures of ferrocenophanes.............................................................. 12

1.5 Examples of the four routes to [n]ferrocenophanes ......................................... 13

1.6 Diagram of the ring strain of ferrocenophanes.................................................. 14

$1.7 \quad$ Reaction to synthesized [5.5]ferrocenophane ……......................................... 15

1.8 Proposed mechanism dehydrosilylation of 1,1'bis-(dimethylsilyl)ferrocene ....... 17

1.9 Structure of polyferrocenylenes, polyferrocenyl siloxanes, and polyferrocenyl

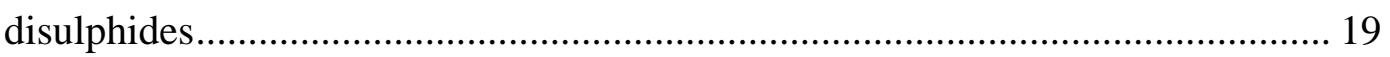

1.10 ROP of Group 14 [1]- and [2]ferrocenophanes ............................................... 20

1.11 General ROP of ferrocenylenes from ferrocenophanes ....................................... 22

1.12 Methods of preparation of ferrocenyl stannanes ............................................... 28

1.13 Routes to various $1,1^{\prime}$ 'bis(chlorostannyl)ferrocenes and $1,1^{\prime}$ 'bis(stannyl)-

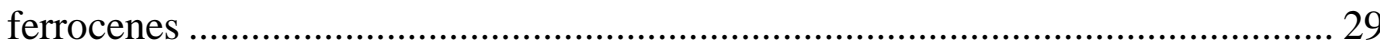

1.14 Synthesis of monolithioferrocene or monoiodoferrocene ..................................... 30

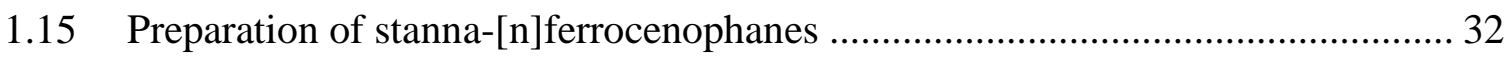

1.16 Synthesis of [1]ferrocenyl stannanes and ROP to form polyferrocenylstannane.. 34

1.17 Route to synthesis of alternating FcSnFcSi oligomers........................................ 35 
1.18 The synthesis of troticenophane monomer and assiociated ring opening

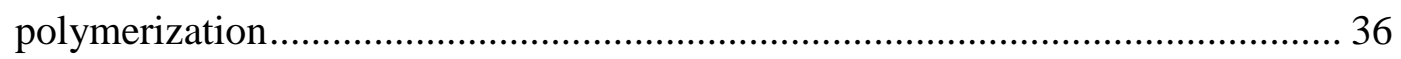

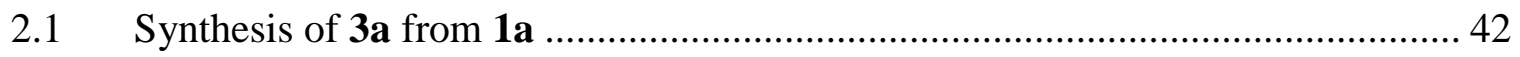

2.2 Metal catalyzed dehydrogenative coupling to form polyferrocenyl stannane 4 ... 44

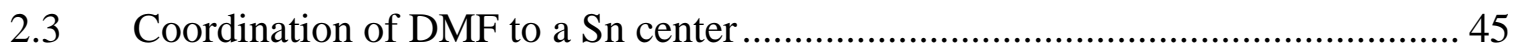

2.4 Dehydrogenative coupling reaction mechanism for 3a to form $4 \ldots \ldots \ldots \ldots \ldots \ldots \ldots . . . . . . . . . .66$

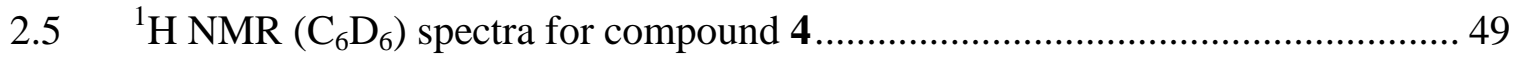

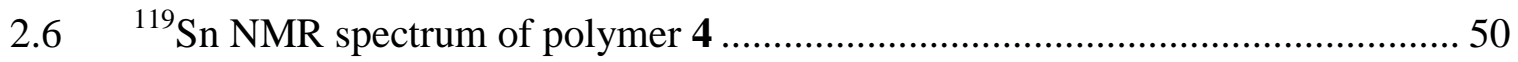

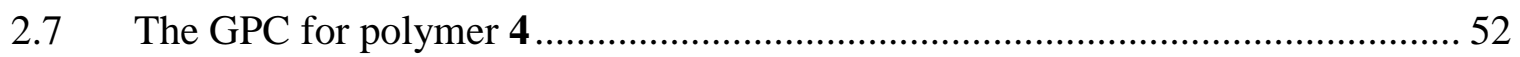

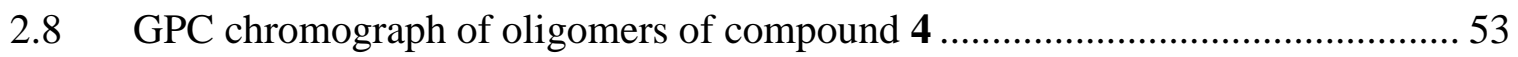

2.9 Cyclic voltammetry of compound 4 at scan rates ......................................... 54

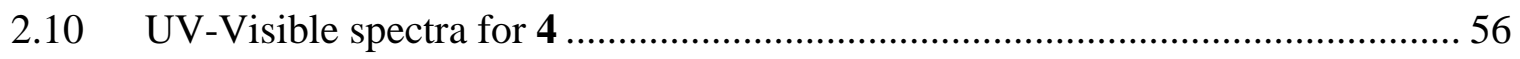

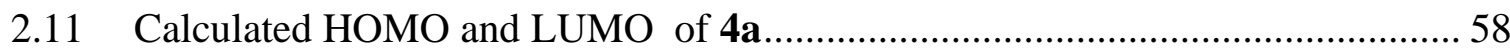

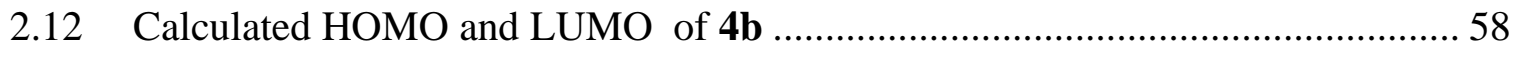

3.1 Previously made ferrocenyl stannanes and stannyl ferrocenophanes .................. 61

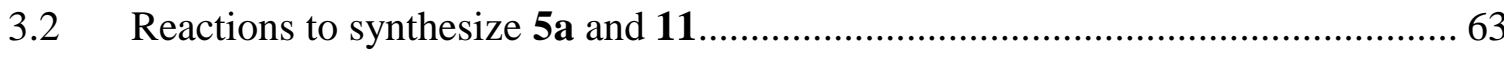

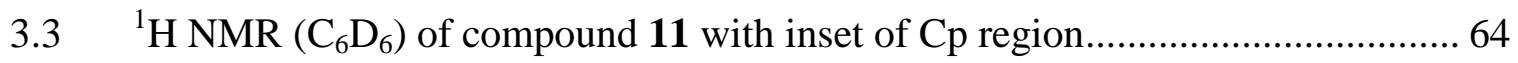

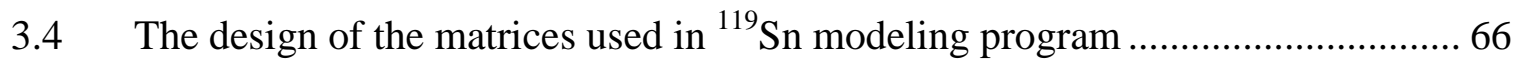

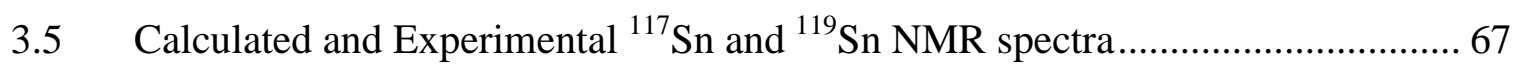

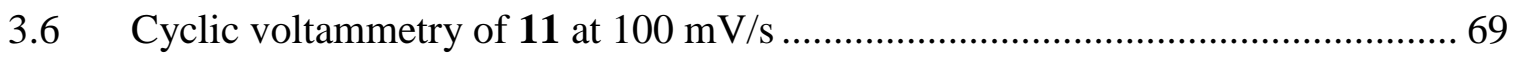


3.7 Structure of compound $\mathbf{1 2 a}-\mathbf{d}, \mathbf{1 3}, \mathbf{1 4}$, and $\mathbf{1 5}$.

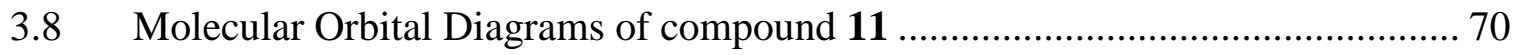

3.9 Comparison of calculated UV-Visible spectra for compounds $\mathbf{9 b}$ and $\mathbf{1 1}$ with

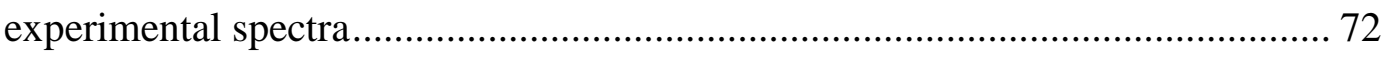

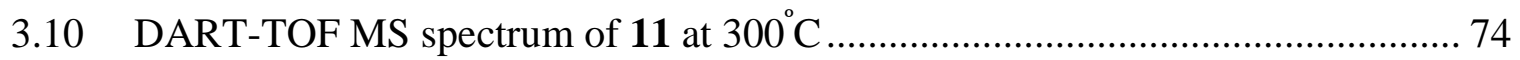




\section{List of Appendices}

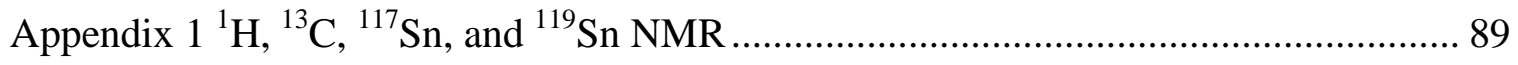

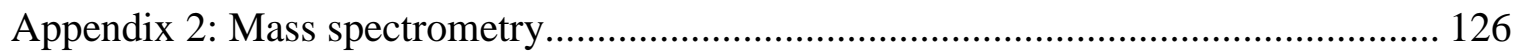

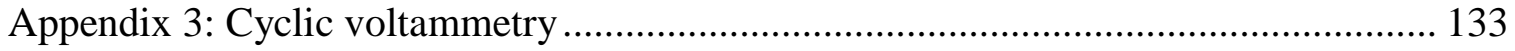

Appendix 4: Sn NMR simulator program for calculating isotopic intensities................ 134

Appendix 5: DFT .mol2 files for optimized structures .......................................... 164 


\section{List of Abbreviations}

\begin{tabular}{|c|c|}
\hline 15-crown-5 & 1,4,7,10,13-Pentaoxacyclopentadecane \\
\hline acac & acetylacetonate \\
\hline $\mathrm{Cp}$ & Cyclopentadiene \\
\hline $\mathrm{CV}$ & Cyclic voltammetry \\
\hline DART & Direct analysis in real time \\
\hline DCM & Dichloromethane \\
\hline $\mathrm{dba}$ & Debenzylideneacetone \\
\hline DFT & Density functional theory \\
\hline DMA & Dynamic mechanical analysis \\
\hline DMF & $N, N$-Dimethyl formamide \\
\hline$n$-Dod & Normal dodecyl \\
\hline DP & Intrinsic viscosity \\
\hline DSC & Differential scanning calorimetry \\
\hline $\mathrm{Et}_{2} \mathrm{O}$ & Diethyl ether \\
\hline GPC & Gel permeation chromatography \\
\hline HMO & Sandorf/Huckel molecular orbital approximation \\
\hline LDF & First principles local density functional method \\
\hline Lineweaver-Burk & $\begin{array}{l}\text { Correlation reacted to the linear reciprocal of the energy against } \\
\text { the length }\end{array}$ \\
\hline LSDA & Local spin density approximation \\
\hline $\mathrm{MeCN}$ & Acetonitrile \\
\hline $\mathrm{MeOH}$ & Methanol \\
\hline $\mathrm{M}_{\mathrm{n}}$ & Number average molecular weight \\
\hline MS & Mass spectrometry \\
\hline $\mathrm{M}_{\mathrm{w}}$ & Weight average molecular weight \\
\hline NMR & Nuclear magnetic resonance \\
\hline
\end{tabular}




$\begin{array}{ll}\text { OTf } & \text { Trifluoromethanesulfonate } \\ \text { PDI } & \text { Polydispersity index } \\ \text { PiPP } & \text { Triisopropylphenyl } \\ \text { PMDTA } & N, N, N^{\prime}, N^{\prime}, N^{\prime \prime} \text {-pentamethyldiethylenetriamine } \\ \text { RALS } & \text { Right angle light scattering } \\ \text { RI } & \text { Refractive index } \\ \text { ROP } & \text { Ring-opening polymerization } \\ \text { SDD } & \text { Dunning/Huzinaga full double zeta up to Ar, Stuttgart/Dresden } \\ \text { electron core potential } \\ \text { Tg } & \text { Glass transition temperature } \\ \text { TD-DFT } & \text { Time dependent density functional theory } \\ \text { THF } & \text { Tetrahydrafuran } \\ \text { TLC } & \text { Thin layer chromatography } \\ \text { TMEDA } & N, N, N \text { ', } N \text { '-Tetramethylethylenediamine } \\ \text { TOF } & \text { Time of flight } \\ \text { UV-Vis } & \text { Ultra violet-visible spectroscopy } \\ \text { ZPE } & \text { Zeroint energy }\end{array}$




\subsection{Introduction}

Polymers are everywhere and are connected to every facet of our modern world. From commodity plastics and rubbers to speciality elastomers and films for use in corrective optics, electronics and engineered materials, polymers are highly visible in everyday life. Within the modern study of polymers, the inorganic and organometallic polymer subset continues to be the basis of important research due to their unusual structural, optical, thermal, and electronic properties. The field of inorganic polymers is so prevalent in materials chemistry today that more than one thousand ${ }^{*}$ review articles and at least one book ${ }^{1}$ have been published on this topic. These polymers have been prepared through a variety of polymerization methods, some of which will be described in the following sections.

\subsection{Polystannanes}

Tin, as far as we know, is the only metal that has the ability to form covalently bonded oligo- and polymeric structures. The unique structural features and unusual electronic properties of polystannanes distinguish them from other Group 14 polymers. There have been at least 2 review articles in the past 12 years on the topic of polystannanes, ${ }^{2,3}$ however due to their relative lack of stability, there has been considerably less recent research into these systems compared to other more stable inorganic polymeric systems.

Polystannanes were likely first discovered in the mid- $19^{\text {th }}$ century and have been synthesized via a variety of routes throughout the last 150 years. $^{3}$ The modern era of polystannanes began in the 1980s with the discovery by Zou et al. ${ }^{4}$ of the Wurtz coupling of

\footnotetext{
* A search of the Scopus database found 1046 review articles on the topic of inorganic polymers. Similarly, a search of the ISI Web Of Knowledge database found 711 inorganic polymer review articles.
} 
dichlorostannanes. Polystannanes have also been successfully prepared by the groups of Price, ${ }^{5}$ Okano, ${ }^{6,7}$ Tilley, ${ }^{8-11}$ Sita, ${ }^{12}$ Caseri, ${ }^{13-16}$ and Foucher. ${ }^{17}$ The methods used by these groups will be discussed in detail in Section 1.1.1.

\subsubsection{Synthesis}

There are three major routes to the preparation of polystannanes (Figure 1.1); Wurtz coupling, electrochemical coupling, and dehydrogenative coupling. In most of these methods, there is often an impurity of 5- and 6-membered cyclic oligomers formed. These impurities are readily identified through ${ }^{119}$ Sn NMR spectroscopy as the polymer will, in most cases, have a lower field signal than the corresponding cyclic oligomers.

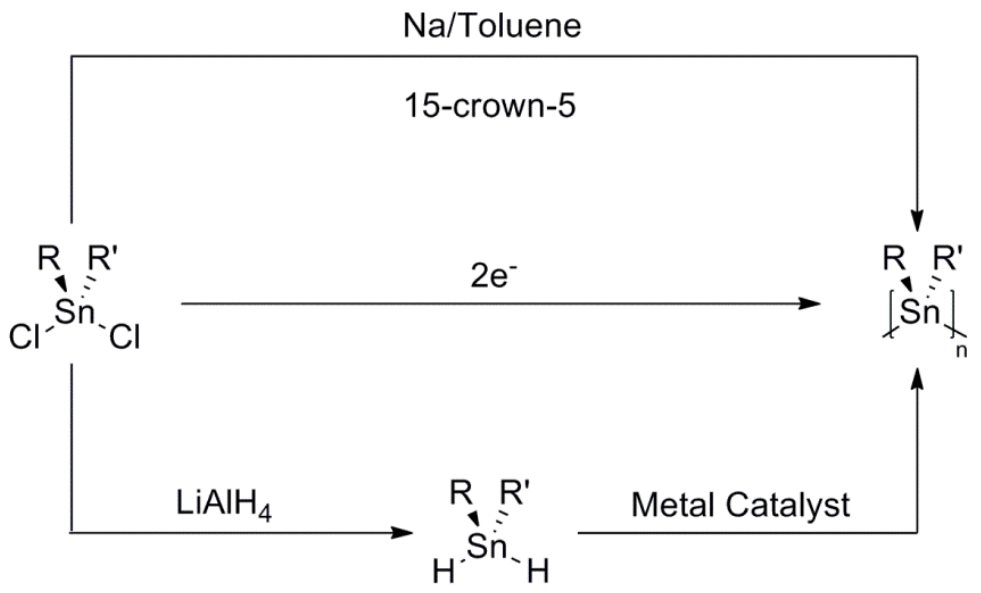

Figure 1.1: Three reaction routes for the synthesis of polystannanes from dichlorostannanes a) Wurtz coupling, b) electrochemical coupling c) reduction of dichlorostannane to form tin dihydrides followed by dehydrogenative coupling.

The preparation of suitable tin-containing monomers for polymerization by either Wurtz or electrochemical coupling (tin dichlorides) or dehydrogenative coupling (tin dihydrides) is well established (Figure 1.1). There are several known syntheses for the preparation of tin chlorides

${ }^{*}\left[\mathrm{Bu}_{2} \mathrm{Sn}\right]_{\mathrm{n}}$ shows a ${ }^{119} \mathrm{Sn}$ NMR peak at $-190 \mathrm{ppm}$ whereas the cyclic $\left(\mathrm{Bu}_{2} \mathrm{Sn}\right)_{5}$ species shows a ${ }^{119} \mathrm{Sn}$ NMR signal at 202 ppm. 
including the controlled thermal redistribution of $\mathrm{R}_{4} \mathrm{Sn}(\mathrm{R}=$ alkyl, aryl $)$ and $\mathrm{SnCl}_{4}$. These reactions are carried out in the absence of solvent and at relatively low temperatures $\left(<120^{\circ} \mathrm{C}\right)$ to form monochlorides $\left(\mathrm{R}_{3} \mathrm{SnCl}\right)$, or at higher temperatures $\left(>120^{\circ} \mathrm{C}\right)$ where the formation of dichlorides $\left(\mathrm{R}_{2} \mathrm{SnCl}_{2}\right)$ becomes more prevalent. These tin dichlorides can then be used for polymerization by Wurtz or electrochemical coupling or further reacted with reducing agents, such as $\mathrm{LiAlH}_{4}$, to form mono- or di- tin hydrides, $\left(\mathrm{R}_{3} \mathrm{SnH}\right.$ or $\left.\mathrm{R}_{2} \mathrm{SnH}_{2}\right)$, the latter of which can be used as a monomer for dehydrogenative polymerization. Tin dialkyl and diaryl dibromides have also been prepared using $\mathrm{Br}_{2}$ as a brominating agent with $\mathrm{R}_{4} \mathrm{Sn}$. Tin dibromides can then be reduced to form tin dihydrides suitable for polymerization. ${ }^{18}$

Wurtz coupling is a reductive process by which a radical is formed from a halogenated species, which goes on to react with a second halogenated species through a method of radical chain growth. Originally carried out in the presence of molten sodium, Zou et al. ${ }^{4}$ modified the Wurtz coupling of dichlorostannanes to employ considerably less harsh conditions. The reaction that Zou performed using toluene as the solvent is carried out first via dispersion of $\mathrm{Na}$ metal at reflux with the help of 15 -crown-5. The reaction is then brought down to a temperature of $60^{\circ} \mathrm{C}$ and the tin dichloride monomer slowly added in additional toluene over several hours. The method was further improved by Price et $a l .{ }^{5}$ who showed that shorter reaction times are a key factor in increasing the size and lowering the dispersity of the polymers formed as well as reducing the percent impurity of cyclic oligomers. An optimal reaction period of $4 \mathrm{~h}$ was found to yield the highest molecular weight polystannanes ${ }^{*}$ with the lowest amount of cyclic oligomers formed (Table 1.1). Wurtz type coupling has also been used to produce co-polymers containing both silicon and tin within the backbone. ${ }^{19,20}$

\footnotetext{
* Examples from the of Wurtz coupling prepared $\left[\mathrm{R}_{2} \mathrm{Sn}\right]_{n}$ where $\mathrm{R}=n-\mathrm{Bu}$ or $\mathrm{Ph}$.
} 
Table 1.1: Wurtz Coupling of $(n-\mathrm{Bu})_{2} \mathrm{SnCl}_{2}$ in toluene at $60^{\circ} \mathrm{C}$ as a function of time. ${ }^{5}$

\begin{tabular}{cccc}
\hline Time (h) & $\mathbf{M}_{\mathbf{n}}\left(\times \mathbf{1 0}^{\mathbf{6}}\right)(\mathbf{D a})$ & $\mathbf{M}_{\mathbf{n}} / \mathbf{M}_{\mathbf{w}}$ & $\mathbf{R}^{\mathbf{a}}$ \\
\hline $\mathbf{1}$ & 1.15 & 1.3 & 0.25 \\
$\mathbf{2}$ & 1.17 & 1.3 & 0.33 \\
$\mathbf{4 . 2}$ & 1.09 & 1.4 & 0.80 \\
$\mathbf{5 . 5}$ & 0.91 & 1.3 & 0.10
\end{tabular}

${ }^{a}$ Ratio of high molecular weight polymer to cyclic oligomers at $1000 \mathrm{Da}$

Wurtz coupling of polystannanes was also carried out by Caseri et al. ${ }^{13}$ in a solution of liquid ammonia at $-78^{\circ} \mathrm{C}$. Wurtz coupling was achieved by a one (all monomer added in one aliquot) or two (monomer separated into two aliquots and added in steps) step methods. Using these processes, Caseri was able to prepare both polymers and copolymers of butyl and phenyl tin systems, with molecular weights $\approx 1 \times 10^{4}$ Da and PDIs of between 2.2 and 3.8.

A more recently discovered route to the preparation of polystannanes was via electrolysis. This was accomplished by Okano et al. ${ }^{6}$ in 1998 who electrochemically reduced $\mathrm{R}_{2} \mathrm{SnCl}_{2}(\mathrm{R}=n$ - $\mathrm{Bu}, n$-Oct $)$ to form the associated polymers. This was achieved in a one compartment cell fitted with a syringe port, a Pt anode and an Ag cathode with tetra- $n$ butylammonium perchlorate as the supporting electrolyte in 1,2-dimethoxyethane. Molecular weights of the polydi(n-butyl)stannanes, $\left(\left[(n-\mathrm{Bu})_{2} \mathrm{Sn}\right]_{n}\right)$, were found to be between $6 \times 10^{3}$ $1.2 \times 10^{4}$ Da with PDIs ranging from 1.3-2.6 respectively, depending on the current efficiency. These reactions were also performed with $\mathrm{RSnCl}_{3}(\mathrm{R}=\mathrm{Me}, n$-Bu, $n$-Oct, $\mathrm{Ph})$ that showed the formation of ladder polystannanes. ${ }^{7}$ These polymers were of the chemical formula $\left[\mathrm{RSnCl}_{\mathrm{x}}\right]_{\mathrm{n}}$ where $\mathrm{x}$ is between 0 and 2. Polystannanes formed this way were not fully characterized,

\footnotetext{
* PDI dependent on substituent and backbone structure.
} 
however they display a UV-visible spectra tailing well into the visible range $(850 \mathrm{~nm})$ with no identifiable peak, indicative of an amorphous network.

Dehydrogenative coupling is the more common method for the synthesis of polystannanes. This involves building Sn-Sn $\sigma$-bonds by the elimination of hydrogen gas. First demonstrated by Tilley et al., ${ }^{8}$ dehydrogenative coupling was successfully achieved using neat $(n-\mathrm{Bu})_{2} \mathrm{SnH}_{2}$ or $\mathrm{Ph}_{2} \mathrm{SnH}_{2}$ dihydrides with a zirconocene based catalyst, $\left[\mathrm{Zr}\left(\eta^{5}-\mathrm{C}_{5} \mathrm{H}_{5}\right)\left(\eta^{5}-\right.\right.$ $\left.\left.\mathrm{C}_{5} \mathrm{Me}_{5}\right)\left(\mathrm{Si}\left(\mathrm{SiMe}_{3}\right)_{3}\right) \mathrm{Me}\right]$, in the absence of light. After $5 \mathrm{~h}$, the resulting polymer was precipitated in dry methanol yielding a linear polystannane.

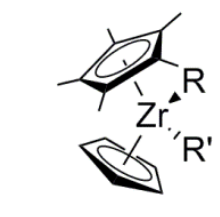

a

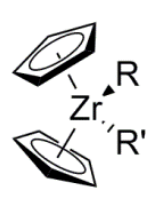

b

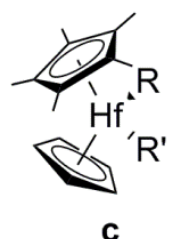

c

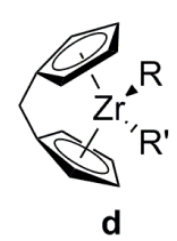

1) $\left.\mathrm{R}=\mathrm{Si}\left(\mathrm{SiMe}_{3}\right)_{3}, \mathrm{R}^{\prime}=\mathrm{Me} 2\right) \mathrm{R}=\mathrm{Si}\left(\mathrm{SiMe}_{3}\right)_{3}, \mathrm{R}^{\prime}=\mathrm{Cl}$ 3) $\mathrm{R}=\mathrm{Me}, \mathrm{R}^{\prime}=\mathrm{Me}$

Figure 1.2: Tilley's catalysts evaluated for the dehydrogentative coupling of $(n-\mathrm{Bu})_{2} \mathrm{SnH}_{2}$. $\mathbf{1}(\mathbf{a}, \mathbf{b}, \mathbf{d}), \mathbf{2}(\mathbf{a}, \mathbf{b}, \mathbf{c}), \mathbf{3}(\mathbf{a}, \mathbf{b}, \mathbf{c})$ under various test conditions.

Tilley $^{9}$ used a defined protocol of adding the neat tin monomer to catalyst $(2 \mathrm{~mol} \%)$ under nitrogen and screened a series of zirconocene based catalysts (Figure 1.2) over different reaction times. These catalysts include various derivatives used in a prior study, ${ }^{9}$ as well as a cationic catalyst, and a catalyst loading with a small amount of solvent. The best polymerization result from this screening was with ansa-2-zirconocene (Figure 1.2, 1d) with $\mathrm{M}_{\mathrm{w}}=6.7 \times 10^{4} \mathrm{Da}$ after $11 \mathrm{~h}$. This catalyst showed a high degree of depolymerisation after $24 \mathrm{~h}$. Tilley was also able to polymerize a series of diaryl tin dihydrides to produce polymers of varying structures and molecular weights (Table 1.2). ${ }^{10}$ 
The zirconocene system ( $\mathrm{a} \mathrm{d}^{0}$ metal) was further studied mechanistically using a hafnium metallocene analogue due to the inability of the zirconocene system to trap intermediate species. ${ }^{11}$ This system showed an $\alpha-\mathrm{H}$ elimination, forming a free stannylene. This was immediately followed by insertion of the stannylene between the $\mathrm{SnH}$ bond.

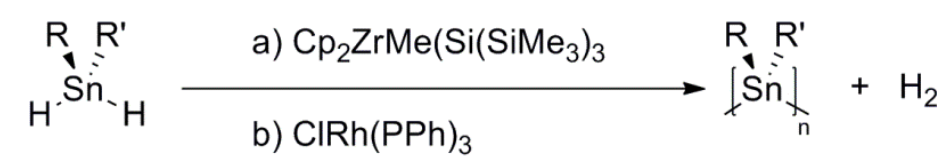

Figure 1.3: Dehydrogenative coupling reactions by a) Tilley $^{9}$ and b) Caseri $^{14,15}$ to synthesize $\left[\mathrm{R}_{2} \mathrm{Sn}\right]_{\mathrm{n}}$.

Sita $^{12}$ and Caseri $^{14,15}$ were also able to synthesis polystannanes through a dehydrogenative coupling reaction involving secondary tin hydrides and rhodium catalysts, $\mathrm{CORh}^{\mathrm{I}}\left(\mathrm{PPh}_{3}\right)_{3} \mathrm{H}$ and $\mathrm{ClRh}^{1}\left(\mathrm{PPh}_{3}\right)_{3}$ (Figure 1.3). Sita, using the same reaction protocol as Tilley was able to make highly branched systems that contained cyclic oligomers within the reaction mixture. Caresi was able to demonstrate good molecular weight control by adding the dialkyl tin monomer drop wise to the Wilkinson's catalyst in DCM, driving the reaction to completion without the production of cyclic oligomers and forming high molecular weight linear $[(n$ $\left.\mathrm{Bu})_{2} \mathrm{Sn}\right]_{\mathrm{n}}$. The polymer was then isolated from solution by cooling the DCM reaction solution. Caseri, ${ }^{16}$ using the same conditions, prepared a series of dialkylstannyl hydrides (Et, $n$-Pr, $n$-Bu, $n$-Pe, $n$-Hex, $n$-Oct, $n$-Dod) that readily formed poly(dialkyl)stannanes using Wilkinson's catalyst. These polymers had $\mathrm{M}_{\mathrm{w}} \approx 10^{4}$ Da and PDIs ranging from 1.5-2.7.

There has been some evidence in the literature indicating that dehydrogenative coupling occurs with other catalytic systems including platinum complexes, ${ }^{21,22}$ Group 4 metallocenes, Group 6 carbonyl complexes, ${ }^{23,24}$ and lanthanide species. $^{25}$ The majority of these systems produced only dimers or small oligomers. The notable exception to this is the platinum complex 
$\left[\left(\kappa^{2}-\mathrm{P}, \mathrm{N}\right)-\mathrm{Ph}_{2} \mathrm{PC}_{2} \mathrm{H}_{4} \mathrm{NMe}_{2}\right] \mathrm{PtMe}_{2}$ from Schubert et al. ${ }^{21,22}$ Using ${ }^{119} \mathrm{Sn}$ NMR spectroscopy they were able to demonstrate that they could synthesize $\left[(n-\mathrm{Bu})_{2} \mathrm{Sn}\right]_{\mathrm{n}}$ with no cyclic oligomers. However, no further research of this system was completed beyond the initial NMR studies.

Foucher et $a l .{ }^{17}$ demonstrated the catalyst free thermally driven dehydrogenative coupling of $(n-\mathrm{Bu})_{2} \mathrm{SnH}_{2}$ to form $\left[(n-\mathrm{Bu})_{2} \mathrm{Sn}\right]_{\mathrm{n}}$. These solvent and catalyst free reactions were carried out under reduced pressure for a period of $6 \mathrm{~h}$. Modest molecular weights $\left(1.8 \times 10^{4} \mathrm{Da}\right)$ and broad polydispersities $(\mathrm{PDI}=6.9)$ were observed through GPC. There was a significant fraction $(20 \%)$ of low molecular weight cyclic oligomers also formed.

\subsubsection{Properties}

Polystannanes are covalently bonded main group metal polymers with interesting properties. Optically, poly(dialkyl)stannanes range from yellow to orange semi-solids. The $\lambda_{\max }$ of $\left[(n-\mathrm{Bu})_{2} \mathrm{Sn}\right]_{\mathrm{n}}$ is at $382 \mathrm{~nm}$ with the $\lambda_{\max }$ values of $360-400 \mathrm{~nm}$ for other alkyl polymers ranging from Et to $n$-Dod substituents. Oligostannanes of diethyl tin $\left(\left[\mathrm{Et}_{2} \mathrm{Sn}\right]_{2-6}\right)$, show a trend towards redshifting from $232 \mathrm{~nm}$ to $325 \mathrm{~nm}$ (UV to visible) as the chains become increasingly longer. ${ }^{26}$ Similarly, $\left[\mathrm{Ph}_{2} \mathrm{Sn}\right]_{\mathrm{n}}\left(\right.$ low $\mathrm{M}_{\mathrm{w}}$ in $\left.\mathrm{THF}^{*}\right)$ is slightly redshifted $\left(\lambda_{\max }=402 \mathrm{~nm}\right)$ compared to dialkyl species. ${ }^{9}$ The addition of different aryl substituents was able to further decrease the band gap of these polystannanes and redshift the $\lambda_{\max }$ of these materials from red to green. ${ }^{10}$ These polymers show $\lambda_{\max }$ values of $432-506 \mathrm{~nm}$ as seen in Table 1.2 .

\footnotetext{
* high molecular weight poly(diphenyl)stannane is insoluble.
} 
Table 1.2: UV-Vis of selected $\left[\mathrm{R}_{2} \mathrm{Sn}\right]_{\mathrm{n}}$.

\begin{tabular}{|c|c|c|}
\hline Substituent $^{\mathrm{a}}$ & Color & $\lambda_{\max }(\mathbf{n m})^{\mathrm{b}}$ \\
\hline$\overline{\mathrm{C}_{6} \mathrm{H}_{5}}$ & Yellow & 402 \\
\hline$p-(t-B u)-C_{6} \mathbf{H}_{4}$ & Orange & 432 \\
\hline$p$-(n-Hex $)-\mathrm{C}_{6} \mathrm{H}_{4}$ & Yellow-orange & 436 \\
\hline$o-\mathrm{Et}-\mathrm{C}_{6} \mathrm{H}_{4}$ & Red-orange & $468^{\mathrm{c}}$ \\
\hline$p-\left(n-\mathrm{BuO}-\mathrm{C}_{6} \mathrm{H}_{4}\right.$ & Orange & 448 \\
\hline$o$-Et-p-(n-Bu)O-C $\mathrm{C}_{6} \mathrm{H}_{4}$ & Dark red & 506 \\
\hline$p-\left(\mathrm{Me}_{3} \mathrm{Si}\right)_{2} \mathrm{~N}-\mathrm{C}_{6} \mathrm{H}_{4}$ & Green & 450 \\
\hline
\end{tabular}

${ }^{a}$ All compounds have the structure $\left[\mathrm{R}_{2} \mathrm{Sn}\right]$ where $\mathrm{R}=$ the substituent. ${ }^{\mathrm{b}}$ Extintion coefficents where not reported for these polymers ${ }^{\mathrm{c}}$ Insoluble therefore the $\lambda_{\max }$ of film was reported instead.

The electronics of polystannanes have been modelled via Sandorfy $\mathrm{HMO}^{27}$ and $\mathrm{LDF}^{28}$ level calculations. When the calculated band gap energies of polystannanes are compared to those of polysilanes $(\mathrm{PSi}=3.89 \mathrm{eV})$ and polygermanes $(\mathrm{PGe}=3.31 \mathrm{eV})$, polystannanes are considerably lower $(\mathrm{PSn}=2.80 \mathrm{eV})$ based on an all 'trans-planar' $(\mathrm{TP})$ geometry. ${ }^{\text {. Calculations }}$ using a 'gauche-helix' (GH) geometry ${ }^{* *}$ lead to larger band gaps following the same trend as the TP geometry $(\mathrm{PSi}=5.94 \mathrm{eV}, \mathrm{PGe}=5.13 \mathrm{eV}, \mathrm{PSn}=4.65 \mathrm{eV})$. A correlation between the length of the system and the band gap was observed showing a rapid increase slowing towards a horizontal asymptote following a Lineweaver-Burk plot. ${ }^{29}$

In these calculations, the molecular orbitals that were associated with the HOVB (Highest Occupied Valence Band) and the LUCB (Lowest Unoccupied Conduction Band) were found.

\footnotetext{
${ }_{*}^{*}$ Trans-planar geometry is a zigzag confirmation with a $\mathrm{Sn}-\mathrm{Sn}-\mathrm{Sn}$-Sn torsion angle equal to zero.

** Gauche-helix geometry is a coil confirmation with a $\mathrm{Sn}-\mathrm{Sn}-\mathrm{Sn}-\mathrm{Sn}$ torsion angle larger than zero.
} 
The HOVB structurally exhibits a $\sigma \sigma$ characteristic between $5 p_{x}$ orbitals of neighbouring tins. The LUCB shows $\sigma^{*}$ characteristic of the $5 \mathrm{p}_{\mathrm{y}}$ and $5 \mathrm{~s}$ orbitals.

Bond lengths and angles of polystannanes are heavily dependent on the nature of the side chain substituent. Sn-Sn bond lengths are generally longer with larger substituents, such as $\left(\mathrm{Me}_{3} \mathrm{Si}\right)_{2} \mathrm{HC}$ or $t-\mathrm{Bu}$. Larger substituents also distort the tetrahedral nature of the $\mathrm{Sn}$ center by increasing bond angles. The changes in bond lengths and bond angles directly correlates to observable and electronic properties such as UV-Vis (band gap), IR/Raman (resonance), NMR chemical shifts, as well as the Sn-Sn coupling in the ${ }^{119} \mathrm{Sn}$ NMR spectroscopy. This was first studied with model compounds by Dräger $e t a l .^{30}$ who explored the electronic and structural properties of tin dimers, trimers, and tetramers. Generally, band gaps were found to decrease with longer Sn-Sn bonds and larger Sn-Sn-Sn angles resulting in a red-shifting of the UV-Vis spectra.

${ }^{119} \mathrm{Sn}$ NMR signals are closely related to the nature and type of substituents at the tin center. Methyl systems display a larger shielding than $n$-butyl, while $t$-butyl substituents result in even greater deshielding. Dräger also found that the experimental ${ }^{119} \mathrm{Sn}$ NMR Sn-Sn ${ }^{1} J$ coupling also correlated to bond length while the ${ }^{2} J$ coupling correlated to bond angle. ${ }^{30}$

Differential Scanning Calorimetry (DSC) of $\left[(n-\mathrm{Bu})_{2} \mathrm{Sn}\right]_{\mathrm{n}}$ show a phase change between crystalline and liquid-crystalline (LC) mesophase structures at approximately ${ }^{*}-25^{\circ} \mathrm{C}$ and the reverse at $0^{\circ} \mathrm{C}$. Alkyl polymers with side chains shorter than $n$-butyl showed only one phase transition. Alkyl polymers with longer side chains showed two reversible phase transitions (see Table 1.3). ${ }^{16}$ Upon further examination of these polymers through microscopy and X-ray

\footnotetext{
* Cycling through heating cooling showed variation of a few degrees, most likely due to size of crystals formed.
} 
diffraction, it was observed that all polymers were birefringent below the first transition. Polystannanes bearing Et, $n$-Pr, $n$-Bu, and $n$-Pe substituents showed no change in birefringence up to $100^{\circ} \mathrm{C}{ }^{*}$ In contrast, $n$-Hex and $n$-Dod polymers showed a decrease in the birefringence above the first transition with $n$-Oct showing no birefringence ${ }^{* *}$ above the first transition. Finally, polystannanes with $n$-Hex, $n$-Dod and $n$-Oct substituents lost all birefringence above the second transition.

Table 1.3: Thermal transitions of $\left[\mathrm{R}_{2} \mathrm{Sn}\right]_{\mathrm{n}} \cdot{ }^{16}$

\begin{tabular}{llcc}
\hline \multicolumn{1}{c}{ Compound } & $\begin{array}{c}\text { First } \\
\text { Transition } \\
\left({ }^{\circ} \mathbf{C}\right)\end{array}$ & $\begin{array}{c}\text { Second } \\
\text { Transition } \\
\left({ }^{\circ} \mathbf{C}\right)\end{array}$ \\
\hline$\left[\mathbf{E t}_{2} \mathbf{S n n}\right]_{\mathbf{n}}$ & heating & 15 & - \\
{$\left[\left(\boldsymbol{n}-\mathbf{P r}{ }_{2} \mathbf{S n}\right]_{\mathbf{n}}\right.$} & cooling & 6 & - \\
& heating & 93 & - \\
{$\left[(\boldsymbol{n}-\mathbf{B u})_{2} \mathbf{S n}\right]_{\mathbf{n}}$} & cooling & 63 & - \\
& heating & 1 & - \\
{$\left[(\boldsymbol{n}-\mathbf{P e})_{2} \mathbf{S n}\right]_{\mathbf{n}}$} & cooling & -26 & - \\
& heating & 6 & 57 \\
{$\left[(\boldsymbol{n} \text {-Hex })_{2} \mathbf{S n}\right]_{\mathbf{n}}$} & cooling & -16 & 42 \\
& heating & 34 & 68 \\
{$\left[(\boldsymbol{n}-\mathbf{O c t t})_{2} \mathbf{S n}\right]_{\mathbf{n}}$} & cooling & 21 & 43 \\
& heating & 29 & 74 \\
{$\left[(\boldsymbol{n}-\mathbf{D o c})_{2} \mathbf{S n}\right]_{\mathbf{n}}$} & cooling & 13 & 58 \\
& heating & 55 & 91 \\
& cooling & 39 & 80
\end{tabular}

The charge mobility of $\left[(n-\mathrm{Bu})_{2} \mathrm{Sn}\right]_{n}$ has been studied via Pulse-Radiolysis Time Resolved Microwave Conductivity (PR-TRMC). ${ }^{31}$ Charge mobilities were found to be from 0.097 and $0.027 \mathrm{~cm}^{2} \mathrm{~V}^{-1} \mathrm{~s}^{-1}$ for crystalline and LC mesophase respectively. This is comparable to

\footnotetext{
* Observations were only made to $100^{\circ} \mathrm{C}$ due to stability issues.

** Properties of materials where refraction is dependent on the polarization and propagation direction of light
} 
charge mobilities previously observed for dialkyl silicon and germanium based polymers as shown in Table 1.4.

Table 1.4: Charge mobility of Group 14 polymers.

\begin{tabular}{|c|c|c|c|c|c|c|}
\hline \multirow[t]{2}{*}{ Compound } & \multicolumn{2}{|c|}{$\begin{array}{c}\text { Transition Temperature }^{\mathbf{a}} \\
{ }^{\circ} \mathrm{C}\end{array}$} & \multicolumn{2}{|c|}{$\begin{array}{c}\Sigma \mu_{1 D} \\
\left(\mathrm{~cm}^{2} V^{-1} s^{-1}\right)\end{array}$} & \multirow[t]{2}{*}{$\begin{array}{l}\lambda_{\max } \\
(\mathbf{n m})\end{array}$} & \multirow[t]{2}{*}{$\begin{array}{c}\mathbf{d}(\mathbf{X}-\mathbf{X}) \\
(\AA)\end{array}$} \\
\hline & $\mathbf{K} \rightarrow \mathbf{M}$ & $\mathbf{M} \rightarrow \mathbf{K}$ & $\mathbf{K}$ & M & & \\
\hline$\left[(n-\mathrm{Bu})_{2} \mathrm{Si}\right]_{\mathrm{n}}$ & 38 & 74 & 0.021 & 0.108 & 315 & 2.35 \\
\hline$\left[(n-H e x)_{2} G e\right]_{n}$ & 23 & 36 & 0.021 & 0.078 & 324 & 2.50 \\
\hline$\left[(n-B u)_{2} \mathrm{Sn}\right]_{\mathrm{n}}$ & -25 & 0 & 0.027 & 0.097 & 382 & 2.85 \\
\hline
\end{tabular}

\subsubsection{Stability}

Polystannanes show a remarkable thermal stability up to $200^{\circ} \mathrm{C}$. However, polystannanes display inherent light and moisture sensitivity. All known polystannanes suffer from stability issues and therefore must be handled in an inert atmosphere void of light. This makes the synthesis, characterization and processing of polystannanes challenging and reduces their value as materials.

Polystannanes have been shown to be air sensitive. ${ }^{6}$ However, when polystannanes are exposed to pure $\mathrm{O}_{2}$, there is no observed depolymerisation. This indicates that the stability issues are due to moisture and not $\mathrm{O}_{2} \cdot{ }^{19}$ The usual method for the evaluation of the stability of polystannanes is to follow the degradation of the UV-Vis $\lambda_{\max }$ signal. When exposed to small amounts of moisture (water) the UV-Vis signal decreases rapidly over time. This decomposition is accelerated by the addition of a wet solvent.

The light sensitivity of polystannanes has been well studied using both NMR and UV-Vis spectroscopies. It was established that solid state polystannanes are considerably more stable 
than dissolved polymers and solvents has a great overall effect on the stability of polystannanes. When dissolved in aromatic or aliphatic solvents such as benzene, toluene or short chain alkenes, stability was very poor, with THF showing only slightly higher stability. When polystannanes are dissolved in chlorinated solvents or solvents such as styrene, a higher stability is observed. The stability of polystannanes can be increased by the addition of radical scavengers or dyes. ${ }^{32}$

The ${ }^{119} \mathrm{Sn}$ NMR chemical shifts for the breakdown products after light exposure range in from +150 to $-200 \mathrm{ppm}$ and have not fully been identified. However, the breakdown to smaller molecular mass 5- and 6-membered cyclic oligomers was observed with little to no further degradation noted. The likely mechanism of degradation is an unzipping of the chains and not random chain cleavage.

\subsection{Ferrocenophanes}
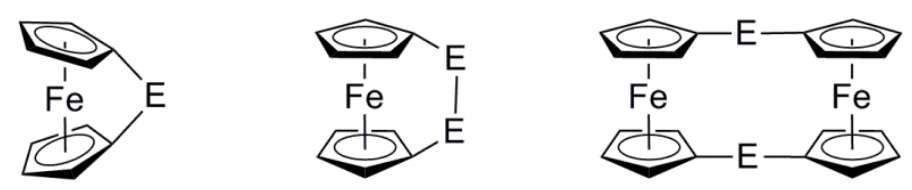

Figure 1.4: The basic structure of from left to right [1]ferrocenophane, [2]ferrocenophane and [1.1]ferrocenophane

Metallocenophanes are macrocyclic structures that contain at least one, and possibly multiple, metallocenes within their cyclic structure. Ferrocenophanes (Figure 1.4) are of particular interest due to the oxidative and light stability of the ferrocene unit. [1]ferrocenophanes (and to a lesser extent [2]- and [3]ferrocenophanes) have been used as monomers for ROP to form polyferrocenylenes (see Section 1.3). Ferrocenophanes where the cyclopentadiene rings of one ferrocene are attached via a bridging unit (also known as ansaferrocenes) are named [n]ferrocenophanes where $\mathrm{n}$ denotes the size of the bridging chain. 
When multiple ferrocenes are involved, a decimal is placed between the lengths of each bridging unit. Therefore a [1.1]ferrocenophane has two ferrocenes that are attached via two bridges with a length of one atom.
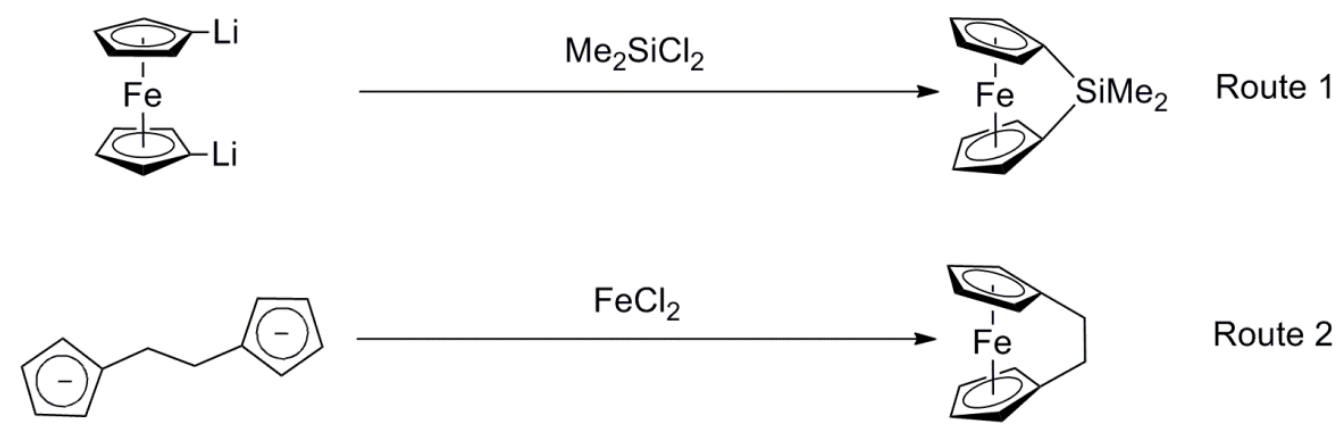

Route 2
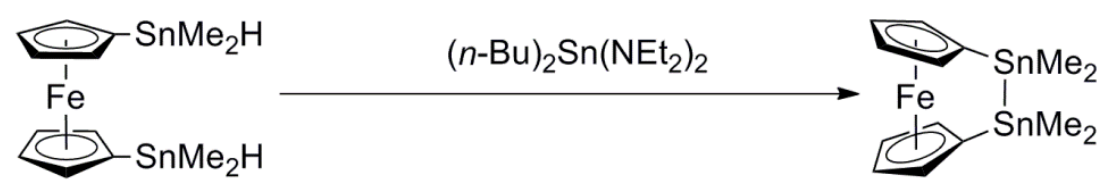

Route 3
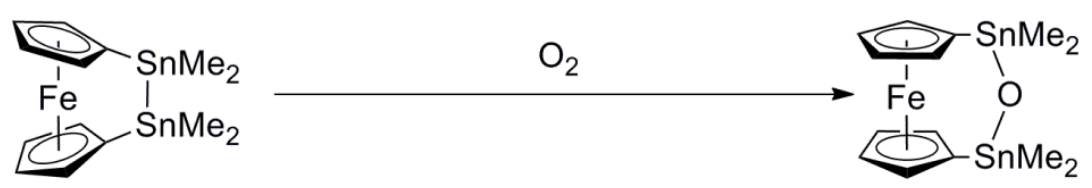

Route 4

Figure 1.5: Examples of the four routes to [n]ferrocenophanes

The synthesis of [1]ferrocenophanes is generally carried out through a salt elimination between $\mathrm{Fe}\left(\eta^{5}-\mathrm{C}_{5} \mathrm{H}_{4} \mathrm{Li}\right)_{2} \bullet$ TMEDA (1,1'dilithioferrocene $\bullet N, N, N^{\prime}, N^{\prime}$ '-tetramethylethylenediamine) and a dichloride $\left(\mathrm{ECl}_{2}\right)$ related to the desired bridging unit (Route 1). This was first described by Osborne, who in $1975^{33}$ synthesized diphenylsilyl-[1]ferrocenophane. Previous to this, several other larger [n]ferrocenophanes had been prepared via three different methods (Figure 1.5). The routes of preparation of [n]ferrocenophanes include building the [n]ferrocenophane from a reaction between a linked bi-cyclopentadiene dianion and $\mathrm{FeCl}_{2}$ (Route 2); ring-closing the cyclophane with substituted ferrocenes (Route 3); and finally ring expansion of an existing 
[n]ferrocenophane (Route 4). ${ }^{34}$ These four routes (Figure 1.5) are the main methods of synthesis of many of the ferrocenophanes known today.

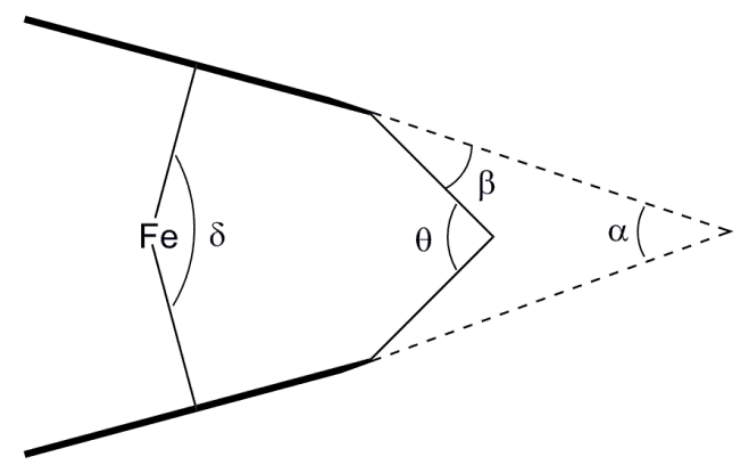

Figure 1.6: Diagram of the ring strain of ferrocenophanes.

The salt elimination method (Route 1) used by Osborne has been used to prepare [1]ferrocenophanes of Group $13(\mathrm{~B}, \mathrm{Al}, \mathrm{Ga}),{ }^{35,36} 14(\mathrm{Si}, \mathrm{Ge}, \mathrm{Sn})^{33,37,38}$ or $15(\mathrm{P}, \mathrm{As})^{37,39}$ as well as Group 4 (Ti, Zi, and Hf). ${ }^{40}$ These [1]ferrocenophanes have considerable ring strain ( $\alpha$ between in Figure 1.5) which makes them prime candidates for ring-opening polymerizations. [2]ferrocenophanes that contain mixed Group 14 elements (Ge-C and $\mathrm{Sn}-\mathrm{C}$ bridged) were synthesized via a similar salt elimination of dilithiated methyl ferrocene $\left(\eta^{5}-\mathrm{C}_{5} \mathrm{H}_{4} \mathrm{CH}_{2} \mathrm{Li}\right) \mathrm{Fe}\left(\eta^{5}\right.$ $\mathrm{C}_{5} \mathrm{H}_{4} \mathrm{Li}$ ) with either dialkyl germanium or tin dichlorides. The tetramethylgermyl[2]ferrocenophane was also prepared through a reaction between $\mathrm{Fe}\left(\eta^{5}-\mathrm{C}_{5} \mathrm{H}_{4} \mathrm{Li}\right)_{2}$ and 1,2dichloro-1,1,2,2-tetramethyldigermane. Other [2]ferrocenophanes can be prepared via the formation of the ferrocene with the bridge already in place (Route 2), eg. ethylene bridged [2]ferrocenophane; or through a ring closing reaction of a 1,1'-substituted ferrocene, like in the case of 1,1,2,2-tetramethylstannyl-[2]ferrocenophane (see Section 1.4). Several [n]ferrocenophanes where $\mathrm{n}$ is greater than two have been isolated including elements in Group $13,14,{ }^{41} 15$ and $16,{ }^{42}$ usually through expansion reactions (Route 4 in Figure 1.5). 


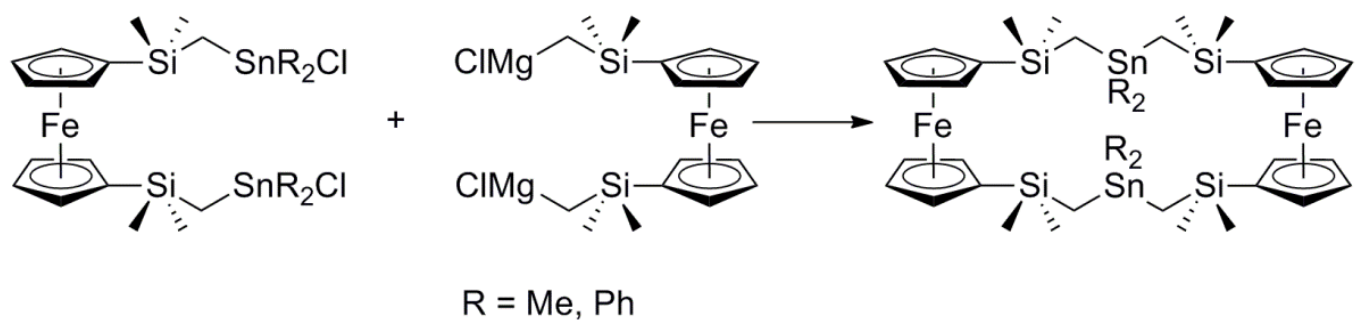

Figure 1.7: Reaction to prepare a [5.5] ferrocenophane.

Larger homogeneous* ${ }^{*}$ n.m]ferrocenophanes have been of interest to organometallic chemists, however there has been relatively little synthetic, commercial, or industrial use of these materials. [1.1]ferrocenophanes containing Group $12(\mathrm{Hg}),{ }^{43} 13$ (B, Ga, In), ${ }^{44-46} 14(\mathrm{C}, \mathrm{Si}, \mathrm{Sn}){ }^{47-}$ ${ }^{50}$ or $15(\mathrm{P}, \mathrm{As})^{51,52}$ have been synthesized through a variety of different methods. The majority of these products have been isolated as a by-product from the synthesis of [1]ferrocenophanes or from the ROP of [1]ferrocenophanes to form polyferrocenylenes, and the yields of these products are typically low. A few larger [2.2]ferrocenophanes containing mainly first row elements have also been synthesized, ${ }^{53}$ however there has been little research into their material properties. Jurkschat et al. prepared a [5.5]ferrocenophane through a Grignard reaction of two 1,1'disubstituted ferrocenes (Figure 1.7). ${ }^{54,55}$

\subsection{Polyferrocenylenes}

Considerable research effort has been focused on the synthesis of inorganic polymers with specific tunable properties that may be useful in optic and electronic technologies. One such polymeric system under consideration is polymers that contain ferrocene, both as a substituent or as a part of the backbone of the polymer. There has been several review articles published on the

\footnotetext{
* Only one element is present in the main chain of the bridge of homogeneous [n.m]ferrocenophanes.
} 
topic of polyferrocenes. ${ }^{56-58}$ A very brief history of the synthesis of ferrocene-containing polymers and their some of their key properties will be discussed in this section.

\subsubsection{Synthesis}

Since its discovery in the middle of the $20^{\text {th }}$ century, ferrocene has been utilized in a variety of chemical and biochemical sensing systems. This is largely due to its interesting optoelectric properties, its excellent structural stability, and unique bonding structure. Within a few years of ferrocene's discovery, polymers containing ferrocene as a pendant group were prepared by Arimoto and Haven. ${ }^{59}$ These polymers were synthesized through both radical and acid catalyzed polymerization of vinylferrocene. Homopolymers and copolymers with methyl methacrylate, styrene and 2-chloro-1,3-butadiene were also synthesized forming ferrocene containing materials with various physical properties.

Polymers containing ferrocene and optionally another bridging group within the backbone of the polymer, or polyferrocenylenes, have been largely synthesized through two methods; condensation or ring-opening polymerization (ROP). Of these two routes, condensation is a more established method, but often leads to low molecular weight polymers or oligomers. By contrast, ROP of [1]ferrocenophanes affords high molecular weight polymers as well as demonstrating a living nature, offering greater control over the polymers synthesized. For the most part, ROP of [1]ferrocenophanes is the preferred method of synthesis of high molecular weight ferrocene-based polymers. 


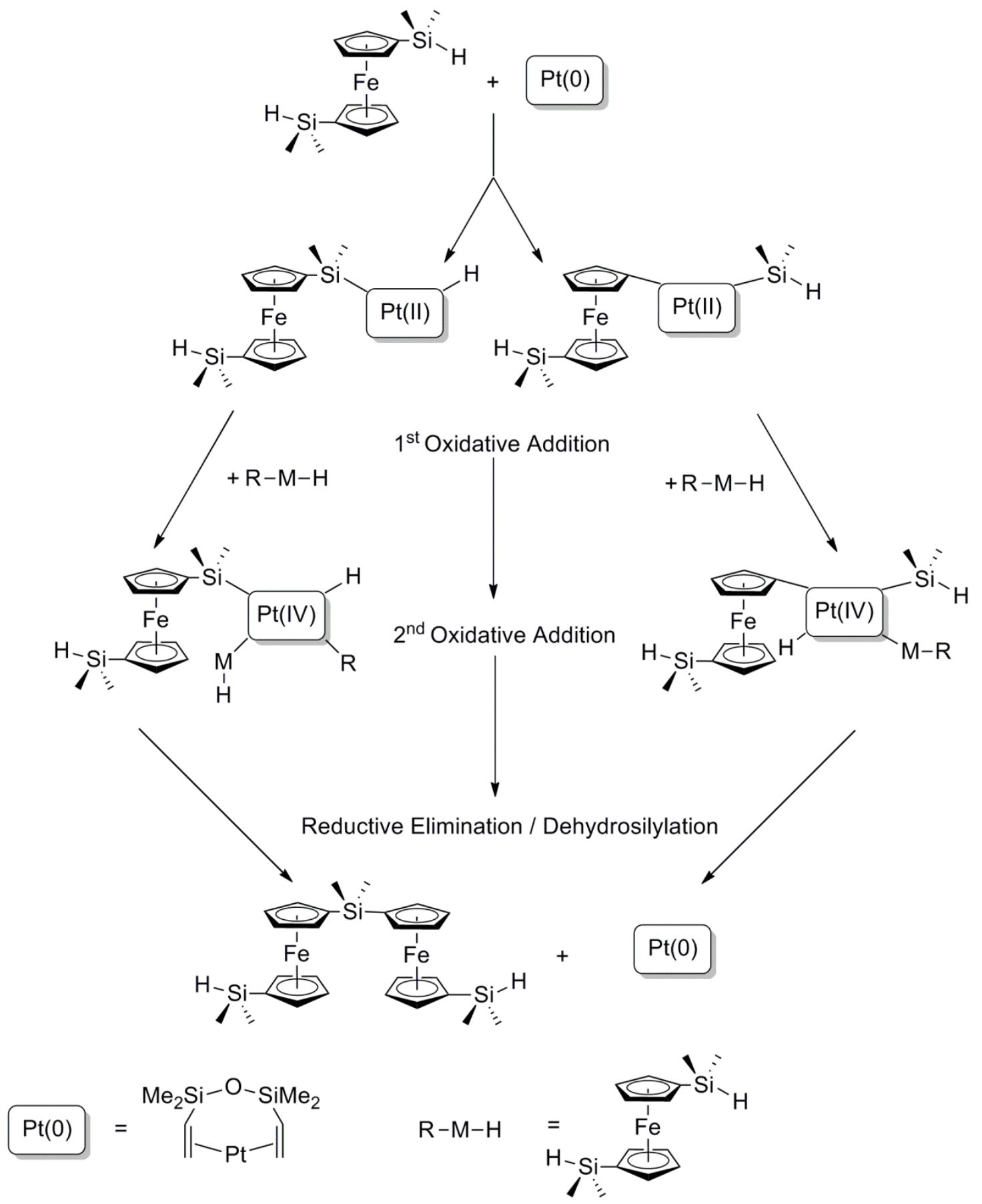

Figure 1.8: Proposed mechanism dehydrosilylation of $\mathrm{Fe}\left(\eta^{5}-\mathrm{C}_{5} \mathrm{H}_{4} \mathrm{SiMe}_{2} \mathrm{H}\right)_{2}{ }^{60}$ 
The first macromolecular structures with ferrocene as part of the backbone were prepared by Korshak ${ }^{61}$ through radical recombination. ${ }^{*}$ Later, Neuse described the radical recombination reaction of $t$-butyl hydrogen peroxide with ferrocene at high temperatures to form insoluble homopolymers of ferrocene (polyferrocenylene). ${ }^{62}$ Around the same time, low molecular weight a poly(mercuri)-ferrocenylene was prepared though the reaction of 1.1'dichloromercuriferrocene with either ethanolic sodium iodide or aqueous sodium thiosulfate. ${ }^{63}$ Poly(mercuri)ferrocenylene was further reacted in molten ferrocene to form low molecular weight $\left(\mathrm{M}_{\mathrm{n}}=3.5 \times 10^{3} \mathrm{Da}\right)$ polyferrocenylene. Neuse reacted equal parts $\mathrm{Fe}\left(\eta^{5}-\mathrm{C}_{5} \mathrm{H}_{4} \mathrm{Li}\right)_{2} \bullet \mathrm{TMEDA}$ and $\mathrm{Fe}\left(\eta^{5}-\mathrm{C}_{5} \mathrm{H}_{4} \mathrm{I}\right)_{2}$ and was able to prepare a slightly larger $\left(\mathrm{M}_{\mathrm{n}}=6.2 \times 10^{3} \mathrm{Da}\right)$ polyferrocenylene $\left[\mathrm{Fe}\left(\eta^{5}-\mathrm{C}_{5} \mathrm{H}_{4}\right)_{2}\right]_{\mathrm{n}}{ }^{64}$ These materials were not, however, well characterized. Polyferrocenylene was also prepared by Yamamoto et al. ${ }^{65}$ via a condensation of ferrocenyl dihalides in the presence of $\mathrm{Mg}$ to form mainly insoluble oligomers with an $\mathrm{M}_{\mathrm{n}} \approx 3 \times 10^{3} \mathrm{Da}^{* *}$ When Nishihara et al. ${ }^{66}$ reacted $[\mathrm{Na}]\left[\left(\eta^{5}-\mathrm{C}_{5} \mathrm{H}_{4}(n-\mathrm{Hex})\right)\right]$ with iodide and $n$-BuLi, the bicyclopentadiene dianion, $[\mathrm{Na}]_{2}$ $\left[\left(\mathrm{C}_{5} \mathrm{H}_{3}(n-\mathrm{Hex})\right)_{2}\right]$, was formed. The product was further reacted with $\mathrm{FeCl}_{2} \bullet \mathrm{THF}_{2}$ to form $\left[\left(\eta^{5-}\right.\right.$ $\left.\left.\mathrm{C}_{5} \mathrm{H}_{4}(n-\mathrm{Hex})\right)_{2} \mathrm{Fe}\right]_{\mathrm{n}}$ of $\mathrm{M}_{\mathrm{n}}=5 \times 10^{3}$ Da and a PDI of $1.2 .^{* * *}$ Rausch et al. ${ }^{67}$ performed an Ullman coupling reaction to synthesize oligoferrocenylene in the melt through a copper catalyzed reaction. Ullman coupling of $\mathrm{Fe}\left(\eta^{5-} \mathrm{C}_{5} \mathrm{H}_{4} \mathrm{I}\right)_{2}$ catalyzed by copper was later used by Foucher et $a l{ }^{68}$ to prepare modest molecular weight polyferrocenylene of $\mathrm{M}_{\mathrm{w}}=5.2 \times 10^{3}(\mathrm{PDI}=3.1)$. Ullman coupling to produce soluble polyferrocenylenes was also carried out using $\mathrm{Fe}\left(\eta^{5-}\right.$ $\left.\mathrm{C}_{5} \mathrm{H}_{3}(\mathrm{Me}) \mathrm{I}\right)_{2}\left(\mathrm{M}_{\mathrm{w}}=2.0-3.4 \times 10^{3} \mathrm{Da}, \mathrm{PDI}=1.21-1.35\right)$ and as well as the $\mathrm{Fe}\left(\eta^{5-} \mathrm{C}_{5} \mathrm{H}_{3}\left(\mathrm{SiMe}_{3}\right) \mathrm{I}\right)_{2}$ $\left(\mathrm{M}_{\mathrm{w}}=3.6-8.6 \times 10^{3} \mathrm{Da}, \mathrm{PDI}=1.60-3.01\right)$.

\footnotetext{
* Radical recombination was originally carried out by Korshak however was not fully described until Neuse investigated it in 1966.

${ }_{* *}$ Calculated by Elemental Analysis assuming end group of halide.

${ }^{* * *}$ Polymer was separated via GPC from smaller oligomeric species.
} 
Condensation reactions to form oligomeric and low to medium molecular weight polymeric species that contain both ferrocene and a spacer molecule in the backbone have been also been carried out. Rosenberg was able to prepare polyferrocenylsilanes (both dimethyl and diphenyl) of low molecular weights (methyl $\mathrm{M}_{\mathrm{w}}=1 \times 10^{3}$ Da and phenyl $\mathrm{M}_{\mathrm{w}}=7 \times 10^{3} \mathrm{Da}$ ) through a condensation of $\mathrm{Fe}\left(\eta^{5}-\mathrm{C}_{5} \mathrm{H}_{4} \mathrm{Li}\right)_{2} \bullet$ TMEDA with dihalosilanes. ${ }^{58}$ Foucher et al. ${ }^{60}$ using the Karstedt's catalyst was able to synthesis oligomeric $\left[\mathrm{Fe}\left(\eta^{5-} \mathrm{C}_{5} \mathrm{H}_{4}\right)_{2} \mathrm{SiMe}_{2}\right]_{n}$ through a dihydrosilylation of $\mathrm{Fe}\left(\eta^{5}-\mathrm{C}_{5} \mathrm{H}_{4} \mathrm{SiMe}_{2} \mathrm{H}\right)_{2}$ in DCM (Figure 1.8). When this reaction was carried out in DMF the reaction formed a polyferrocenyl disiloxane through an oxygen insertion, forming polymers of molecular weight of $1 \times 10^{5} \mathrm{Da}$ and a PDI of $1.12 .{ }^{69} \mathrm{~A}$ similar oxygen insertion was earlier performed by Nakazawa et $a l^{70}$ using the iron based catalyst $\left(\eta^{5}-\right.$ $\left.\mathrm{C}_{5} \mathrm{H}_{5}\right)(\mathrm{CO})_{2} \mathrm{Fe}(\mathrm{Me})$ to produce the same polyferrocenyl disiloxane. ${ }^{*}$
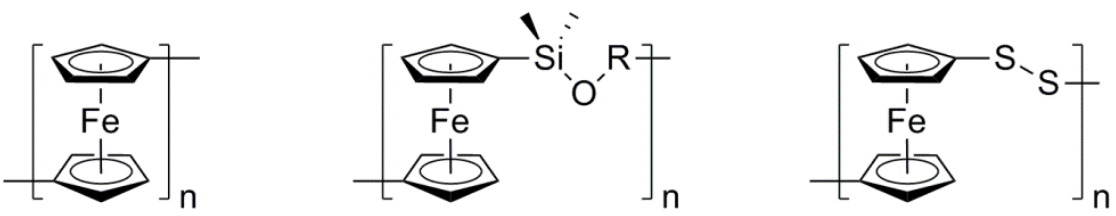

$$
\begin{aligned}
\mathrm{R}= & \mathrm{SiMe}_{2}, \mathrm{SiMe}_{2} \mathrm{OSiMe}_{2}, \mathrm{SiPh}_{2} \mathrm{OSiMe}_{2}, \\
& \mathrm{SiMe}_{2} \mathrm{PhSiMe}_{2} \mathrm{OSiMe}_{2}, \\
& \mathrm{SiMe}_{2} \mathrm{PhPhSiMe}_{2} \mathrm{OSiMe}_{2}
\end{aligned}
$$

Figure 1.9: Structure of polyferrocenylenes, polyferrocenyl siloxanes, and polyferrocenyl disulphides.

Well characterized polyferrocenyl disiloxanes where formed through a reaction between a 1,1'-bis-silylamide ferrocene and a disilanol by Pittman et al. ${ }^{71,72}$ to form polymers $\left[\mathrm{Fe}\left(\eta^{5} \mathrm{C}_{5} \mathrm{H}_{4}\right)_{2} \mathrm{SiMe}_{2}-\mathrm{O}-\mathrm{R}-\mathrm{O}-\mathrm{SiMe}_{2}\right]_{\mathrm{n}}$ where $\mathrm{R}$ is $\mathrm{SiMe}_{2}, \mathrm{SiPh}_{2},\left(\mathrm{SiMe}_{2}\right) \mathrm{Ph}\left(\mathrm{SiMe}_{2}\right)$, and $\left(\mathrm{SiMe}_{2}\right) \mathrm{Ph}-$ $\mathrm{Ph}\left(\mathrm{SiMe}_{2}\right)$. These polymers were found to have molecular weights ranging from $7 \times 10^{3}$ to

\footnotetext{
* The publication originally reported the formation of polyferrocenylbis(dimethyl silane) and were forced to issue a correction due to elemental analysis data being wrong.
} 
$5.1 \times 10^{4} \mathrm{Da}$ with PDI's in the range of 2.01 to 2.72. Condensation reactions have been carried out as well to form an azo-bridged polyferrocene. This was performed through a high pressure reaction with $\mathrm{Fe}\left(\eta^{5}-\mathrm{C}_{5} \mathrm{H}_{4} \mathrm{Li}\right)_{2} \bullet$ TMEDA and $\mathrm{N}_{2} \mathrm{O}$ gas. The resulting polymer had a molecular weight of $8.7 \times 10^{4} \mathrm{Da}$ and a PDI of 6.69 .

Rauchfuss et al. ${ }^{73}$ through a novel ring-opening abstraction, was able to synthesize a disufide bridged polyferrocene utilizing a Lewis base, $(n-\mathrm{Bu})_{3} \mathrm{P}$, initiated polymerization of a trithia-[3]ferrocenophane. The resulting disulfide polymer was insoluble and difficult to characterize. The issue of solubility was resolved by the substitution of one of the cyclopentadiene rings with an $n$-butyl group allowing for processing and characterization. The isolated soluble polymer had a molecular weight ranging from $7 \times 10^{3}-1.5 \times 10^{5} \mathrm{Da}$. These polymers were yellow orange oils and showed thermal stability up to $230^{\circ} \mathrm{C}$.

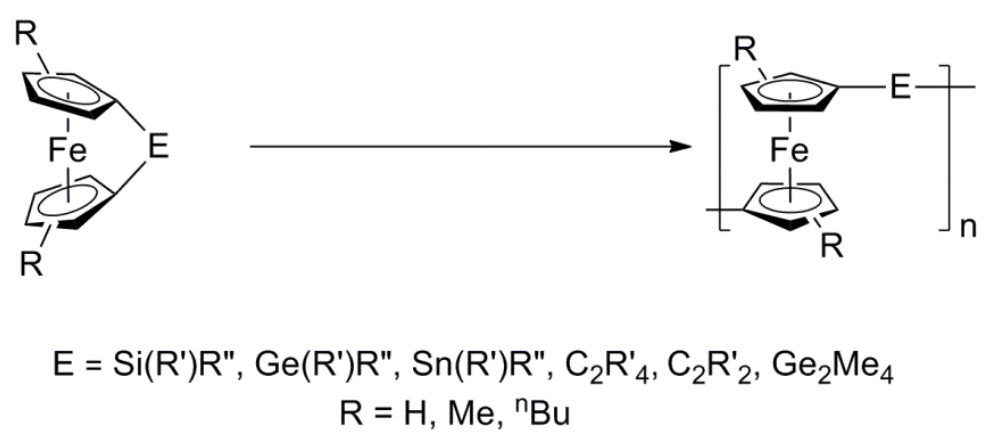

Figure 1.10: ROP of Group 14 [1]- and [2]ferrocenophanes.

As noted previously the preferred method of synthesis of ferrocene polymers is via ringopening polymerization. This was first carried out by Manners et al. ${ }^{74}$ who reported the synthesis of polydimethyl-silylferrocene through a thermal ROP of $\mathrm{Fe}\left(\eta^{5}-\mathrm{C}_{5} \mathrm{H}_{4}\right)_{2} \mathrm{SiMe}_{2}$. The thermal ROP reaction was performed at $150^{\circ} \mathrm{C}$ resulting in polymers that had a $\mathrm{M}_{\mathrm{w}}$ of $5.2 \times 10^{5} \mathrm{Da}$ and a PDI of $\approx 1.5$. In addition to the methyl substituted polymer, the phenyl analogue was also synthesised 
through a similar route. The thermal ROP of $\mathrm{Fe}\left(\eta^{5}-\mathrm{C}_{5} \mathrm{H}_{4}\right)_{2} \mathrm{SiPh}_{2}$ was performed at $210^{\circ} \mathrm{C}$. The polymeric material formed from this reaction was insoluble and therefore not fully characterized.

There have been several experimental conditions used to prepare polyferrocenylsilanes through ROP. These include the use of transition metal catalysts, ${ }^{75,76}$ anionic initiators, ${ }^{77}$ and finally initiation through the use of UV radiation. ${ }^{78-81}$ Both anionic and UV initiated polymerizations were found to be living polymerizations. A considerable amount of control over the molecular weights and polydispersities of this class of polymer has been achieved. ROP has been successfully expended to the preparation a variety single bridged ferrocene based polymers. These include Group $13\left(\mathrm{~B},{ }^{82} \mathrm{Al},{ }^{83} \mathrm{Ga}^{83,84}\right), 14\left(\mathrm{Si},{ }^{74} \mathrm{Ge},{ }^{85,86} \mathrm{Sn}^{*}\right), 15\left(\mathrm{P}^{86}\right)$, and $16\left(\mathrm{~S},{ }^{73,87} \mathrm{Se}^{87}\right)$. Polyferrocenyl-silanes have been synthesized with a variety of substituents including carbon based substitutents (alkyl, ${ }^{86,88}$ alkyne, ${ }^{80}$ and aryl groups ${ }^{88}$ ) chlorides, ${ }^{89}$ and ferrocene. ${ }^{90}$ Finally there have been several polymetallocenes prepared via ROP with different metals including ruthienium $^{83}$ and vanadium. ${ }^{91}$

The living ROP methods of synthesis of $\left[\mathrm{Fe}\left(\eta^{5}-\mathrm{C}_{5} \mathrm{H}_{4}\right) \mathrm{SiMe}_{2}\right]_{\mathrm{n}}$ have been used to produce block copolymers. These copolymers include polystyrene, polydimethylsiloxane, and polyferrocenyl silanes of differing functionality. Additionally, the preparation of di-, tri- and even penta- block copolymers can be accessed through these methods. These polymeric materials have shown great potential in nanomaterial and preceramics, due to their optoelectric properties and ability to self-assemble. ${ }^{57}$

\footnotetext{
${ }^{*}$ See section 1.5 for more information on polyferrocenyl stannanes.
} 


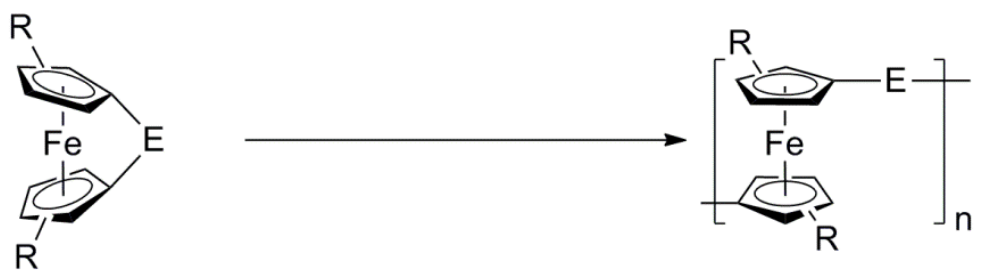

Figure 1.11: General ROP of ferrocenylenes from ferrocenophanes.

Table 1.5: Structure and molecular weight data for ferrocenylenes synthesised through ROP.

\begin{tabular}{|c|c|c|c|c|}
\hline ROP $^{a}$ & $\mathbf{E}^{\mathbf{b}}$ & $\mathbf{R}^{\mathbf{b}}$ & $\mathbf{M}_{\mathrm{w}}(\mathrm{Da})$ & $\overline{\text { PDI }}$ \\
\hline \multirow[t]{11}{*}{ Thermal } & $\mathrm{Me}_{2} \mathrm{Si}^{86}$ & $\mathrm{H}$ & $5.2 \times 10^{5}$ & 1.53 \\
\hline & $\mathrm{Et}_{2} \mathrm{Si}^{86}$ & $\mathrm{H}$ & $7.4 \times 10^{5}$ & 1.54 \\
\hline & ${ }^{n} \mathrm{Bu}_{2} \mathrm{Si}^{86}$ & $\mathrm{H}$ & $8.9 \times 10^{5}$ & 2.6 \\
\hline & ${ }^{n} \mathrm{Hex}_{2} \mathrm{Si}^{86}$ & $\mathrm{H}$ & $1.2 \times 10^{5}$ & 1.58 \\
\hline & $\mathrm{Ph}_{2} \mathrm{Si}$ & $\mathrm{H}$ & $5.1 \times 10^{4}$ & 1.6 \\
\hline & $\mathrm{Me}_{2} \mathrm{Ge}^{86}$ & $\mathrm{H}$ & $2.3 \times 10^{5}$ & 4.42 \\
\hline & $\mathrm{H}_{2} \mathrm{C}-\mathrm{CH}_{2}{ }^{86}$ & $\mathrm{Me}$ & $8.1 \times 10^{4}$ & 1.23 \\
\hline & $\mathrm{PhP}^{86}$ & ${ }^{n} \mathrm{Bu}$ & $/^{\mathrm{d}}$ & $d^{\mathrm{d}}$ \\
\hline & $\mathrm{PhP}$ & $\mathrm{Me}_{3} \mathrm{Si}$ & $6.6 \times 10^{5}$ & 1.98 \\
\hline & $S^{87}$ & $\mathrm{Me}$ & $1.15 \times 10^{4}$ & 1.95 \\
\hline & $\mathrm{R}^{\prime} \mathrm{Ga}^{\mathrm{e}}$ & $\mathrm{H}$ & $4.8 \times 10^{5}$ & 3.3 \\
\hline \multirow[t]{2}{*}{ MC } & $\mathrm{HC}=\mathrm{CH}^{\mathrm{c}, 92}$ & $\mathrm{H}$ & $2.1 \times 10^{4}$ & 1.91 \\
\hline & $\mathrm{Me}_{2} \mathrm{Si}$ & $\mathrm{H}$ & $1.3 \times 10^{5}$ & 1.08 \\
\hline $\mathbf{A}$ & $\mathrm{Me}_{2} \mathrm{Si}^{77}$ & $\mathrm{H}$ & $9.4 \times 10^{5}$ & 1.09 \\
\hline $\mathbf{U V}$ & $\mathrm{Me}_{2} \mathrm{Si}^{81}$ & $\mathrm{H}$ & $7.8 \times 10^{5}$ & 1.12 \\
\hline
\end{tabular}

${ }^{\mathrm{a}}$ Type of ROP, MC = metal calalyst, $\mathrm{A}=$ anionic, ${ }^{\mathrm{b}}$ see figure 1.11 for further structural detail ${ }^{\mathrm{c}}$ value for norbornene copolymer ${ }^{\mathrm{d}}$ adsorbed to GPC column ${ }^{\mathrm{e}} \mathrm{R}$ ' $=2$-(3,5-di-t-butylphentyl)- $N, N-$ dimethylmethanamine

Ring opening polymerization has also been used to synthesize polyferrocenes with two Group 14 atoms in the bridge. This includes $\mathrm{CH}_{2} \mathrm{CH}_{2},{ }^{93} \mathrm{HC}=\mathrm{CH}^{92}$ and $\mathrm{GeMe}_{2} \mathrm{GeMe}_{2} \cdot{ }^{94}$ The only evidence of a dibridge later Group 14 containing ferrocene polymer was prepared by Mochida $e t$ $a l .{ }^{94}$ who carried out ROP of tetramethyl-digermanyl-[2]-ferrocenophane with a few select Pd 
and Pt catalysts. The resulting polyferrocenyl bis(dimethylgermane) had molecular weights of $2 \times 10^{4}-5 \times 10^{5} \mathrm{Da}$, and PDI's ranging from 1.7-2.6.

\subsubsection{Properties}

One of the more interesting properties of polyferrocenylenes is their electrochemical behaviour. First described for biferrocene, cyclic voltammetry presented two defined redox waves $\left({ }^{1} \mathrm{E}_{1 / 2}=0.31 \mathrm{~V}\right.$ and ${ }^{2} \mathrm{E}_{1 / 2}=0.64 \mathrm{~V}$ relative to ferrocene $)$. This is due to strong $\mathrm{Fe}-\mathrm{Fe}$ interactions between connecting ferrocenes. Tri- and quater-ferrocenes presented one redox event separated by approximately $\Delta \mathrm{E}_{1 / 2} \approx 0.2 \mathrm{~V}$ for every Fe center contained in the molecule. Oligomeric dimethylsilyl bridged ferrocene ${ }^{*}$ species showed similar cyclic voltammetry to that of the unbridged oligoferrocenes with the presence of multiple peaks based on the length of the oligomers. All oligomeric systems with an odd number of iron centers showed only two redox waves $\left({ }^{1-3} \Delta \mathrm{E}_{1 / 2} \approx 0.22 \mathrm{~V}\right)$, the lowest of them being broader and having a larger integration. These uneven redox waves are due to two separate undefined oxidations within the first redox event. The systems with an even number of ferrocenes (other than the dimer) showed three redox waves $\left({ }^{1-2} \Delta \mathrm{E}_{1 / 2} \approx 0.15 \mathrm{~V},{ }^{1-3} \Delta \mathrm{E}_{1 / 2} \approx 0.22 \mathrm{~V}\right)$ however the integration of the central event decreased with an increase in the size of oligomers. A study carried out by Pannell et al. ${ }^{95}$ using ferrocene dimers separated by a small dimethylsilane chain $(n=0,1,2,3,6)$ as model compounds showed a decrease in the $\Delta \mathrm{E}_{1 / 2}$ with an increase in the chain length of the spacer between adjacent ferrocenes. In these model systems interactions between ferrocenes with three spacers showed little peak resolution while six spacers were completely insulating.

\footnotetext{
* Oligomeric species, although they do not show the exact same properties as polymeric materials are good model compounds for electrochemical interactions.
} 
Table 1.6: Glass transition temperature, colour, and $\mathrm{CV}$ of $\left[\mathrm{Fe}\left(\eta^{5}-\mathrm{C}_{5} \mathrm{H}_{4}\right) \mathrm{E}\right]_{\mathrm{n}}$.

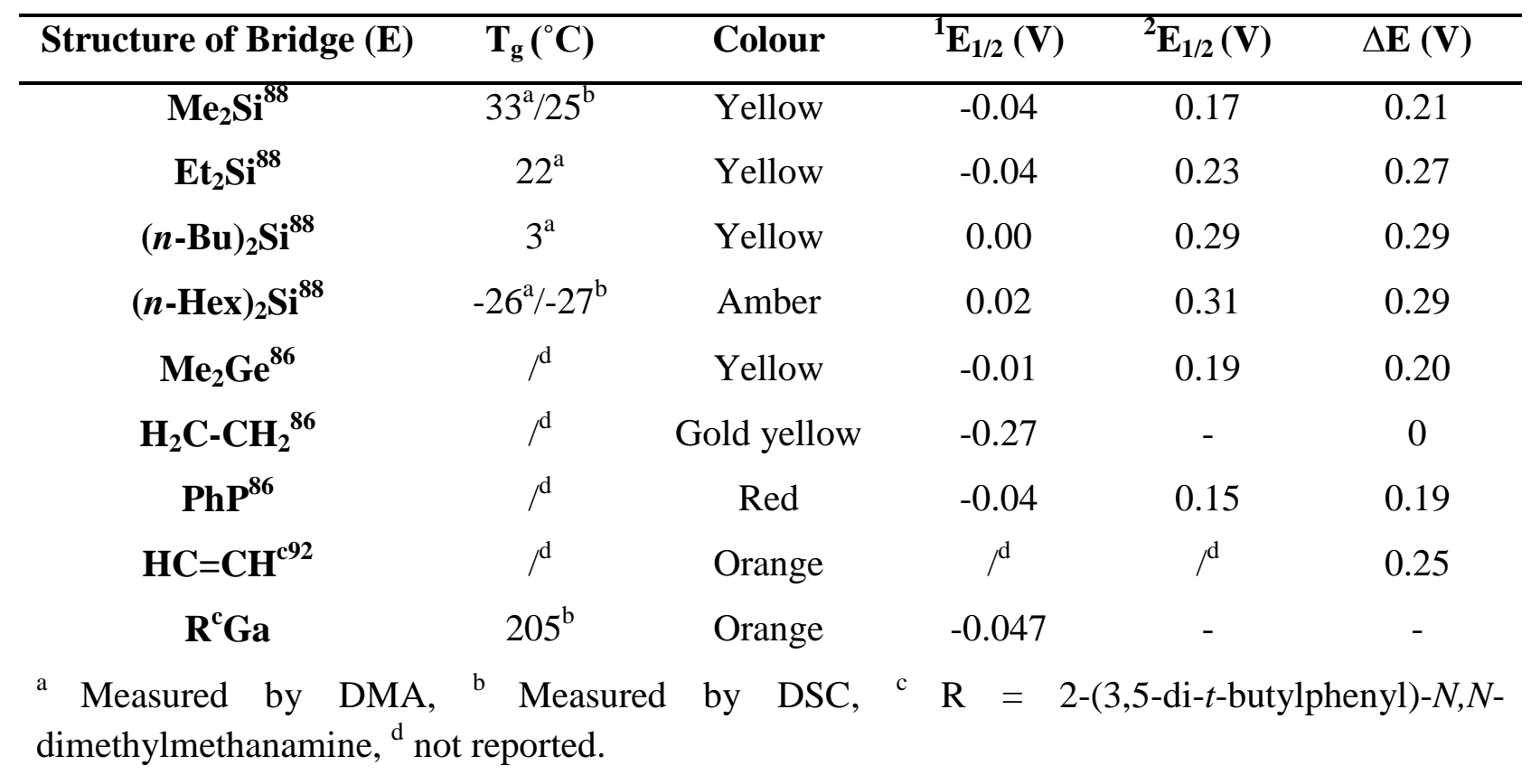

The cyclic voltammetry of bridged polyferrocenyldialkylsilanes displayed two redox waves with $\Delta \mathrm{E}_{1 / 2}$ values ranging from $0.21-0.29 \mathrm{~V}$ indicating significant interaction between the Fe centers. When ferrocene based oligomers are bridged with an insulating methylene carbon, there is a notable decrease in the interaction between the Fe centers resulting in a smaller $\Delta \mathrm{E}_{1 / 2}$ $(0.1 \mathrm{~V})$. The insertion of an ethylene group between adjacent ferrocenes reduces the $\mathrm{Fe}-\mathrm{Fe}$ interaction to $0 \mathrm{~V},{ }^{86}$ however if the ethylene group is replaced with a vinyl group then the system regains its conductivity with a $\Delta \mathrm{E}=0.25 \mathrm{~V}$. Similarly, $\mathrm{GeMe}_{2}$ bridged polyferrocenes showed a slightly decreased ability to communicate with adjacent Fe centers $(\Delta \mathrm{E}=0.20 \mathrm{~V})$ while a $\mathrm{PPh}$ bridge decreased interactions even further $(\Delta \mathrm{E}=0.19 \mathrm{~V})$. This is likely due to the increased distance between the Fe centers. When GaR was introduced into the backbone, it showed a similar insulating effect to that of a single $\mathrm{C}$ bridge displaying two undefined oxidation events and one broad reduction event. 
The thermal properties of polyferrocenylenes are largely dependent on the composition of the bridge. Smaller substituents on the bridge allow for a tighter packing space and less free volume within the molecular structure of the polymer. As a result, the $\mathrm{T}_{\mathrm{g}}$ (glass transition temperature) of polyferrocenylenes decrease with length of the linear side chain $(\mathrm{Me}>\mathrm{Et}>n$-Bu>$n$-Hex). ${ }^{88}$ However the insertion of ferrocene within the polymer backbone raises the $\mathrm{T}_{\mathrm{g}}$ significantly. For example $\left.\left[\mathrm{Fe} \eta^{5}-\mathrm{C}_{5} \mathrm{H}_{4}\right)_{2} \mathrm{Si}(n-\mathrm{Bu})_{2}\right]_{\mathrm{n}}$ has a $\mathrm{T}_{\mathrm{g}}=3^{\circ} \mathrm{C}$, while the $\mathrm{T}_{\mathrm{g}}$ for $\left[(n-\mathrm{Bu})_{2} \mathrm{Sn}\right]_{\mathrm{n}}$ is found at $-40^{\circ} \mathrm{C}$. In general, symmetrically bridged polyferrocenylenes have lower glass transition temperatures than unsymmetrical ones. This can be seen through polyferrocenylsilylchlorides $\left(\mathrm{Si}(\mathrm{Cl}) \mathrm{Me}\right.$ or $\left.\mathrm{SiCl}_{2}\right)$ which have glass transition temperatures of $29^{\circ} \mathrm{C}\left(\mathrm{SiCl}_{2}\right)$ and $59^{\circ} \mathrm{C}(\mathrm{Si}(\mathrm{Cl}) \mathrm{Me})$ respectively. ${ }^{89}$

The optical nature of polymers that include metallocenes in the backbone is primarily based on the type of metallocene involved. This is due to the nature of the metallocene electronic structure. As a result, polyferrocenylenes are yellow to red in color. Polyferrocenylsilanes with dialkyl chains show a slight increase in their $\lambda_{\max }$ as chain length increases $(430-450 \mathrm{~nm}){ }^{88}$ These polydi(alkyl)ferrocenylsilanes are yellow in color with the exception of $\left[\mathrm{Fe}\left(\eta^{5}\right.\right.$ $\left.\left.\mathrm{C}_{5} \mathrm{H}_{4}\right)_{2} \mathrm{Si}(n-\mathrm{Hex})_{2}\right]_{\mathrm{n}}$ which is amber. Silylchloride bridged polyferrocenylenes are orange in color, as are the germanium and vinyl bridge polyferrocenylenes, ${ }^{89}$ while phosphorus-bridged polymers are red in color.

\footnotetext{
${ }^{*}$ The $\mathrm{T}_{\mathrm{g}}$ of $n$-Hex polysilane $\left(\mathrm{T}_{\mathrm{g}}=-52.5^{\circ} \mathrm{C}\right)$ is much lower than that of the ferrocene analogue $\left(\mathrm{T}_{\mathrm{g}} \approx 26^{\circ} \mathrm{C}\right)$ as well.
} 
Table 1.7: Refractive indices for various polyferrocenylenes.

\begin{tabular}{|c|c|c|c|}
\hline Structure of Bridge & $\overline{\mathbf{R}}$ & RI (598 nm) & Std Dev RI's \\
\hline \multirow[t]{7}{*}{$\mathbf{S i}^{\prime}(\mathbf{R}) \mathbf{R}^{\prime}$} & $\mathrm{R}=\mathrm{Me}, \mathrm{R}^{\prime}=\mathrm{CH}_{2} \mathrm{CH}_{2} \mathrm{CF}_{3}$ & 1.599 & 0.007 \\
\hline & $\mathrm{R}=\mathrm{Me}, \mathrm{R}^{\prime}=\mathrm{Et}$ & 1.663 & 0.004 \\
\hline & $\mathrm{R}=\mathrm{Me}, \mathrm{R}^{\prime}=\mathrm{Me}$ & 1.678 & 0.003 \\
\hline & $\mathrm{R}=\mathrm{Me}, \mathrm{R}^{\prime}=\mathrm{Ph}$ & 1.681 & 0.004 \\
\hline & $\mathrm{R}=\mathrm{Me}, \mathrm{R}^{\prime}=p-\mathrm{C}_{6} \mathrm{H}_{4} \mathrm{Br}$ & 1.682 & 0.003 \\
\hline & $\mathrm{R}=\mathrm{Me}, \mathrm{R}^{\prime}=$ ferrocenyl & 1.696 & 0.001 \\
\hline & $\mathrm{F}=\mathrm{Me}, \mathrm{R}^{\prime}=$ thienyl & 1.691 & 0.000 \\
\hline $\operatorname{Ge}(R) R^{\prime}$ & $\mathrm{R}=\mathrm{Me}, \mathrm{R}^{\prime}=\mathrm{Me}$ & 1.689 & 0.002 \\
\hline \multirow[t]{2}{*}{ PR } & $\mathrm{R}=p-\mathrm{C}_{6} \mathrm{H}_{4}{ }^{\mathrm{t}} \mathrm{Bu}$ & 1.663 & 0.004 \\
\hline & $\mathrm{R}=\mathrm{Ph}$ & 1.737 & 0.003 \\
\hline \multirow[t]{2}{*}{$\mathbf{P}(\mathbf{S}) \mathbf{R}$} & $\mathrm{R}=p-\mathrm{C}_{6} \mathrm{H}_{4}{ }^{\mathrm{t}} \mathrm{Bu}$ & 1.668 & 0.006 \\
\hline & $\mathrm{R}=\mathrm{Ph}$ & 1.723 & 0.006 \\
\hline \multirow[t]{2}{*}{$\mathbf{P}(\mathbf{S e}) \mathbf{R}$} & $\mathrm{R}=p-\mathrm{C}_{6} \mathrm{H}_{4}{ }^{\mathrm{t}} \mathrm{Bu}$ & 1.713 & 0.007 \\
\hline & $\mathrm{R}=\mathrm{Ph}$ & 1.747 & 0.004 \\
\hline
\end{tabular}

The tuneable refractive indices (RI) of these polymers and optical dispersion of these materials show promise in optics and optical electronics. Refractive indices were measured with a spectroscopic ellipsometer at $589 \mathrm{~nm}$, as well as several different wavelengths to determine optical dispersion. Polyferrocenylsilanes, $\left[\mathrm{Fe}\left(\eta^{5}-\mathrm{C}_{5} \mathrm{H}_{4}\right)_{2} \mathrm{Si}(\mathrm{R}) \mathrm{R}{ }^{\prime}\right]_{\mathrm{n}}$, have a range of RIs from $1.599\left(\mathrm{R}=\mathrm{Me}, \mathrm{R}^{\prime}=\mathrm{CH}_{2} \mathrm{CH}_{2} \mathrm{CF}_{3}\right)$ to $1.696\left(\mathrm{R}=\mathrm{Me}, \mathrm{R}^{\prime}=\right.$ thienyl $)$. For $\left[\mathrm{Fe}\left(\eta^{5}-\mathrm{C}_{5} \mathrm{H}_{4}\right) \mathrm{GeMe}_{2}\right]_{\mathrm{n}}$, the RI was found to be slightly higher (1.689) than its silyl analogue (1.678). Polyferrocenyl stannanes were also measured and will be discussed in Section 1.5.2. Polyferrocenylphosphines, 
$\left[\mathrm{Fe}\left(\eta^{5} \mathrm{C}_{5} \mathrm{H}_{4}\right)_{2} \mathrm{PR}\right]_{\mathrm{n}}$ and phosphine sulfides and phosphine selenides $\left[\mathrm{Fe}\left(\eta^{5}-\mathrm{C}_{5} \mathrm{H}_{4}\right)_{2} \mathrm{P}\left(\mathrm{E}^{*}\right) \mathrm{R}\right]_{\mathrm{n}}$ show refractive indices larger any known Group 14 polyferrocenylenes ranging from 1.669-1.737 for phosphines and 1.668-1.747 for phosphine sulfides and selenides.

Using the experimental refractive indices seen in Table 1.7, the molar refractions $\left(\mathrm{R}_{\mathrm{m}}\right)$ for the backbone of each polymer can be calculated. The molar refraction is a measure of the effect that one portion of a molecular has on the refractive index of the bulk material and is directly proportional to the change in refractive index. To calculate the molar refraction eqn. 1 is used where $\mathrm{n}$ is the refractive index, $\mathrm{V}_{\mathrm{m}}$ is the molar volume and $\mathrm{R}_{\mathrm{i}}$ is the molar refraction for different parts of the molecule (ie. the backbone of the polymer, or the substituents).

$$
\frac{n^{2}-1}{n^{2}+1} V_{m}=R_{m}=\sum_{i} R_{i}
$$

Since the molar refraction of a given substance is equal to the sum of the molar refractions of individual parts (Eqn. 1) then the molar refraction of the backbone repeat units of the polymer can be calculated. The series of molar refractions for the polyferrocenylenes is $\mathrm{Si}$ (57.2) < Ge (58.9) < P (63.2).* The molar refractions can be used to calculate hypothetical refractive indices for polymers that have not yet been synthesized allowing for molecular tailoring to produce desired optical properties. ${ }^{96}$

Materials that possess high refractive indices can already be produced through conjugation of organic polymers, and through suspension of metal atoms throughout polymeric materials. However, the importance of polyferrocenylenes in this regard is their ability to retain a low amount of optical dispersion with higher refractive indices. This is not true for either

\footnotetext{
${ }^{*} \mathrm{E}=\mathrm{S}$ or $\mathrm{Se}$

${ }^{* * *}$ For polyferrocenyl stannanes see section 1.5.2
} 
conjugated organics or the suspension of metal atoms. This is based on the calculation of Abbe's number ${ }^{*}$ which is inversely proportional to the optical dispersion. ${ }^{97}$

\subsection{Ferrocenyl stannanes}
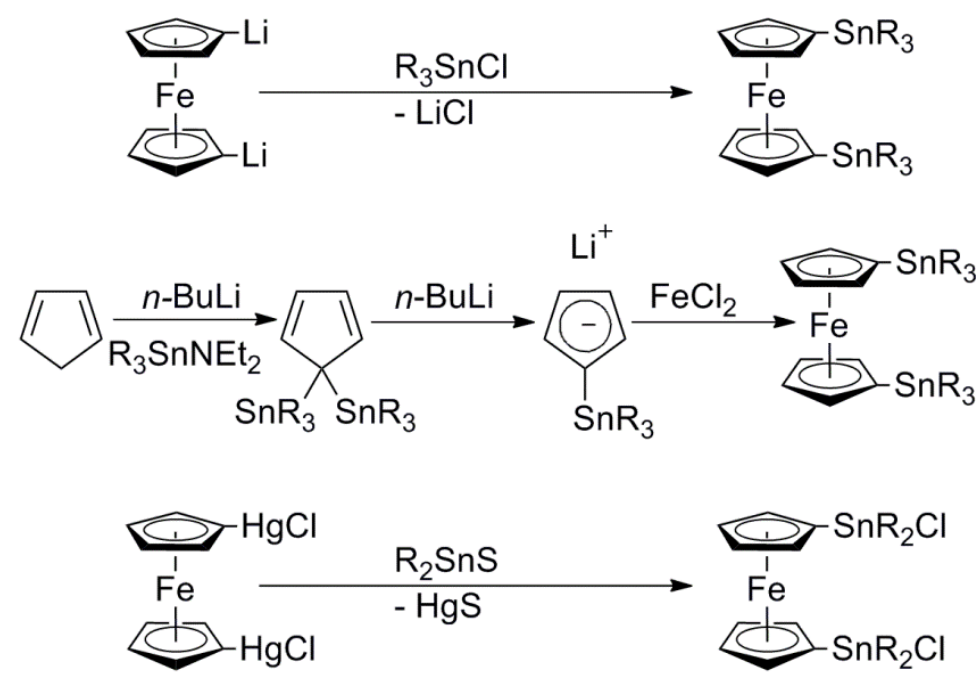

Figure 1.12: Methods of preparation of ferrocenyl stannanes.

Almost immediately after the discovery of ferrocene in 1951, ferrocenyl silanes ${ }^{98,99}$ were reported, and within a decade the first example of ferrocenyl germanes. ${ }^{100}$ Beyond a few US patents, ${ }^{101,102}$ another decade passed before the synthesis of ferrocenyl stannanes was carried out. Dodo et al. ${ }^{103}$ were able to produce a series $(\mathrm{Et}, n-\mathrm{Pr}, n-\mathrm{Bu})$ of $\left(\eta^{5}-\mathrm{C}_{5} \mathrm{H}_{4} \mathrm{SnR}_{2} \mathrm{H}\right){ }_{2} \mathrm{Fe}$ through the reaction of $\mathrm{Fe}\left(\eta^{5}-\mathrm{C}_{5} \mathrm{H}_{4} \mathrm{Li}\right)_{2} \bullet \mathrm{TMEDA}$ with trialkylstannyl halides. Ferrocenyl stannanes have also been prepared by first substituting the cyclopentadiene anion with $\mathrm{Me}_{3} \mathrm{SnNEt}_{2}$ (Figure 1.12). The resulting $\mathrm{C}_{5} \mathrm{H}_{4}\left(\mathrm{SnMe}_{3}\right)_{2}$ reacted with $n$-BuLi to remove one trimethylstannyl group and resulting in the formation of the lithium salt $[\mathrm{Li}]\left[\mathrm{C}_{5} \mathrm{H}_{4} \mathrm{SnMe}_{3}\right]$. The salt was then added to $\mathrm{FeCl}_{2}$ to form the disubstituted tin ferrocene through a salt elimination of $\mathrm{LiCl}^{104}$

\footnotetext{
*Abbe's number is a ratio of the refractive indices at different wavelengths.
} 
Dinh et al. ${ }^{105}$ prepared the first chlorostannyl ferrocene in the literature. Both $\mathrm{Fe}\left(\eta^{5}\right.$ $\left.\mathrm{C}_{5} \mathrm{H}_{4} \mathrm{SnR}_{2} \mathrm{H}\right)_{2}$ and $\mathrm{Fe}\left(\eta^{5}-\mathrm{C}_{5} \mathrm{H}_{4} \mathrm{SnR}_{2} \mathrm{Cl}\right)_{2}(\mathrm{R}=$ alkyl $)$ were prepared via an exchange reaction with $\mathrm{Fe}\left(\eta^{5}-\mathrm{C}_{5} \mathrm{H}_{4} \mathrm{SnHgCl}\right)_{2}$ with $\mathrm{R}_{2} \mathrm{SnS}$. The monosubstituted ferrocenyl stannanes have been synthesized through the same method. Dinh was also able to synthesis the phenyl analogue through the same route.

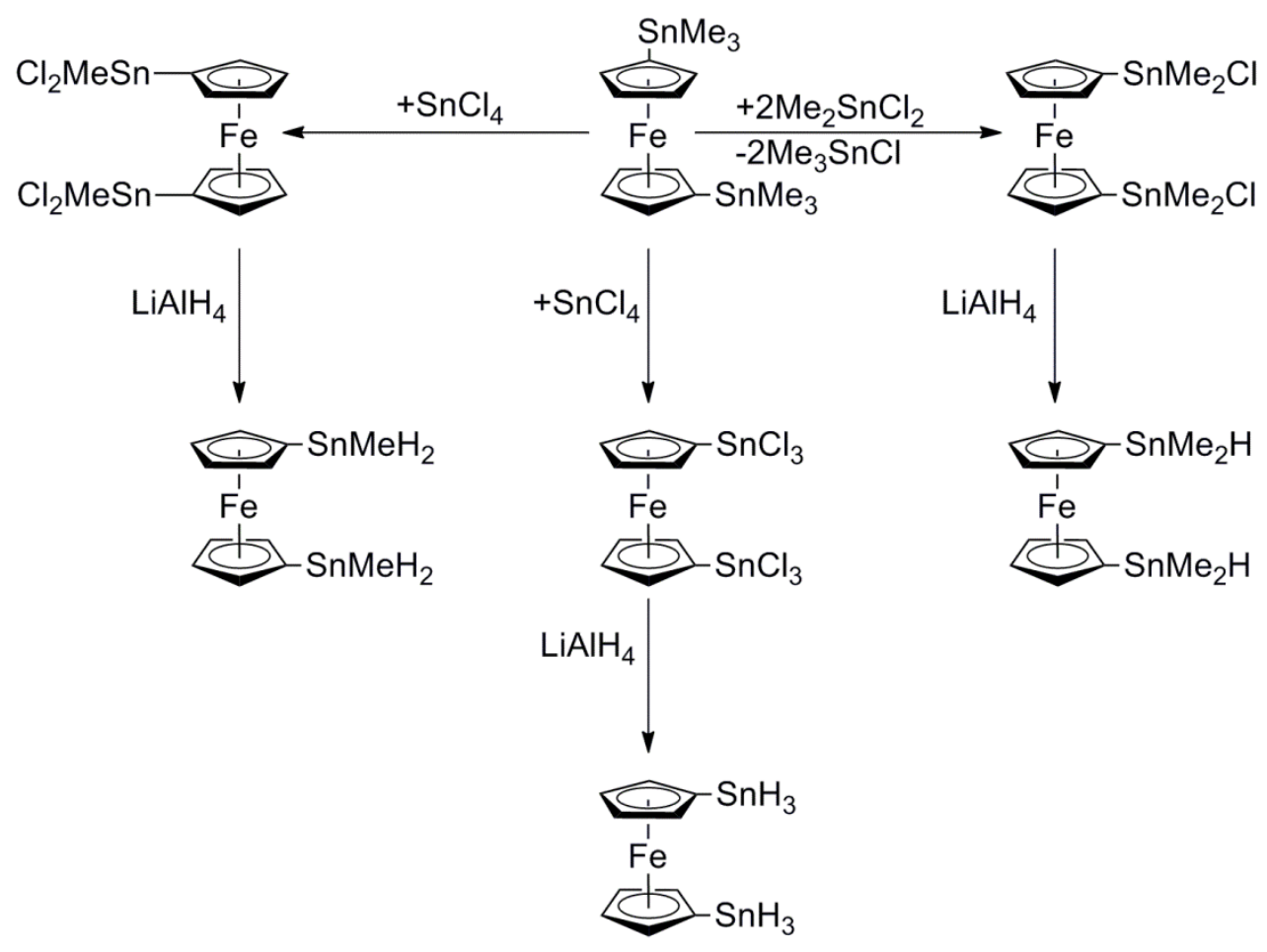

Figure 1.13: Routes to various 1,1 'bis(chlorostannyl)ferrocenes and 1,1'bis(stannyl)ferrocenes.

Herberhold and Wrackmeyer were able to synthesize the $\mathrm{Fe}\left(\eta^{5}-\mathrm{C}_{5} \mathrm{H}_{4} \mathrm{SnMe}_{2} \mathrm{Cl}\right)_{2}$ through a redistribution reaction between $\mathrm{Fe}\left(\eta^{5}-\mathrm{C}_{5} \mathrm{H}_{4} \mathrm{SnMe}_{3}\right)_{2}$ and two equivalents of $\mathrm{Me}_{2} \mathrm{SnCl}_{2}$ at $140^{\circ} \mathrm{C}$. This route was an improvement over the Dinh method as there was no use of mercury as either a reagent or a by-product; however this was only performed with methyltins. Herberhold and Wrackmeyer were also the first to prepare the corresponding ferrocenyl tin hydride through a reduction of the $\mathrm{Fe}\left(\eta^{5}-\mathrm{C}_{5} \mathrm{H}_{4} \mathrm{SnMe}_{2} \mathrm{Cl}\right)_{2}{ }^{41}$ This involved reacting $\mathrm{Fe}\left(\eta^{5}-\mathrm{C}_{5} \mathrm{H}_{4} \mathrm{SnMe}_{2} \mathrm{Cl}\right)_{2}$ with 
$\mathrm{LiAlH}_{4}$ at $0^{\circ} \mathrm{C}$ under inert atmosphere. Further studies of the reactivity of the $\mathrm{Fe}\left(\eta^{5}-\mathrm{C}_{5} \mathrm{H}_{4} \mathrm{SnMe}_{3}\right)_{2}$ system lead to production of a series of disubstituted mono-, di- and tri-chlorides, as well as the corresponding hydrides (Figure 1.13). ${ }^{106}$

A variety of interesting structural ferrocenyl stannanes have produced through the systems described. Lenze et al. was able to prepare a series of multi-substituted methylstannylferrocenes through reactions with mono- and dilithioferrocene as well as through the initial formation of substituted cyclopentadiene rings that were then further reacted with $\mathrm{FeCl}_{2}$ to form the corresponding ferrocene analogue. ${ }^{107} \mathrm{Wu}$ et al. ${ }^{108}$ employed a mercury exchange with alkyl tin to form a 6-coodinate tin involving two ferrocenes, two chlorines and two aryl imines. Using $\left(\eta^{5}-\mathrm{C}_{5} \mathrm{H}_{4} \mathrm{SnCl}_{3}\right) \mathrm{Fe}\left(\eta^{5}-\mathrm{C}_{5} \mathrm{H}_{5}\right)$ synthesized through a modified method Herberhold and Wrackmeyer used to prepare $\mathrm{Fe}\left(\eta^{5}-\mathrm{C}_{5} \mathrm{H}_{4} \mathrm{SnCl}_{3}\right)_{2} ;{ }^{106}$ Dehnen et al. carried out a reaction with dry $\mathrm{Na}_{2} \mathrm{~S}$ to form a sulfur stannylferrocene cage. ${ }^{109}$

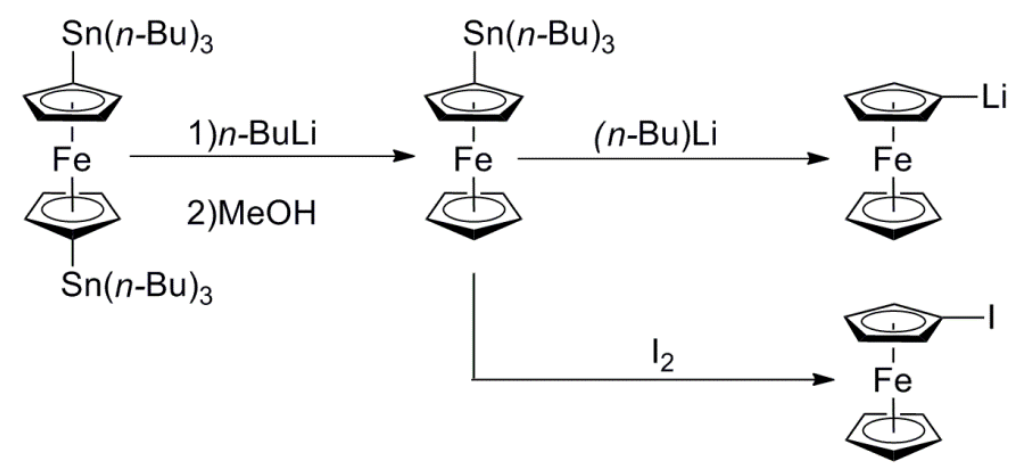

Figure 1.14: Synthesis of monolithio- or monoiodoferrocene.

In general the primary use of ferrocenyl stannanes is for the synthesis of monolithioferrocene and monoiodoferrocene. This can be achieved via a synthesis of $\left(\eta^{5}-\right.$ $\left.\mathrm{C}_{5} \mathrm{H}_{4} \mathrm{Sn}(n-\mathrm{Bu})_{3}\right)_{2} \mathrm{Fe}$ by Dodo's method. The substituted ferrocene is then reacted with one 
equivalent of $n$-BuLi producing a monolithiated (tri(n-butyl)stannyl)ferrocene. This product can either be reacted with another suitable halide to produce an unsymmetrical ferrocene ${ }^{110}$ or quenched with $\mathrm{MeOH}$ to form $\left(\eta^{5}-\mathrm{C}_{5} \mathrm{H}_{4} \mathrm{Sn}(n-\mathrm{Bu})_{3}\right) \mathrm{Fe}\left(\eta^{5}-\mathrm{C}_{5} \mathrm{H}_{5}\right)$ ferrocene, ${ }^{111}$ which then can be reacted with a further equivalent of $n$ - BuLi to form $\left(\eta^{5}-\mathrm{C}_{5} \mathrm{H}_{4} \mathrm{Li}\right) \mathrm{Fe}\left(\eta^{5}-\mathrm{C}_{5} \mathrm{H}_{5}\right)$, or the stannyl group can be exchanged via a reaction with $\mathrm{I}_{2}$ to form $\left(\eta^{5}-\mathrm{C}_{5} \mathrm{H}_{4} \mathrm{I}\right) \mathrm{Fe}\left(\eta^{5}-\mathrm{C}_{5} \mathrm{H}_{5}\right)$ and $(n-\mathrm{Bu})_{3} \mathrm{SnI}$ Figure 1.14). ${ }^{112,113}$ The unsymmetrical ferrocene species have been used to form interesting small molecules, ${ }^{114}$ or undergone further manipulation to form polymers. ${ }^{115}$

Seyferth et $a .^{50}$ was the first to synthesis a homogenous bridged stannyl[n]ferrocenophane in a very small yield $(\approx 3 \%)$. During a failed attempt to prepare $\mathrm{Fe}\left(\eta^{5}-\right.$ $\left.\mathrm{C}_{5} \mathrm{H}_{4}\right)_{2} \mathrm{Sn}(n-\mathrm{Bu})_{2}$, Seyferth was able to isolate, along with considerable polymeric material, the corresponding [1.1]ferrocenophane. Manners later discovered the route to stannyl[1]ferrocenophanes involves the use of sterically bulky substituents. ${ }^{38,116}$ They synthesized both the $\mathrm{Fe}\left(\eta^{5}-\mathrm{C}_{5} \mathrm{H}_{4}\right)_{2} \mathrm{Sn}(t-\mathrm{Bu})_{2}$ and the $\left(\eta^{5}-\mathrm{C}_{5} \mathrm{H}_{4}\right)_{2} \mathrm{SnMes} 2$ through a reaction of $\mathrm{Fe}\left(\eta^{5}-\mathrm{C}_{5} \mathrm{H}_{4} \mathrm{Li}\right)_{2}$ with $\mathrm{R}_{2} \mathrm{SnCl}_{2}(\mathrm{R}=t$-Bu and Mes).

The preparation of [2]- and [3]ferrocenophanes with di- or tristanna bridging units was carried out by Herberhold and Wrackmeyer (Figure 1.15). ${ }^{41}$ They were able to perform an intramolecular dehydrogenative coupling of $\mathrm{Fe}\left(\eta^{5}-\mathrm{C}_{5} \mathrm{H}_{4} \mathrm{SnMe}_{2} \mathrm{H}\right)_{2}$ in the presence of $\mathrm{R}_{2} \mathrm{Sn}\left(\mathrm{NEt}_{2}\right)_{2}$ when $\mathrm{R}=\mathrm{Et}, \quad i$-Pr, and $n$ - $\mathrm{Bu}$ to prepare $1,1^{\prime}, 2,2^{\prime}$-tetramethyldistanna[2]ferrocenophane $\mathrm{Fe}\left(\eta^{5}-\mathrm{C}_{5} \mathrm{H}_{4}\right)_{2}\left(\mathrm{SnMe}_{2}\right)_{2}$. When the same reaction was carried out with $\mathrm{Me}_{2} \mathrm{Sn}\left(\mathrm{NEt}_{2}\right)_{2}$ a deamination coupling reaction occurred to form $1,1^{\prime}, 2,2^{\prime}, 3,3^{\prime}$ hexamethyltristanna-[3]ferrocenophane $\mathrm{Fe}\left(\eta^{5}-\mathrm{C}_{5} \mathrm{H}_{4}\right)_{2}\left(\mathrm{SnMe}_{2}\right)_{3}$ in a $43 \%$ yield. $^{41}$ 
$\mathrm{Fe}\left(\eta^{5}-\mathrm{C}_{5} \mathrm{H}_{4}\right)_{2}\left(\mathrm{SnMe}_{2}\right)_{2}$ have been reacted with a series of Group $15(\mathrm{P})^{117}$ and $16(\mathrm{O}, \mathrm{S}$, $\mathrm{Se}, \mathrm{Te})^{118}$ reactants allowing for insertion between the $\mathrm{Sn}-\mathrm{Sn}$ bond to form heterogeneous 1,3distanna-[3]ferrocenophanes. Pt metal complexes were also shown to insert between the Sn-Sn bond of a $\mathrm{Fe}\left(\eta^{5}-\mathrm{C}_{5} \mathrm{H}_{4}\right)_{2}\left(\mathrm{SnMe}_{2}\right)_{2} \cdot{ }^{119}$ When elemental $\mathrm{S}$, Se, or Te were reacted $\mathrm{Fe}\left(\eta^{5}-\right.$ $\left.\mathrm{C}_{5} \mathrm{H}_{4}\right)_{2}\left(\mathrm{SnMe}_{2}\right)_{3}$ the central $\mathrm{Sn}$ was replaced with the corresponding chalcogen. When reacted with $\mathrm{I}_{2}$, the central $\mathrm{Sn}$ of the [3]ferrocenophane was removed as $\mathrm{Me}_{2} \mathrm{SnI}_{2}$ to from $\mathrm{Fe}\left(\eta^{5}\right.$ $\left.\mathrm{C}_{5} \mathrm{H}_{4} \mathrm{SnMe}_{2} \mathrm{I}\right)_{2} \cdot{ }^{120}$

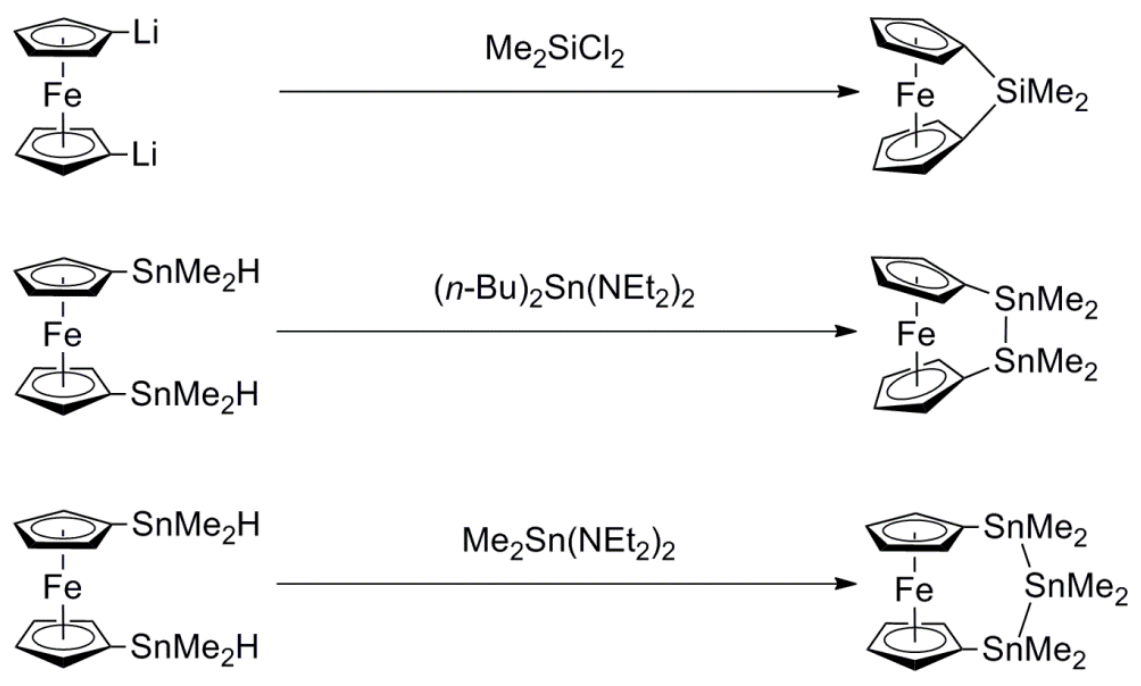

Figure 1.15: Preparation of stanna-[n]ferrocenophanes.

There has been some reports of the insertion of metal carbonyl groups into the $\mathrm{Sn}-\mathrm{C}$ bond of [1]ferrocenophanes. When the insertion is performed with iron, $\mathrm{Fe}(\mathrm{CO})_{4}$ inserts to form the corresponding [2]ferrocenophane. However when $\mathrm{Co}_{2}(\mathrm{CO})_{8}$ is reacted with di(t-butyl)stannyl[1]ferrocenophane, a ketone bridged biferrocene is formed with $\mathrm{SnMe}_{2} \mathrm{Co}(\mathrm{CO})_{4}$ attached to the free cyclopentadiene ring of each ferrocene. ${ }^{121}$ 


\subsection{Polyferrocenyl stannanes}

Currently there are only a few known polyferrocenyl stannanes ${ }^{38,116,122}$ present in the literature, as well as one polyruthenocenyl stannane ${ }^{123}$ and one polytroticenyl stannane* ${ }^{* 24}$ Due to limited methods of preparation and the small sampling of stannyl-[1]ferrocenophanes requiring sterically large substituents, the study of polyferrocenylstannanes has been limited. Attempts to synthesize less sterically bulky stannyl-[1]ferrocenophanes leads instead largely to the production of [1.1]ferrocenophanes and polymer.

\subsubsection{Synthesis}

In 1996 Manners et al. ${ }^{38,116}$ was able to ring open [1]ferrocenophanes $\mathrm{Fe}\left(\eta^{5}-\mathrm{C}_{5} \mathrm{H}_{4}\right)_{2} \mathrm{SnR}_{2}$ where $\mathrm{R}$ was either $t$-butyl or mesityl, to form high molecular weight polyferrocenylstannanes. When $\left[\mathrm{Fe}\left(\eta^{5}-\mathrm{C}_{5} \mathrm{H}_{4}\right)_{2} \mathrm{Sn}(t-\mathrm{Bu})_{2}\right]_{\mathrm{n}}$ was left in ambient temperatures for several days ROP spontaneously occurred to form $\left[\mathrm{Fe}\left(\eta^{5}-\mathrm{C}_{5} \mathrm{H}_{4}\right)_{2} \mathrm{Sn}(t-\mathrm{Bu})_{2}\right]_{\mathrm{n}}$, that was found to have a bimodal distribution of molecular weights at $2.3 \times 10^{5} \mathrm{Da}$ and $1.5 \times 10^{4} \mathrm{Da}$ with PDIs of 1.8 and 3.0 respectively. Thermal ROP of the $t$-butyl [1]ferrocenophane at $150^{\circ} \mathrm{C}$ produced polymer with a $\mathrm{M}_{\mathrm{w}}$ of $1.5 \times 10^{5} \mathrm{Da}$ and a PDI of 1.6 (Figure 1.16). When $\mathrm{Fe}\left(\eta^{5}-\mathrm{C}_{5} \mathrm{H}_{4}\right)_{2} \mathrm{Sn}(t-\mathrm{Bu})_{2}$ was dissolved in toluene, non-catalyzed ROP occurred in only $6 \mathrm{~h}$. The resulting high molecular weight polymer had an $\mathrm{M}_{\mathrm{w}}$ of $9.0 \times 10^{6} \mathrm{Da}$ and a PDI of 1.6. After $1 \mathrm{~h}$, a low conversion (20\%) with a molecular weight of $6.3 \times 10^{5} \mathrm{Da}$ (PDI of 1.3) providing evidence that the polymerization is chain growth in nature. In the presence of chlorinated solvents such as $\mathrm{CHCl}_{3}$, lower molecular weight polymer $\left(\mathrm{M}_{\mathrm{w}}=1 \times 10^{4} \mathrm{Da}, \mathrm{PDI}=2.2\right)$, as well as the $[1.1]$ ferrocenophane $\left[\mathrm{Fe}\left(\eta^{5}-\mathrm{C}_{5} \mathrm{H}_{4}\right)_{2} \mathrm{Sn}(t-\mathrm{Bu})_{2}\right]_{2}$ formed within $6 \mathrm{~h}$.

\footnotetext{
* troticene is the metallocene $\left(\eta^{5}-\mathrm{C}_{5} \mathrm{H}_{5}\right) \mathrm{Ti}\left(\eta^{7}-\mathrm{C}_{7} \mathrm{H}_{7}\right)$
} 


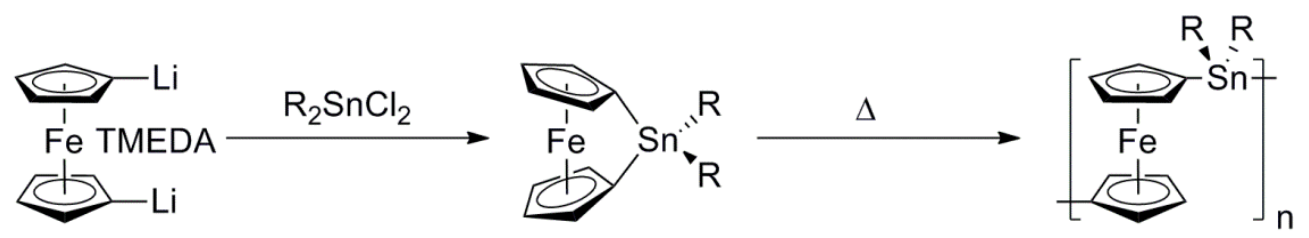

Figure 1.16: Synthesis of [1]ferrocenyl stannanes and ROP to form polyferrocenylstannane. When $\mathrm{M}=\mathrm{Fe} \mathrm{R}=(t$-Bu$)$, Mes, and PiPP, when $\mathrm{M}=\mathrm{Ru} \mathrm{R}=\mathrm{Mes}$.

Compared to the $\mathrm{Fe}\left(\eta^{5}-\mathrm{C}_{5} \mathrm{H}_{4}\right)_{2} \mathrm{Sn}(t-\mathrm{Bu})_{2}$, the mesityl substituted monomer showed a reduced ability to undergo ROP. Mesityl monomers required heating for $6 \mathrm{~h}$ at $180^{\circ} \mathrm{C}$ (compared to $30 \mathrm{~min}$ at $150^{\circ} \mathrm{C}$ for the $t$-butyl monomer) before polymerization was completed. Completely stable when solvent free in ambient temperatures, these tin [1]ferrocenophanes took up to $30 \mathrm{~d}$ in solvents to ring open. Polymers formed via thermal ROP had molecular weight of around $1.5 \times 10^{5}$ Da with the largest polymers synthesized in solution $\left(\mathrm{C}_{6} \mathrm{D}_{6}\right)$ at ambient temperatures for $15 \mathrm{~d}$ with molecular weight of $1.35 \times 10^{6} \mathrm{Da}$, PDI of 1.3 and a conversion of $50 \%$.

Attempts to synthesize less sterically bulky tin containing [1]ferrocenophanes was less successful and produced only low to moderate molecular weight oligomeric species as well as cyclic [1.1]ferrocenophanes. These materials had molecular weights of $\mathrm{M}_{\mathrm{w}}=1.4 \times 10^{3} \mathrm{Da}$. The only reported polydispersity index was that of the $\left[\mathrm{Fe}\left(\eta^{5}-\mathrm{C}_{5} \mathrm{H}_{4}\right)_{2} \mathrm{Sn}(t-\mathrm{Bu})_{2}\right]_{n}{ }^{86}$ with a PDI of 2.3.

The ROP of stannyl-[1]ferrocenophane to form polyferrocenylstannanes was initially believed to proceed through a radical mechanism, however there is no evidence for radicals ${ }^{*}$ within ambient temperature reactions. ${ }^{125}$ Furthermore, the addition of neutral nucleophiles dramatically increased the rate of reaction. When reacted with excess pyridine $\left(0.1 \mathrm{M}\right.$ in $\left.\mathrm{C}_{6} \mathrm{H}_{6}\right)$, the $\mathrm{Fe}\left(\eta^{5}-\mathrm{C}_{5} \mathrm{H}_{4}\right)_{2} \mathrm{SnMes}_{2}$ polymerization reached $95 \%$ conversion in $24 \mathrm{~h}$ compared to the ${ }^{*}$ negative radical trap and ineffective radical initiator of $\mathrm{AIBN}$ and $\mathrm{Bu}_{3} \mathrm{SnH}$ at $60^{\circ} \mathrm{C}$ 
control $<3 \%$ conversion in $24 \mathrm{~h}$ at ambient temperatures. Due to the fact that pyridine did not add to the polymer, it was rationalized that the mechanism involved an attack of the $\mathrm{Sn}-\mathrm{C}$ bond of one monomer by another. Similar results were discovered with the addition of a cationic species such as $\operatorname{ROTf}\left(\mathrm{R}=\mathrm{H}\right.$ or $\left.(n-\mathrm{Bu})_{3} \mathrm{Sn}\right) .{ }^{126}$

Pannell et al. ${ }^{122}$ was also able to prepare and ring open the bulky $\mathrm{Fe}\left(\eta^{5}-\mathrm{C}_{5} \mathrm{H}_{4}\right)_{2} \mathrm{SnPiPP}_{2}$ via a similar method. Thermal ROP was performed at $180^{\circ} \mathrm{C}$ for $2 \mathrm{~h}$ to form polymeric material which, after precipitation in hexanes, was insoluble in organic solvents.
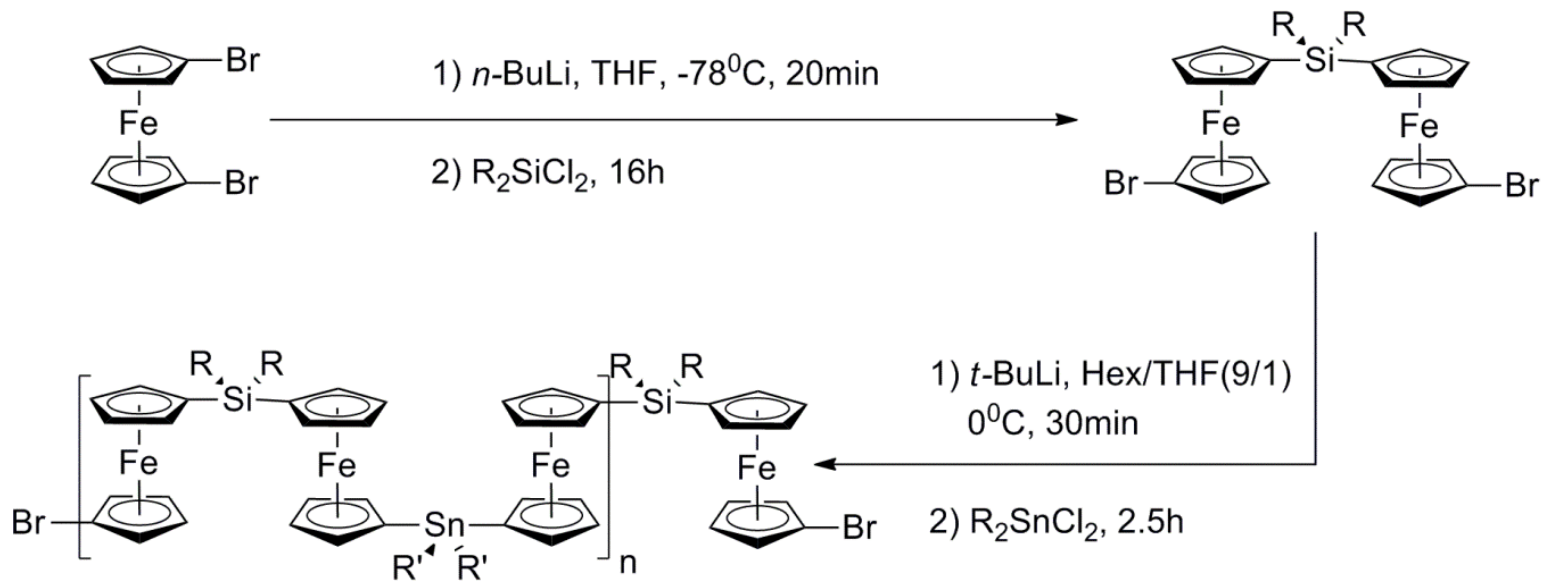

Figure 1.17: Route to synthesis of alternating FcSnFcSi oligomers. $\mathrm{R}=\mathrm{Me}, \mathrm{Et} ; \mathrm{R}$ ' $=\mathrm{Me}, n-\mathrm{Bu}$, $t-\mathrm{Bu}$

Muller et al. ${ }^{127}$ in an attempt to synthesis [1.1]ferrocenophanes with alternating bridges of silicon and tin, was able to prepare oligomers of up to 10 repeating units of linear alternating ferrocenyl silanes and ferrocenyl stannanes $\left[\left(\eta^{5}-\mathrm{C}_{5} \mathrm{H}_{4}\right) \mathrm{Fe}\left(\eta^{5}-\mathrm{C}_{5} \mathrm{H}_{4}\right)-\left(\mathrm{SiR}_{2}\right)-\left(\eta^{5}-\mathrm{C}_{5} \mathrm{H}_{4}\right) \mathrm{Fe}\left(\eta^{5}-\mathrm{C}_{5} \mathrm{H}_{4}\right)-\right.$ $\left(\mathrm{SnR}_{2}{ }_{2}\right)^{-]^{* *}}\left(\mathrm{R}=\mathrm{Me}\right.$ and $\mathrm{Et}, \mathrm{R}^{\prime}=\mathrm{Me}, n-\mathrm{Bu}$, and $\left.t-\mathrm{Bu}\right)$ as well as cyclic species of alternating ferrocenyl silanes and ferrocenyl stannanes of up to 11 repeating units. This was accomplished

\footnotetext{
* this is not surprising and follows with previously synthesised diarylsilyl and diarylgermyl ferrocene based polymers.

*this is the formula for the dimer, and the reapeating unit that will always end with a ferrocenyl silane.
} 
first by preparing a ferrocenyl silane dimer with two brominated cyclopentadiene rings, which was further reacted with $n$-BuLi, and finally with $\mathrm{R}_{2} \mathrm{SnCl}_{2}$ (see Figure 1.17 ) to form linear and cyclic oligomeric species. Molecular weights of these oligomers ranged from $2.1-2.9 \times 10^{3} \mathrm{Da}$ with PDI's around 1.4 with two exceptions. Both oligomers (Me and Et silane) containing ( $n$ $\mathrm{Bu})_{2} \mathrm{Sn}$ showed larger molecular weights of $6.3 \times 10^{3}(\mathrm{Me})$ and $5.9 \times 10^{3}(\mathrm{Et}) \mathrm{Da}$ with PDI's of 2.52 and 2.26 respectively.
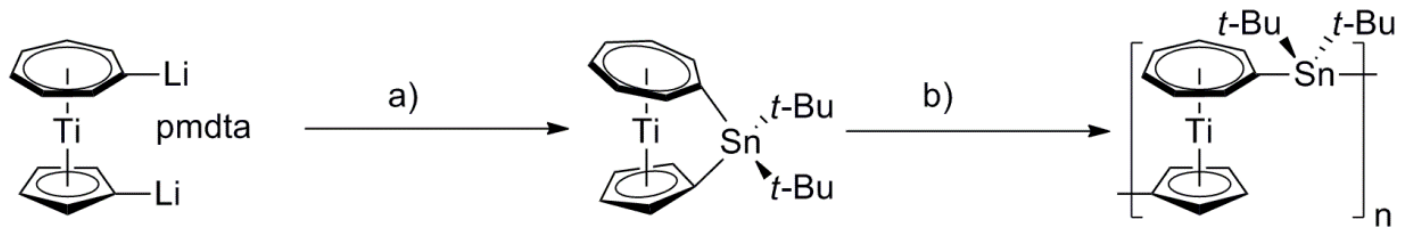

Figure 1.18: The synthesis of troticenophane monomer and associated ring opening polymerization a) $(t-\mathrm{Bu})_{2} \mathrm{SnCl}_{2}$ at $-78^{\circ} \mathrm{C}$ in hexane b) $240^{\circ} \mathrm{C}$ solvent free or $2 \% n$ - $\mathrm{BuLi}$ in $\mathrm{THF}$ at room temperature.

Other polymetallocenyl stannanes have been synthesised. The first was a thermal ROP of (dimesityl)stannyl-[1]ruthenocenophane to form a polyruthenocene dimesitylstannane, $\left[\operatorname{Ru}\left(\eta^{5}\right.\right.$ $\left.\left.\mathrm{C}_{5} \mathrm{H}_{4}\right)_{2} \mathrm{Sn}(\mathrm{Mes})_{2}\right]_{\mathrm{n}}{ }^{123}$ Through DSC, the thermal ROP of $\mathrm{Ru}\left(\eta^{5}-\mathrm{C}_{5} \mathrm{H}_{4}\right)_{2} \mathrm{Sn}(\mathrm{Mes})_{2}$ commences at $181^{\circ} \mathrm{C}$. When ROP was carried out at $200^{\circ} \mathrm{C}$ for $4.5 \mathrm{~h}$ a yield of $45 \%$ of the polymer was obtained, with a molecular weight of $6.2 \times 10^{5} \mathrm{Da}$ and a PDI of 2.28. Recently, an oligomeric troticenylstannane was synthesized through a thermal ROP (onset of polymerization occurred at $233^{\circ} \mathrm{C}$, DSC) of di-t-butylstanna-[1]troticenophane at $240^{\circ} \mathrm{C} .{ }^{124}$ When $n$-BuLi was added to the same monomer in THF, polytroticenylstannane was formed through an anionic initiated ROP. Polymers recovered had a molecular weight of $1.7 \times 10^{3} \mathrm{Da}$ for the thermal ROP and $1.4 \times 10^{4} \mathrm{Da}$ for the anionic ROP with PDI's of 1.4 and 1.9 respectively (Figure 1.18). 


\subsubsection{Properties}

Polyferrocenyl stannanes display interesting optical, electronic, thermal, and structural properties. They are for the most part air and light stable which is typical of tetra alkyl or aryl tin compounds $\left(\mathrm{R}_{4} \mathrm{Sn}\right.$ where $\mathrm{R}=$ alkyl or aryl $)$.

Thermally, polyferrocenyl stannanes show diverse properties that can be related to the rigidity of the tin bridge. ${ }^{*}$ The $\left[\mathrm{Fe}\left(\eta^{5}-\mathrm{C}_{5} \mathrm{H}_{4}\right)_{2} \mathrm{Sn}(t-\mathrm{Bu})_{2}\right]_{\mathrm{n}}$ prepared by Manners had a $\mathrm{T}_{\mathrm{g}}$ of $124^{\circ} \mathrm{C}$ and a thermal decomposition at $210^{\circ} \mathrm{C}$ breaking down to a red/gold ceramic. This thermal stability is much lower than that of polyferrocenylsilanes, ${ }^{128}$ in contrast to the much more rigid $\left[\mathrm{Fe}\left(\eta^{5}-\mathrm{C}_{5} \mathrm{H}_{4}\right)_{2} \mathrm{SnMes}_{2}\right]_{\mathrm{n}}$ which showed a glass transition at $208^{\circ} \mathrm{C}$ with thermal decomposition beginning at $320^{\circ} \mathrm{C}$ forming a gold ceramic. With a $\mathrm{T}_{\mathrm{g}}$ of $221^{\circ} \mathrm{C}$ and thermal decomposition occurring at $270^{\circ} \mathrm{C}$, the $\left[\mathrm{Ru}\left(\eta^{5}-\mathrm{C}_{5} \mathrm{H}_{4}\right)_{2} \mathrm{SnMes}_{2}\right]_{\mathrm{n}}$ had similar thermal properties to its ferrocenyl analogue. The $\left[\mathrm{Fe}\left(\eta^{5}-\mathrm{C}_{5} \mathrm{H}_{4}\right)_{2} \mathrm{SnPiPP}_{2}\right]_{\mathrm{n}}$ also shows a thermal decomposition between $300^{\circ} \mathrm{C}$ and $400^{\circ} \mathrm{C}$, although no glass transition was reported.

Metallocene based polymers have optical properties determined by the metallocene within their structure. Ferrocene based polymers are usually yellow to red in color. The polyferrocenyl stannanes are no exception, with the $\lambda_{\max }$ of the $t$-butyl and mesityl polymer 452 $\mathrm{nm}$ (with a shoulder at $340 \mathrm{~nm}$ ) and $445 \mathrm{~nm}$ respectively. The ruthenocenyl stannanes polymer synthesised formed a white powder, while the troticene polymer was green in color.

Refractive indexes for polymers synthesized by Manners et al. have been studied extensively. ${ }^{96,97}$ The ferrocenyl stannane based polymers show refractive indexes of $1.64(t-\mathrm{Bu})$ and $1.66(\mathrm{Mes})$ measured at $589 \mathrm{~nm}$. From the refractive index, the molar refraction of the

\footnotetext{
* The rigidity of the tin bridge is based on among other things the steric bulk of the substituents attached to the tin.
} 
backbone was calculated to be $63.2^{*} \mathrm{~cm}^{3} \cdot \mathrm{mol}^{-1}$ which was larger those that of Si and Ge. A theoretical calculation can be performed using the molar refraction values to predict the refractive index of unknown polyferrocenylstannanes substituted by methyl or napthyl at 1.73 (methyl) and 1.80 (napthyl). These values were higher than those measured for polyferrocenylsilanes, polyferrocenylgermanes, and polyferrocenylphosphines. The RI of the $\left[\mathrm{Ru}\left(\eta^{5}-\mathrm{C}_{5} \mathrm{H}_{4}\right)_{2} \mathrm{SnMes}_{2}\right]_{\mathrm{n}}$ was found to be 1.66 , the same as the $\left[\mathrm{Fe}\left(\eta^{5}-\mathrm{C}_{5} \mathrm{H}_{4}\right)_{2} \mathrm{SnMes}\right]_{n}$. The optical dispersion of these polymers was also calculated. The optical dispersion of polyferrocenyl stannanes was larger than that of polyruthenocenyl stannanes but still lower than organic and metal dispersed polymer of the same refractive indices. ${ }^{* *}$

Table 1.8: Electronic properties of ferrocenyl stannanes.

\begin{tabular}{cccc}
\hline $\mathbf{E}^{\mathbf{a}}$ & ${ }^{1} \mathbf{E}_{\mathbf{1 / 2}}(\mathbf{V})^{\mathbf{b}}$ & ${ }^{1} \mathbf{E}_{\mathbf{1} / \mathbf{2}}(\mathbf{V})^{\mathbf{b}}$ & $\Delta \mathbf{E}_{\mathbf{1 / 2}}(\mathbf{V})$ \\
\hline$(\boldsymbol{n}-\mathbf{B u})_{\mathbf{2}} \mathbf{S i}^{\mathbf{8 6}}$ & 0.00 & 0.29 & 0.29 \\
$(\boldsymbol{n}-\mathbf{B u})_{2} \mathbf{S n}^{86}$ & -0.06 & 0.18 & 0.24 \\
$(\boldsymbol{t}-\mathbf{B u})_{2} \mathbf{S n}^{116}$ & 0.00 & 0.24 & 0.24 \\
$\mathbf{M e s}_{\mathbf{2}} \mathbf{S n}^{116}$ & -0.07 & 0.14 & 0.21
\end{tabular}

${ }^{a}$ where $\mathrm{E}$ is the bridging unit polymers with the molecular formular $[\mathrm{FcE}]^{\mathrm{b}}$ all values are referenced to ferrocene/ferrocenium redox event.

Electronically, polyferrocenyl stannanes have the same affect that is observed by ferrocenyl silanes and germanes, specifically two redox events observed in cyclic voltammetry $(\mathrm{CV})$. The observed $\mathrm{E}_{1 / 2}$ values for that of polyferrocenyl stannanes are seen in Table 1.8.

\footnotetext{
${ }^{*}$ See section 1.3.2 for details of calculation.

** Based on calculation of Abbe's number, which is inversely proportional to optical dispersion.
} 


\subsection{Research objectives}

The wide scale preparation of novel tin bridged ferrocene based polymers has to date met limited success due to the small number of monomers available for polymerization. The main objectives of this research to address this issue by synthesizing tin polymers by the synthesis of ferrocene based polymers via dehydrogenative of reactive monomers which avoids the need to prepare a large number of [1]ferrocenophanes. A further goal is to identify find a simple method of producing stannyl-[2]ferrocenophanes, as monomers for ROP. Finally the ROP of stannyl[2]ferrocenophanes to prepare dibridged polyferrocenyl distannanes will be investigated. 


\subsection{Polymerisation of Novel Polyferrocenyl Dimethyl Stannyl Polymers}

\subsection{Introduction:}

Since its discovery, ferrocene has been used in the modification of molecular structure. This is due, in part, to its structural stability and interesting optoelectric properties. The first examples of oligo- and low molecular weight polyferrocenyl silanes, $\left[\mathrm{Fe}\left(\eta^{5}-\mathrm{C}_{5} \mathrm{H}_{4}\right)_{2} \mathrm{SiR}\right]_{n}$ were prepared through the condensation of $\mathrm{Fe}\left(\eta^{5}-\mathrm{C}_{5} \mathrm{H}_{4} \mathrm{Li}\right)_{2}$ with chlorosilanes. ${ }^{58}$

The first well characterized high molecular weight polyferrocenylene was prepared in 1992 by Rauchfuss et al. ${ }^{73}$ who was able to ring open, by a novel ring abstraction, trithia[3]ferrocenophane through the use of a Lewis base, $(n-\mathrm{Bu})_{3} \mathrm{P}$, initiated reaction to form polyferrocenylene persulfide. In that same year Manners et al. synthesized high molecular weight $\left[\mathrm{Fe}\left(\eta^{5}-\mathrm{C}_{5} \mathrm{H}_{4}\right)_{2} \mathrm{SiMe}_{2}\right]_{n}$ through a thermal ring opening polymerization of a strained $\mathrm{Fe}\left(\eta^{5}\right.$ -

$\left.\mathrm{C}_{5} \mathrm{H}_{4}\right)_{2} \mathrm{SiMe}_{2}{ }^{74}$ Manners et al. were also able to perform ROP of these monomers to form $\left[\mathrm{Fe}\left(\eta^{5}-\right.\right.$ $\left.\left.\mathrm{C}_{5} \mathrm{H}_{4}\right)_{2} \mathrm{SiR}_{2}\right]_{\mathrm{n}}$ using transition metal catalysts, ${ }^{75,76}$ anionic initiators, ${ }^{77}$ and $\mathrm{UV}$ radiation. ${ }^{78-81}$ Since then, the synthesis, production, and characterization of different polyferrocenes have been of great interest to materials science. Ferrocene polymers that include bridging elements containing Groups 13-16 $6^{83-87}$ have been synthesized through ROP of the corresponding [1]ferrocenophanes in high molecular weights and low PDI's.

Ferrocene based polymers containing a Group 14 element have been extensively studied. The Manners group has developed a large variety of these polyferrocenylenes containing C, Si, and Ge by ROP methods. ${ }^{85,86,92-94}$ Previous work in the Foucher group ${ }^{60,69}$ has described the preparation of $\left[\mathrm{Fe}\left(\eta^{5}-\mathrm{C}_{5} \mathrm{H}_{4}\right)_{2} \mathrm{SiMe}_{2}\right]_{\mathrm{n}}$ through a desilylative coupling in DCM as well as a unique 
polyferrocenyl disiloxane through the oxygen insertion reaction in DMF of $\mathrm{Fe}\left(\eta^{5}-\mathrm{C}_{5} \mathrm{H}_{4} \mathrm{SiMe}_{2} \mathrm{H}\right)_{2}$ using Karstedt's catalyst. Similar reactions to produce polyferrocenyl disiloxanes were also carried out by Nakazawa et al. ${ }^{70}$ using an iron based catalyst $\left(\left(\eta^{5}-\mathrm{C}_{5} \mathrm{H}_{5}\right)\left(\mathrm{CO}_{2}\right) \mathrm{FeMe}\right)$. Mochida $e t$ $a l .{ }^{94}$ was able to synthesize the only known dibridged ferrocene based polymer containing a later Group 14 element. A dibridged ferrocenyl germane polymer was prepared via a ROP of 1,1,2,2tetramethyldigermyl-[2]ferrocenophane using both $\mathrm{Pt}(\mathrm{acac})_{2}$ and $\mathrm{Pd}_{2}(\mathrm{dba})_{3}$ as transition metal catalysts.

There are four examples of polyferrocenyl stannanes in the literature to date. Due to the nature of tin, bulky $\mathrm{R}$ groups must be used to stabilize stannyl [1]ferrocenophanes, which undergo thermal ROP. Manners was able to synthesize lower molecular weight $n$-Bu polymers through a condensation reaction of $\mathrm{Fe}\left(\eta^{5}-\mathrm{C}_{5} \mathrm{H}_{4} \mathrm{Li}\right)_{2}$ and $(n-\mathrm{Bu})_{2} \mathrm{SnCl}_{2} ;{ }^{86}$ whereas the $t$-butyl and mesityl polymers were prepared through the thermal ${ }^{38,116}$ and nucleophilic ${ }^{126} \mathrm{ROP}^{*}$ of the $t$-Bu and Mes stannyl-[1]ferrocenophane. Pannell ${ }^{122}$ also successfully synthesized and thermally ringopened the diisoproylphenyl stannyl [1]ferrocenophane. Manners ${ }^{123}$ was also able to ROP a tinbridged [1]ruthenocenophane thermally to form the only known polyruthenocenylstannane.

\subsection{Results and discussion}

\subsubsection{Synthesis of monomers}

The preparation of monomers for condensation polymerization was carried out through a similar method to that reported by Herberhold and Wrackmeyer. ${ }^{41}$ Firstly, $\left(\eta^{5}\right.$ $\left.\mathrm{C}_{5} \mathrm{H}_{4} \mathrm{Li}\right)_{2} \mathrm{Fe} \cdot \mathrm{TMEDA}$ was prepared through a lithiation of ferrocene in the presence of TMEDA.

\footnotetext{
${ }^{*}$ The $n$-butyl polymer was attempt to synthesize the $n$-butyl [1]-ferrocenophane.
} 
The $\mathrm{Fe}\left(\eta^{5}-\mathrm{C}_{5} \mathrm{H}_{4} \mathrm{Li}\right)_{2} \bullet$ TMEDA was separated as an orange powder and stored under inert atmosphere conditions at room temperature.

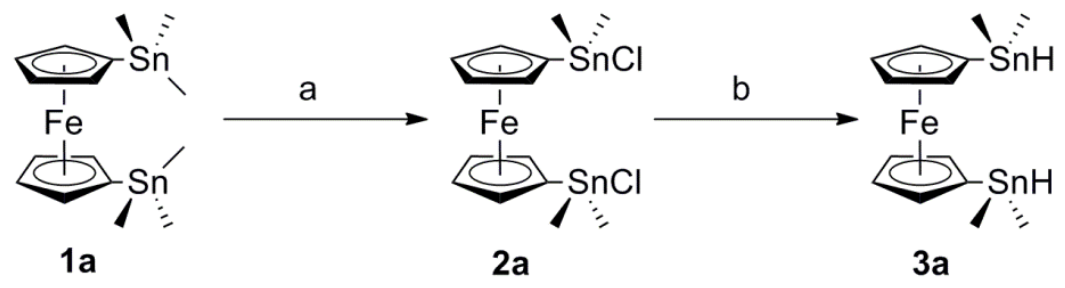

Figure 2.1: Synthesis of 3a from $1 \mathrm{a}$ via reactions a) $\mathrm{Me}_{2} \mathrm{SnCl}_{2}$ at $140^{\circ} \mathrm{C}$ in static vacuum for $3 \mathrm{~h}$ and b) $\mathrm{LiAlH}_{4}$ in $\mathrm{Et}_{2} \mathrm{O}$ at $0^{\circ} \mathrm{C}$ in inert atmosphere for $5 \mathrm{~h}$.

The preparation of $\mathrm{Fe}\left(\eta^{5}-\mathrm{C}_{5} \mathrm{H}_{4} \mathrm{SnMe}_{3}\right)_{2}$, 1a was carried out via a salt elimination reaction between the $\mathrm{Fe}\left(\eta^{5}-\mathrm{C}_{5} \mathrm{H}_{4} \mathrm{Li}\right)_{2} \bullet \mathrm{TMEDA}$ and $\mathrm{Me}_{3} \mathrm{SnCl}$. The resulting orange oil was moisture, light, and thermally stable up to $200^{\circ} \mathrm{C}$. By-products of this reaction include a small amount monosubstituted trimethylstannyl ferrocene (5-10\%) as well as unreacted ferrocene (1-2\%). Byproducts were in vacuo at $180^{\circ} \mathrm{C}$ and purified product was recovered in a $95 \%$ yield. Through a redistribution reaction involving $\mathrm{Me}_{2} \mathrm{SnCl}_{2}$ and $\mathbf{1 a}$ carried out at $140^{\circ} \mathrm{C}$, forming $\mathrm{Fe}\left(\eta^{5}\right.$ $\left.\mathrm{C}_{5} \mathrm{H}_{4} \mathrm{SnMe}_{2} \mathrm{Cl}\right)_{2}, \mathbf{2 a}$ (Figure 2.1) and $\mathrm{Me}_{3} \mathrm{SnCl}$. Compound 2a (dark orange-green oil), was not fully purified, however it was placed in vacuo to remove some of the $\mathrm{Me}_{3} \mathrm{SnCl}$ by-product and its purity monitored by ${ }^{119} \mathrm{Sn}$ NMR spectroscopy. Compound $2 \mathbf{a}$ was immediately reduced with excess ${ }^{*} \mathrm{LiAlH}_{4}$, yielding the dihydride $\mathrm{Fe}\left(\eta^{5}-\mathrm{C}_{5} \mathrm{H}_{4} \mathrm{SnMe}_{2} \mathrm{H}\right)_{2} \mathbf{3 a}$, recovered as a dark orange oil in $82 \%$ yield. The mono-substituted dimethylstannyl ferrocene, 3a' was sometimes present as a by-product, however this was removed in vacuo at $90^{\circ} \mathrm{C}$. 3a is stable under $\mathrm{N}_{2}$ in ambient temperatures and in light for a few weeks. When left for an extended period of time under inert

* excess $\mathrm{LiAlH}_{4}$ allowed any remaining $\mathrm{Me}_{3} \mathrm{SnCl}$ to be reduced to $\mathrm{Me}_{3} \mathrm{SnH}$. $\mathrm{Me}_{3} \mathrm{SnH}$ is more volatile than its chlorinated counterpart and therefore can be removed completely in vacuo with little effort. 
conditions, spontaneous dehydrogenative coupling occurs to form oligomeric di-bridged ferrocenyl stannane 4 (Figure 2.2).

An attempt was made to synthesize $\mathrm{Fe}\left(\eta^{5}-\mathrm{C}_{5} \mathrm{H}_{4} \mathrm{Sn}(n-\mathrm{Bu})_{2} \mathrm{H}\right)_{2}, \mathbf{3 b}$ through two different routes. Firstly, through a salt elimination reaction, $\mathbf{1 b}$ was prepared in a $85 \%$ yield and purified at $230^{\circ} \mathrm{C}$ in vacuo. When a redistribution reaction was performed on compound $\mathbf{1 b}$, the result was a mixture of chlorinated species of $\mathrm{Fe}\left(\eta^{5}-\mathrm{C}_{5} \mathrm{H}_{4} \mathrm{Sn}(n-\mathrm{Bu})_{2} \mathrm{Cl}\right)_{2} \quad(\mathbf{2 b}), \quad \mathrm{Fe}\left(\eta^{5}-\mathrm{C}_{5} \mathrm{H}_{4} \mathrm{Sn}(n\right.$ $\left.\mathrm{Bu}) \mathrm{Cl}_{2}\right)_{2}$, and $\mathrm{Fe}\left(\eta^{5}-\mathrm{C}_{5} \mathrm{H}_{4} \mathrm{SnCl}_{3}\right)_{2}$. The redistribution of $\mathbf{1 b}$ did not proceed in the same fashion as 1a due to the difference in boiling points of $\mathrm{Me}$ and $n$-Bu tin chlorides. $\mathrm{Me}_{3} \mathrm{SnCl}$ boils at a lower temperature than $\mathrm{Me}_{2} \mathrm{SnCl}_{2}$; whereas the boiling point of $(n-\mathrm{Bu})_{3} \mathrm{SnCl}$ is higher than $(n$ $\mathrm{Bu})_{2} \mathrm{SnCl}_{2}$. In the redistribution of $\mathbf{1 a}$, the reaction is driven forward by the removal of $\mathrm{Me}_{3} \mathrm{SnCl}$; however in the redistribution of $\mathbf{1 b},(n-\mathrm{Bu})_{3} \mathrm{SnCl}$ remain in the reaction and is allowed to react further. Attempts to purify $\mathbf{2 b}$ were unsuccessful, due to its reactivity with silica, and the ability for $\mathbf{2 b}$ to undergo redistribution at temperatures needed for distillation.

A second unsuccessful route to the synthesis of $\mathbf{3 b}$, was to first synthesize $\operatorname{di}(n$-butyl)(diethylamine)tin chloride, $\left((n-\mathrm{Bu})_{2} \mathrm{SnClNEt}_{2}\right)$ through a salt elimination of lithium diethylamide $\left(\mathrm{LiNEt}_{2}\right)$ with one equivalent to $(n-\mathrm{Bu})_{2} \mathrm{SnCl}_{2}$. Due to the nature of $\mathrm{Sn}-\mathrm{N}$ bonds the resulting compound was impure and reactive in moisture, on silica, or when heated in vacuo. When the reaction with $\mathrm{Fe}\left(\eta^{5}-\mathrm{C}_{5} \mathrm{H}_{4} \mathrm{Li}\right)_{2} \bullet$ TMEDA was carried out, a viscous oil was recovered displaying the presence of at least 3 distinct, inseparable species. No further efforts to obtain this species were attempted. 


\subsubsection{Condensation polymerization}

Attempts to polymerize 3a were initially carried out thermally at $120^{\circ} \mathrm{C}$ and $150^{\circ} \mathrm{C}$. Observations by ${ }^{119} \mathrm{Sn}$-NMR spectroscopy revealed that both the 1,1,2,2-tetramethyldistanna[2]ferrocenophane $\mathbf{5 a}$, as well as polymer $\mathbf{4}$ were formed via a thermally driven dehydrogenative coupling reaction. Unfortunately, up to $50 \%$ of the reaction mixture was found to be an insoluble solid, which is likely cross-linked polyferrocenyl stannane.

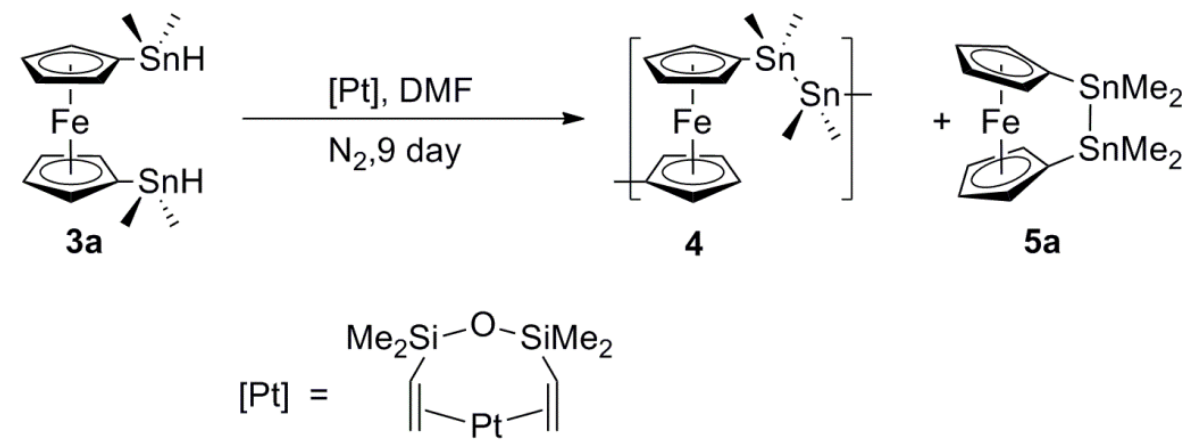

Figure 2.2: Metal catalyzed dehydrogenative coupling to form 4 .

Polymerization of 3a via a Pt catalyzed condensation was performed in $N, N$-dimethyl formamide (DMF) at room temperature in inert atmosphere (Figure 1.8). By ${ }^{1} \mathrm{H}$ NMR spectroscopy the resulting polymer was determined to be the polyferrocenyl bis(dimethyl)stannane, 4 . This was a surprising result based on earlier research that was carried out by this group involving $\mathrm{Fe}\left(\eta^{5}-\mathrm{C}_{5} \mathrm{H}_{4} \mathrm{SiMe}_{2} \mathrm{H}\right)_{2}$. When the reaction to Figure 1.8 was performed on $\mathrm{Fe}\left(\eta^{5}-\mathrm{C}_{5} \mathrm{H}_{4} \mathrm{SiMe}_{2} \mathrm{H}\right)_{2}$ at $90^{\circ} \mathrm{C}$ in inert atmosphere, oxygen insertion to form a Si-OSi bond was observed lead to the formation of $\left[\mathrm{Fe}\left(\eta^{5}-\mathrm{C}_{5} \mathrm{H}_{4} \mathrm{SiMe}_{2}\right)_{2} \mathrm{O}\right]_{\mathrm{n}}{ }^{69}$ The oxygen source was attributed to the Pt catalyzed reduction of DMF to form $\mathrm{NMe}_{3}$ and subsequent release of oxygen. When a condensation reaction using $\mathrm{Fe}\left(\eta^{5}-\mathrm{C}_{5} \mathrm{H}_{4} \mathrm{SiMe}_{2} \mathrm{H}\right)_{2}$ with the Karstedt's catalyst was 
carried out in DCM, a desilylative reaction to form the mono-bridged polymer $\left[\mathrm{Fe}\left(\eta^{5}-\right.\right.$ $\left.\left.\mathrm{C}_{5} \mathrm{H}_{4}\right)_{2} \mathrm{SiMe}_{2}\right]_{\mathrm{n}}$ occurred.

When dehydrogenative coupling was performed on $\mathbf{3 a}$ in the absence of light, the reaction did not proceed at the same rate. Additionally, only the synthesis of smaller oligomeric species were detected by GPC. When the polymerization of 3a was carried out in DMF at higher temperatures $\left(>40^{\circ} \mathrm{C}\right)$ or highly concentrated $(>20 \% \mathrm{w} / \mathrm{w})^{*} 40 \%$ of the product recovered was insoluble polymer. This was at first surprising given the fact that the monomer was heated to $90^{\circ} \mathrm{C}$ in vacuo and showed no dehydrogenative coupling through this process. The insoluble solid is likely associated with a cross-linked polyferrocenyl stannane, however there is little definitive evidence based on the lack of solubility of this compound. The cross-linked polymers likely form due to a lowering of the stability of the Sn-Me bond because of coordination of DMF to the Sn center of $\mathbf{3 a}$.

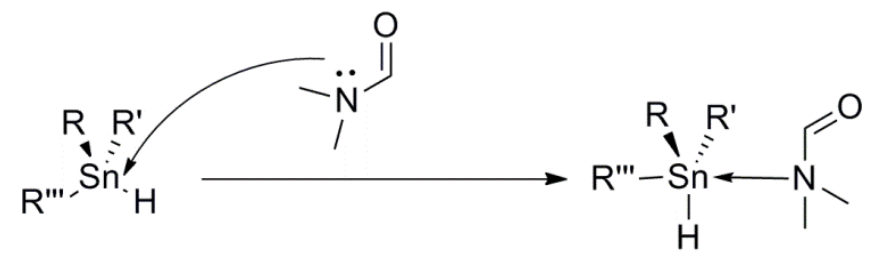

Figure 2.3: Coordination of DMF to a Sn center change the shape form tetrahedral to trigonal bypyrimidal.

Evidence in the literature ${ }^{125}$ suggests that amides are good coordinating agents with organo tin compounds. The coordination of $\mathrm{N}$ to $\mathrm{Sn}$ causes $\mathrm{Sn}-\mathrm{C}$ bonds to expand due to the larger amount of electron density on the Sn center, decreasing the already low stability of these bonds. The Sn center will shift from tetrahedral to trigonal bypyramidal geometry (Figure 2.3). When heat is added to $\mathrm{N} \rightarrow \mathrm{Sn}-\mathrm{C}$ systems, C-Sn bonds become more susceptible to breaking and

\footnotetext{
* Concentration of reactions is measured in w/w due to the ease of weighing solvent in the inert atmosphere system.
} 
thus a site for crosslinking is formed. This hyper coordination is also a possible reason why this reaction occurs at such low temperatures. In this instance, the coordination of DMF to the Sn center of 3a causes elongation of the $\mathrm{Sn}-\mathrm{H}$ bond, destabilizing it, and making it more reactive to coupling reactions.

Condensation polymerization of $\mathbf{3 a}$ in the presense of Karstedt's catalyst was performed in DMF over a period of $3 \mathrm{~d}$. After the reaction was quenched with $\mathrm{MeOH}$, analysis of the crude material by ${ }^{119}$ Sn NMR spectroscopy displayed only the shifts for compounds $\mathbf{4}$ and $\mathbf{5 a}$.

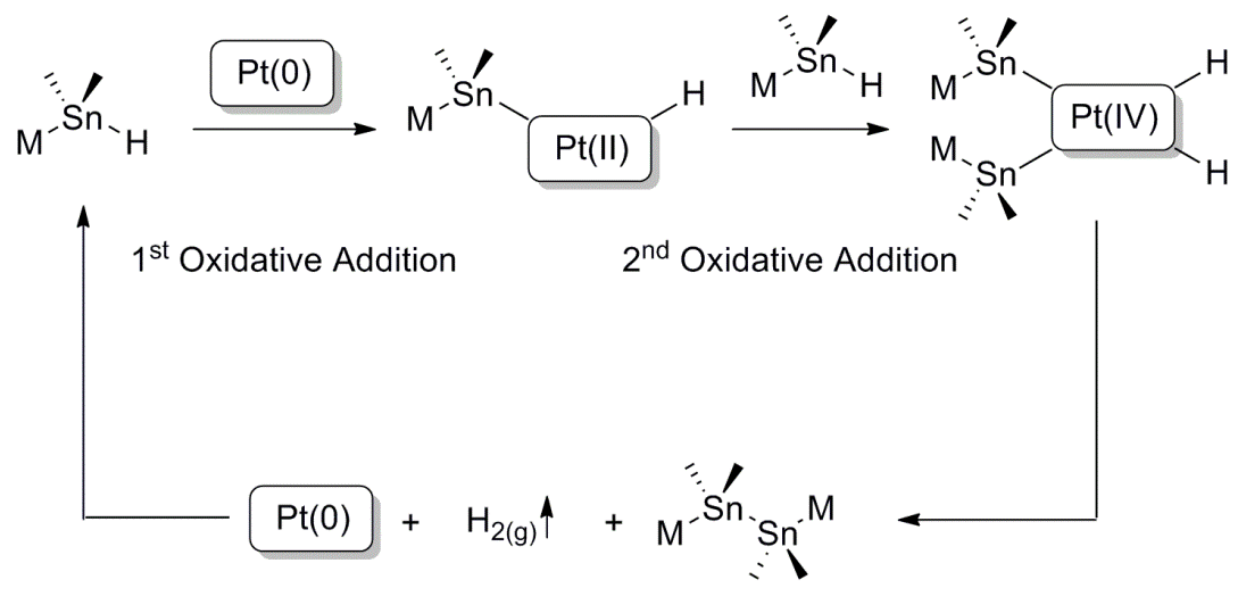

Reductive Elimination
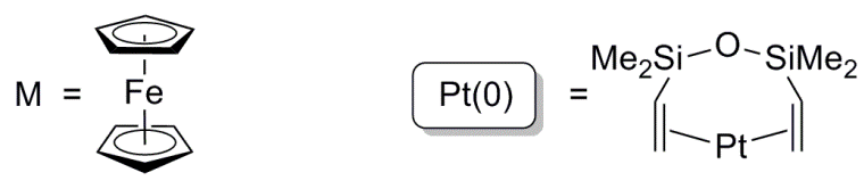

Figure 2.4: Dehydrogenative coupling reaction mechanism for 3a to form 4.

Dehydrogenative coupling of 3a was also performed for several days in $\mathrm{C}_{6} \mathrm{H}_{6}$, using a [Pt] catalyst. Using $\mathrm{C}_{6} \mathrm{H}_{6}$ as a solvent required higher temperatures and longer reaction times to drive the reaction forward $\left(70^{\circ} \mathrm{C}, 3 \mathrm{~d}\right)$. The longer reaction time as well as the higher temperature of reaction is most likely due to the inability of $\mathrm{C}_{6} \mathrm{H}_{6}$ to coordinate to the $\mathrm{Sn}$ center. 
A proposed mechanism for the dehydrogenative coupling of $\mathbf{3 a}$ to form $\mathbf{4}$ follows a similar pathway as the proposed mechanism for the dehydrogenative coupling of $\left(\eta^{5}-\right.$ $\left.\mathrm{C}_{5} \mathrm{H}_{4} \mathrm{SiMe}_{2} \mathrm{H}\right)_{2} \mathrm{Fe}$ by Foucher et al. ${ }^{60}$ The reaction begins (Figure 2.4) with an oxidative addition of $\mathrm{Pt}(0)$ into the $\mathrm{Sn}-\mathrm{H}$ bond to form a $\mathrm{Pt}(\mathrm{II})$ complex. Unlike the analogous reaction with the $\mathrm{Si}$ $\mathrm{H}$ (Figure 1.8), there is no preference for insertion into the Sn-C bond. Instead, a second oxidative addition occurs as the Pt(II) complex inserts into a second unit of $\mathbf{3 a}$ to form a $\mathrm{Pt}(\mathrm{IV}$ ) complex. Finally there is a reductive elimination to reform $\mathrm{Pt}(0)$ and create a $\mathrm{Sn}-\mathrm{Sn}$ bond with concomitant the release $\mathrm{H}_{2}(g)$ as a by-product.

\subsubsection{Ring-opening polymerization}

The synthesis of $\mathbf{5 a}$ as a polymerizable monomer for the ring-opening polymerization was attempted through the same method originally used by as Herberhold and Wrackmeyer. ${ }^{41}$ Attempts to prepare 5a in this way resulted in the formation of a previously unreported larger ferrocenophane, as well as minimal amount of the desired product (5\%). An improved method utilizing $\mathrm{Pd}_{2}(\mathrm{dba})_{3}$ to facilitate the intramolecular dehydrogenative coupling of 3a to form 5a was discovered and all monomer was prepared via this new method. The novel reaction to synthesize 5a and the characterization and structural determination of the novel ferrocenophane will be discussed in detail in Section 3.0.

An attempt was made to synthesize polyferrocenyl distannanes through a metal catalyzed ROP of 5a. This was carried out based on previous work by Mochida et al. who performed the ROP of 1,1,2,2-tetramethyldigermyl-[2]ferrocenophane. ${ }^{94}$ Several metal catalysts where employed, and these reactions where monitored by ${ }^{119} \mathrm{Sn}$ NMR spectroscopy. 
All ROPs were carried out in $\mathrm{C}_{6} \mathrm{H}_{6}$ with $\mathrm{Pt}(\mathrm{acac})_{2}, \mathrm{Pd}_{2}(\mathrm{dba})_{3}$, and $\mathrm{Pd}\left(\mathrm{PPh}_{3}\right)_{4}$ catalysts at low concentrations. Reaction temperatures varied from RT to $60^{\circ} \mathrm{C}$. All reactions proceeded slowly, with a trace of oligomeric material evident in analysis by ${ }^{119} \mathrm{Sn}$ NMR spectroscopy and were not further purified. The only reaction that showed any substantial polymer formation was when the $\mathrm{Pd}\left(\mathrm{PPh}_{3}\right)_{4}$ catalyst was utilized.

The $\mathrm{Pd}\left(\mathrm{PPh}_{3}\right)_{4}$ catalyzed reaction was carried out at $60^{\circ} \mathrm{C}$ for $3 \mathrm{~d}$ in the dark. The resulting polymer was precipitated from minimal amount of THF into MeOH. Two ${ }^{119} \mathrm{Sn}$ NMR signals where detected at $-11.63 \mathrm{ppm}$ and at $104.72 \mathrm{ppm}$, the latter of which is now identified as the chemical shift for the distanna bridged polymer 4 . The resonance detected at -11.63 has not been identified, however this could be an end group, or a Pd inserted complex of compound 5a that is not soluble in $\mathrm{MeOH}$.

\subsubsection{Characterization by ${ }^{1} \mathrm{H},{ }^{13} \mathrm{C}$, and ${ }^{119} \mathrm{Sn}$ NMR}

All compounds were identified by ${ }^{119}$ Sn NMR spectroscopy and in almost all cases contained only one unique $\mathrm{Sn}$ environment. Compounds 1a, 3a, 4, 5a were studied by ${ }^{1} \mathrm{H},{ }^{13} \mathrm{C}$ and ${ }^{119} \mathrm{Sn}$ NMR spectroscopy. After redistribution reaction of $\mathbf{1 a}$ with $\mathrm{Me}_{2} \mathrm{SnCl}_{2}$ compound $\mathbf{2 a}$ was confirmed by ${ }^{119}$ Sn NMR spectroscopy. Compound 5a was identified as a by-product in several dehydrogenative coupling reactions by its distinct ${ }^{119} \mathrm{Sn}$ NMR signal at $-43 \mathrm{ppm}$. Compound 4 was prepared in two different solvents (DMF and $\mathrm{C}_{6} \mathrm{H}_{6}$ ), extensive NMR evaluations were only carried out on polymer prepared in DMF.

Compounds 1a and 3a were readily identifed by their ${ }^{119}$ Sn NMR shifts at -5.6 and -101.3 ppm respectively. With the addition of chlorine to the $\mathrm{Sn}$ center, the ${ }^{119} \mathrm{Sn}$ chemical resonances moved down field to $126.8 \mathrm{ppm}$, similar to values reported by Herberhold. ${ }^{106}$ Both 1a and 3a 
were shifted down field from their mono-substituted analogues, with ${ }^{119}$ Sn NMR shifts at -4.86 and -101.91 ppm respectively. ${ }^{1} \mathrm{H}$ NMR spectra for 1a and 3a displayed two cyclopentadiene protons that were split into pseudo triplets ranging between 3.9-4.6 ppm. The methyl protons of 1a are present as a singlet at $0.28 \mathrm{ppm}\left(\mathrm{CDCl}_{3}\right)$ with one set of Sn satellites $\left({ }^{1} J_{\mathrm{Sn}-\mathrm{H}}=54.3 \mathrm{~Hz}\right)$. With the introduction of a hydride, the methyl chemical shift was split into a doublet $\left({ }^{2} J=2.3\right.$ $\mathrm{Hz})$ and two sets of satellites $\left({ }^{1} J_{\mathrm{Sn}-\mathrm{H}}=59.0 \mathrm{~Hz}\right)$. The tin hydride chemical shift was split into a septet at $5.47 \mathrm{ppm}\left({ }^{2} J=2.3 \mathrm{~Hz}\right)$.

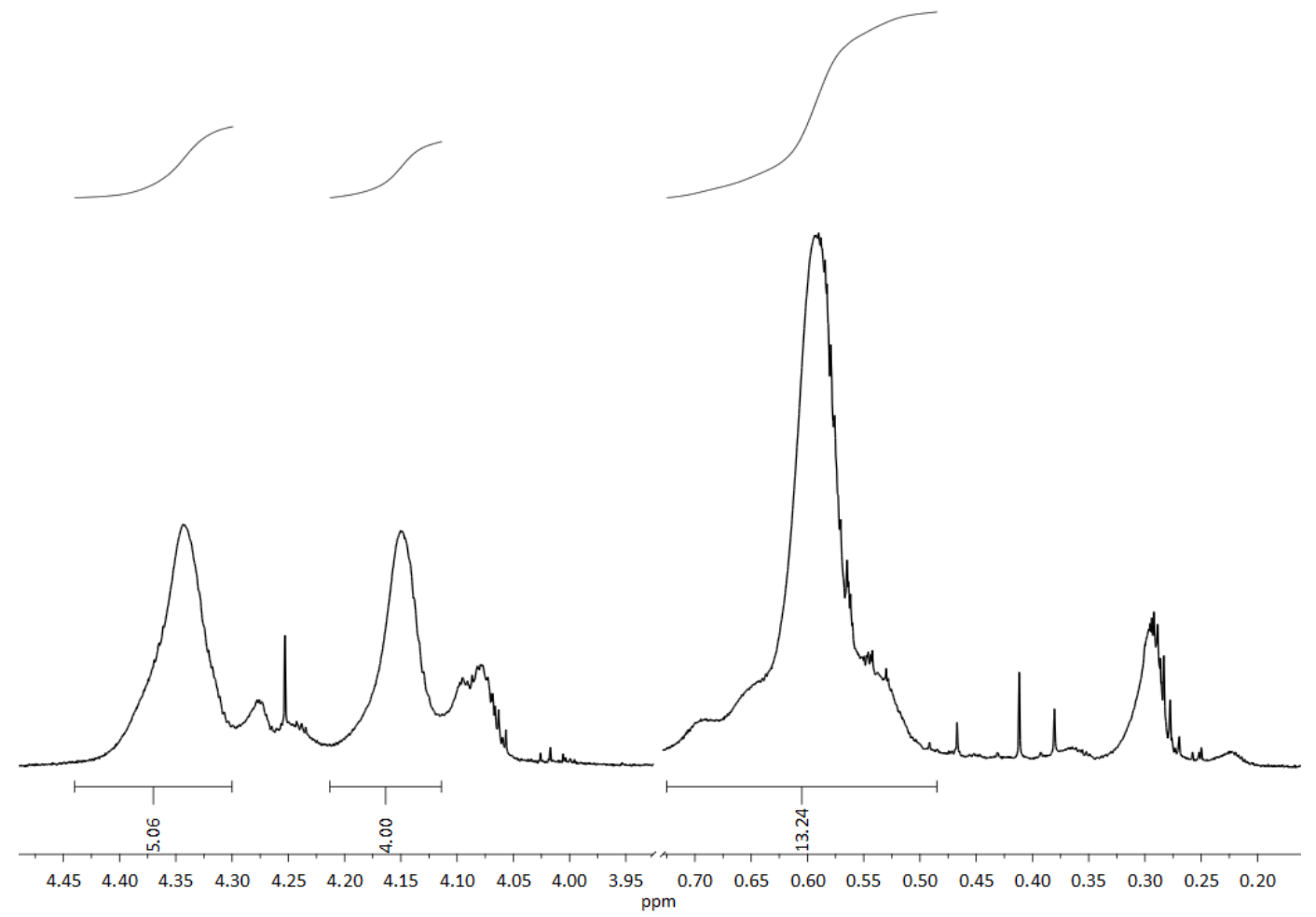

Figure 2.5: ${ }^{1} \mathrm{H} \mathrm{NMR}\left(\mathrm{C}_{6} \mathrm{D}_{6}\right)$ spectra for compound 4 .

The ${ }^{1} \mathrm{H}$ NMR (Figure 2.5) spectra of polymer 4 displayed broad shifts associated with two cyclopentadiene proton environments at 4.35 and $4.15 \mathrm{ppm}$, and one methyl environment of 
$0.60 \mathrm{ppm}$ integrating for approximately $4,4,12$ protons respectively. The methyl shift at 0.60 ppm has one set of broad satellites $\left({ }^{1} J_{\mathrm{Sn}-\mathrm{H}}=236.6 \mathrm{~Hz}\right)$. Also visible in the ${ }^{1} \mathrm{H}$ NMR spectra were broad end groups with chemical shifts of 4.27 and $4.08 \mathrm{ppm}$ for the cyclopentadiene region, and 1.24 for the methyl shift respectively. Based on the integration of the spectra, the structure was believed to be the dibridged polymer 4 instead of the mono-bridged analogue. Due to the apparent instability of this material, obtaining providing a clean ${ }^{1} \mathrm{H}$ NMR has been a challenge.
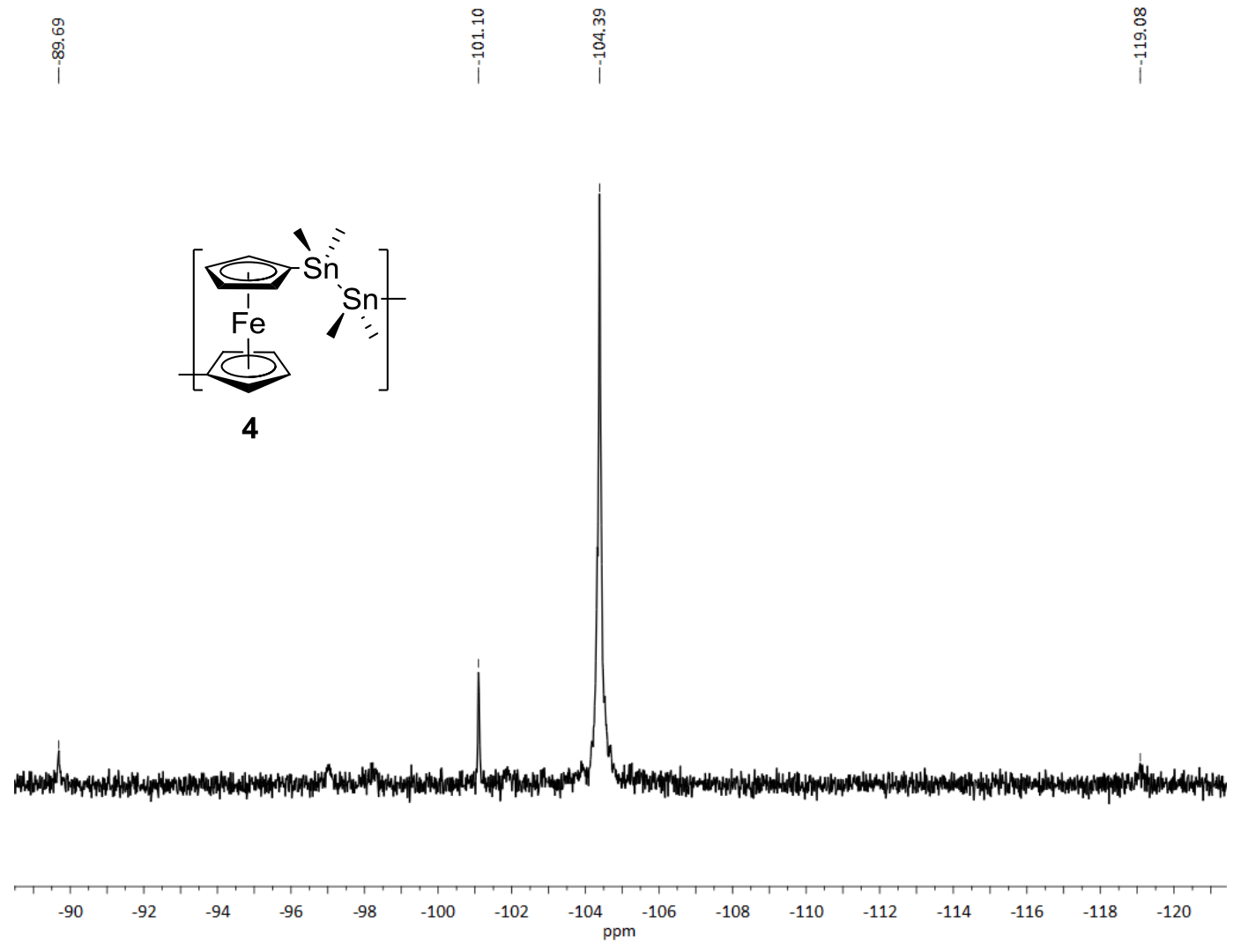

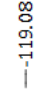

Figure 2.6: ${ }^{119} \mathrm{Sn}$ NMR spectrum of polymer 4 that contains the main polymer peak (-104.4 $\mathrm{ppm})$ the ${ }^{119} \mathrm{Sn} /{ }^{117} \mathrm{Sn}$ coupling pattern $(-89.7 \mathrm{ppm}$ and $-119.1 \mathrm{ppm})$ and the end group $(-101.1$ ppm).

The crude ${ }^{119}$ Sn NMR (Figure 2.6) spectra confirmed the presence of compound 5a as the by-product of condensation polymerization. Compound $\mathbf{5 a}$ is present in most reactions where $\mathbf{3 a}$ 
is a reactant. The ${ }^{119} \mathrm{Sn}$ NMR shift of $\mathbf{5 a}$ is easily identified at $-43 \mathrm{ppm}$ with a large set of ${ }^{119} \mathrm{Sn} /{ }^{117} \mathrm{Sn}$ satellites $\left({ }^{1} J=5261.5 \mathrm{~Hz}\right)$. When the sample is purified through precipitation in anhydrous $\mathrm{MeOH}$, three chemical shifts are visible. A large shift at $-104.4 \mathrm{ppm}$ was identified as polymer 4 and displayed one set of ${ }^{119} \mathrm{Sn} /{ }^{117} \mathrm{Sn}$ satellites $\left({ }^{1} J=4381.2 \mathrm{~Hz}\right)$. The coupling constant is within reason for that of a ${ }^{119} \mathrm{Sn} /{ }^{117} \mathrm{Sn}{ }^{1} J$ coupling constant between adjacent tins. This is hard evidence for a Sn-Sn bond within the structure of the polymer. Present in the precipitated polymer 4 was a small shift at $-5.70 \mathrm{ppm}$ (Appendix 1.5). The nature of this chemical environment is still unknown, however it must either be associated with polymer 4 (in the form of a stannoxane end group or impurity) or a separate polymer (possibly the mono-bridged ferrocenyl dimethyl stannane). Other than the main ${ }^{119} \mathrm{Sn}$ chemical shift for compound $\mathbf{4}$, only a small end group resonance at -101.10 and a chemical shift for $\mathbf{5 a}$ at $-43 \mathrm{ppm}$ was observed.

Polymer 4 was also characterized by ${ }^{13} \mathrm{C}$ NMR spectroscopy. Three broad chemical shifts were detected for the main chain of the polymer, as well as two smaller end group chemical shifts. These chemical shifts were identified as the cyclopentadiene shifts at $74.62,71.23$ and 69.32 (for the ipso-C) ppm and a methyl shift at $-8.68 \mathrm{ppm}$. There was no observed ${ }^{119} \mathrm{Sn} /{ }^{13} \mathrm{C}$ coupling, however that was not surprising due to the broad nature of the chemical shifts and the low natural abundance of ${ }^{13} \mathrm{C}$ and ${ }^{119} \mathrm{Sn}$ or ${ }^{117} \mathrm{Sn}$ isotopes. The two small resonances that were associated with end groups were observed at 74.82 and $71.41 \mathrm{ppm}$, slightly down field from main chain polymer peaks.

The presence of end group resonances in the NMR spectra $\left({ }^{1} \mathrm{H},{ }^{13} \mathrm{C},{ }^{119} \mathrm{Sn}\right)$, of 4 more accurately describe a low molecular weight polymer. When the methyl end group was integrated by ${ }^{1} \mathrm{H}$ NMR spectroscopy and compared to the main methyl polymer, the end group shift is 
approximately $12.9 \%$ of the signal intensity of the main chain polymer. This suggests that there are approximately $8\left(\mathrm{SnMe}_{2}\right)_{2}$ bridges in the backbone of this polymer, with a $\mathrm{M}_{n} \approx 4300 \mathrm{Da}$.

\subsubsection{Molecular weight determination by GPC}

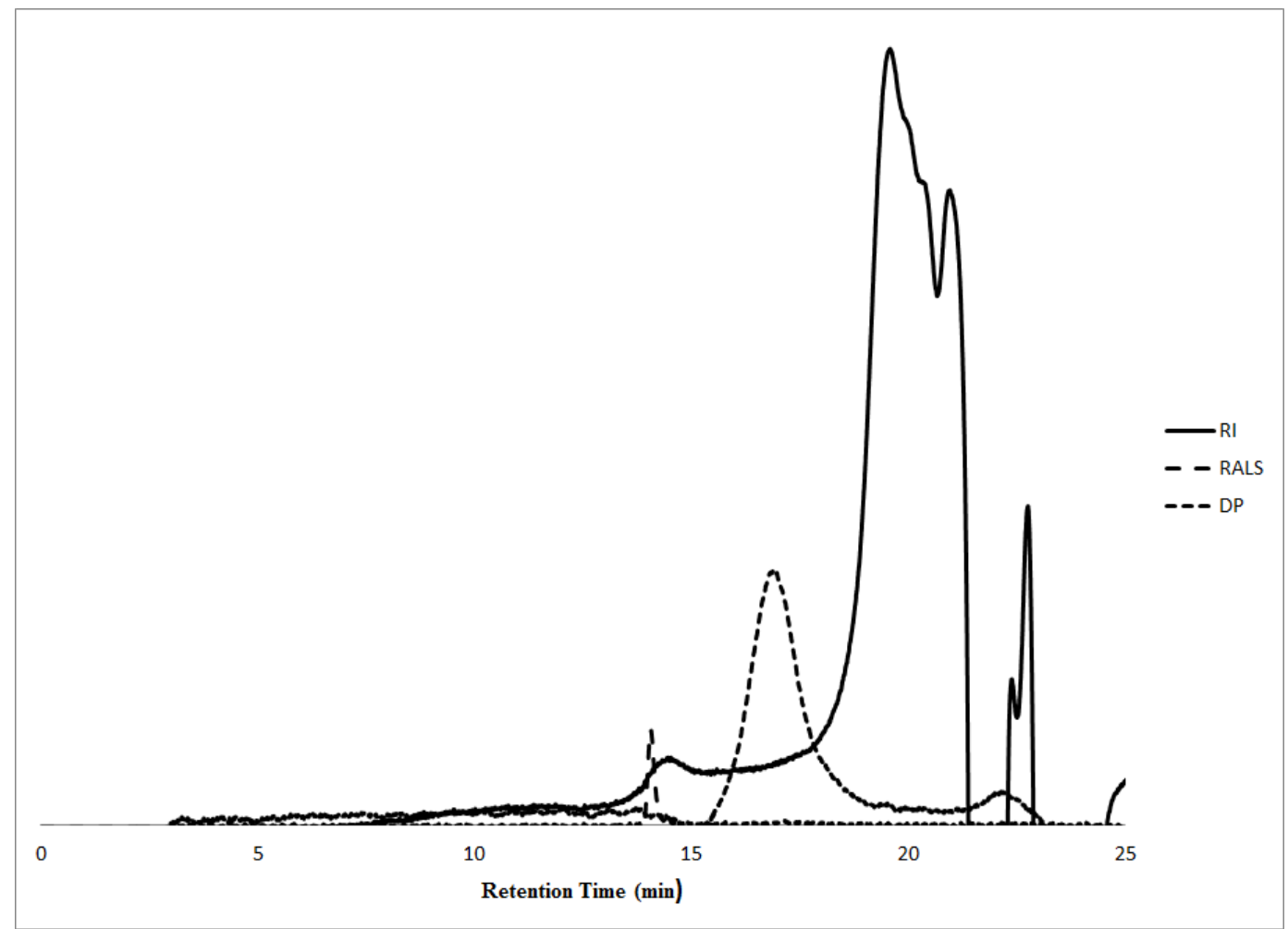

Figure 2.7: The GPC chromatogram for polymer 4 prepared in THF.

Gel permeation chromatography (GPC), along with ${ }^{1} \mathrm{H}$ NMR spectroscopy, was used to determine the molecular weight of polymer $\mathbf{4}$ prepared by dehydrogenative coupling of 3a. For these largely oligomeric species the use of GPC was found to be problematic for the determination of molecular weights. A high concentration of polymer $(>10 \mathrm{mg} / \mathrm{mL})$ was needed to obtain a small amount of signal, and the RI detector had an extremely low response for the polymeric signal. However, from the right angle light scattering (RALS) and the intrinsic viscosity (DP) the size of compound $\mathbf{4}$ estimated (from the reaction of $\mathbf{3 a}$ in $\mathrm{C}_{6} \mathrm{H}_{6}$ ) was approximately at $5 \times 10^{4} \mathrm{Da}$. A large response in the RI was visible later in the chromatograph, 
and is most likely due to the presence of oligomeric species in the sample even after precipitation in anhydrous methanol.

When polymer 4 was prepared in the absence of light in DMF (Figure 2.8), the GPC chromatograph displayed no evidence of high molecular weight polymer. The resulting GPC chromatograph displayed three distinct peaks at about 20 min retention time. These peaks were most likely oligomeric species based on the large retention times. Accurate an molecular weight calculation could not be performed due to a lack of light scattering of oligomeric species.

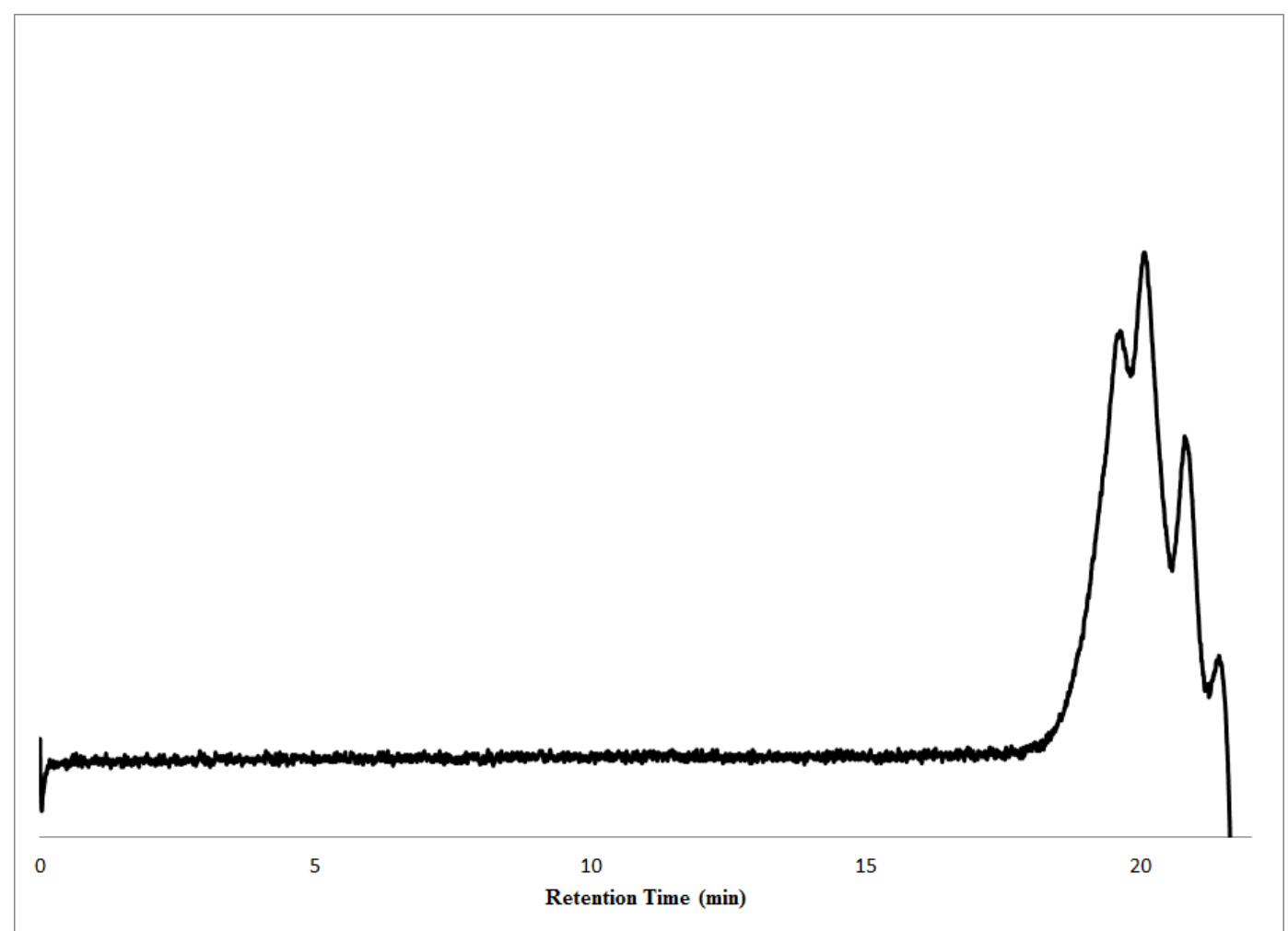

Figure 2.8: The GPC chromatograph of oligomers of 4 in THF. 


\subsubsection{Electrochemistry}

Electrochemical studies were used to probe the electronic nature of $\mathbf{4}$. Through cyclic voltammetry, the conductive nature of these materials can be understood fully. The relative communication between the iron centers is generally reduced when the distance between them is increased (Section 1.3.2).

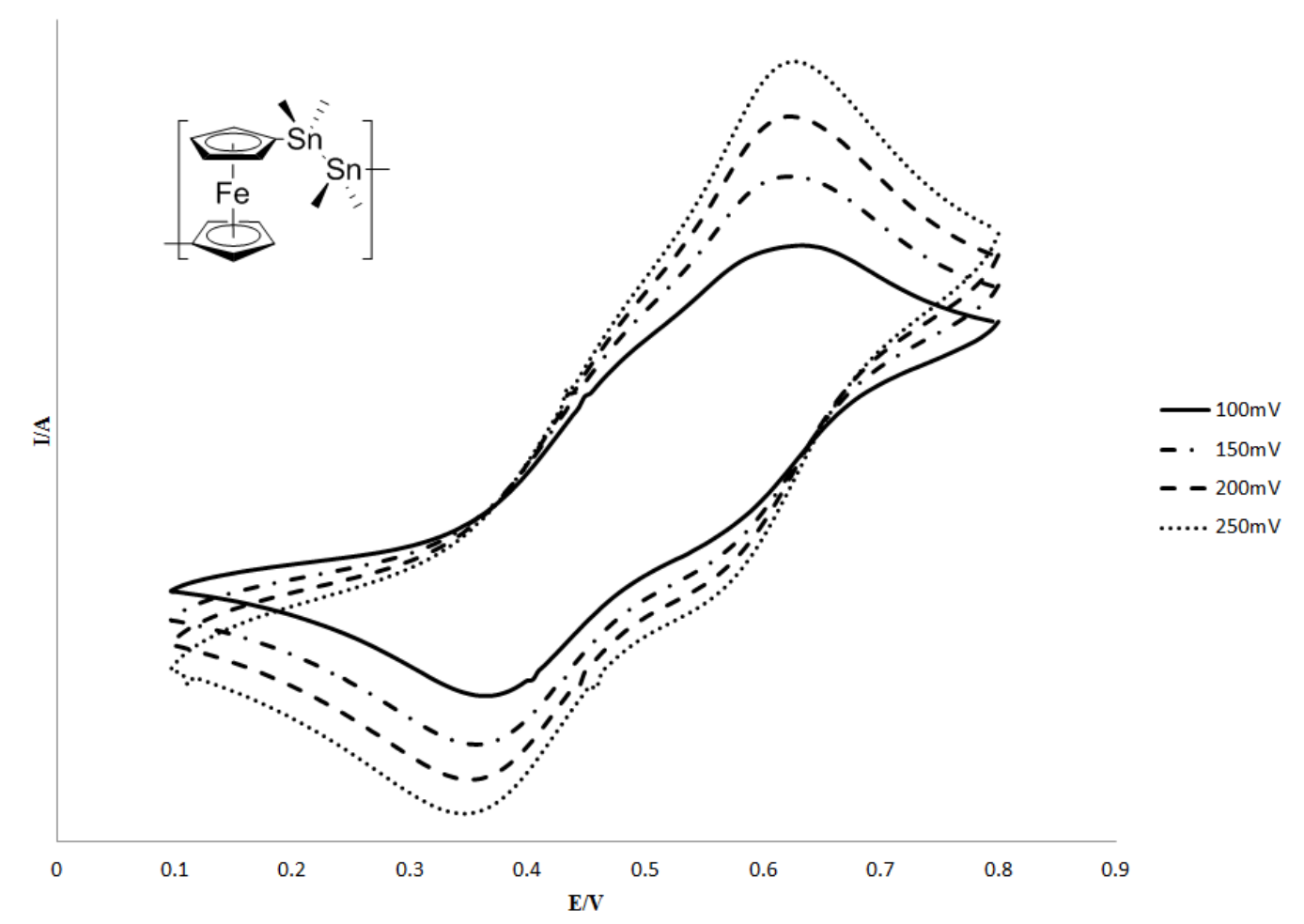

Figure 2.9: Cyclic voltammetry of compound 4 at various scan rates.

For compound 4, there were two identifiable redox waves present in the CV (Figure 2.9) with ${ }^{1} \mathrm{E}_{1 / 2}$ and ${ }^{2} \mathrm{E}_{1 / 2}$ of $-0.16 \mathrm{~V}$ and $0.02 \mathrm{~V}$ respectively $\left(\Delta \mathrm{E}_{1 / 2}=0.18 \mathrm{~V}\right)$. When this is compared with known monobridged polyferrocenyl stannanes (Table 2.1) a loss of interaction was observed. Pannell's model ferrocenyl silane dimers ${ }^{95}$ also display a loss of communication with expansion of the bridge from 1 to 2 units. Pannell's dimers showed a $\approx 27 \%$ of communication 
between ferrocenes $\left(\Delta \mathrm{E}_{1 / 2}=0.15 \mathrm{~V}\right.$ for monobridged and $0.11 \mathrm{~V}$ for dibridged ferrocenyl silane dimers) when switching between the mono and dibridged dimers. The degree of electronic communication between known monobridged polyferrocenyl stannanes and polymer $\mathbf{4}$ is comparable.

Table 2.1: Cyclic voltammetry of $\left[\mathrm{Fe}\left(\eta^{5}-\mathrm{C}_{5} \mathrm{H}_{4}\right)_{2} \mathrm{E}\right]_{\mathrm{n}}$.

\begin{tabular}{cccc}
\hline Bridge Structure (E) & ${ }^{1} \mathbf{E}_{1 / 2}(\mathbf{V})$ & ${ }^{2} \mathbf{E}_{1 / 2}(\mathbf{V})$ & $\Delta \mathbf{E}_{1 / 2}(\mathbf{V})$ \\
\hline$(\boldsymbol{n}-\mathbf{B u})_{2} \mathbf{S n}$ & -0.06 & 0.18 & 0.24 \\
$(\boldsymbol{t}-\mathbf{B u})_{2} \mathbf{S n}$ & 0.00 & 0.24 & 0.24 \\
$(\mathbf{M e s})_{2} \mathbf{S n}$ & -0.07 & 0.14 & 0.21 \\
$\mathbf{M e}_{2} \mathbf{S n M e}_{2} \mathbf{S n}$ & -0.02 & 0.16 & 0.18
\end{tabular}

This loss of interaction can be attributed to several different factors. Firstly, redox waves are broad in the $\mathrm{CV}$, obfuscating the signal which will affect the measurement of the $\mathrm{E}_{1 / 2}$ locations. Secondly, the loss of interaction between iron centers may be associated with a loss of through space interaction. ${ }^{*}$ Finally, when smaller, less bulky substituents are attached to Sn, a loss of interaction between Fe centers is often observed. Although not a direct correlation, the monobridged ferrocenyl silane polymers show a voltage drop of $\approx 28 \%\left(\Delta \mathrm{E}_{1 / 2}\right.$ for $\left[\mathrm{Fe}\left(\eta^{5}-\right.\right.$ $\left.\left.\mathrm{C}_{5} \mathrm{H}_{4}\right)_{2} \mathrm{SiMe}_{2}\right]_{\mathrm{n}}$ is $0.21 \mathrm{~V}$ vs $\Delta \mathrm{E}_{1 / 2}$ of $0.29 \mathrm{~V}$ for $\left.\left[\mathrm{Fe}\left(\eta^{5}-\mathrm{C}_{5} \mathrm{H}_{4}\right)_{2} \mathrm{Si}(n-\mathrm{Bu})_{2}\right]_{\mathrm{n}}\right) n$-butyl is exchanged with a methyl substituent. ${ }^{86}$ This, in combination with the first two effects, explains why the loss of signal is as large as in the case of Pannell's model ferrocenyl silane dimers.

\footnotetext{
* The loss of through space interaction has cited behind the loss of communication between Fe centers of other bridged polyferrocenylenes.
} 


\subsubsection{UV-Visible spectroscopy and DFT studies}

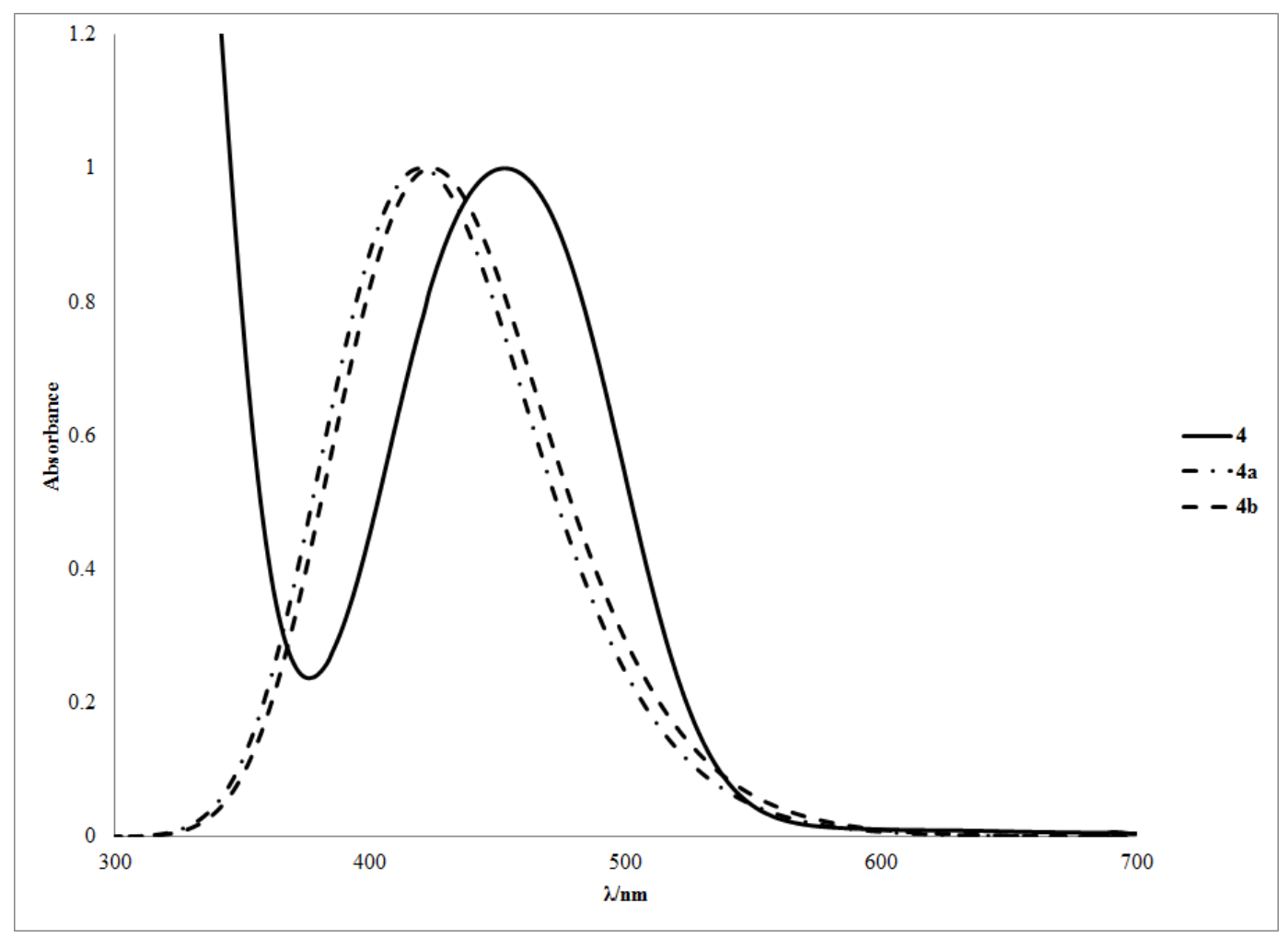

Figure 2.10: UV-Visible spectra in $\mathrm{C}_{6} \mathrm{H}_{6}$ for $\mathbf{4}$ and the TD-DFT calculated spectra for $\mathbf{4 a}$ and $\mathbf{4 b}$.

The UV-Visible spectrum of compound 4 was carried out in $\mathrm{C}_{6} \mathrm{H}_{6}$. The $\lambda_{\max }$ of this polymer was found to be $452 \mathrm{~nm}\left(\varepsilon=115.98 \mathrm{~L} \mathrm{~mol}^{-1} \cdot \mathrm{cm}^{-1}\right)$ similar to other polyferrocenylenes which generally have a $\lambda_{\max } \approx 450 \mathrm{~nm}$. A series of UV-Visible spectra were collected for oligomers of 4 that were prepared in absence of light in DMF. After 100 spectra were collected at $30 \mathrm{~s}$ intervals (Figure 2.10), no degradation of the $\lambda_{\max }$ absorbance was observed. It was later determined by GPC that the sample used was largely oligomeric, rather than polymeric in nature and therefore could theoretically possess higher light stability. Polymer $\mathbf{4}$ displays a certain degree of light stability as it can be processed under atmospheric conditions with limited degradation. However, if left under atmospheric conditions for extended periods, polymer 4 degraded into an insoluble material. 
To better understand the electronic structure of compound 4, Density Functional Theory (DFT) studies were carried out on the dimeric and trimeric model system of this polymer, $\mathbf{4 a}$ and 4b respectively. The computational software Gaussian 09 revision C01 was utilized for these DFT studies, which were performed using the Local Spin Density Approximation (LSDA) method and the SDD* basis set. The effectiveness of this method/basis set was determined, along with several other method/basis sets, in a calculation of a basic ferrocene unit. LSDA/SDD was found to be the best at approximating the systems in the lowest amount of calculation time.

When the molecular orbitals of $\mathbf{4 a}$ were calculated, the nature of the electronic transition was apparent (Figure 2.11). The HOMO of 4a shows a bonding orbital that communicates between the two bridging Sn atoms. As well, there is electron density within the $\pi \mathrm{d}\left(\mathrm{z}^{2}\right)$ system of both ferrocene moieties. This is also true of $\mathbf{4 b}$ (Figure 2.12), where the $\sigma$-conjugation is clearly present within both bridges of the molecule. The electronic structure of the LUMO orbitals shows conjugation through the $\pi$ system of the ipso $\mathrm{C}$ on both ferrocenes for $\mathbf{4 a}$ and the central ferrocene in $\mathbf{4 b}$ as well as empty anti-bonding orbitals of the connected Sn. The HOMO-LUMO energy gap was calculated for both the $\mathbf{4 a}$, and $\mathbf{4 b}$ and was found to be $2.86 \mathrm{eV}$ and $2.81 \mathrm{eV}$ respectively.

The TD-DFT was performed on $\mathbf{4 a}$ to estimate the UV-Visible spectrum. A calculated $\lambda_{\max }$ at $422 \mathrm{~nm}$ is $0.18 \mathrm{eV}(7 \%)$ higher in energy than the experimental value. Polymers typically generally have a lower gap energy than oligomeric or model systems.

* SDD basis set uses the Dunning/Huzinaga full double zeta (D95) basis set for atoms up to Ar and the Stuttgart/Dresden electron core potential (ECP) for the reminder of the periodic table. 

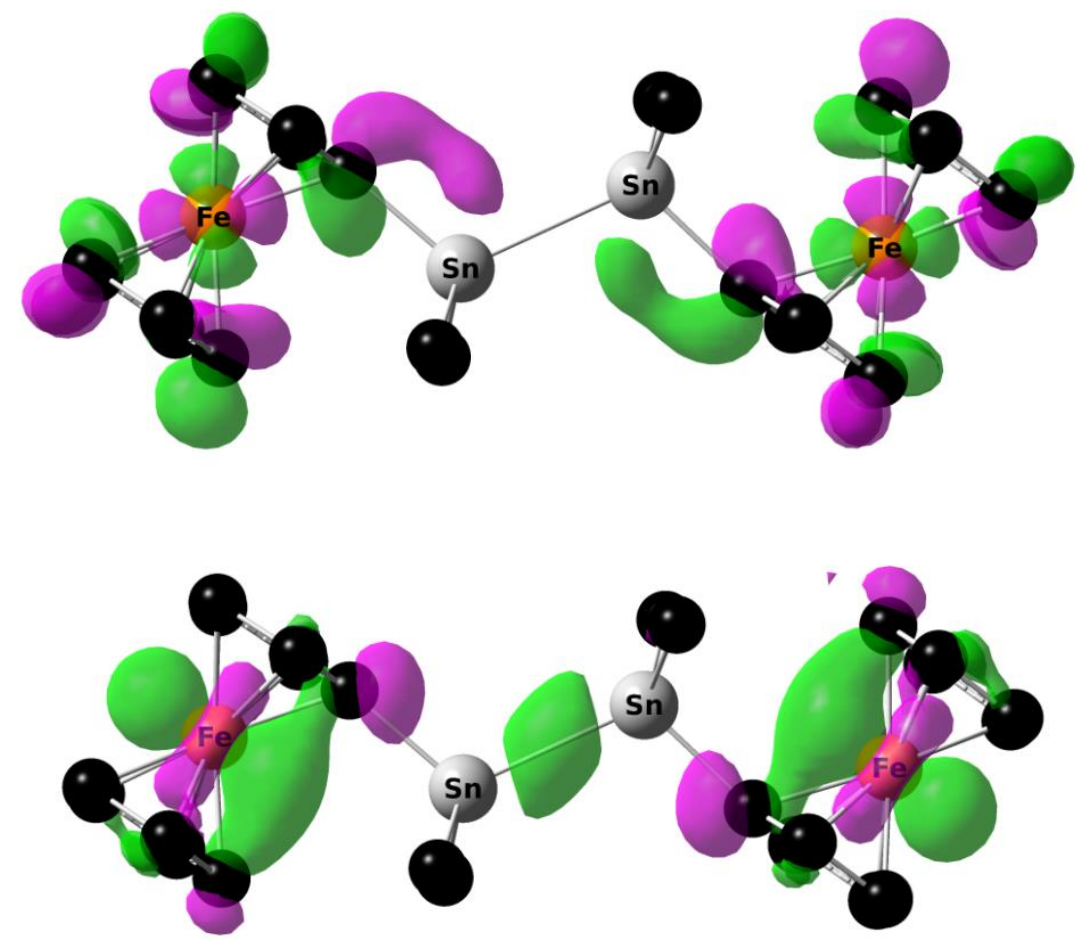

Figure 2.11: Calculated HOMO (below) and LUMO (above) of $\mathbf{4 a}$.
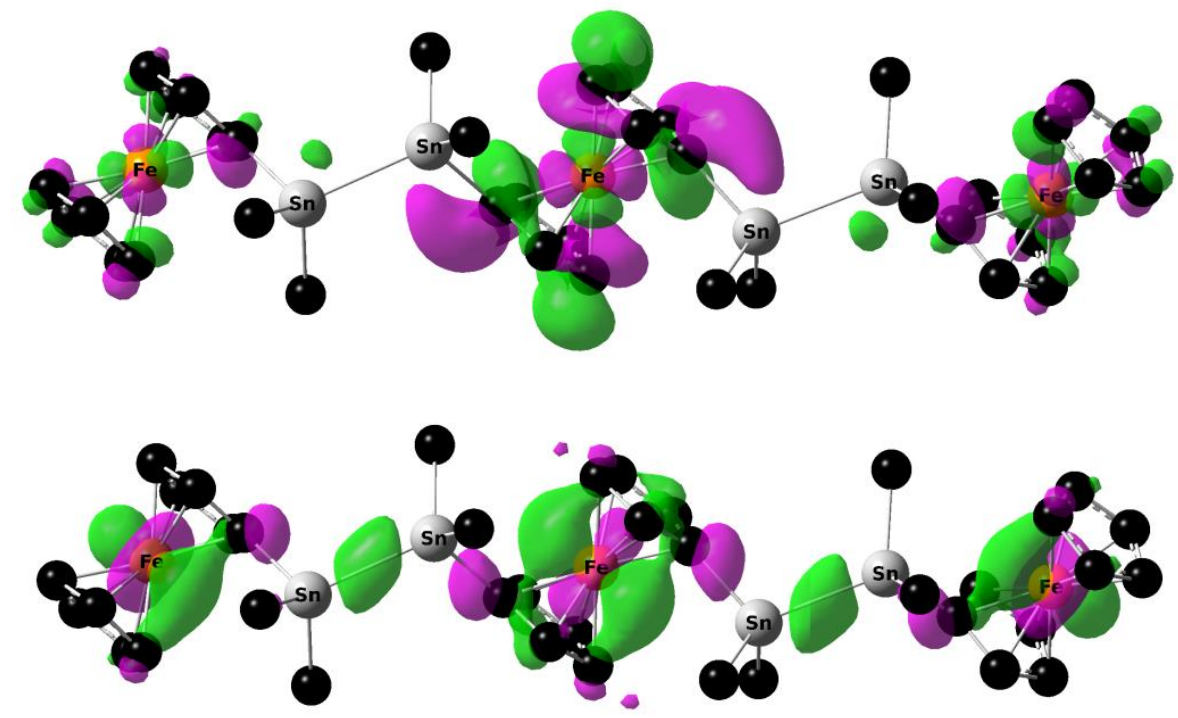

Figure 2.12: Calculated HOMO (below) and LUMO (above) of $\mathbf{4 b}$. 


\subsection{Conclusion}

The first dibridged tin containing polyferrocenylene, $\left[\mathrm{Fe}\left(\eta^{5}-\mathrm{C}_{5} \mathrm{H}_{4} \mathrm{SnMe}_{2}\right)_{2}\right]_{\mathrm{n}}, 4$ was synthesized through a metal catalyzed polymerization of 3a. Polymer 4 was successfully prepared through a condensation reaction in both DMF and $\mathrm{C}_{6} \mathrm{H}_{6}$ using the Karstedt's catalyst. Evidence for polymer 4 was also detected in the ROP of $\mathbf{5 a}$ using $\mathrm{Pd}\left(\mathrm{PPh}_{3}\right)_{4}$. Strong evidence that 4 is a low to moderate molecular weight polymer was confirmed by the integration of the

proton resonances in the ${ }^{1} \mathrm{H}$ NMR spectra in addition to presence of ${ }^{119} \mathrm{Sn} /{ }^{117} \mathrm{Sn}$ coupling which is characteristic of a $\mathrm{Sn}-\mathrm{Sn}$ bond.

Cyclic voltammetry was also used to explore the electronic interaction between two adjacent Fe centers where a significant interaction was observed between adjacent Fe centers despite an increased Fe-Fe distance. TD-DFT was used in combination with UV-Visible spectroscopy of polymer $\mathbf{4}$ to further delve into the nature of the electronic interaction of these distannyl ferrocene polymers. In these studies, electron density was located in a $\sigma$ bond between the distannane bridge of a model system at the HOMO energy level. 


\subsection{Synthesis and Spectral Electrochemical Properties of a Symmetrical Tristanna-Bridged [3.3]Ferrocenophane}

\subsection{Introduction}

[n.n]Ferrocenophanes are macrocyclic organometallic ring systems that contain two ferrocene moieties linked to each other through their cyclopentadienyl rings. Several examples of symmetrical [1.1]ferrocenophanes containing Group $12(\mathrm{Hg}),{ }^{43} 13(\mathrm{~B}, \mathrm{Ga}, \mathrm{In}),{ }^{44-46} 14(\mathrm{C}, \mathrm{Si}$, $\mathrm{Sn})^{47-50}$ or $15(\mathrm{P}, \mathrm{As})^{51,52}$ linking moieties have been described since the late 1960s. Very recently, several new [1.1]ferrocenophanes containing $\mathrm{Al}, \mathrm{Ga}$, or $\mathrm{Si}$ bridging elements containing intramolecularly coordinating ligands have been synthesised by the Müller group. ${ }^{129}$ Larger symmetrical macrocyclic [1.1]ferrocenophanes were also reported by Manners et al. for species with either five or six alternating linked ferrocenes and dimethylsilyl groups. ${ }^{130}$ Such [n.n]ferrocenes with one or two heteroatom spacer atom(s) usually display strong electronic communication between the ferrocenyl centers as evidenced by cyclic voltammetry, with sequential, well separated, multi-step oxidation potentials as a result of the intimate structural connectivity of the metal centers.

The first tin-containing [1.1]ferrocenophane $(\mathbf{6 a}, \mathrm{R}=n$ - $\mathrm{Bu})$ was reported by Seyferth ${ }^{50}$ who isolated, in very low yield (3\%), a crystalline product in the attempted preparation of the strained di- $n$-butylstanna[1]ferrocenophane $\left(\mathbf{7 a}, \mathrm{R}=n\right.$-Bu). The groups of Manners ${ }^{116}$ and Pannell $^{122}$ successfully prepared and polymerized examples of ring-strained stanna[1]ferrocenophanes (7b-d) in to polyferrocenylstannanes $(\mathbf{8 b}-\mathbf{d})$. Also isolated from the solution polymerizations of monomers $(\mathbf{7 b}, \mathbf{7} \mathbf{c})$ were tin-containing [1.1] ferrocenophanes $(\mathbf{6 b}$, 6c) in modest yields (20-30\%). Concurrently, Herberhold and co-workers ${ }^{41}$ described the 
synthesis of the closely related [2]- and [3]ferrocenophanes with tetramethyldistannanediyl 5a and hexamethyltristannyl 9a bridges via the reductive coupling reactions of 1,1'bis(dimethylstannyl)ferrocene 3a with dialkylstannyldiamines $\left(\mathbf{1 0 a}=(n-\mathrm{Bu})_{2} \mathrm{Sn}\left(\mathrm{NEt}_{2}\right)_{2}, \mathbf{1 0 b}=\right.$ $\left.\mathrm{Me}_{2} \mathrm{Sn}\left(\mathrm{NEt}_{2}\right)_{2}\right)$. A more sterically hindered distanna[2]ferrocenophane $\mathbf{5 b}$ was recently prepared by Braunschweig via salt elimination of dilithioferrocene•tmeda (tmeda $=N, N, N^{\prime}, N^{\prime}-$ tetramethylethylenediamine) with the bulky dichlorodistannane, $t-\mathrm{Bu}_{4} \mathrm{Sn}_{2} \mathrm{Cl}_{2}$, in good yield. ${ }^{131}$

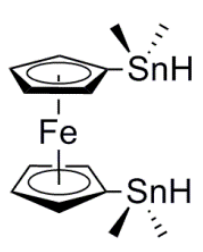

3

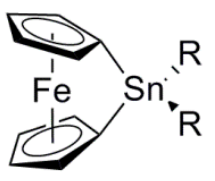

$7 b-d$

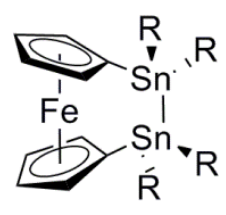

$5 a-b$

$(\mathrm{R}=\mathrm{Me}, \mathrm{t}-\mathrm{Bu})$

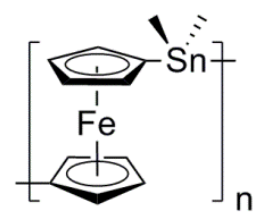

$8 a-d$

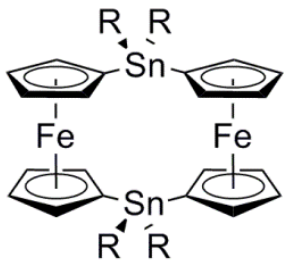

6a-d

( $n$-Bu, $t-B u, M e s, \mathrm{Et})$

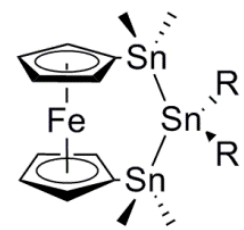

9a-b

$(\mathrm{R}=\mathrm{Me}, \mathrm{t}-\mathrm{Bu})$

(R = $t-\mathrm{Bu}$, Mes, Trip) $\quad(\mathrm{R}=n-\mathrm{Bu}, t-\mathrm{Bu}$, Mes, Trip)

Figure 3.1: previously made ferrocenyl stannanes and stannyl ferrocenophanes.

There have been a few examples of larger [n.n]ferrocenophanes in the literature $54,55,132$ including a tin-containing [5.5]ferrocenophane with two $\left(\mathrm{Me}_{2} \mathrm{SiCH}_{2}\right)_{2} \mathrm{SnMe}_{2}$ bridges isolated by Jurkschat and coworkers ${ }^{54}$ in a $60 \%$ yield. We report herein, the isolation, in modest yield, the first example of a symmetrical tin-containing [3.3]ferrocenophane, its characterization by NMR spectroscopy and identification by mass spectrometry, and detail the electronic properties investigated by UV-Vis spectroscopy and cyclic voltammetry. 


\subsection{Results and discussion}

Our interest in Group 14 metallocenes has been focused on the preparation of oligo- and polymetallocenes with at least two bridging atoms between ferrocene units. In particular, dehydrogenative coupling reactions of suitable Group 14 hydrides such as 3a, and metalcatalyzed ring-opening polymerization of novel monomers like the [2]ferrocenophane 5a, have been targeted. Following procedures outlined by Herberhold and Wrackmeyer, ${ }^{41}$ we readily prepared 3a in comparable yields and purity. Room temperature dehydrogenative coupling of 3a to yield 5a was then attempted with a few Group 9 and 10 metal catalysts. These results are listed in Table 1.

Table 3.1. Comparison of catalytic activity for main group and transition metal catalysts in the ring-closing formation of $\mathbf{4 a}$ from 6.

\begin{tabular}{|c|c|c|c|}
\hline Catalyst & Mol ratio Cat. to 3 & $\%$ Yield of $5 a$ & Reference \\
\hline$\overline{P t(\text { acac })_{2}}$ & $0.13: 1$ & No reaction & This work \\
\hline $\mathrm{CIRh}\left(\mathbf{P P h}_{3}\right)_{3}$ & $0.007: 1$ & No reaction & This work \\
\hline $\operatorname{Pd}_{2}(\mathrm{dba})_{3}$ & 0.043:1 & 90 & This work \\
\hline$(n-\mathrm{Bu})_{2} \mathrm{Sn}\left(\mathrm{NEt}_{2}\right)_{2}$ & $1: 1$ & 5 & This work \\
\hline$(n-\mathrm{Bu})_{2} \mathrm{Sn}\left(\mathrm{NEt}_{2}\right)_{2}$ & $1: 1$ & 52 & 41 \\
\hline $\mathrm{Hg}\left(\mathrm{SiMe}_{3}\right)_{2}$ & $1.3: 1$ & 29 & 41 \\
\hline
\end{tabular}


Of the three catalyst examined, an efficient intramolecular dehydrogenative coupling of 3a to form 5a was only observed with catalytic amounts of $\operatorname{Pd}_{2}(\mathrm{dba})_{3}$ (tris(dibenzylideneacetone)dipalladium(0)). This proceeded with an isolated product yield of 90\%. By contrast, compound 5a previously synthesized by Herberhold et al., ${ }^{41}$ used a stoichiometric quantity of $\mathbf{1 0 a}$ at higher dilution resulting in only a $52 \%$ yield.

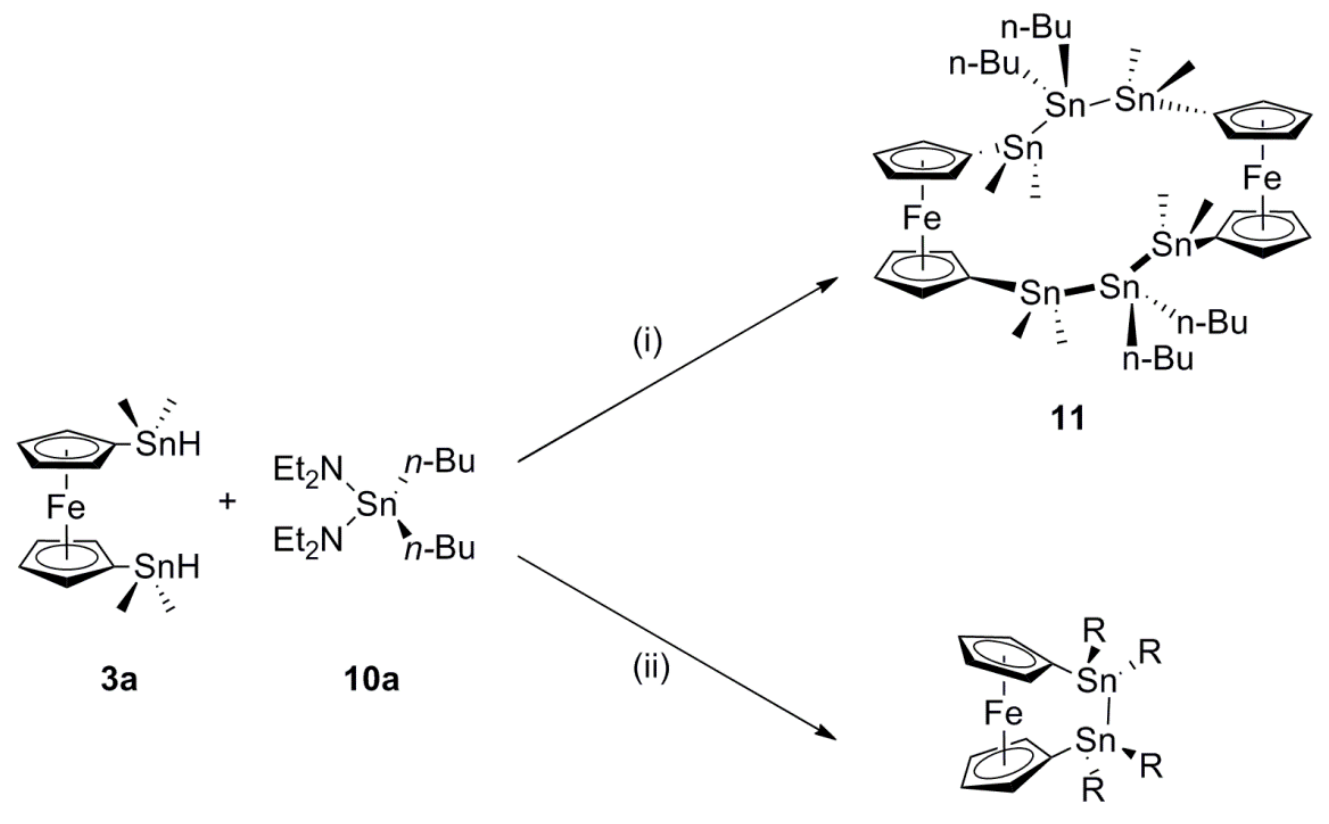

$5 a$

Figure 3.2: (i) $\mathrm{Et}_{2} \mathrm{O}([\mathbf{3 a}],[10 \mathrm{a}]=0.1 \mathrm{M}),, 0^{\circ} \mathrm{C} 1 \mathrm{hr}$, reflux $3 \mathrm{hr}$, hexanes/silica col. (82\% yield of 11), (ii) $\mathrm{Et}_{2} \mathrm{O}([\mathbf{3 a}],[10 \mathrm{a}] 0.02 \mathrm{M}) 0^{\circ} \mathrm{C} 1 \mathrm{hr}$, reflux $2 \mathrm{hr}, 3: 2 \mathrm{DCM} / \mathrm{hexanes} /$ silica col. (52\% yield of $\mathbf{5 a}$ ).

Under an inert atmosphere, the reaction of 3a (Scheme 1) with a stoichiometric equivalent of 10a in $\mathrm{Et}_{2} \mathrm{O}$ solution was initially carried out at $0^{\circ} \mathrm{C}$, followed by heating this mixture to reflux temperature (3 $\mathrm{hr}$ ) to ensure ring-closing, to give 5a. When this process was performed by Herberhold, purification by a silica gel column using a DCM/hexanes (3:2) in an inert atmosphere $\left(\mathrm{N}_{2}(\mathrm{~g})\right)$ resulted in a 52\% recovery of 5a. In our hands, the reactants were used independently at both the same and at a higher concentration $(5 \times)$ than Herberhold and TLC 
performed using an identical DCM/hexanes mixture. Unfortunately, this resulted in a considerable "streaking" being observed on the TLC plate. Conversely, development in neat hexanes (also under $\mathrm{N}_{2}(\mathrm{~g})$ ) yielded two distinct spots by TLC. The crude sample was purified by silica gel chromatography eluting with neat hexanes, with two distinct fractions being collected. This accounted for approximately $87 \%$ of the product mass (11 and $\mathbf{9 a})$; the remainder of the reaction material remained on the column and could not be recovered.

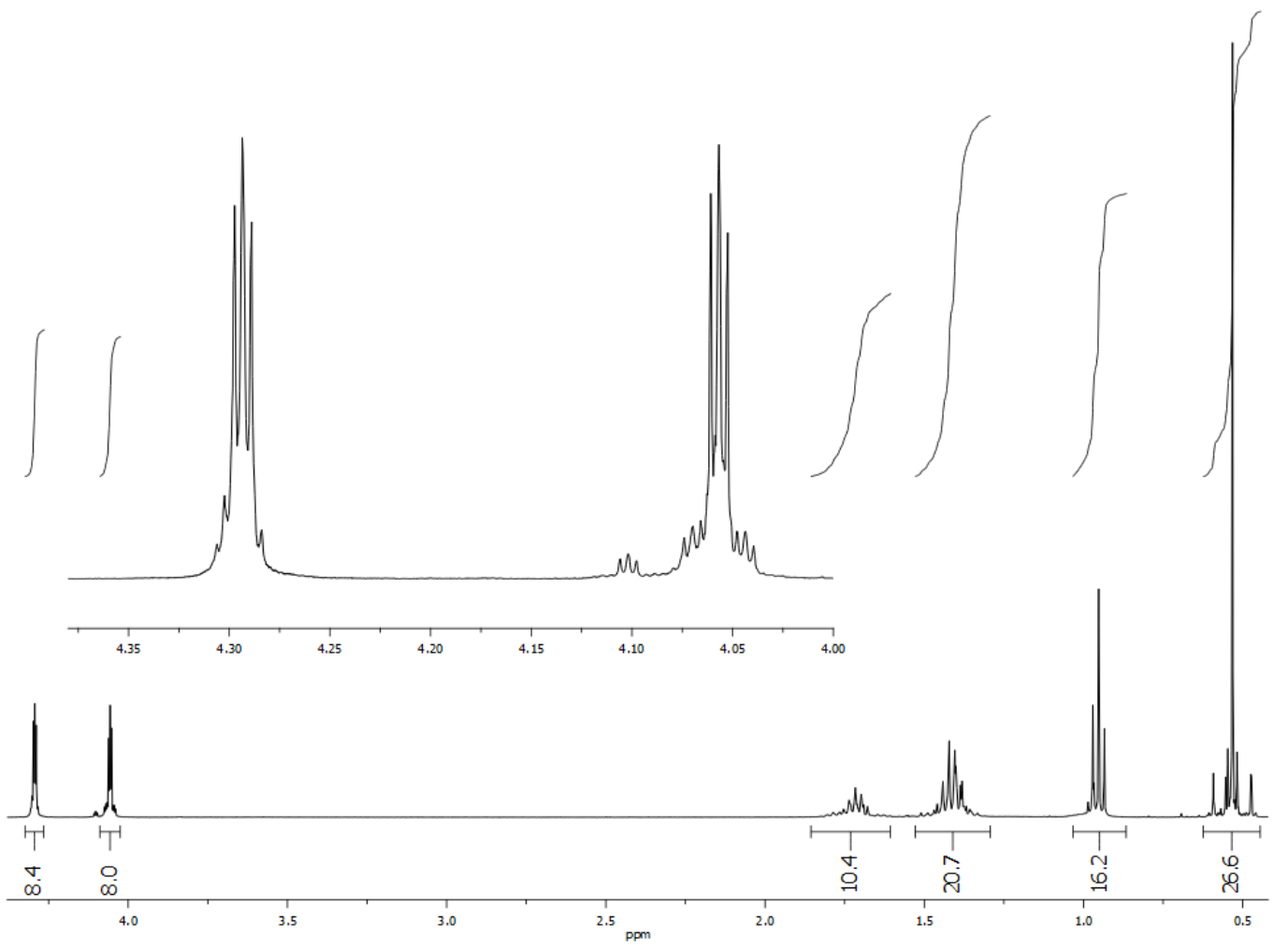

Figure 3.3. ${ }^{1} \mathrm{H}$ NMR $\left(\mathrm{C}_{6} \mathrm{D}_{6}\right)$ of compound $\mathbf{1 1}$ with inset of $\mathrm{Cp}$ region.

Surprisingly, analysis by NMR $\left({ }^{119} \mathrm{Sn} ; \mathrm{C}_{6} \mathrm{D}_{6}\right)$ confirmed the smaller second fraction (5\% of the recovered materials) was $\mathbf{5 a}$ displaying a resonance at $-43 \mathrm{ppm}$. By contrast, the first fraction, recovered as a bright, orange oil (stable for short periods in air), was isolated in an $82 \%$ yield. Initial attempts to carry out the NMR analysis of both the $1^{\text {st }}$ and $2^{\text {nd }}$ fractions in $\mathrm{CDCl}_{3}$ 
resulted in broad, unresolved resonances in the $\mathrm{Cp}$ and $n$-butyl regions, indicative of immediate decomposition in this solvent. When the NMR $\left({ }^{1} \mathrm{H}\right.$, Figure 1$)$ of the first fraction was analysed in $\mathrm{C}_{6} \mathrm{D}_{6}$, a highly symmetrically substituted [n.n]ferrocenphane, with a detectable trace of another $1,1^{\text {' }}$-ferrocene or ferrocenophane containing compound ( $<1 \%$ by $\left.{ }^{1} \mathrm{H} \mathrm{NMR}\right)$ along with ferrocene, were revealed. Both trace contaminants were subsequently removed via column chromatography; however attempts to crystallize compound $\mathbf{1 1}$ were unsuccessful.

\subsubsection{Sn NMR and NMR simulation}

The ${ }^{119} \mathrm{Sn}$ NMR $\left(\mathrm{C}_{6} \mathrm{D}_{6}\right.$; Figure 3.4$)$ spectrum of this first fraction proved less straightforward with the two largest resonances assigned to the $\left(\mathrm{SnMe}_{2}\right)$ substituent at -100.4 and the $\left(\operatorname{Sn}(n-\mathrm{Bu})_{2}\right)$ group at -211.8 ppm respectively, with a chemical shift difference $(\Delta \delta)$ of $\approx 112$ ppm. Multiple isotopic couplings were also identified at each resonance cluster. A simulation of the ${ }^{117} \mathrm{Sn}$ and ${ }^{119} \mathrm{Sn}$ NMR spectra was then conducted to elucidate whether the symmetrical ferrocenophane contained one (9b) or two (11) ferrocene units and to accurately predict the expected ${ }^{117} \mathrm{Sn} /{ }^{119} \mathrm{Sn}$ isotopic coupling patterns.

$$
P_{\text {Pattern }}=\sum I \times\left(\frac{\prod P_{S n}}{100^{(X \times Y)}}\right)
$$

At present, there are no readily available NMR modelling tools to accurately predict ${ }^{117} \mathrm{Sn} /{ }^{119} \mathrm{Sn}$ coupling patterns, particularly for compounds that possess multiple $\mathrm{Sn}$-Sn bonds. The data generated from our in-house ${ }^{117} \mathrm{Sn}$ and ${ }^{119} \mathrm{Sn}$ NMR simulator (see appendix S5 for program data) for the signal intensities is within reasonable agreement with the patterns of coupling observed experimentally, although direct integration of these peak intensities is

obviously not possible. This is due to a few factors, including the nature of ${ }^{117} \mathrm{Sn}\left[{ }^{1} \mathrm{H}\right]$ or ${ }^{119} \mathrm{Sn}$ $\left[{ }^{1} \mathrm{H}\right]$ experiments where small intensity deviations are likely due to the low intensity of $\mathrm{Sn}-\mathrm{Sn}$ 
couplings based on natural abundance. The system was calculated based on equation (2) were $\mathrm{P}_{\text {Pattern }}$ is the total probability of each pattern occurring, $\mathrm{I}$ is equal the number of identical systems, $\mathrm{P}_{\mathrm{Sn}}$ is the probability that a tin atom will be one of the NMR active nuclei and $\mathrm{X}$ and $\mathrm{Y}$ are the number of bridging tins and the number of ferrocenes in the structure respectively. Equation 2 is based a matrix derived from the structure of the [3.3]ferrocenophane as seen in Figure 3.4.

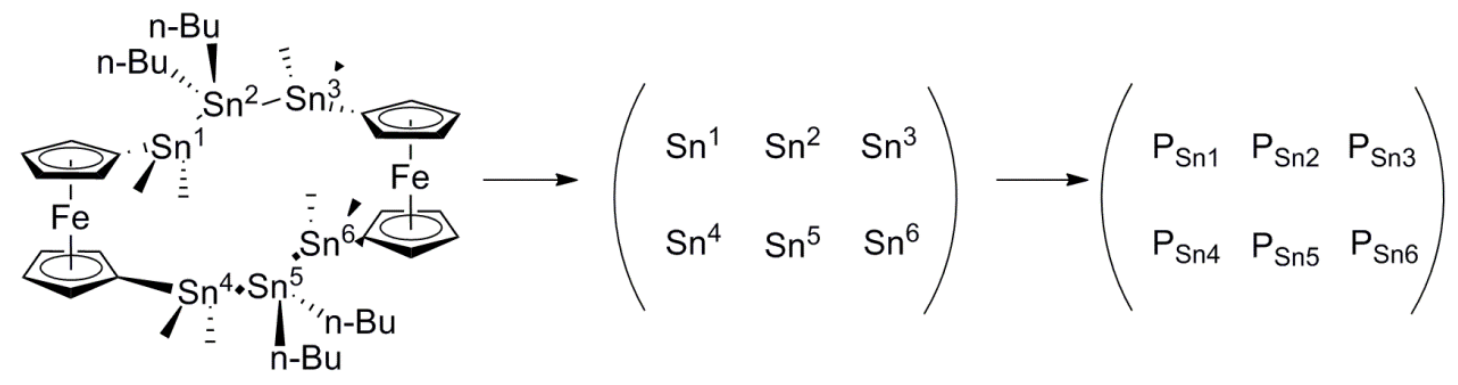

Figure 3.4: The design of the matrices used in ${ }^{119} \mathrm{Sn}$ modeling program.

In the simulated and experimental ${ }^{119} \mathrm{Sn}$ spectrum (Figure $2 \mathrm{a}, \mathrm{b}$ ) of 11, the two largest calculated intensities were experimentally fixed at $-100.5\left(\mathrm{SnMe}_{2}\right)$ and at $-211.8\left(\mathrm{Sn}(n-\mathrm{Bu})_{2}\right)$ ppm respectively. Calculated resonance satellites were located based on experimental coupling constants. Using a statistical model (eqn 2), ${ }^{117} \mathrm{Sn} /{ }^{119} \mathrm{Sn}$ and ${ }^{119} \mathrm{Sn} /{ }^{119} \mathrm{Sn}$ satellite intensities were calculated with intensities above $1 \%$ of the largest signal, identifying 12 (2 singlets and 5 doublet) resonances, which was two less than observed experimentally.

There were several additional predicted peaks of low calculated intensities that are not observed. It should be noted, that while both compounds (9b and 11) would be expected to have the same coupling patterns on a statistical basis, chemical shifts for the different tin environments should be distinct. The two smaller resonances at -90.8 and $-221.2 \mathrm{ppm}(\Delta \delta=$ $130.4 \mathrm{ppm}$ ) were tentatively assigned as $\mathbf{9 b}$ based on the assignment of the ${ }^{119} \mathrm{Sn}$ resonances by 
Herberhold for the hexamethyltristannane bridged [3]ferrocenophane, 9a, $(-102.5,-249.3 \mathrm{ppm} ; \Delta$ $\delta=146.7 \mathrm{ppm}) .{ }^{41}$ Similar results were also found in the simulation of the ${ }^{117} \mathrm{Sn}$ spectra for compound 11.
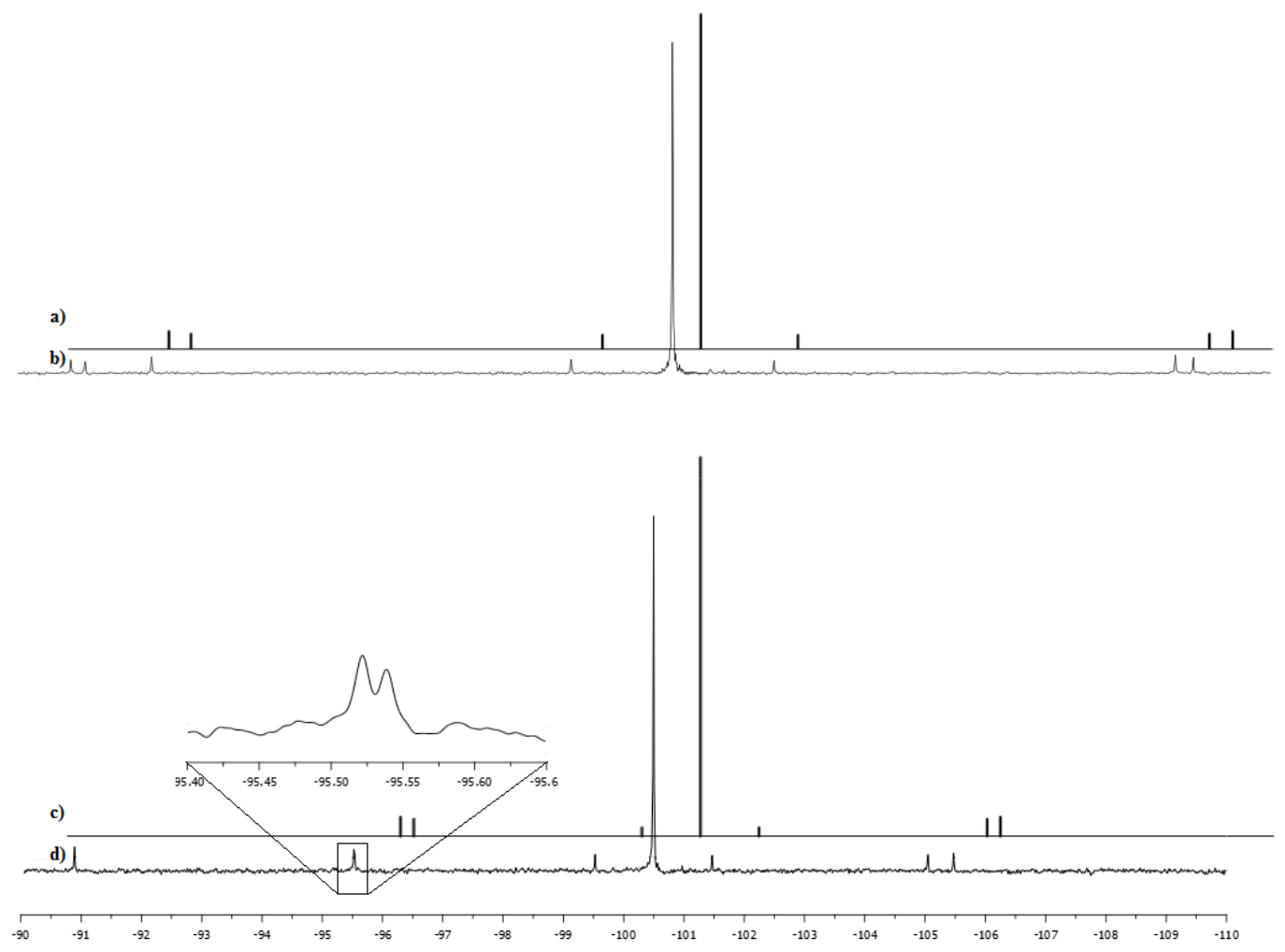

Figure 3.5: a) Calculated and b) Experimental ${ }^{119} \mathrm{Sn}$ and c) Calculated and d) Experimental ${ }^{117} \mathrm{Sn}$ NMR spectra of the $\mathrm{SnMe}_{2}$ resonance for compound 11. Calculated spectra shifted -1 ppm.

\subsubsection{Electrochemistry}

Further evidence for the [3.3]ferrocenophane structure of $\mathbf{1 1}$ was sought by employing cyclic voltammetry. An important metric of the communication between bridged ferrocenes is the degree to which they respond to oxidation/reduction as independent (insulated, single wave) or dependent (delocalized, two or more waves) metallocenes. The difference in the $\Delta \mathrm{E}$ for 
model systems (6a-c, 12a) containing a single bridging element or singly bridged polymers (8a-

c, $8 \mathbf{e})$ is heteroatom dependent. ${ }^{86}$

Table 3.2: Half-potentials for bridged bisferrocenes and selected ferrocene polymers.

\begin{tabular}{|c|c|c|c|c|c|}
\hline Compound & Bridge & ${ }^{1} \mathbf{E}_{1 / 2},{ }^{2} \mathbf{E}_{1 / 2},[\mathbf{V}]$ & $\Delta \mathbf{E},[\mathbf{V}]$ & $d\left(\mathrm{Fe}^{\cdots \cdots} \mathrm{Fe}\right),[\AA]$ & Ref \\
\hline 4 & $-\mathrm{Me}_{2} \mathrm{SnMe}_{2} \mathrm{Sn}-$ & $-0.2,0.16$ & 0.18 & $9.63^{*}$ & $\dagger$ \\
\hline $6 \mathbf{a}$ & $-(n-\mathrm{Bu})_{2} \mathrm{Sn}-$ & $0.11,0.31$ & 0.20 & 5.50 & $50,133(\mathrm{a})$ \\
\hline $6 b$ & $-(t-\mathrm{Bu})_{2} \mathrm{Sn}-$ & $-0.06,0.21$ & 0.27 & $5.474(1)$ & $116(\mathrm{~b})$ \\
\hline 6c & -(Mes) $)_{2} \mathrm{Sn}-$ & $0.01,0.27$ & 0.28 & $5.248(1)$ & $116(b)$ \\
\hline $8 \mathbf{a}$ & $-(n-\mathrm{Bu})_{2} \mathrm{Sn}-$ & $-0.60,0.18$ & 0.24 & - & $86(\mathrm{~b})$ \\
\hline $8 b$ & $-(t-\mathrm{Bu})_{2} \mathrm{Sn}-$ & $0.00,0.24$ & 0.24 & - & $116(\mathrm{~b})$ \\
\hline $8 c$ & $-(\mathrm{Mes})_{2} \mathrm{Sn}-$ & $-0.07,0.14$ & 0.21 & - & $116(\mathrm{~b})$ \\
\hline 11 & $-\mathrm{Me}_{2} \mathrm{Sn}(n-\mathrm{Bu})_{2} \mathrm{SnMe}_{2} \mathrm{Sn}-$ & $0.01,0.23$ & 0.22 & $8.49^{*}$ & $\dagger^{(\mathrm{c})}$ \\
\hline $12 a$ & $-\mathrm{Me}_{2} \mathrm{Si}-$ & $0.00,0.15$ & 0.15 & $6.83^{*}$ & 95 (d) \\
\hline $12 b$ & $-\left(\mathrm{Me}_{2} \mathrm{Si}\right)_{2-}$ & $-0.02,0.09$ & 0.11 & $8.84,8.80^{*}$ & 95 (d) \\
\hline $12 \mathrm{c}$ & $-\left(\mathrm{Me}_{2} \mathrm{Si}\right)_{3^{-}}$ & $-0.04,0.04$ & 0.08 & $10.2^{*}$ & 95 (d) \\
\hline $12 d$ & $-\left(\mathrm{Me}_{2} \mathrm{Si}_{6^{-}}\right.$ & 0.58 & 0 & $16.9 *$ & 95(d) \\
\hline 13 & $-\mathrm{Me}_{2} \mathrm{Sn}-$ & $\mathrm{n} / \mathrm{a}$ & $\mathrm{n} / \mathrm{a}$ & $6.12^{*}$ & 105 \\
\hline 14 & $-\mathrm{N}=\mathrm{C}=\mathrm{N}-$ & $0.09,0.29$ & 0.20 & $7.64^{*}$ & $134(\mathrm{e})$ \\
\hline
\end{tabular}

All values normalized to $\mathrm{Fc} / \mathrm{Fc}+$ couple. Conditions: (a) $\mathrm{DCM} / 0.1 \mathrm{M}\left[\mathrm{N}(n-\mathrm{Bu})_{4}\right]\left[\mathrm{BF}_{4}\right]$, (b) $\mathrm{DCM} / 0.1 \mathrm{M}\left[\mathrm{N}(n-\mathrm{Bu})_{4}\right]\left[\mathrm{PF}_{6}\right]$, (c) $\mathrm{MeCN} / 0.1 \mathrm{M}\left[\mathrm{N}(n-\mathrm{Bu})_{4}\right]\left[\mathrm{BF}_{4}\right]$, (d) DCM/0.1M $\left[\mathrm{NEt}_{4}\right]\left[\mathrm{ClO}_{4}\right]$, (e) $\mathrm{DMF} / 0.1 \mathrm{M}\left[\mathrm{N}(n-\mathrm{Bu})_{4}\right]\left[\mathrm{ClO}_{4}\right]$. * Calculated using Gaussian 9 (see below). $\dagger$ This work. 


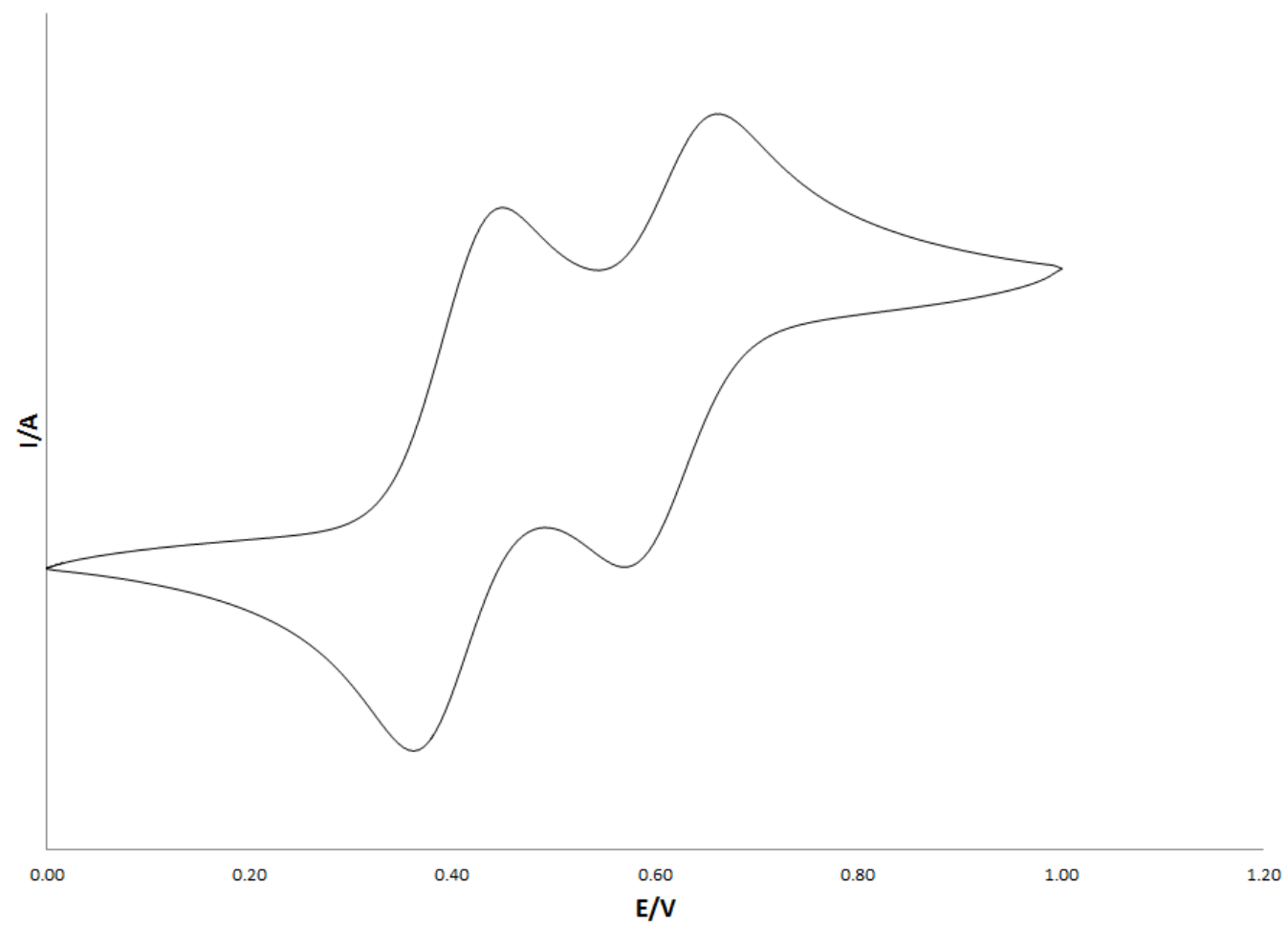

Figure 3.6: Cyclic voltammetry of $\mathbf{1 1}$ at $100 \mathrm{mV} / \mathrm{s}$ in a $\mathrm{MeCN}$ solution containing $0.1 \mathrm{M}[\mathrm{N}(n$ $\left.\mathrm{Bu})_{4}\right]\left[\mathrm{BF}_{4}\right]$ as supporting electrolyte.

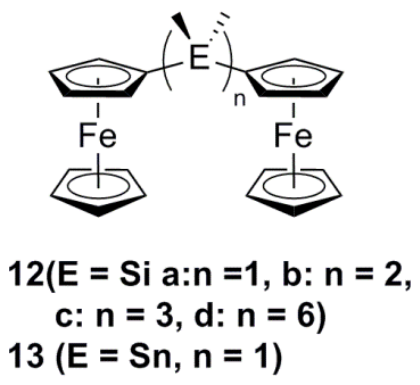

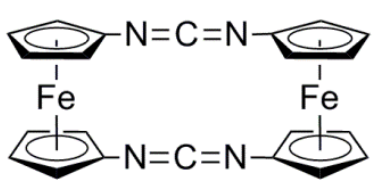

14

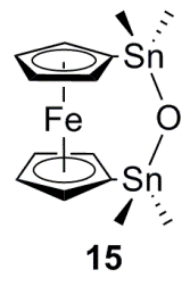

15

Figure 3.7: Structure of compound 12a-d, 13, 14, and 15.

This effect is smaller when compared to non-bridged polymetallocenes or metallocenes linked by conjugated vinyl or acetylene spacers that are assumed to communicate exclusively along a $\pi$ orbital backbone. Ferrocene units bridged by a later Group 14 (Si, Ge, Sn) dialkyl or diaryl unit are believed to communicate both through the $\sigma$-bonded bridge and through direct Fe••Fe interactions. ${ }^{130}$ Model ferrocenes and polyferrocenes bridged by two or more spacers show substantially less interaction between metal centers, with ethylene bridges being essentially fully insulating. ${ }^{86}$ Previous work by Pannell, who prepared a series of bisferrocenes with mono-, 
di-, tri-, and hexa(dimethylsilane) bridges (12a-d), reported a lower level of communication between metal centers as the bridge length increased (Table 2). ${ }^{95}$ Beyond three bridging (dimethysilylene) units, only a single reversible wave is observed by cyclic voltammetry. [1.1]Ferrocenophanes $(\mathbf{6 b}, \mathbf{6 c})$ show a similar degree of electronic communication $(\Delta \mathrm{E} \approx 0.25 \mathrm{~V})$ compared to singly bridged bisferrocenes. In the case of the [3.3]ferrocenophane 11, cyclic voltammetry (Figure 3) in $\mathrm{MeCN}$ reveals two oxidation/reduction events at ${ }^{1} \mathrm{E}_{1 / 2}$ of $0.01 \mathrm{~V}$, and ${ }^{2} \mathrm{E}_{1 / 2}$ of $0.23 \mathrm{~V}$. The $\Delta \mathrm{E}$ of $0.22 \mathrm{~V}$ for $\mathbf{1 1}$ indicates a considerable degree of communication between ferrocene units and is within the same range as known tin-containing [1.1]ferrocenophanes (6a-c) $)^{116,133}$ and mono-tin-bridged ferrocenyl polymers $(\mathbf{8 a - c}, \mathbf{8 e})^{86,116,133}$ or the fully $\pi$-conjugated [3.3]bisferrocene $\mathbf{1 4} .^{134,135}$ The partial oxidation of $\mathbf{1 1}$ likely leads to a Class II mixed valence compound according to the Robin-Day classification. ${ }^{136}$ In the case of $\mathbf{1 1}$, this would suggest that electronic communication between ferrocene units is facilitated through both the $\pi$ conjugation of the ferrocene ring system and the $\sigma$ conjugation of the stannyl bridge.

\subsubsection{DFT modelling and UV-Vis spectroscopy}
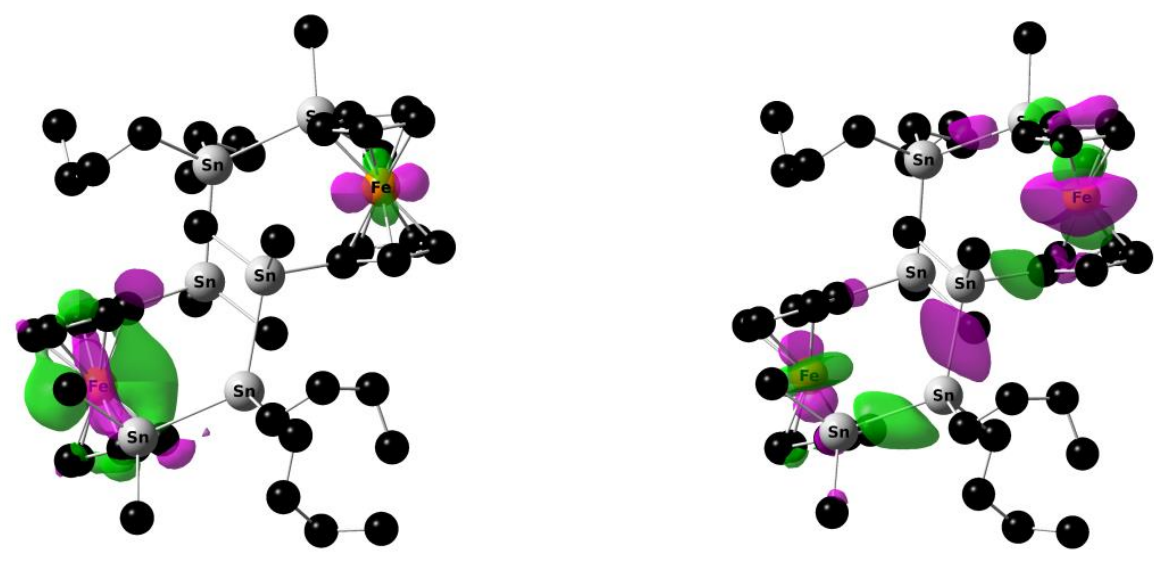

Figure 3.8: Molecular Orbital Diagrams of the HOMO Orbital of compound 11 (left) and the SOMO Orbital of its radical monocation (right). 
Computational modeling was performed on compounds $\mathbf{1 1}$ and $\mathbf{9 b}$ as well as several other similar structured compounds (5a, 12a-d, 13). Gaussian 9 was used for DFT and TD-DFT calculations and confirmed by zero point energy calculations. The LSDA method with the SDD basis set was used to calculate and optimize electronic and bonding structures. The electronics of 11 (Figure 4a) was then compared to its experimental $\lambda_{\max }$ value. The calculations from TD-DFT describe two minor energy transitions (HOMO/LUMO+1, HOMO-1/LUMO+1) and one major energy transition (HOMO-2/LUMO). The Fe $\cdots$ Fe distance of known ferrocenyl silanes, stannanes, and ferrocenophanes were calculated and compared to those of calculated $\mathbf{1 1}$ and $\mathbf{9 b}$. The HOMO-2/LUMO gap energy experimentally established by UV-Vis spectroscopy for compound 11 was $2.72 \mathrm{eV}$ (calculated for $\lambda_{\max }=455.1 \mathrm{~nm}$ in $\mathrm{Et}_{2} \mathrm{O}$ ). The calculated HOMO/LUMO energy gap for $\mathbf{1 1}$ was found to be $2.93 \mathrm{eV}$ using LSDA/SDD (7\% difference from experimental). Calculated energies are often larger than actual values, which agree with similar calculations Gao et al. ${ }^{137}$ performed with Pt compounds.

TD-DFT was used to simulate UV-Visible spectra and was compared to experimental spectra (Figure 3.8). The simulated spectra for compound $\mathbf{1 1}$ was in a higher agreement with the experimental spectra than the simulated for $\mathbf{9 b}$. DFT calculations were also performed on a singularly oxidized species of $\mathbf{1 1}$ (Figure $4 \mathrm{~b}$ ). Communication is predicted between the ferrocene centers along the tin bridge in the SOMO and lower energy orbitals (Figure 4). These conduction orbitals were approximately $1 \mathrm{eV}$ lower than the SOMO which was centered on one of the ferrocene units, consistent with the experimental electrochemistry undertaken in solution. 


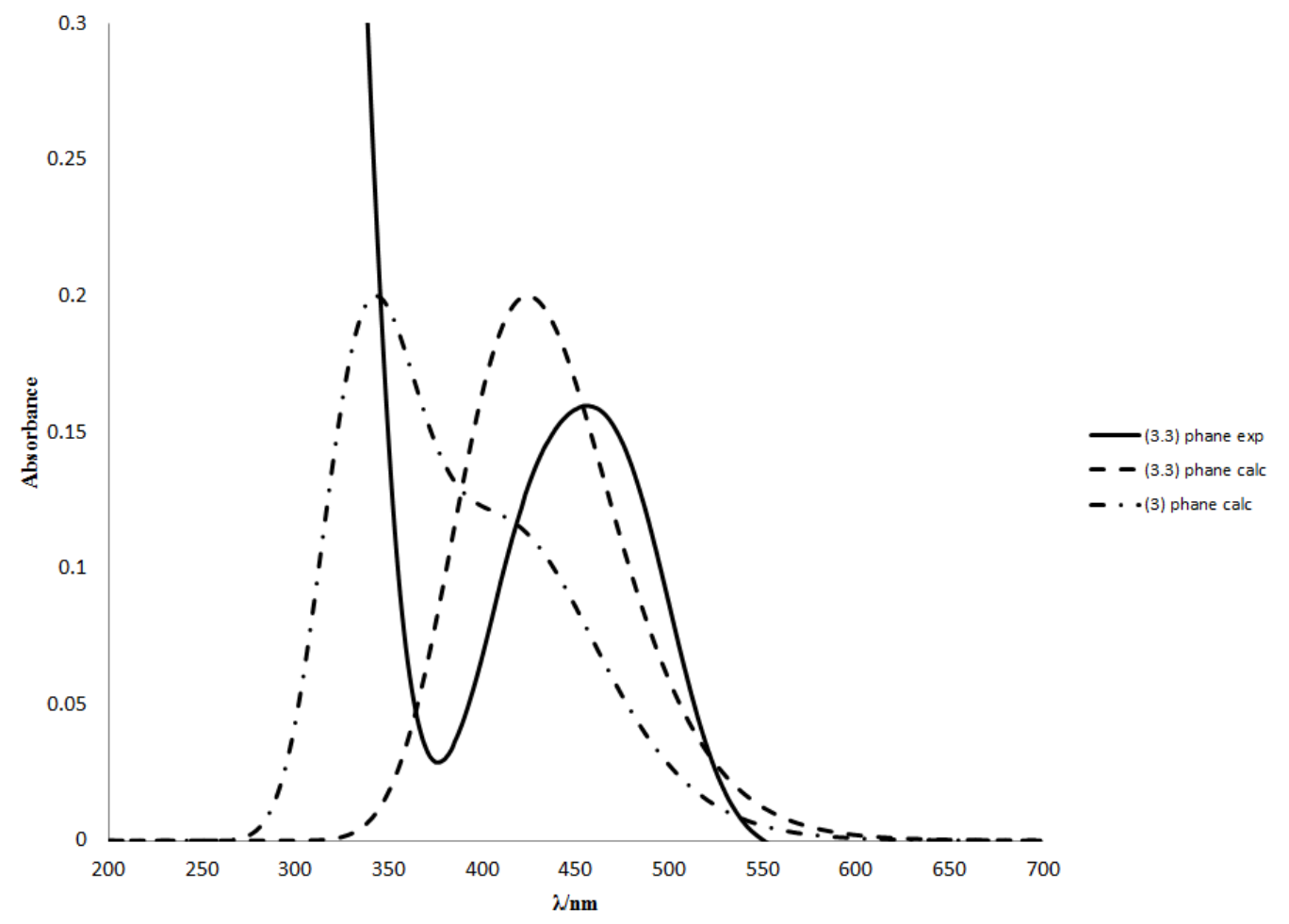

Figure 3.9: Comparison of calculated UV-Visible spectra for compounds $\mathbf{9 b}$ and $\mathbf{1 1}$ with the $\mathrm{UV}-\mathrm{Vis}$ spectrum of $\mathbf{1 1}$ in $\mathrm{Et}_{2} \mathrm{O}$.

\subsubsection{Mass spectrometry}

DART-TOF* mass spectrometry was also performed on compound 11. The DART mass spectrum shown in Figure 5 was obtained at $300^{\circ} \mathrm{C}$ and provides direct evidence for the presence of compound 11 with a cluster of peaks centered at $\mathrm{m} / \mathrm{z}$ 1428.9, which corresponds to a protonated molecular cation of formula $\left[\mathrm{C}_{44} \mathrm{H}_{76} \mathrm{Fe}_{2} \mathrm{Sn}_{6}+\mathrm{H}\right]$. The peak within the cluster found at 1433.86 was calculated at $\mathrm{m} / \mathrm{z}$ 1433.8621. Several other peaks are observed in the DART-MS spectrum and indicate that [3.3]ferrocenophane is both thermally labile and reactive under the conditions of the DART ionization. The DART ionization process produces singly-charged ions via gas-phase proton transfer and is akin to the classical mechanism of chemical ionization * Direct Analysis in Real Time - Time Of Flight 
(CI). ${ }^{138}$ The analyte molecule must first be vaporized in the heated DART stream and so the ionization efficiency is related directly to the volatility of the analyte species. Higher molecular weight products will therefore generally require higher temperatures to promote efficient ionization; however, in the case of reactive or thermally labile compounds, the higher temperature may also contribute to extensive degradation.

In addition to the parent ion species $[\mathrm{M}+\mathrm{H}]^{+}$, several of the most abundant peaks in the DART-MS spectrum have been identified which support the assignment of compound 11. These include: loss of $-\mathrm{Bu}_{2} \mathrm{Sn}\left(\mathrm{m} / \mathrm{z}\right.$ 1196.8), loss of $-\mathrm{Me}_{2} \mathrm{SnSnBu}_{2}(\mathrm{~m} / \mathrm{z}$ 1044.8), scission of compound 11 into two halves ${ }^{*}(\approx m / z$ 713.9) and other assignable ferrocenophanes that include oxygen atoms in their structures (Table 3). When the sample was left in the heated DART stream for an extended period of time (e.g. 10-20s), the intensity of the peak at $\mathrm{m} / \mathrm{z} 1428.9$ decreased and a strong peak was observed centered at $\mathrm{m} / \mathrm{z}$ 498.9. This likely corresponds to the known oxygen containing [3]ferrocenophane 15 (Figure 3.7).

To provide further certainty towards the identity of 11, DART-TOF mass spectra were measured at several temperatures $\left(100^{\circ}-300^{\circ} \mathrm{C}\right)$ and the results are listed in Appendix S3. Unsurprisingly, the signal for the protonated $\mathbf{1 1}$ is not observed at low temperatures $\left(100^{\circ} \mathrm{C}\right)$, however, decomposition products of $\mathbf{1 1}$ as well as new species that include oxygen were detected. As the temperature was further increased from $200^{\circ} \mathrm{C}$ to $300^{\circ} \mathrm{C}$, a distinguishable protonated molecular species appeared (m/z 1428.9), as well as peaks associated with larger fragmentation products including the loss of a single $\operatorname{Sn}\left(n-\mathrm{Bu}_{2}\right)$ unit at $\mathrm{m} / \mathrm{z} 1196.8$ and a new peak at $\mathrm{m} / \mathrm{z} 1212.8$ that corresponds to the addition of oxygen to this latter species.

\footnotetext{
* Compound $\mathbf{1 1}$ is divided into two halves differing only by either a proton or an electron.
} 


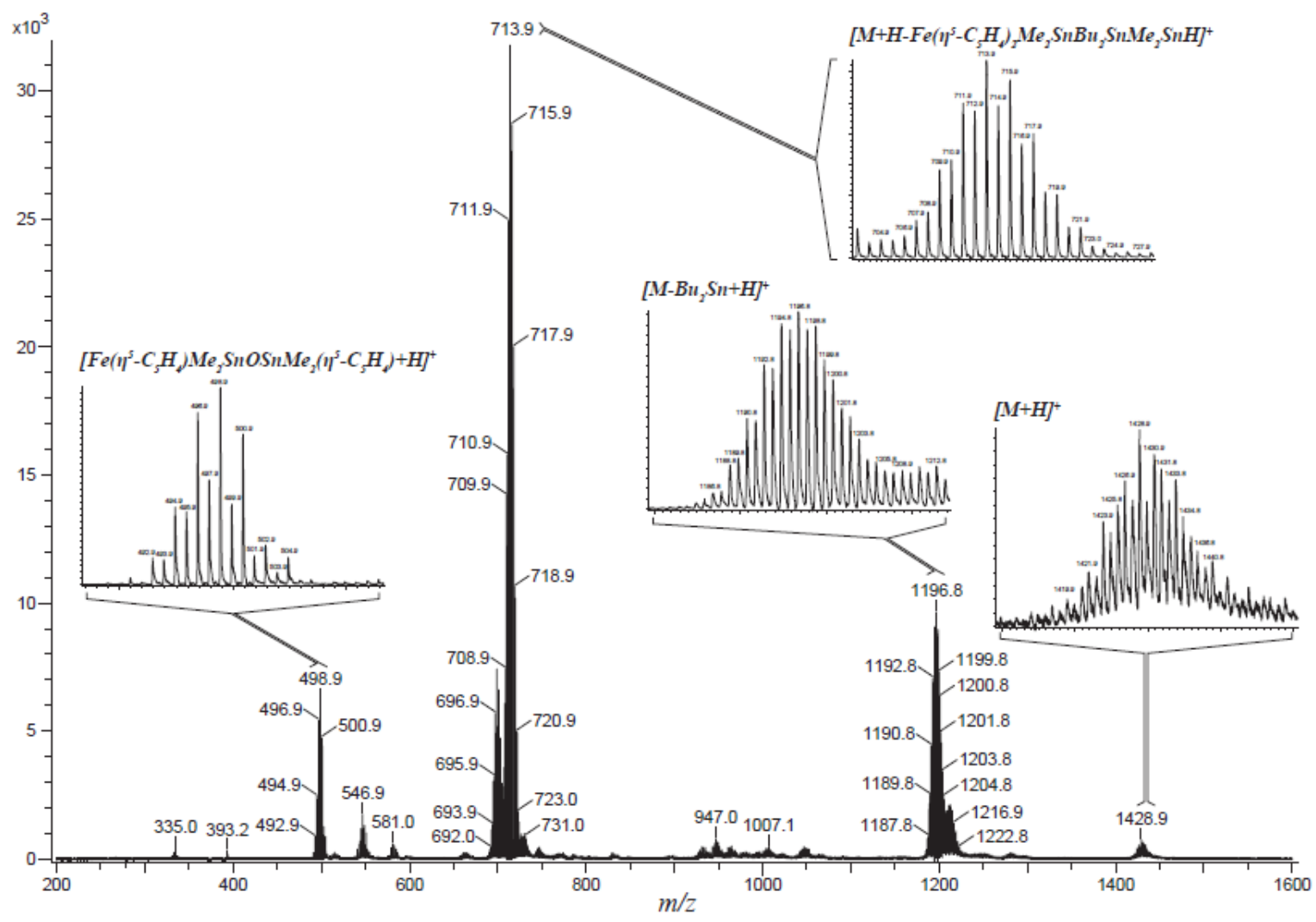

Figure 3.10: DART-TOF MS spectrum of 11 at $300^{\circ} \mathrm{C}$.

Due to the structural symmetry of the products $\mathbf{1 1}$ and $\mathbf{9 b}$, the possibility for dimerization of $\mathbf{9 b}$ to form $\mathbf{1 1}$ during the ionization process was also considered. In this case the protonated molecule $[\mathrm{M}+\mathrm{H}]^{+}$of $\mathbf{9 b}$ was expected at $\mathrm{m} / z$ 714.9 but was found to be absent from the DARTMS spectrum. Rather, the peak observed at $m / z 713.9$ is a decomposition product of the $[\mathrm{M}+\mathrm{H}]^{+}$ ion of 11. DART-TOF-MS was also performed at different skimmer potentials ranging from $20 \mathrm{~V}-80 \mathrm{~V}$ with a constant temperature of $200^{\circ} \mathrm{C}$ (Table 2). Application of a higher skimmer voltage in the interface region of the mass spectrometer effectively increases the energy of collisions and prevents dimerization. As the skimmer potential was raised, the peaks at $\mathrm{m} / \mathrm{z}$ 1428.9, as well as peaks larger than $\mathrm{m} / \mathrm{z} 713.9$ were found in relatively higher abundance. At a 
skimmer potential of $80 \mathrm{~V}$, the $\mathrm{m} / \mathrm{z} 1428.9$ was still detected and provides good evidence that this is not a dimer of $\mathbf{9 b}$, but is in fact the molecular charged species derived from $\mathbf{1 1}$.

Table 3.3: DART-TOF-MS relative abundance of mass fragments @ $200^{\circ} \mathrm{C}$ and $300^{\circ} \mathrm{C}$.

\begin{tabular}{|c|c|c|c|}
\hline \multirow[t]{2}{*}{$\mathbf{m} / \mathbf{z}$} & \multirow[t]{2}{*}{ Fragment } & \multicolumn{2}{|c|}{$\mathbf{R A}(\%)$} \\
\hline & & $200^{\circ} \mathrm{C}$ & $300^{\circ} \mathrm{C}$ \\
\hline 1428.9 & {$[\mathrm{M}+\mathrm{H}]^{+}$} & 0.8 & 2.3 \\
\hline 1212.8 & {$[\mathrm{M}+\mathrm{OH}]^{+}-\left[\mathrm{Bu}_{2} \mathrm{Sn}\right]$} & 30 & 6.5 \\
\hline 1196.8 & {$[\mathrm{M}+\mathrm{H}]^{+}-\left[\mathrm{Bu}_{2} \mathrm{Sn}\right]$} & 44 & 30.3 \\
\hline 1046.8 & {$[\mathrm{M}]^{+}-\left[\mathrm{Me}_{2} \mathrm{SnSnBu}_{2}\right]$} & 7.7 & - \\
\hline 996.8 & {$[\mathrm{M}+\mathrm{H}]^{+}+\mathrm{O}_{2}-\left[\left(\mathrm{Bu}_{2} \mathrm{Sn}\right)_{2}\right]$} & 32 & - \\
\hline 713.9 & {$[\mathrm{M}]^{+}-\left[\mathrm{Fe}\left(\eta^{5}-\mathrm{C}_{5} \mathrm{H}_{4}\right) \mathrm{Me}_{2} \mathrm{SnBu}_{2} \mathrm{SnMe}_{2} \mathrm{Sn}\left(\eta^{5}-\mathrm{C}_{5} \mathrm{H}_{4}\right)\right]$} & 67 & 100 \\
\hline 698.9 & {$[\mathrm{M}]^{+}-\left[\mathrm{Fe}\left(\eta^{5}-\mathrm{C}_{5} \mathrm{H}_{4}\right) \mathrm{SnMe}_{2} \mathrm{SnBu}_{2} \mathrm{SnMe}_{2}\left(\eta^{5}-\mathrm{C}_{5} \mathrm{H}_{4}\right)\right]$} & 7.4 & 24.4 \\
\hline \multirow[t]{2}{*}{546.9} & {$[\mathrm{M}]^{+}-\left[\left(\eta^{5}-\mathrm{C}_{5} \mathrm{H}_{4}\right) \mathrm{Fe}\left(\eta^{5}-\mathrm{C}_{5} \mathrm{H}_{4}\right) \mathrm{SnMe}_{2} \mathrm{SnBu}_{2} \mathrm{SnMe}_{2}\left(\eta^{5}-\right.\right.$} & - & 5.5 \\
\hline & $\left.\left.\mathrm{C}_{5} \mathrm{H}_{4}\right) \mathrm{Fe}\left(\eta^{5}-\mathrm{C}_{5} \mathrm{H}_{4}\right)\right]$ & & \\
\hline \multirow[t]{2}{*}{498.9} & {$[\mathrm{M}+\mathrm{OH}]^{+}-\left[\left(\eta^{5}-\mathrm{C}_{5} \mathrm{H}_{4}\right) \mathrm{Fe}\left(\eta^{5}-\mathrm{C}_{5} \mathrm{H}_{4}\right) \mathrm{SnMe}_{2} \mathrm{SnBu}_{2} \mathrm{SnMe}_{2}\left(\eta^{5}-\right.\right.$} & 100 & 19.4 \\
\hline & $\left.\left.\mathrm{C}_{5} \mathrm{H}_{4}\right) \mathrm{Fe}\left(\eta^{5}-\mathrm{C}_{5} \mathrm{H}_{4}\right)+\mathrm{Bu}_{2} \mathrm{Sn}\right]$ & & \\
\hline
\end{tabular}




\subsection{Conclusion}

A new higher yielding catalytic route to the previously known distanna-bridged [2]ferrocenophane, 5a, was identified. Species of this type will be used for future polymerization investigations in the preparation of polyferrocenes with two tin bridges. The first tristannabridged [3.3]ferrocenophane $\mathbf{1 1}$ was also synthesised in good yield through a reaction of 1,1'bis(dimethylstannyl)ferrocene 3 and di- $n$-butylbis(diethylamino)stannane 10a. An in-house Sn NMR simulation program was used effectively to model the complex Sn NMR spectrum of compound $\mathbf{1 1}$ and was found to be in good agreement with the experimental values. MS characterization provides strong evidence to support the assignment of [3.3]ferrocenophane $\mathbf{1 1}$. Finally, characterization of the electrical properties of $\mathbf{1 1}$ revealed exceptionally strong communication between ferrocene centers through the tristannana-bridge that is within the same magnitude as a single tin-bridged [1.1]ferrocenophane compound, which was also supported by DFT modelling. 


\subsection{Experimental}

\subsection{Equipment and procedures}

Most solvents (THF, $\mathrm{Et}_{2} \mathrm{O}$, hexanes) were dispensed from an MBraun MB-SPS solvent system to remove trace water and oxygen. DMF was distilled over activated molecular sieves to remove trace water. All reagents where purchased from Sigma-Aldrich with the exception of tin chlorides which were purchased from both Strem and Sigma-Aldrich. All reagents were used as received. Standard Schlenk techniques were used with all air sensitive compounds. $\left(\eta^{5}-\right.$ $\mathrm{C}_{5} \mathrm{H}_{4} \mathrm{Li}$ )Fe-TMEDA was synthesized according to literature procedure. ${ }^{139}$ Di- $n$ butylbis(diethylamino)stannane 10a was prepared according to a reported procedure. ${ }^{33}$ Elemental Analysis was performed by Atlantic Microlab, Inc. of Norcross Georgia.

\subsubsection{Nuclear magnetic resonance}

${ }^{1} \mathrm{H}$ NMR (400 MHz), ${ }^{13} \mathrm{C}$ NMR (100.6 MHz) and ${ }^{119} \mathrm{Sn}$ NMR (79.5 MHz) spectra were recorded on a Bruker Avance $400 \mathrm{MHz}$ NMR spectrometer with a BBFO 5-mm direct probe. A ${ }^{1} \mathrm{H}$ pulse width of $30^{\circ}$ was used, acquiring a spectral window of $8223 \mathrm{~Hz}(20 \mathrm{ppm})$ using a relaxation delay of $1 \mathrm{~s}$, acquisition time $3.98 \mathrm{~s}$, 32k points (16 scans). The ${ }^{1} \mathrm{H} 90^{\circ}$ pulse width was $10.4 \mu \mathrm{s} . \mathrm{A}{ }^{13} \mathrm{C}$ pulse width of $30^{\circ}$ was used, acquiring a spectral window of $24038 \mathrm{~Hz}$ (239 ppm) using a relaxation delay of $2 \mathrm{~s}$, acquisition time $1.36 \mathrm{~s}, 32 \mathrm{k}$ points (4096 scans). The ${ }^{13} \mathrm{C} 90^{\circ}$ pulse width was $8.7 \mu \mathrm{s}$. A ${ }^{119} \mathrm{Sn}$ pulse width of $30^{\circ}$ was used, $8.75 \mu$ s, acquiring a spectral window of $100000 \mathrm{~Hz}(670 \mathrm{ppm})$ using a relaxation delay of $1 \mathrm{~s}$, acquisition time $0.33 \mathrm{~s}$, 32k points (15360 scans) with inverse gated proton decoupling. ${ }^{117} \mathrm{Sn}$ NMR (249.29 MHz) spectra were recorded on an Agilent DD2 $700 \mathrm{MHz}$ NMR spectrometer. For ${ }^{117} \mathrm{Sn}$ NMR, a pulse width of $30^{\circ}$ was used, $4.03 \mu \mathrm{s}$, acquiring a spectral window of $62500 \mathrm{~Hz}(250.7 \mathrm{ppm})$ using 256k points with inverse 
gated proton decoupling. ${ }^{1} \mathrm{H}$ and ${ }^{13} \mathrm{C}$ were referenced internally to the deuterated solvent resonances, while ${ }^{117,119} \mathrm{Sn}$ was referenced to external tetramethylstannane. All $J$ coupling values are reported as absolute values.

\subsection{3 ${ }^{119}$ Sn NMR simulator}

A statistical analysis model (see Appendix 4) was developed to identify all ${ }^{119} \mathrm{Sn}-{ }^{119} \mathrm{Sn}$ and ${ }^{117} \mathrm{Sn}-{ }^{117} \mathrm{Sn}$ coupling patterns that arise from the ${ }^{117} \mathrm{Sn}$ or ${ }^{119} \mathrm{Sn}$ NMR spectra of compound 11. As well, this simulator was used with values given for 2,2-dibutyl-1,1,3,3-tetramethyltristannanediyl-[3]-ferrocenophane $\mathbf{9 b}$ as a method of control. Integration for these peaks were calculated by first building a matrix of matrices representing all possible permutations of isotopes. Each smaller matrix was then assigned a probability (intensity) and spectra. All identical coupling patterns were summed and normalized to the largest singlet. Chemical shift assignments were estimated from the chemical shift difference of the two largest resonances, with smaller coupling resonances centered on each peak. Several peaks generated by the simulation are not observed in the actual spectra as they integrate for less than $0.2 \%$ strength of the largest signal and are below the signal to noise cut-off.

\subsubsection{Cyclic voltammetry}

Experiments were performed under inert atmosphere conditions $\left(\mathrm{N}_{2}(g)\right)$ through the use of Schlenk conditions. Prior to analysis, samples were degassed for $5 \mathrm{~min}$. Samples of compound 4 and 11 for electrochemistry were prepared at $1 \times 10^{-5} \mathrm{M}$ in DCM and MeCN respectively. [N $(n-$ $\left.\mathrm{Bu})_{4}\right]\left[\mathrm{BF}_{4}\right]$ was used as a supporting electrode in $\approx 0.1 \mathrm{M}$ concentration. Electrochemisty for compound 4 and 11 were performed on a MetroOhm FRA2 $\mu$ AUTOLAB type II and type III 
respectively, Potentiostat/Galvanostat with a glassy carbon working electrode, Pt counter electrode, and a $\mathrm{Ag} / \mathrm{AgCl}$ Reference Electrode between 0.1-1.0V potentials.

\subsubsection{Density functional theory calculations}

Gaussian 9 Inc. revC1 was used for all Density Functional Theory (DFT) and Time Dependent (TD-DFT) calculations using the LSDA method with the SDD basis set to determine electronic and bonding structures for $4 \mathbf{a}, \mathbf{4 b}, \mathbf{9 a}$, and 11. Zero point energy (ZPE) calculations found no imaginary frequencies and therefore confirmed that all structures where in a local minimum (see Appendix 5).

\subsubsection{UV-Visible spectroscopy}

UV-Vis was carried out on a Perkin Elymer Lambda 20 UV-VIS Spectrophotometer. Original samples were collected in the range of 300-800 nm with consecutive data runs collected at $30 \mathrm{~s}$ intervals for 100 spectra. All samples were prepared in $\mathrm{C}_{6} \mathrm{H}_{6}$ at a concentration $\approx 10^{-3} \mathrm{M}$.

\subsubsection{Gel permeation chromatography}

Gel Permeation Chromatography (GPC) was performed on a Visocotek GPCmax VE2001 with a TDA302 triple detector system. Chromatograph was collected at $1.0 \mathrm{~mL} / \mathrm{min}$ using a (need info) column. Sample was prepared at $10 \mathrm{mg} / \mathrm{mL}$ in dry THF. DMF oligomers were run with the UV absorbing agent benzotriazole-5-carboxylic acid.

\subsubsection{Mass spectrometry}

Time-of-flight mass spectrometry analyses were performed using a JMS-T1000LC mass spectrometer (JEOL Inc., Peabody, MA) equipped with a Direct Analysis in Real Time (DART) ionization source (DART-SVP, Ionsense Inc., Saugus, MA). The DART source was operated 
with $\mathrm{He}$ gas and the temperature was adjusted in the range $100-400^{\circ} \mathrm{C}$. Isotopic distributions for the observed ionic species were calculated using the Mass Center utility (JEOL) and were in good agreement with the measured mass spectra.

\subsection{Preparation of 1,1'-bis(trimethyl stannyl) ferrocene 1a}

Exactly $5.71 \mathrm{~g}(17.7 \mathrm{mmol})$ of $\left(\eta^{5}-\mathrm{C}_{5} \mathrm{H}_{4} \mathrm{Li}\right) \mathrm{Fe} \bullet \mathrm{TMEDA}$ was added to a $500 \mathrm{~mL}$ Schlenk flask in an $\mathrm{N}_{2}(g)$ atmosphere. To this flask $150 \mathrm{~mL}$ of dry hexanes was added. $7.01 \mathrm{~g}(35.2 \mathrm{mmol})$ of $\mathrm{Me}_{3} \mathrm{SnCl}$ was added to a separate $50 \mathrm{~mL}$ Schlenk flask, which was then diluted with $50 \mathrm{~mL}$ of dry hexanes. Both flasks where cooled to $0^{\circ} \mathrm{C}$ under $\mathrm{N}_{2}(g)$. The $\mathrm{Me}_{3} \mathrm{SnCl}$ solution was added slowly to the $\mathrm{Fe}\left(\eta^{5}-\mathrm{C}_{5} \mathrm{H}_{4} \mathrm{Li}\right) \cdot \mathrm{TMEDA}$ solution. The reaction was allowed to stir for $12 \mathrm{~h}$ under an inert environment. $\mathrm{LiCl}$ was filtered off, and the resulting oil purified at $130^{\circ} \mathrm{C}$ in vacuoo to remove TMEDA and byproducts. The NMR $\left({ }^{1} \mathrm{H},{ }^{119} \mathrm{Sn}\right)$ chemical shifts were similar to reported values. ${ }^{106}$ Yield 81\%, $7.34 \mathrm{~g}$ (dark red oil). ${ }^{1} \mathrm{H}-\mathrm{NMR}\left(400.130 \mathrm{MHz}, \mathrm{CDCl}_{3}, \delta\right): 4.272(\mathrm{~m}, 4 \mathrm{H}$, Cp), 4.033 (m, 4H, Cp), 0.277 (s, $\left.{ }^{2} J_{\text {Me-Sn }}=54.3 \mathrm{~Hz}, 18 \mathrm{H}, \mathrm{CH}_{3}\right)$ ppm. ${ }^{119} \mathrm{Sn}-\mathrm{NMR}(149.211 \mathrm{MHz}$, $\left.\mathrm{CDCl}_{3}, \delta\right):-5.56 \mathrm{ppm}$.

\subsection{Preparation of 1,1'-bis(dimethyl stannyl) ferrocene 3a}

Exactly $7.22 \mathrm{~g}(14.1 \mathrm{mmol})$ of $\mathbf{1 a}$ was added to a $250 \mathrm{~mL}$ Schlenk flask, followed by 6.20 $\mathrm{g}(28.2 \mathrm{mmol})$ of $\mathrm{Me}_{2} \mathrm{SnCl}_{2}$. The reaction was placed under static vacuum then heated to $140^{\circ} \mathrm{C}$. After $3 \mathrm{~h}$ the flask was allowed to cool to room temperature and dynamic vacuum was applied to remove $\mathrm{Me}_{3} \mathrm{SnCl}$. The intermediate, $\mathbf{2 a}$, was reacted further without purification and identified only by ${ }^{119} \mathrm{Sn}$ NMR spectroscopy $\left(\delta=126.8 \mathrm{ppm}, \mathrm{CDCl}_{3}\right.$ ), in good agreement with reported literature values. ${ }^{106}$ 
Approximately $150 \mathrm{~mL}$ of $\mathrm{Et}_{2} \mathrm{O}$ was added to the previous reaction mixture. $58 \mathrm{~mL}$ ( 58 mmol) of $\mathrm{LiAlH}_{4}(1 \mathrm{M}$ in Et $2 \mathrm{O})$ was added to a separate $1000 \mathrm{~mL}$ Schlenk flask and diluted with an additional $50 \mathrm{~mL}$ of $\mathrm{Et}_{2} \mathrm{O}$. Both flasks where then cooled to $0^{\circ} \mathrm{C}$, and the solution of $2 \mathbf{a}$ was added drop wise to the $\mathrm{LiAlH}_{4}$ solution over a period of $1 \mathrm{~h}$. The reaction was allowed to warm to room temperature. After $5 \mathrm{~h}$ the reaction was quenched with degassed water. The product was extracted with $\mathrm{Et}_{2} \mathrm{O}$, and dried over $\mathrm{MgSO}_{4}$ and finally the $\mathrm{Et}_{2} \mathrm{O}$ removed in vacuo. The resulting oil was distilled at $90^{\circ} \mathrm{C}\left(1 \times 10^{-3} \mathrm{mmHg}\right)$ and stored under $\mathrm{N}_{2}(g)$ at $-33^{\circ} \mathrm{C}$. The chemical shifts are similar to those previously reported by Herberhold and Wrackmeyer. ${ }^{106}$ Yield 82\%, $5.59 \mathrm{~g}$ (dark orange oil). ${ }^{1} \mathrm{H}-\mathrm{NMR}\left(400.130 \mathrm{MHz}, \mathrm{C}_{6} \mathrm{D}_{6}, \delta\right.$ ): 5.468 (septet, $\left.{ }^{3} J_{\mathrm{SnH}-\mathrm{Me}}=2.3 \mathrm{~Hz}, 2 \mathrm{H}, \mathrm{SnH}\right) 4.245$ (m, 4H, Cp), $4.013(\mathrm{~m}, 4 \mathrm{H}, \mathrm{Cp}), 0.274\left(\mathrm{~d},{ }^{2} J_{\mathrm{Me}-\mathrm{Sn}}=59.0 \mathrm{~Hz},{ }^{3} J_{\mathrm{Me}-\mathrm{SnH}}=2.3 \mathrm{~Hz}, 12 \mathrm{H}, \mathrm{CH}_{3}\right) \mathrm{ppm}$. ${ }^{13} \mathrm{C}-\mathrm{NMR}\left(100.613 \mathrm{MHz}, \mathrm{C}_{6} \mathrm{D}_{6}, \delta\right): 74.88(\mathrm{Cp}), 71.24(\mathrm{Cp}), 68.31$ (ipso-Cp), -11.07 ( ${ }^{1} J_{\mathrm{Me}-\mathrm{Sn}}=$ $\left.369.7 \mathrm{~Hz}, \mathrm{CH}_{3}\right)$ ppm. ${ }^{119} \mathrm{Sn}-\mathrm{NMR}\left(149.211 \mathrm{MHz}, \mathrm{C}_{6} \mathrm{D}_{6}, \delta\right):-101.31 \mathrm{ppm}$.

\subsection{Preparation of 1,1'-bis(tributyl stannyl) ferrocene $1 \mathrm{~b}$}

A $20.39 \mathrm{~g}(63 \mathrm{mmol})$ sample of $\left(\eta^{5}-\mathrm{C}_{5} \mathrm{H}_{4} \mathrm{Li}\right)_{2} \mathrm{Fe} \cdot \mathrm{TMEDA}$ was added to a $500 \mathrm{~mL}$ Schlenk flask in an $\mathrm{N}_{2}(g)$ atmosphere. To this flask $150 \mathrm{~mL}$ of hexanes was added followed by the slow addition of $37 \mathrm{~mL}(136 \mathrm{mmol})$ of $(n-\mathrm{Bu})_{3} \mathrm{SnCl}$. The reaction was allowed to stir for $12 \mathrm{~h}$ under an $\mathrm{N}_{2}(\mathrm{~g})$. $\mathrm{LiCl}$ was filtered off and the resulting oil purified in vacuoo at $210^{\circ} \mathrm{C}$ to remove TMEDA and byproducts. Chemical shift are similar to those previously reported by Dodo. ${ }^{103}$ Yield 85\%, $41.0 \mathrm{~g}$ (dark orange oil). ${ }^{1} \mathrm{H}$ NMR $\left(400.130 \mathrm{MHz}, \mathrm{CDCl}_{3}, \delta\right): 4.243$ (m, 4H, Cp), 3.973 (m, 4H, Cp), $1.574\left(\mathrm{tt},{ }^{3} J=7.8 \mathrm{~Hz},{ }^{3} J=7.8 \mathrm{~Hz}, 12 \mathrm{H}, \mathrm{SnCH}_{2} \mathrm{CH}_{2} \mathrm{CH}_{2} \mathrm{CH}_{3}\right.$ ), 1.359 (tq, ${ }^{3} J=$ $\left.7.3 \mathrm{~Hz},{ }^{3} \mathrm{~J}=7.3 \mathrm{~Hz}, 12 \mathrm{H}, \mathrm{SnCH}_{2} \mathrm{CH}_{2} \mathrm{CH}_{2} \mathrm{CH}_{3}\right), 1.021\left(\mathrm{t},{ }^{2} \mathrm{~J}_{\mathrm{Sn}-\mathrm{CH} 2}=26.6 \mathrm{~Hz}, 12 \mathrm{H},{ }^{3} \mathrm{~J}=8.2 \mathrm{~Hz}\right.$, $\left.\mathrm{SnCH}_{2} \mathrm{CH}_{2} \mathrm{CH}_{2} \mathrm{CH}_{3}\right), 0.920\left(\mathrm{t},{ }^{3} \mathrm{~J}=7.3 \mathrm{~Hz}, 18 \mathrm{H}, \mathrm{SnCH}_{2} \mathrm{CH}_{2} \mathrm{CH}_{2} \mathrm{CH}_{3}\right)$ ppm. ${ }^{13} \mathrm{C}-\mathrm{NMR}(100.613$ $\left.\mathrm{MHz}, \mathrm{C}_{6} \mathrm{D}_{6}, \delta\right): 74.74\left({ }^{2} J_{119 \mathrm{Sn}-\mathrm{Cp}}=21.7 \mathrm{~Hz},{ }^{2} J_{117 \mathrm{Sn}-\mathrm{Cp}}=20.6 \mathrm{~Hz}, \mathrm{Cp}\right), 71.16\left({ }^{3} J_{119 \mathrm{Sn}-\mathrm{Cp}}=17.6 \mathrm{~Hz}\right.$, 
$\left.{ }^{3} J_{117 \mathrm{Sn}-\mathrm{Cp}}=17.0 \mathrm{~Hz}, \mathrm{Cp}\right), 68.95$ (ipso-Cp), $29.75\left({ }^{3} J_{\mathrm{Sn}-\mathrm{CH} 2}=9.9 \mathrm{~Hz}, \mathrm{CH}_{2} \mathrm{CH}_{2} \mathrm{CH}_{2} \mathrm{CH}_{3}\right), 27.88$

$\left({ }^{2} J_{119 S \mathrm{Sn}-\mathrm{CH} 2}=28.5 \mathrm{~Hz},{ }^{2} J_{119 \mathrm{Sn}-\mathrm{CH} 2}=27.2 \mathrm{~Hz}, \mathrm{CH}_{2} \mathrm{CH}_{2} \mathrm{CH}_{2} \mathrm{CH}_{3}\right), 14.00\left(\mathrm{CH}_{2} \mathrm{CH}_{2} \mathrm{CH}_{2} \mathrm{CH}_{3}\right), 10.67$

$\left({ }^{1} J_{\mathrm{Sn}-\mathrm{CH} 2}=172.7 \mathrm{~Hz},{ }^{1} J_{\mathrm{Sn}-\mathrm{CH} 2}=165.0 \mathrm{~Hz}, \mathrm{CH}_{2} \mathrm{CH}_{2} \mathrm{CH}_{2} \mathrm{CH}_{3}\right)$ ppm. ${ }^{119} \mathrm{Sn}$ NMR $(149.211 \mathrm{MHz}$, $\left.\mathrm{CDCl}_{3}, \delta\right):-19.09 \mathrm{ppm}$.

\subsection{Attempted preparation of 1,1'-bis(chlorodi(n-butyl) stannyl) ferrocene $2 b$ through route 1}

In an inert atmosphere, $2.65 \mathrm{~g}(5.5 \mathrm{mmol})$ of $\mathbf{1 b}$ was added to a Schlenk flask. This was followed by $3.32 \mathrm{~g}(10.9 \mathrm{mmol})$ of $(n-\mathrm{Bu})_{2} \mathrm{SnCl}_{2}$. The reaction was placed under static vacuum and heated to $150^{\circ} \mathrm{C}$. The reaction was allowed to stir for $2 \mathrm{~d}$. The reaction was monitored by ${ }^{119}$ Sn NMR spectroscopy and found to be impure. Purification through distillation was unsuccessful as a result no further analysis of these products was carried out.

\subsection{Attempted preparation of 1,1'-bis(chlorodi(n-butyl) stannyl)}

\section{ferrocene $2 b$ through route 2}

In an inert atmosphere, $2.0 \mathrm{~g}(6.2 \mathrm{mmol})$ of $\left(\eta^{5}-\mathrm{C}_{5} \mathrm{H}_{4} \mathrm{Li}\right)_{2} \mathrm{Fe} \cdot \mathrm{TMEDA}$ along with $200 \mathrm{~mL}$ of dry hexane was added to a Schlenk flask. In a separate Schlenk flask, $4.22 \mathrm{~g}(12.3 \mathrm{mmol})$ of $(n-\mathrm{Bu})_{2} \mathrm{Sn}\left(\mathrm{NEt}_{2}\right) \mathrm{Cl}$ was dissolved in $50 \mathrm{~mL}$ of dry hexanes. The $(n-\mathrm{Bu})_{2} \mathrm{Sn}\left(\mathrm{NEt}_{2}\right) \mathrm{Cl}$ solution was added to the slurry of $\left(\eta^{5}-\mathrm{C}_{5} \mathrm{H}_{4} \mathrm{Li}\right)_{2} \mathrm{Fe} \cdot \mathrm{TMEDA}$ and allowed to stir at RT overnight. The reaction mixture was filtered to remove $\mathrm{LiCl}$, and solvent removed in vacuoo. The crude product mixture was a sticky dark orange oil. All attempts to purify through distillation and column chromatography were unsuccessful. 


\subsection{Preparation of polybis(dimethyl stannyl) ferrocene 4 route 1}

Exactly $1.008 \mathrm{~g}(2.1 \mathrm{mmol})$ of $\mathbf{3 a}$ was added to a dry $50 \mathrm{~mL}$ Schlenk flask in a $\mathrm{N}_{2}$ atmosphere. This was dissolved in $5 \mathrm{~mL}$ of DMF. To this solution $94 \mathrm{mg}$ of a $2 \%$ solution of Karstedt's catalyst in xylenes $(0.0049 \mathrm{mmol}$ of active catalyst $)$ was added. The reaction was stirred under dynamic nitrogen at ambient room temperature for $3 \mathrm{~h}$. After the $3 \mathrm{~h}, 1 \mathrm{~mL}$ of $\mathrm{MeOH}$ was added to quench the reaction. Solvent was then removed under high vacuum. The sticky orange reaction mixture was dissolved in minimal THF and precipitated into $\approx 400 \mathrm{~mL}$ of dry $\mathrm{MeOH}$ to remove oligomers, as well as other by-products.

For the main polymer 4: ${ }^{1} \mathrm{H}$ NMR $\left(400.130 \mathrm{MHz}, \mathrm{C}_{6} \mathrm{D}_{6}, \delta\right): 4.342$ (s, br, $\left.4 \mathrm{H}, \mathrm{Cp}\right), 4.276$ (s, br, Cp end group), 4.150 (s, br, 4H, Cp), 4.079 (s, br, Cp end group), 0.594 (s, br, ${ }^{2} J_{\mathrm{Me}-\mathrm{Sn}}=$ $236.59 \mathrm{~Hz}, 4 \mathrm{H}, \mathrm{Me}$ ), 0.294 (s, br, ${ }^{2} J_{\mathrm{CH} 3-\mathrm{Sn}}=57.74 \mathrm{~Hz}, 4 \mathrm{H}, \mathrm{Me}$ end group) ppm. ${ }^{13} \mathrm{C}-\mathrm{NMR}$ (100.613 MHz, $\left.\mathrm{C}_{6} \mathrm{D}_{6}, \delta\right): 74.82$ (Cp end group), $74.62(\mathrm{Cp}), 71.41$ (Cp end group) $71.23(\mathrm{Cp})$, 69.32 (ipso-Cp), -8.68 $\left(\mathrm{CH}_{3}\right)$ ppm. ${ }^{119} \mathrm{Sn}-\mathrm{NMR}\left(149.211 \mathrm{MHz} \mathrm{C}_{6} \mathrm{D}_{6}, \delta\right)$ : -101.01 (end group), $104.39\left({ }^{1} J_{119 \mathrm{Sn}-117 \mathrm{Sn}}=5261.5 \mathrm{~Hz}\right) \mathrm{ppm} . \lambda_{\max }=452.4 \mathrm{~nm}\left(\varepsilon=115.98 \mathrm{~L} \cdot \mathrm{mol}^{-1} \cdot \mathrm{cm}^{-1}\right)$.

\subsection{Preparation of polybis(dimethyl stannyl)ferrocene 4 route 2}

Exactly $0.48 \mathrm{~g}(0.99 \mathrm{mmol})$ of $\mathbf{3 a}$ was added to a dry Schlenk flask in a $\mathrm{N}_{2}$ atmosphere. This was dissolved in $3.1 \mathrm{~mL}$ of $\mathrm{C}_{6} \mathrm{H}_{6}$. To the solution $55 \mathrm{mg}$ of a $2 \%$ solution of Karstedt's catalyst in xylenes $(0.0028 \mathrm{mmol}$ of active catalyst) was added drop wise. The reaction was heated to $70^{\circ} \mathrm{C}$ and allowed to stir for $3 \mathrm{~d}$. The reaction mixure was then allowed to cool and solvent was removed in vасиоо. Reaction mixture was dissolved in minimal tetrahydrafuran and precipitated into $\approx 400 \mathrm{~mL}$ of $\mathrm{MeOH}$ to remove oligomers as well as by-products. See above for characterization. 


\subsection{Ring-opening polymerization of 5 a to form polybis(dimethyl}

\section{stannyl) ferrocene 4}

To a Schlenk flask, $0.195 \mathrm{~g}(0.4 \mathrm{mmol})$ of $\mathbf{5 b}$ was added under an inert atmosphere. To this, $0.016 \mathrm{~g}(0.0012 \mathrm{mmol})$ of $\mathrm{Pd}\left(\mathrm{PPh}_{3}\right)_{4}$ was added in $5 \mathrm{~mL}$ of $\mathrm{C}_{6} \mathrm{H}_{6}$. The reaction was heated to $60^{\circ} \mathrm{C}$ and allowed to stir for $3 \mathrm{~d}$ under dymanic $\mathrm{N}_{2}(g)$. The reaction was studied by ${ }^{119} \mathrm{Sn}$ NMR spectroscopy and determined to be incomplete. The crude reaction mixture was dissolved in minimal THF and precipitated into $\mathrm{MeOH}$. Only characterization that was possible was ${ }^{119} \mathrm{Sn}$ NMR spectroscopy. ${ }^{119}$ Sn NMR (149.211, $\left.\mathrm{C}_{6} \mathrm{D}_{6}, \delta\right):-11.627$ (unknown), -104.73 (4).

\subsection{Preparation of 1,1,2,2-tetramethyl-distannanediyl-}

\section{[2]ferrocenophane 5 a from the reaction of 3 with $\mathbf{P d}_{2}(\mathrm{dba})_{3}$}

A $1.0 \mathrm{~g}$ ( $2.07 \mathrm{mmol})$ sample of $\mathbf{3}$ was added to a $50 \mathrm{~mL}$ Schlenk flask. To the flask was added $10 \mathrm{~mL}$ of $\mathrm{C}_{6} \mathrm{H}_{6}$ and $0.081 \mathrm{~g}(0.09 \mathrm{mmol})$ of $\mathrm{Pd}_{2}(\mathrm{dba})_{3}$. The mixture was then allowed to stir for $24 \mathrm{~h}$ at room temperature under $\mathrm{N}_{2}(\mathrm{~g}) . \mathrm{C}_{6} \mathrm{H}_{6}$ was removed in vacuo. The mixture was dissolved in hexane then filtered under $\mathrm{N}_{2}(\mathrm{~g})$ to remove residual $\operatorname{Pd}_{2}(\mathrm{dba})_{3}$. This data was in good agreement to data reported by Herberhold. ${ }^{41}$ Yield $=90 \%, 0.8973 \mathrm{~g}$ (orange solid). ${ }^{1} \mathrm{H}-$ $\operatorname{NMR}\left(400.130 \mathrm{MHz}, \mathrm{C}_{6} \mathrm{D}_{6}, \delta\right): 4.36\left(\mathrm{~m}, J=1.6 \mathrm{~Hz}, J_{\mathrm{Cp}-\mathrm{Sn}}=4.8 \mathrm{~Hz}, 4 \mathrm{H}, \mathrm{Cp}\right), 4.23(\mathrm{~m}, J=1.6 \mathrm{~Hz}$, Cp), $0.41\left(\mathrm{~s},{ }^{2} J_{\mathrm{Me}-119 \mathrm{Sn}}=50.1 \mathrm{~Hz},{ }^{2} J_{\mathrm{Me}-117 \mathrm{Sn}}=48.0 \mathrm{~Hz},{ }^{3} J_{\mathrm{Me}-\mathrm{Sn}}=15.3 \mathrm{~Hz}, \mathrm{SnMe}\right) \mathrm{ppm} .{ }^{13} \mathrm{C}-\mathrm{NMR}$ $\left(100.613 \mathrm{MHz}, \mathrm{C}_{6} \mathrm{D}_{6}, \delta\right): 77.84\left({ }^{2} J_{119 \mathrm{Sn}^{-13 \mathrm{C}}}=49.9 \mathrm{~Hz},{ }^{2} J_{117 \mathrm{Sn}-13 \mathrm{C}}=49.9 \mathrm{~Hz}\right.$, ipso-Cp), 74.58 $\left({ }^{2} J_{119 / 117 \mathrm{Sn}^{-13 \mathrm{C}}}=44.9 \mathrm{~Hz}, \mathrm{C} 2, \mathrm{C} 5\right), 69.34\left({ }^{3} J_{119 / 117 \mathrm{Sn}^{-13 \mathrm{C}}}=32.7 \mathrm{~Hz},{ }^{4} J_{119 / 117 \mathrm{Sn}^{-} 13 \mathrm{C}}=4.8 \mathrm{~Hz}, \mathrm{C} 3\right.$, C4), $-8.43\left({ }^{1} J_{119 \mathrm{Sn}^{-13 \mathrm{C}}}=241.6 \mathrm{~Hz},{ }^{1} J_{117 \mathrm{Sn}^{-13 \mathrm{C}}}=230.5 \mathrm{~Hz},{ }^{2} J_{119 \mathrm{Sn}^{-1} 13 \mathrm{C}}=91.0 \mathrm{~Hz},{ }^{2} J_{117 \mathrm{Sn}^{-1} 13 \mathrm{C}}=86.5\right.$ $\left.\mathrm{Hz}, \mathrm{SnCH}_{3}\right)$ ppm. ${ }^{119} \mathrm{Sn}-\mathrm{NMR}\left(149.211, \mathrm{C}_{6} \mathrm{D}_{6}, \delta\right):-43.0\left(\mathrm{~s}, J_{119 \mathrm{Sn}-117 \mathrm{Sn}}=5261.5 \mathrm{~Hz}\right) \mathrm{ppm}$. 


\subsection{Attempted preparation of 5a with $\mathrm{Pt}(\mathrm{acac})_{2}$}

A $0.50 \mathrm{~g}(1.03 \mathrm{mmol})$ sample of $\mathbf{3 a}$ was added to a $50 \mathrm{~mL}$ Schlenk flask. To the flask was added $5.0 \mathrm{~mL}$ of $\mathrm{C}_{6} \mathrm{H}_{6}$ and $0.012 \mathrm{~g}(0.031 \mathrm{mmol})$ of $\mathrm{Pt}(\mathrm{acac})_{2}$. The mixture was then allowed to stir for $2 \mathrm{~d}$ at room temperature under $\mathrm{N}_{2}(\mathrm{~g})$. The mixture was then filtered under $\mathrm{N}_{2}(\mathrm{~g})$ to remove $\mathrm{Pt}(\mathrm{acac})_{2}$, and the solvent reduced in vacuoo. Analysis by ${ }^{1} \mathrm{H}$ and ${ }^{119} \mathrm{Sn}$ NMR $\left(\mathrm{C}_{6} \mathrm{D}_{6}\right)$ revealed only the presence of starting material 3a.

\subsection{Attempted preparation of 5a with $\mathrm{CIRh}\left(\mathrm{PPh}_{3}\right)_{3}$}

A $0.50 \mathrm{~g}(2.07 \mathrm{mmol})$ sample of $\mathbf{3 a}$ was added to a $50 \mathrm{~mL}$ Schlenk flask. To the flask was added $25 \mathrm{~mL}$ of DCM with $0.012 \mathrm{~g}(0.013 \mathrm{mmol})$ of $\mathrm{ClRh}\left(\mathrm{PPh}_{3}\right)_{3}$. The mixture was allowed to stir for

$4 \mathrm{~d}$ at room temperature under $\mathrm{N}_{2}(\mathrm{~g})$. The mixture was then filtered under $\mathrm{N}_{2}(\mathrm{~g})$ to remove $\mathrm{ClRh}\left(\mathrm{PPh}_{3}\right)_{3}$, and the solvent reduced in vacuoo. Analysis by ${ }^{1} \mathrm{H}$ and ${ }^{119} \mathrm{Sn} \mathrm{NMR}\left(\mathrm{C}_{6} \mathrm{D}_{6}\right)$ revealed only the presence of starting material 3a.

\subsection{Preparation of $1,1,14,14$-tetra-n-butyl-2,2,13,13,15,15,26,26- octamethyl-1,2,13,14,15,26-hexastanna-[3.3]ferrocenophane 11 (low dilution)}

A $2.0 \mathrm{~g}$ (4.1 mmol) sample of $\mathbf{3 a}$ was added to a 3-neck round bottomed flask and diluted with $40 \mathrm{~mL}$ of $\mathrm{Et}_{2} \mathrm{O}$. A $1.56 \mathrm{~g}(4.2 \mathrm{mmol})$ of $\mathbf{1 0 a}$ was added in a separate Schlenk flask and diluted with $30 \mathrm{~mL}$ of $\mathrm{Et}_{2} \mathrm{O}$. Both flasks were cooled to $0^{\circ} \mathrm{C}$ and the solution containing compound 10a was added slowly (over a 30 min period) via double tip cannula to the flask containing 6. The mixture was then heated to reflux for $2 \mathrm{~h}$ and then allowed to cool to RT. All 
volatiles were then removed in vacuoo. The crude product was run through a silica column in an $\mathrm{N}_{2}(\mathrm{~g})$ atmosphere eluting with pure hexanes. Recovered Yield $=82 \%, 4.80 \mathrm{~g}$ (light orange oil) of $\mathbf{1 1}, 5 \%, 0.099 \mathrm{~g}$ (orange solid) of $\mathbf{5 a}$.

For 11: ${ }^{1} \mathrm{H}-\mathrm{NMR}\left(400.130 \mathrm{MHz}, \mathrm{C}_{6} \mathrm{D}_{6}, \delta\right): 4.294\left(\mathrm{~m}, J=1.6 \mathrm{~Hz},{ }^{4} J_{\mathrm{Cp}-\mathrm{Sn}}=7.4 \mathrm{~Hz}, 8 \mathrm{H}, 3,4-\right.$ $\mathrm{H} \mathrm{Cp}), 4.058\left(\mathrm{~m}, J=1.6 \mathrm{~Hz},{ }^{3} J_{\mathrm{Cp}-\mathrm{Sn}}=10.4 \mathrm{~Hz}, 8 \mathrm{H}, 2,5-\mathrm{H} \mathrm{Cp}\right), 1.717(\mathrm{~m}, 8 \mathrm{H}$, $\left.\mathrm{SnCH}_{2} \mathrm{CH}_{2} \mathrm{CH}_{2} \mathrm{CH}_{3}\right), 1.421\left(\mathrm{~m}, 16 \mathrm{H}, \mathrm{SnCH}_{2} \mathrm{CH}_{2} \mathrm{CH}_{2} \mathrm{CH}_{3}\right), 0.953(\mathrm{t}, J=7.3 \mathrm{~Hz}, 12 \mathrm{H}$, $\left.\mathrm{CH}_{2} \mathrm{CH}_{2} \mathrm{CH}_{2} \mathrm{CH}_{3}\right), 0.532\left(\mathrm{~s},{ }^{2} J_{119 \mathrm{Sn}-\mathrm{Me}}=47.9 \mathrm{~Hz},{ }^{2} J_{117 \mathrm{Sn}-\mathrm{Me}}=45.9 \mathrm{~Hz},{ }^{3} J_{\mathrm{SnBu}-\mathrm{SnMe}}=11.7 \mathrm{~Hz}\right.$, $\left.24 \mathrm{H}, \mathrm{SnCH}_{3}\right)$ ppm. ${ }^{13} \mathrm{C}-\mathrm{NMR}\left(100.613 \mathrm{MHz}, \mathrm{C}_{6} \mathrm{D}_{6}, \delta\right): 75.70\left({ }^{2} J_{119 \mathrm{Sn}^{-13 \mathrm{C}}}=48.5 \mathrm{~Hz},{ }^{2} J_{117 \mathrm{Sn}^{-13 \mathrm{C}}}=\right.$ $\left.46.5 \mathrm{~Hz},{ }^{3} J_{119 / 117 \mathrm{Sn}^{-13 \mathrm{C}}}=9.8 \mathrm{~Hz}, \mathrm{C} 2, \mathrm{C} 5\right), 71.04\left({ }^{1} J_{119 \mathrm{Sn}^{-1} 13 \mathrm{C}}=34.5 \mathrm{~Hz},{ }^{2} J_{117 \mathrm{Sn}^{-13 \mathrm{C}}}=33.2 \mathrm{~Hz}\right.$, $\left.{ }^{3} J_{119 / 117 \mathrm{Sn}^{-1} 13 \mathrm{C}}=4.4 \mathrm{~Hz}, \mathrm{C} 3, \mathrm{C} 4\right) 69.13\left({ }^{1} J_{119 / 117 \mathrm{Sn}^{-13 \mathrm{C}}}=336 \mathrm{~Hz}\right.$, ipso-Cp $), 32.92\left({ }^{3} J_{119 \mathrm{Sn}^{-1}{ }^{-13 \mathrm{C}}=13.1}\right.$ $\left.\mathrm{Hz},{ }^{3} J_{117 \mathrm{Sn}^{-} 13 \mathrm{C}}=17.1 \mathrm{~Hz}, \mathrm{SnCH}_{2} \mathrm{CH}_{2} \mathrm{CH}_{2} \mathrm{CH}_{3}\right), 27.67\left({ }^{2} J_{119 \mathrm{Sn}^{-13 \mathrm{C}}}=53.18 \mathrm{~Hz},{ }^{2} J_{117 \mathrm{Sn}^{-1} 13 \mathrm{C}}=51.0\right.$ $\left.\mathrm{Hz},{ }^{4} J_{119 \mathrm{Sn}^{-1} 13 \mathrm{C}}=3.4 \mathrm{~Hz},{ }^{4} J_{117 \mathrm{Sn}^{-13 \mathrm{C}}}=1.9 \mathrm{~Hz}, \mathrm{SnCH}_{2} \mathrm{CH}_{2} \mathrm{CH}_{2} \mathrm{CH}_{3}\right), 13.94\left(\mathrm{SnCH}_{2} \mathrm{CH}_{2} \mathrm{CH}_{2} \mathrm{CH}_{3}\right)$,

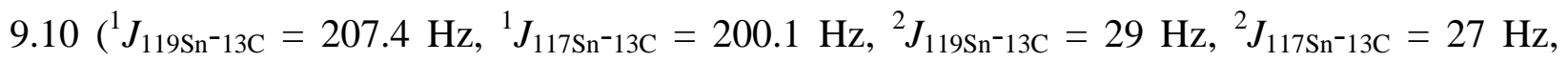
$\left.\mathrm{SnCH}_{2} \mathrm{CH}_{2} \mathrm{CH}_{2} \mathrm{CH}_{3}\right),-8.12\left({ }^{1} J_{119 \mathrm{Sn}^{-13 \mathrm{C}}}=239.9 \mathrm{~Hz},{ }^{1} J_{117 \mathrm{Sn}^{-13 \mathrm{C}}}=229.2 \mathrm{~Hz},{ }^{2} J_{119 \mathrm{Sn}^{-1} 13 \mathrm{C}}=36.9 \mathrm{~Hz}\right.$, $\left.{ }^{2} J_{117 \mathrm{Sn}^{-13 \mathrm{C}}}=35.2 \mathrm{~Hz},{ }^{3} J_{119 \mathrm{Sn} 117 \mathrm{Sn}{ }^{-13 \mathrm{C}}}=16.3 \mathrm{~Hz}, \mathrm{SnCH}_{3}\right) \mathrm{ppm} .{ }^{119} \mathrm{Sn}-\mathrm{NMR}\left(149.211 \mathrm{MHz}, \mathrm{C}_{6} \mathrm{D}_{6}\right.$,

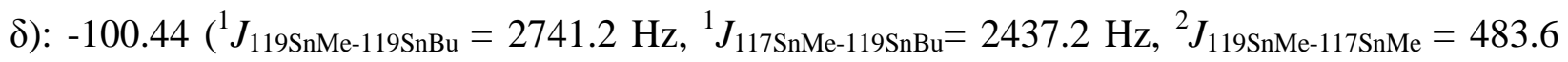
$\left.\mathrm{Hz}, S n \mathrm{Me}_{2}\right),-211.75\left({ }^{1} J_{119 \mathrm{SnBu}-119 \mathrm{SnMe}}=2638.5 \mathrm{~Hz},{ }^{1} J_{119 \mathrm{SnBu}-117 \mathrm{SnMe}}=2437.9 \mathrm{~Hz}, \mathrm{SnBu}_{2}\right) \mathrm{ppm}$. ${ }^{117} \mathrm{Sn}-\mathrm{NMR}\left(249.472 \mathrm{MHz}, \mathrm{C}_{6} \mathrm{D}_{6}, \delta\right):-100.5\left({ }^{1} J_{117 \mathrm{SnMe}-119 \mathrm{SnBu}}=2480.7 \mathrm{~Hz},{ }^{1} J_{117 \mathrm{SnMe}-117 \mathrm{SnBu}}=\right.$ $\left.2370.6 \mathrm{~Hz},{ }^{2} J_{117 \mathrm{SnMe}-117 \mathrm{SnMe}}=483.7 \mathrm{~Hz}, \mathrm{SnM} \mathrm{Me}_{2}\right),-211.84\left({ }^{1} J_{117 \mathrm{SnBu}-119 \mathrm{SnMe}}=2478.8 \mathrm{~Hz},{ }^{1} J_{117 \mathrm{SnBu}-}\right.$ $\left.{ }_{117 \mathrm{SnMe}}=2372.2 \mathrm{~Hz}, S n \mathrm{Bu}_{2}\right)$ ppm. $\mathrm{R}_{\mathrm{f}}=0.5$ (hexanes). HRMS (DART-TOF) calcd. for $\mathrm{C}_{44} \mathrm{H}_{76} \mathrm{Fe}_{2} \mathrm{Sn}_{6}$ : 1433.8621; found 1433.8588. E.A.: Anal. Calcd C, 36.98; H, 5.36. Found: C, 36.94; H, 5.37. 


\subsection{Preparation of $1,1,14,14-t e t r a-n-b u t y l-2,2,13,13,15,15,26,26-$ octamethyl-1,2,13,14,15,26-hexastanna-[3.3]ferrocenophane 11 (high dilution)}

The preceding reaction was run under identical conditions at higher dilution $(0.20 \mathrm{~g}, 0.41$ mmol of 3, $10 \mathrm{~mL}$ of $\mathrm{Et}_{2} \mathrm{O}, 0.16 \mathrm{~g}, 0.42 \mathrm{mmol}$ of $\left.\mathbf{1 0 a}\right)$ resulting in similar yield of products $\mathbf{5 a}$ and 11. Recovered Yield $=64 \%, 0.375 \mathrm{~g}$ (light orange oil) of 11, 7.5\%, 0.015g (orange solid) of 5a.

For 11: ${ }^{119} \mathrm{Sn}-\mathrm{NMR}\left(149.211 \mathrm{MHz}, \mathrm{C}_{6} \mathrm{D}_{6}, \delta\right):-100.43\left({ }^{1} J_{119 \mathrm{SnMe}-119 \mathrm{SnBu}}=2741.2 \mathrm{~Hz}\right.$, $\left.{ }^{1} J_{117 \mathrm{SnMe}-119 \mathrm{SnBu}}=2437.2 \mathrm{~Hz},{ }^{2} J_{119 \mathrm{SnMe}-117 \mathrm{SnMe}}=483.6 \mathrm{~Hz}, \operatorname{Sn} \mathrm{Me}_{2},\right),-211.79\left({ }^{1} J_{119 \mathrm{SnBu}-119 \mathrm{SnMe}}=\right.$ $\left.2638.5 \mathrm{~Hz},{ }^{1} J_{119 \mathrm{SnBu}-117 \mathrm{SnMe}}=2437.9 \mathrm{~Hz}, S_{n B u}\right) \mathrm{ppm}$.

For 5a: ${ }^{119} \mathrm{Sn}-\mathrm{NMR}\left(149.211, \mathrm{C}_{6} \mathrm{D}_{6}, \delta\right):-42.4\left(\mathrm{~s}, J_{119 \mathrm{Sn}-117 \mathrm{Sn}}=5261.5 \mathrm{~Hz}\right) \mathrm{ppm}$. 


\subsection{Conclusion}

A novel polymer polybis(dimethyl stannyl)ferrocene, 4, was synthesized through a dehydrogenative coupling condensation polymerization. The crude polymer was not fully purified, however it was characterized by ${ }^{1} \mathrm{H},{ }^{13} \mathrm{C}$ and ${ }^{119} \mathrm{Sn}$ NMR spectroscopy, as well as through cyclic voltammetry, gel permation chromatography and UV-Visible spectrocopy. Additionally, model systems where studied through DFT calculations. This polymer is the first evidence of a dibridged polyferrocenyl distannane. The polymer was found to be of low to moderate molecular weight and maintained a degree of electronic communication that is similar to known monobridged polyferrocenyl stannanes. The presence of an intramolecularly coupled [2]ferrocenophane was also discovered as a byproduct of this polymerization.

The first tristanna-bridged [3.3]ferrocenophane, 11, was discovered through an amine coupling of a tin amine 10a, and 1,1'-bis(dimethyl stannyl) ferrocene 3a. This [3.3]ferrocenophane was fully characterized through ${ }^{1} \mathrm{H},{ }^{13} \mathrm{C}$ and ${ }^{119} \mathrm{Sn}$ NMR and UV-Visible spectroscopies, mass spectrometry, and cyclic voltammetry. The [3.3]ferrocenophane was found to maintain strong interation between connected ferrocenes despite the large distance between $\mathrm{Fe}$ centers of the connected ferrocenes.

Finally, a new and much improved synthesis of 1,1,2,2-tetramethyldistannanediyl[2]ferrocenophane, 5a, was found. This metal catalyzed intramolecular dehydrogenative coupling employed $\mathrm{Pd}_{2}(\mathrm{dba})_{3}$ as a catalyst with a yield of $90 \%$. This was a significant improvement on work previously carried out by Herberhold and Wrackmeyer. ${ }^{41}$ 


\section{Appendix}

Appendix $1{ }^{1} \mathrm{H},{ }^{13} \mathrm{C},{ }^{117} \mathrm{Sn}$, and ${ }^{119} \mathrm{Sn}$ NMR

Appendix 1.1: 1a

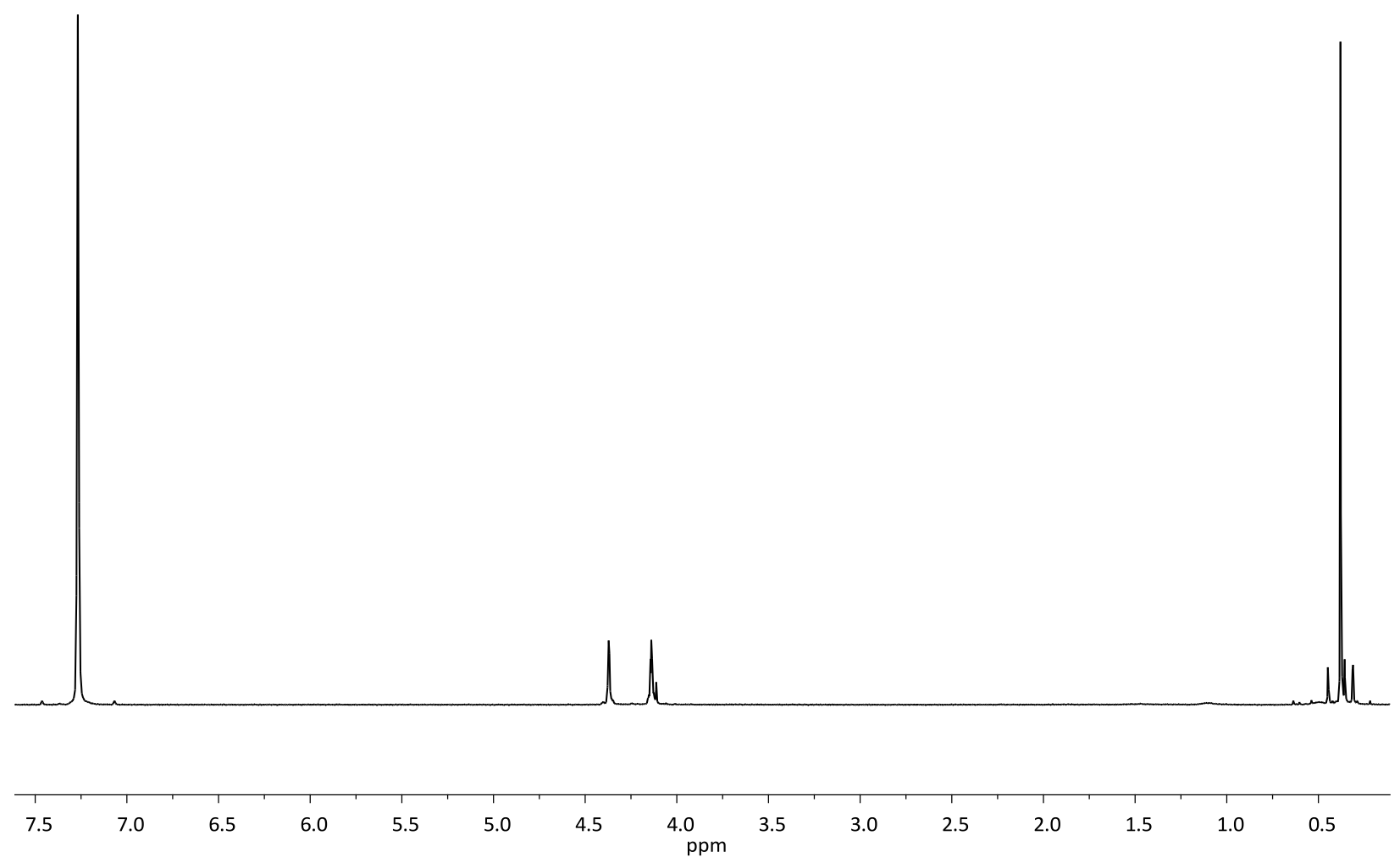

Figure A1.1: ${ }^{1} \mathrm{H} \mathrm{NMR}\left(\mathrm{CDCl}_{3}\right)$ of $\mathbf{1 a}$. 


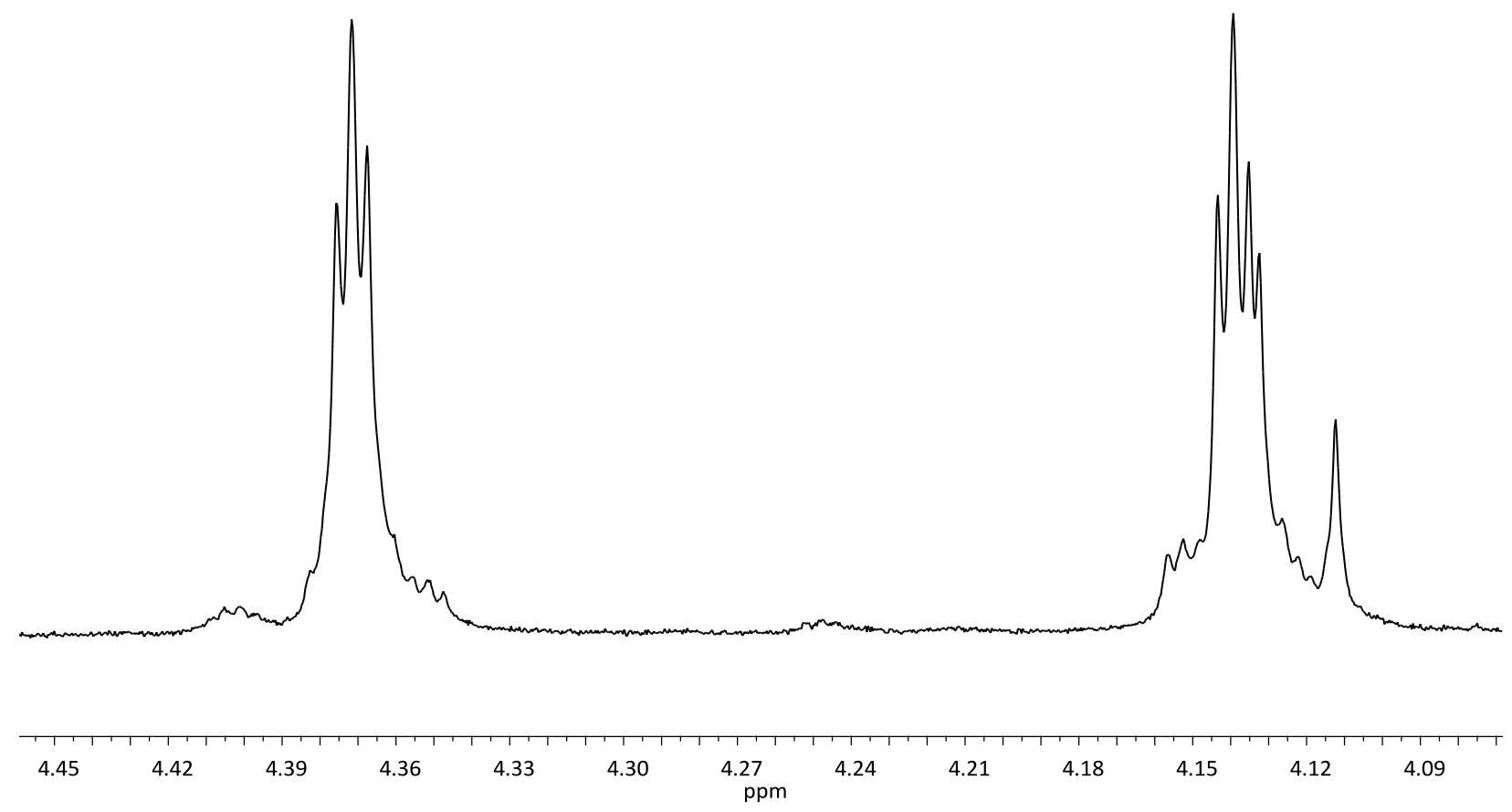

Figure A1.2: Cyclopentadiene region of ${ }^{1} \mathrm{H} \mathrm{NMR}\left(\mathrm{CDCl}_{3}\right)$ of $\mathbf{1 a}$. 


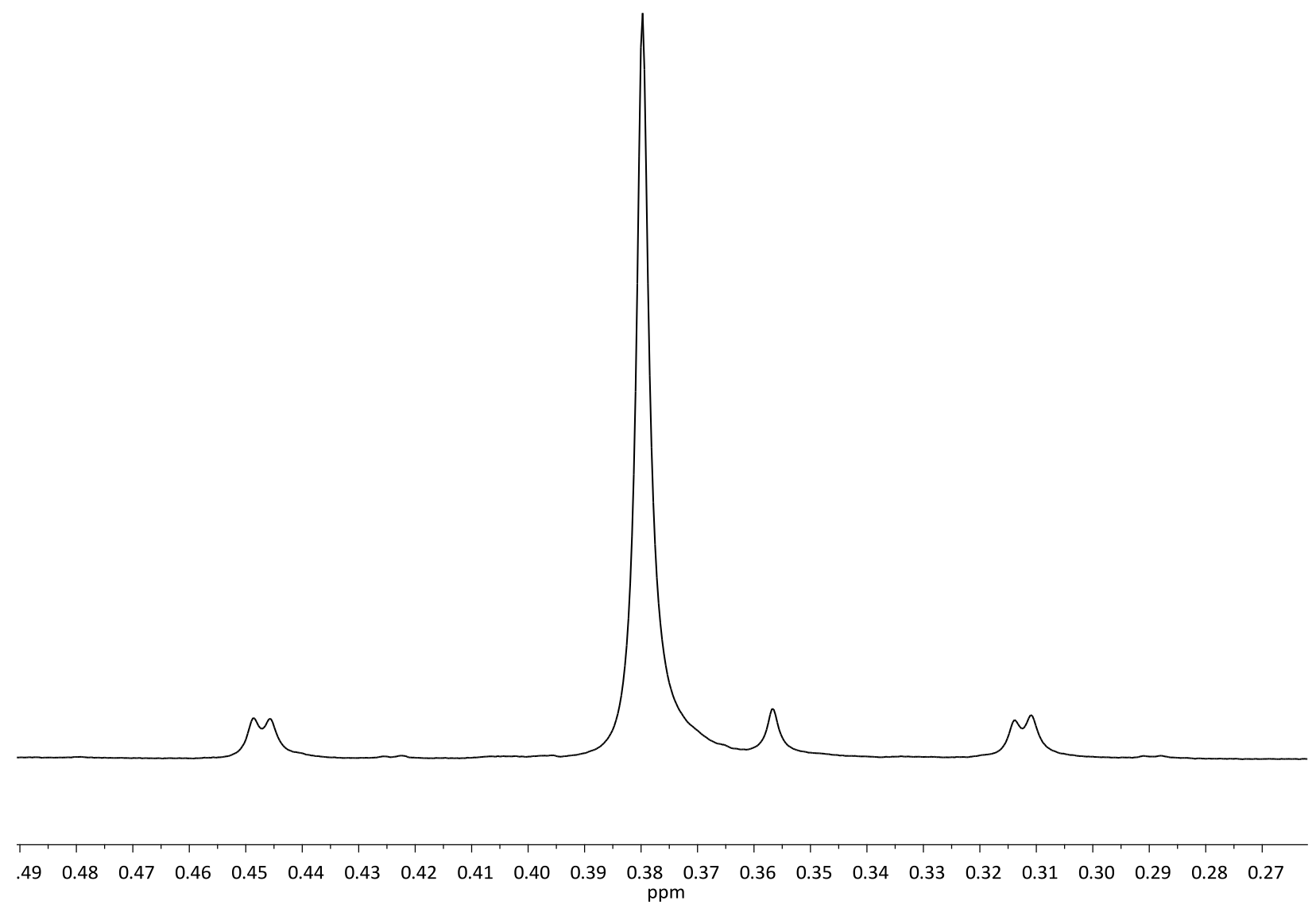

Figure A1.3: Methyl region of ${ }^{1} \mathrm{H} \mathrm{NMR}\left(\mathrm{CDCl}_{3}\right)$ of $\mathbf{1 a}$. 


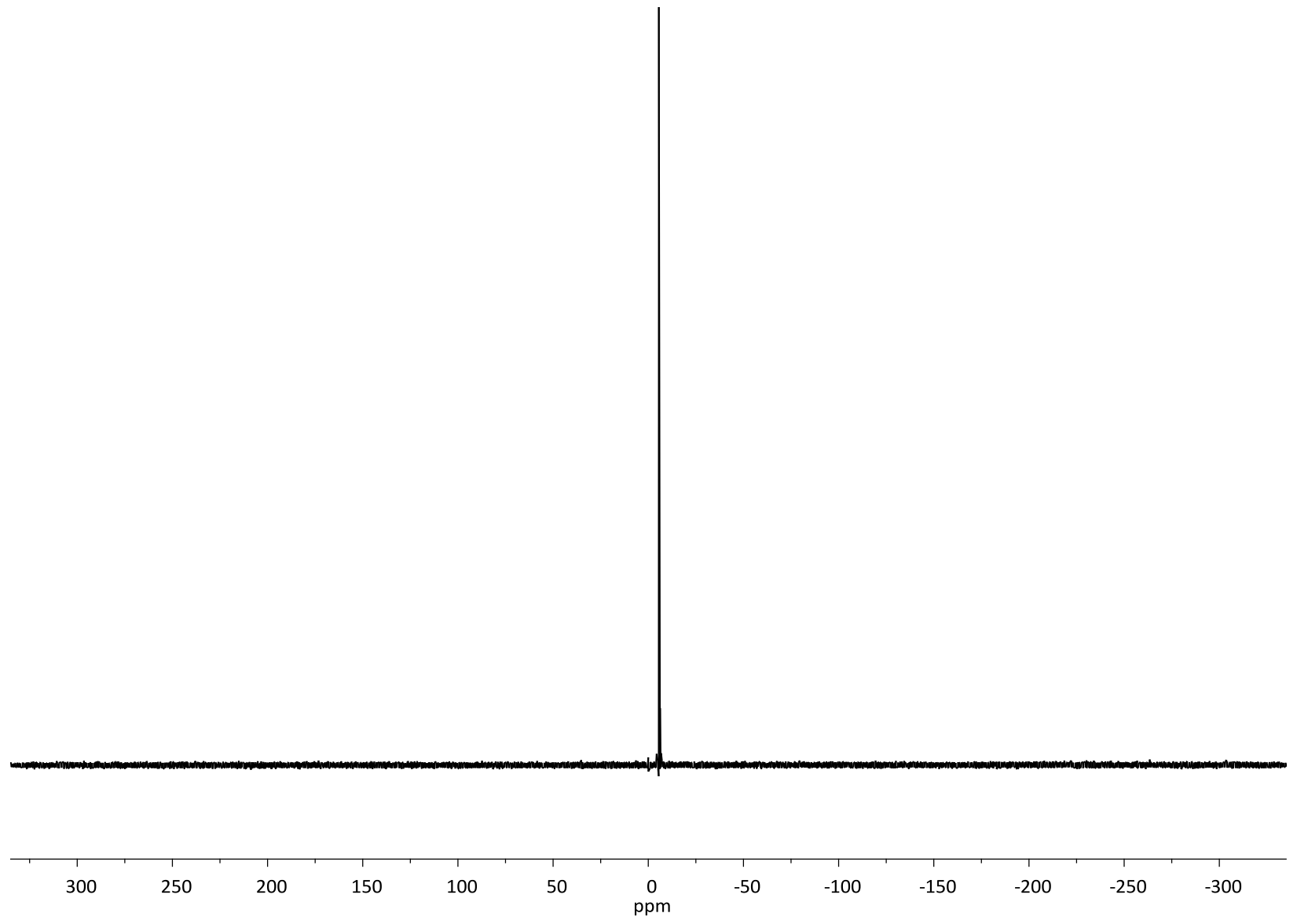

Figure A1.4: ${ }^{119} \mathrm{Sn} \mathrm{NMR}\left(\mathrm{CDCl}_{3}\right)$ of $\mathbf{1 a}$. 
Appendix 1.2: 2a

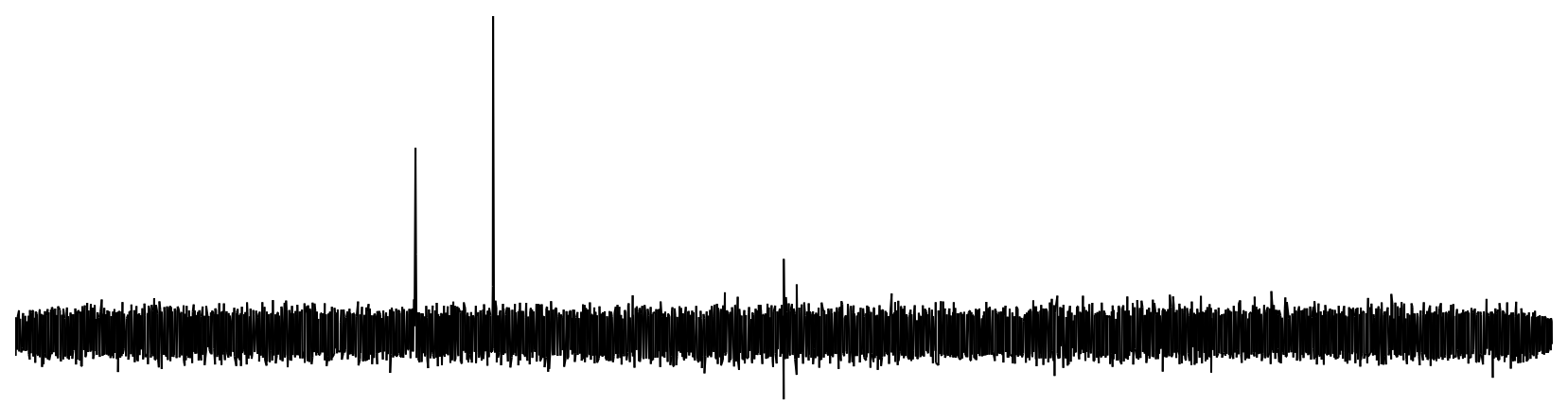

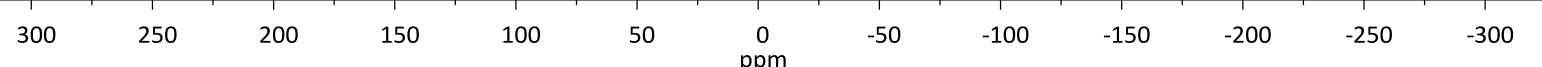

Figure A1.5: ${ }^{119} \mathrm{Sn} \mathrm{NMR}\left(\mathrm{CDCl}_{3}\right)$ of crude $\mathbf{2 a}$. 


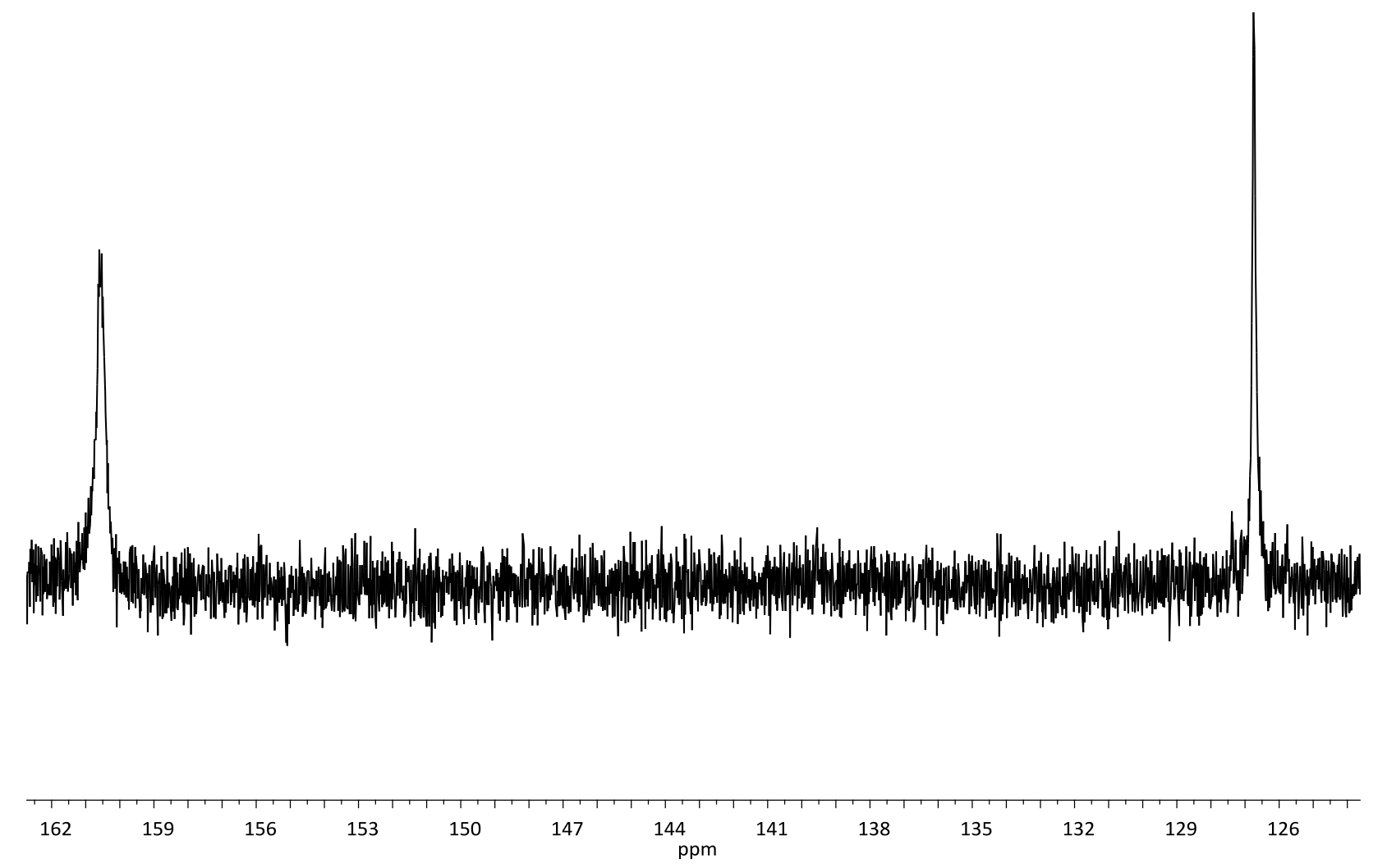

Figure A1.6: ${ }^{119} \mathrm{Sn} \mathrm{NMR}\left(\mathrm{CDCl}_{3}\right)$ Crude 2a, signal at $126.8 \mathrm{ppm}$ is $\mathbf{2 a}$ and signal at $160 \mathrm{ppm}$ is $\mathrm{Me}_{3} \mathrm{SnCl}$. 
Appendix 1.3: 3a

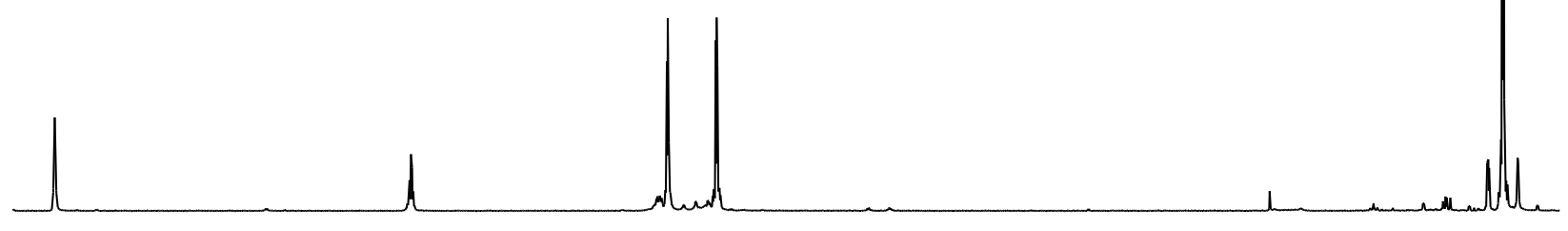

\begin{tabular}{llllllllllllll}
\hline 7.0 & 6.5 & 6.0 & 5.5 & 5.0 & 4.5 & 4.0 & 3.5 & 3.0 & 2.5 & 2.0 & 1.5 & 1.0 & 0.5
\end{tabular}

Figure A1.7: ${ }^{1} \mathrm{H}$ NMR $\left(\mathrm{C}_{6} \mathrm{D}_{6}\right)$ of $\mathbf{3 a}$. 


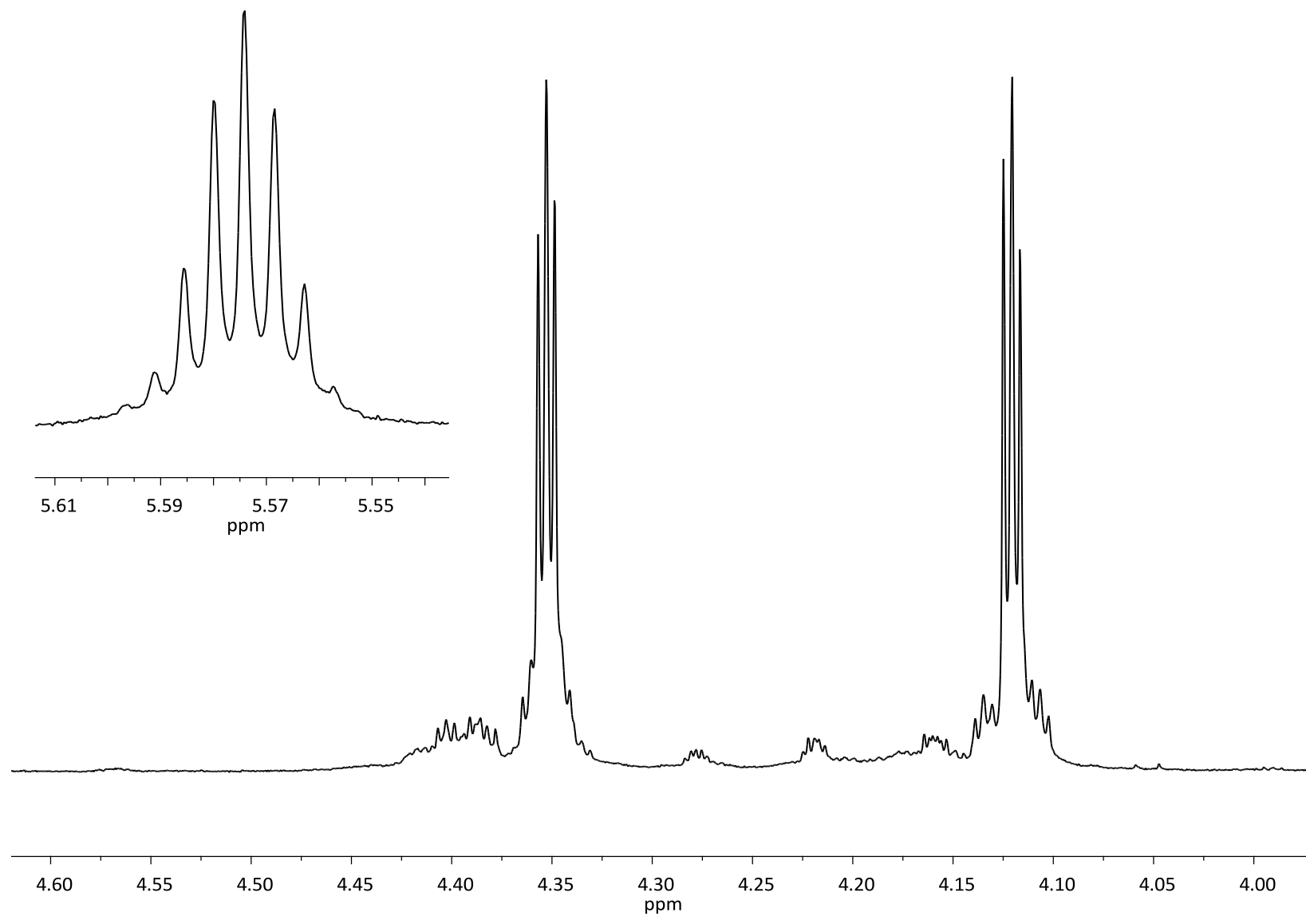

Figure A1.8: cyclopentadiene region ${ }^{1} \mathrm{H}$ NMR $\left(\mathrm{C}_{6} \mathrm{D}_{6}\right)$ of $\mathbf{3 a}$ with insert of hydride region. 


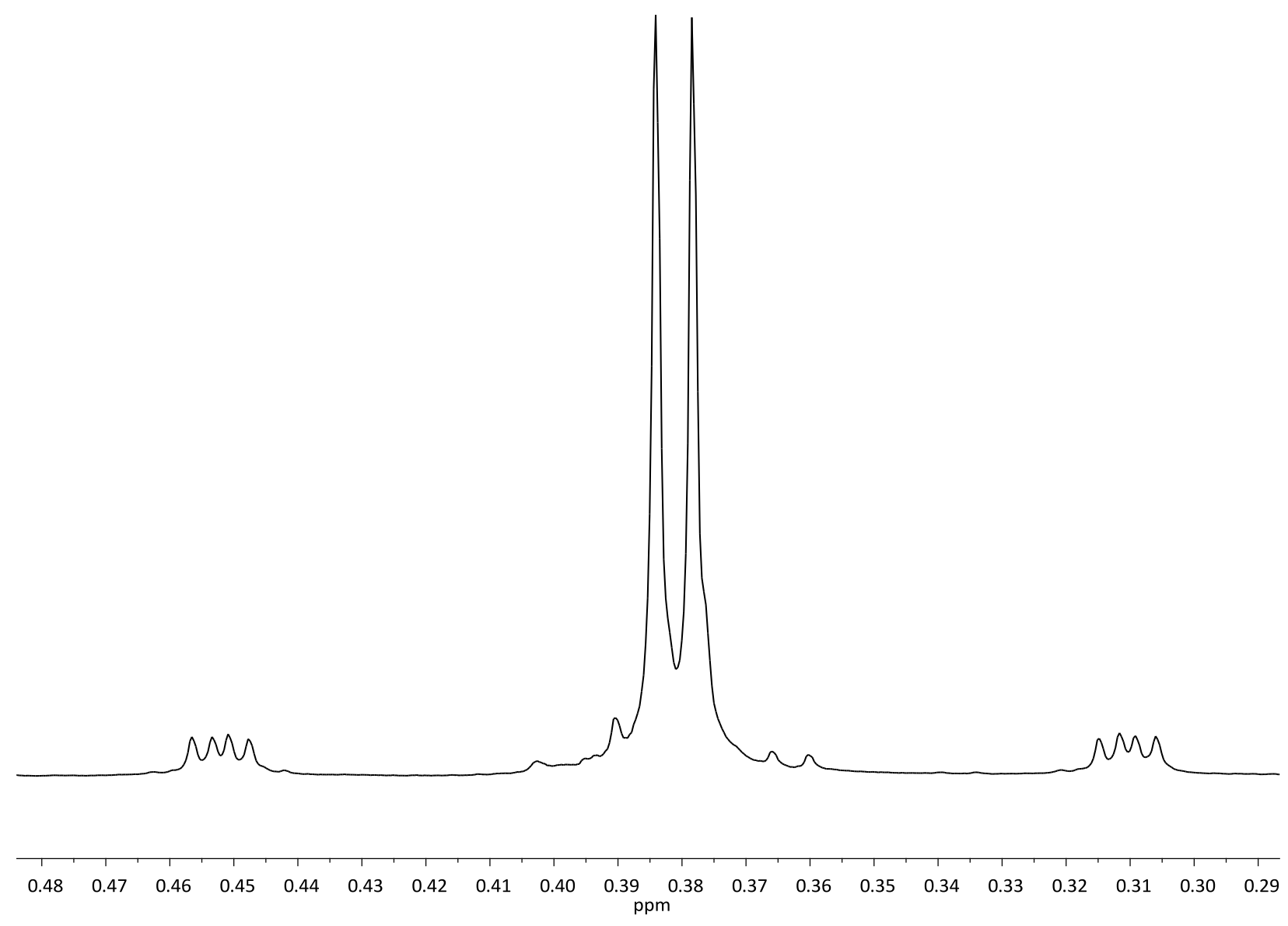

Figure A1.9: Methyl region ${ }^{1} \mathrm{H}$ NMR $\left(\mathrm{C}_{6} \mathrm{D}_{6}\right)$ of $\mathbf{3 a}$. 


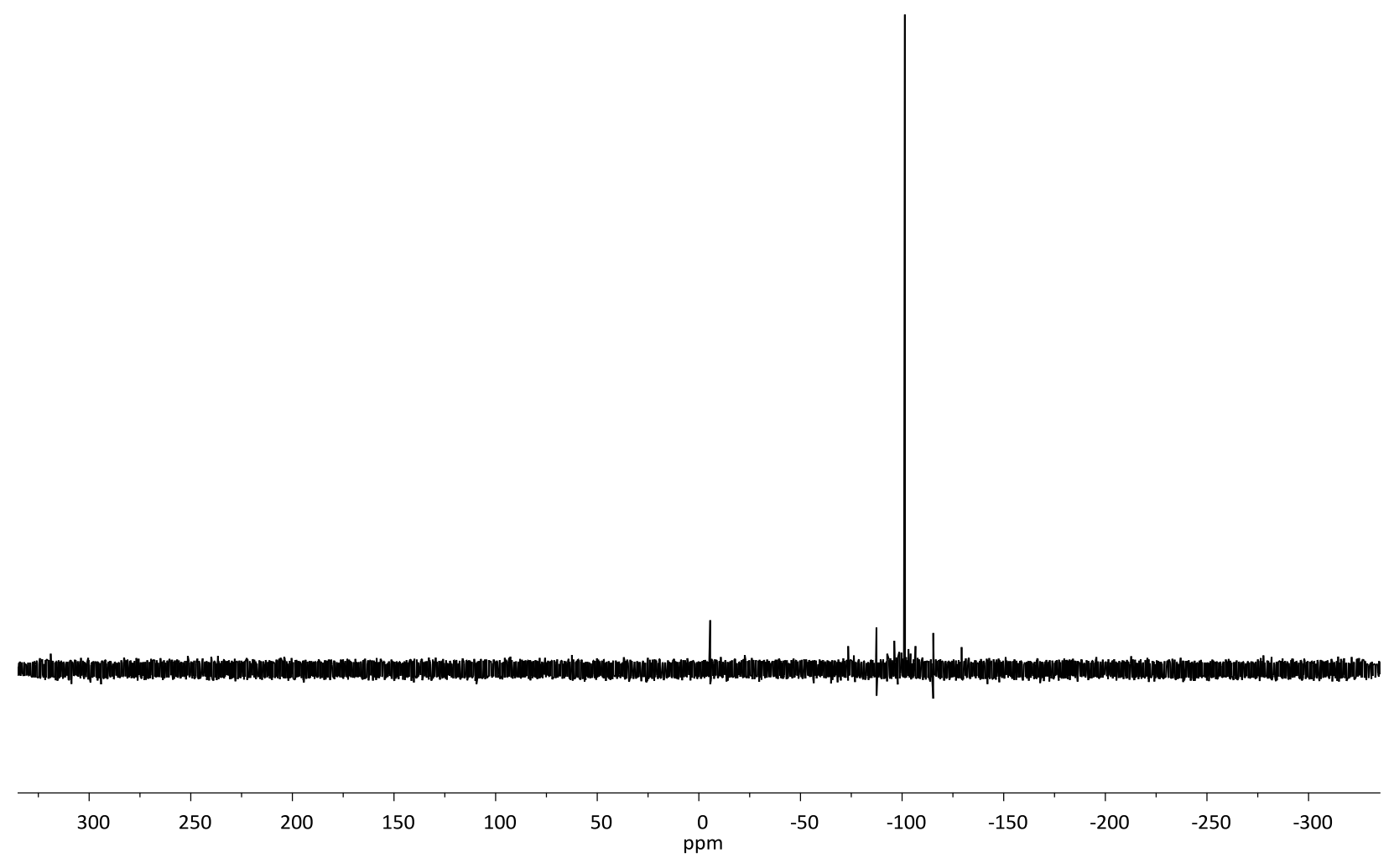

Figure A1.10: ${ }^{119} \mathrm{Sn}$ NMR $\left(\mathrm{C}_{6} \mathrm{D}_{6}\right)$ of 3a, the chemical shift found at $-6 \mathrm{ppm}$ is unreacted $\mathbf{1 a}$. 
Appendix 1.4: 1b

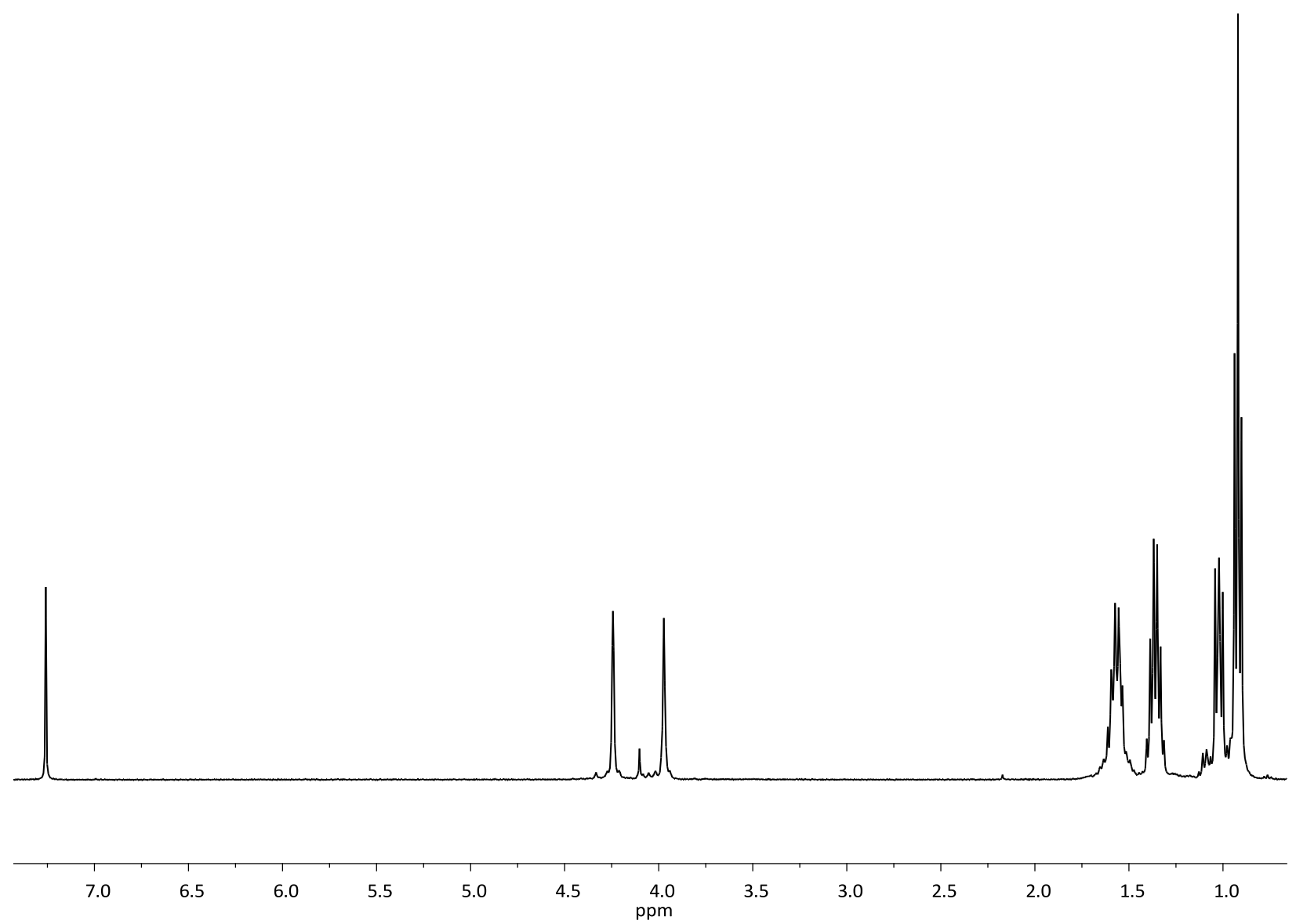

Figure A1.11: ${ }^{1} \mathrm{H} \mathrm{NMR}\left(\mathrm{CDCl}_{3}\right)$ of $\mathbf{1 b}$. 


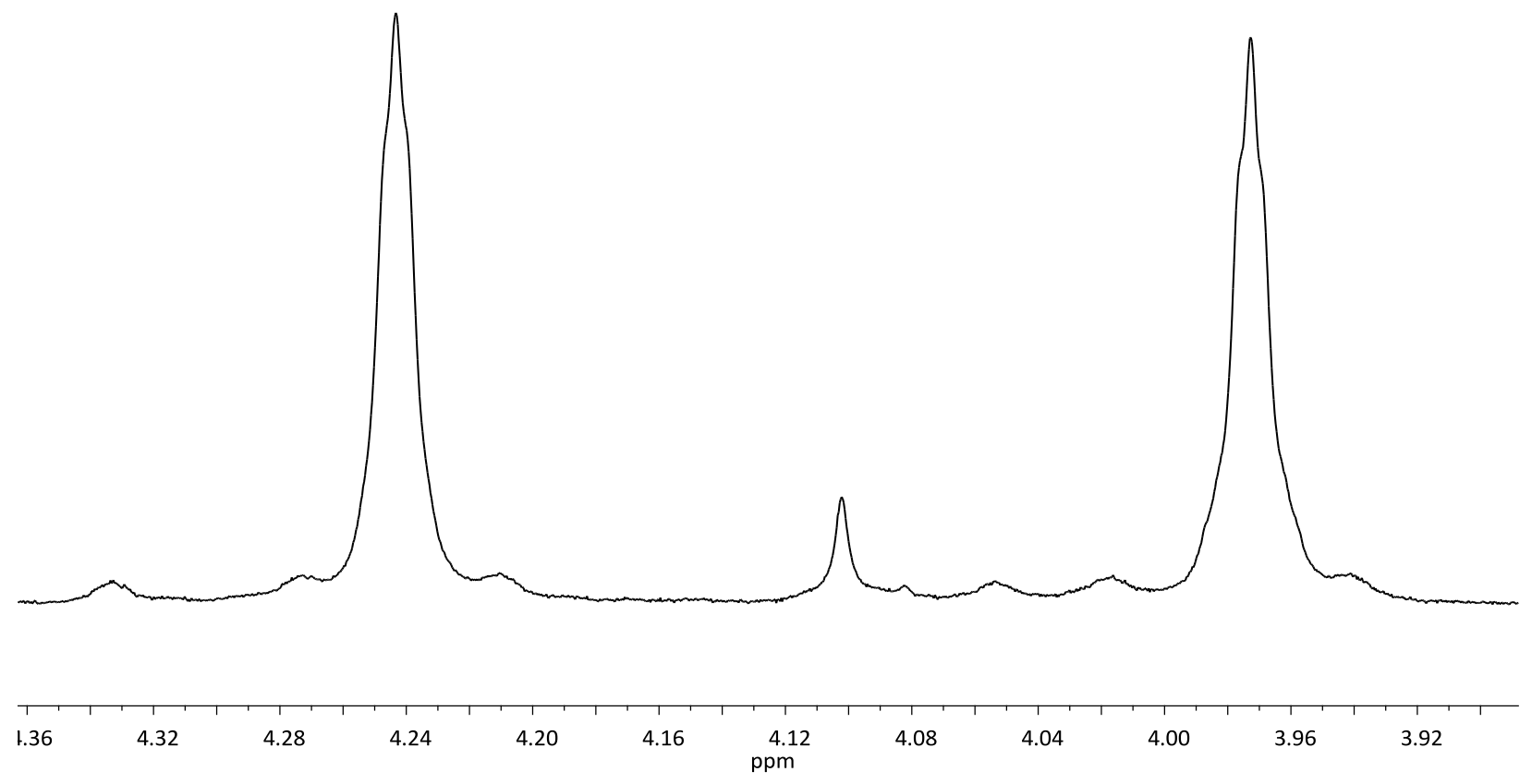

Figure A1.12: Cyclopentadiene region of ${ }^{1} \mathrm{H} \mathrm{NMR}\left(\mathrm{CDCl}_{3}\right)$ of $\mathbf{1 b}$. 


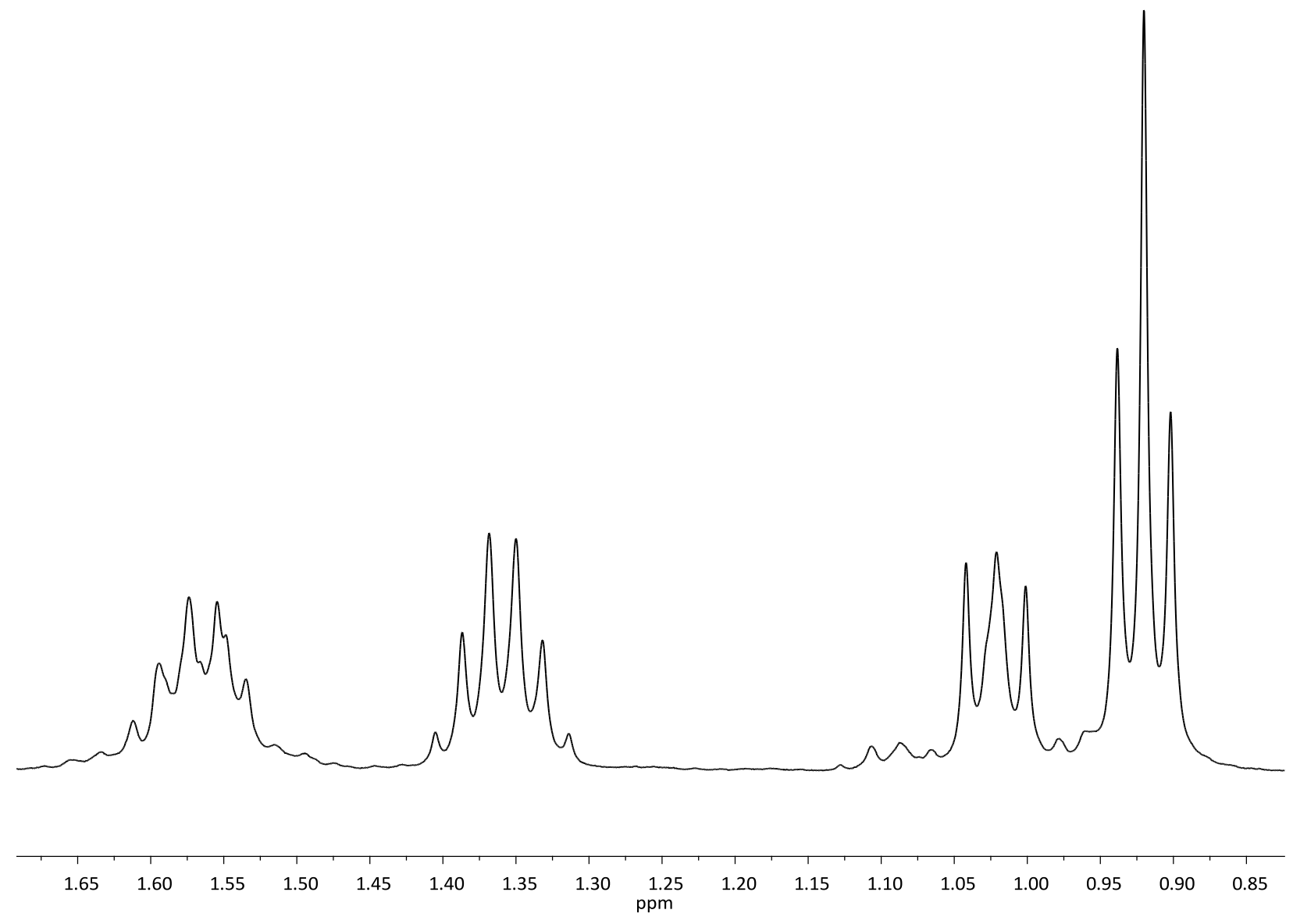

Figure A1.13: Methyl region of ${ }^{1} \mathrm{H}$ NMR $\left(\mathrm{CDCl}_{3}\right)$ of $\mathbf{1 b}$. 


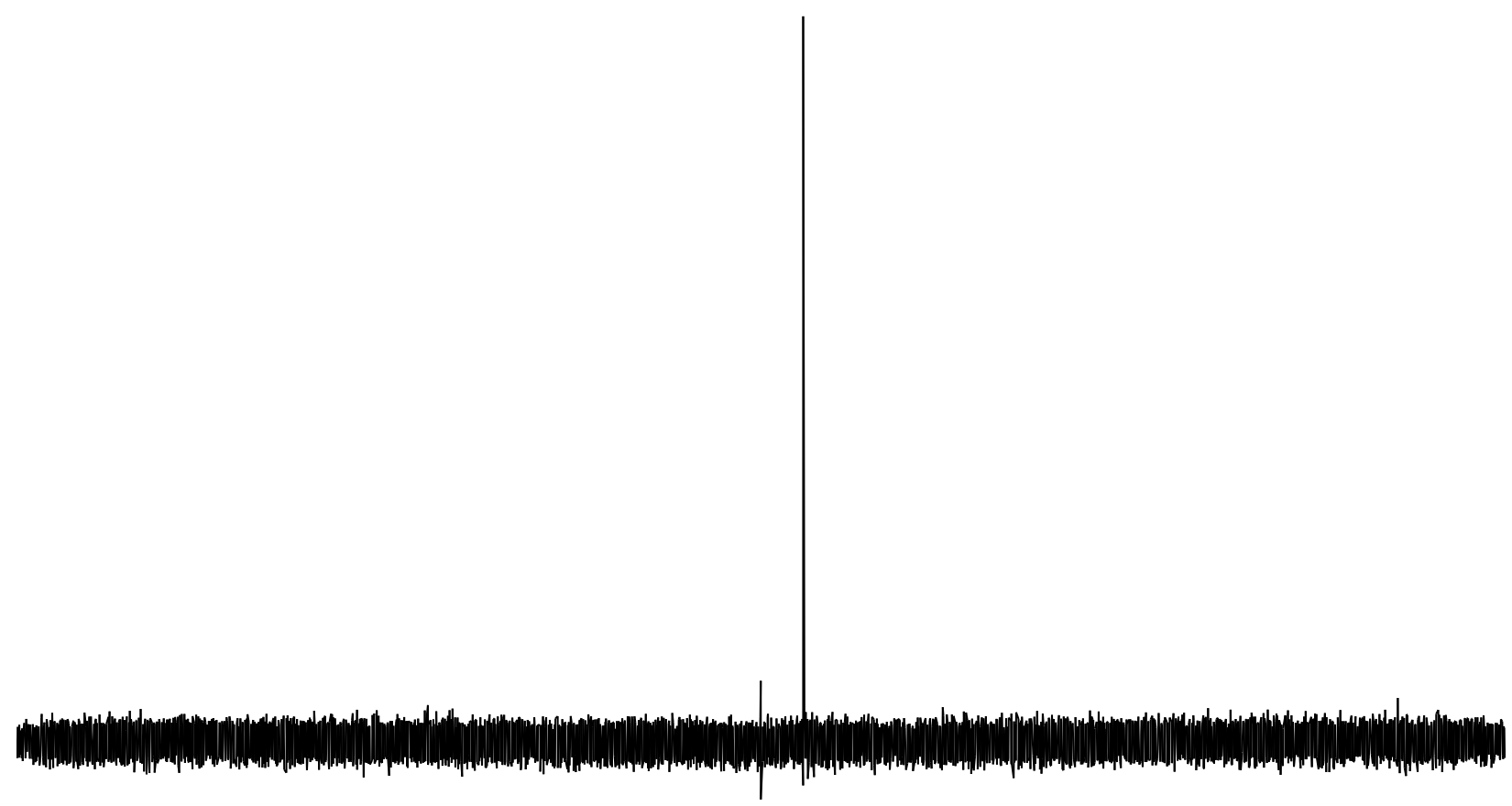

\begin{tabular}{|c|c|c|c|c|c|c|c|c|c|c|c|c|}
\hline 300 & 250 & 200 & 150 & 100 & 50 & $\begin{array}{c}0 \\
\mathrm{ppm}\end{array}$ & -50 & -100 & -150 & -200 & -250 & -300 \\
\hline
\end{tabular}

Figure A1.14: ${ }^{119} \mathrm{Sn} \mathrm{NMR}\left(\mathrm{CDCl}_{3}\right)$ of $\mathbf{1 b}$. 
Appendix 1.5: 4 formed through Condensation polymerization.

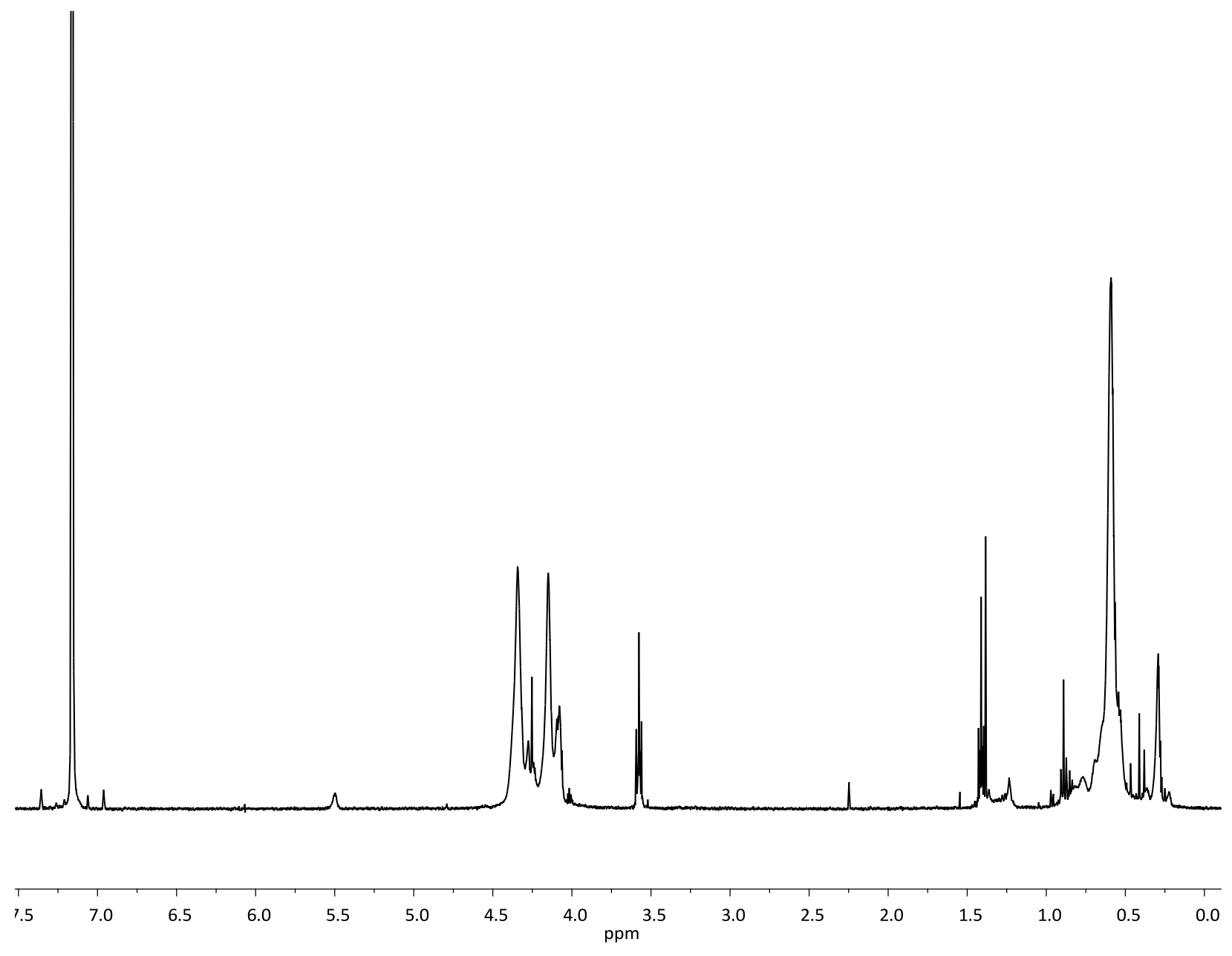

Figure A1.15: ${ }^{1} \mathrm{H}$ NMR $\left(\mathrm{C}_{6} \mathrm{D}_{6}\right)$ of 4 . 


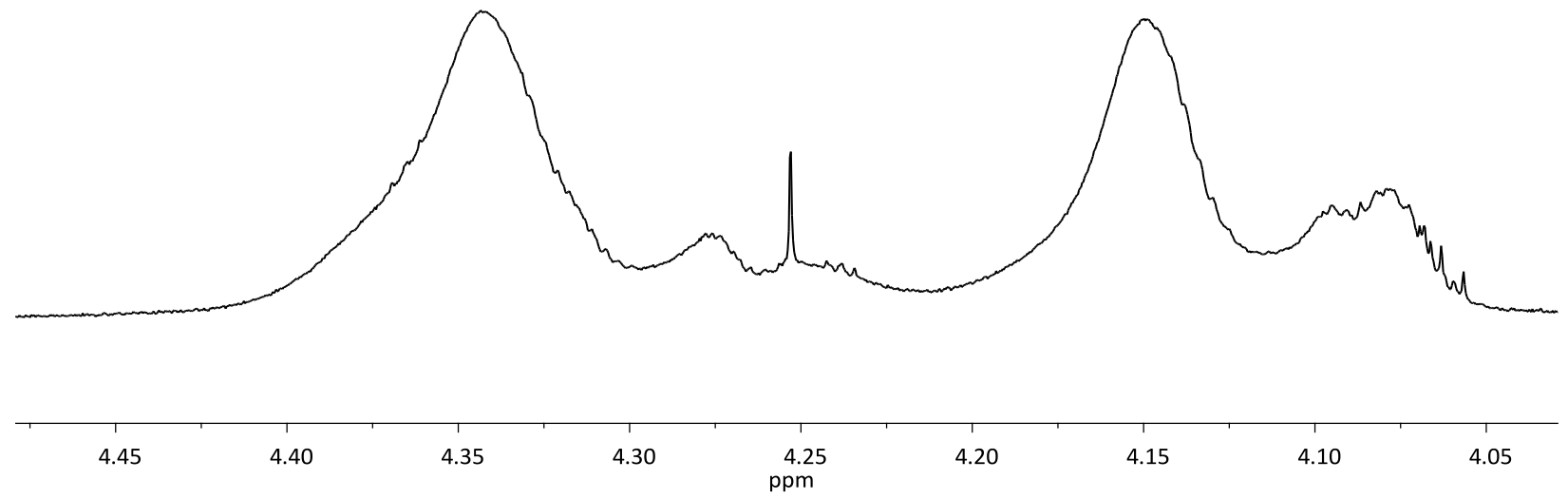

Figure A1.16: Cyclopentadiene region of ${ }^{1} \mathrm{H}$ NMR $\left(\mathrm{C}_{6} \mathrm{D}_{6}\right)$ of 4 . 


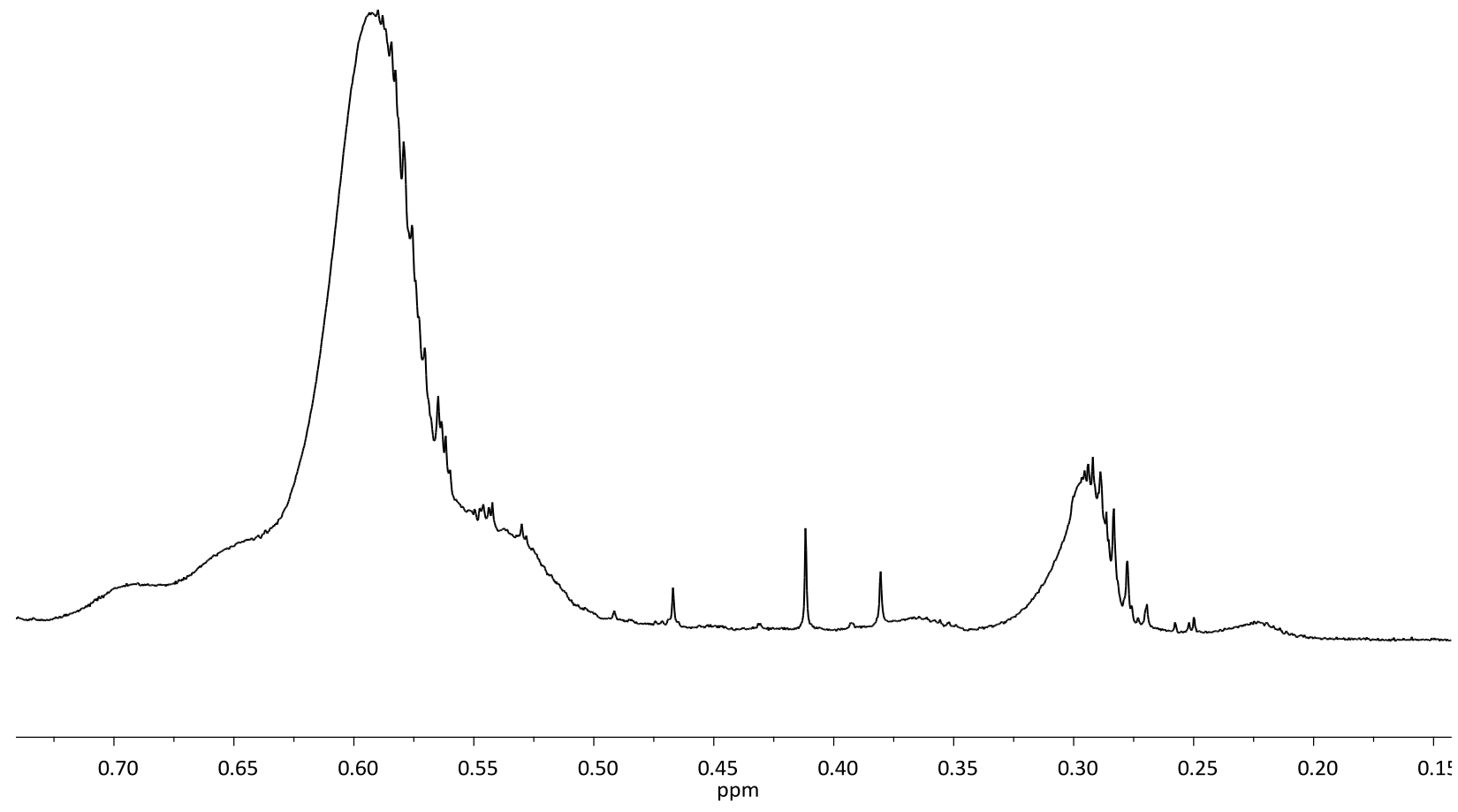

Figure A1.17: Methyl region of ${ }^{1} \mathrm{H}$ NMR $\left(\mathrm{C}_{6} \mathrm{D}_{6}\right)$ of 4 . 


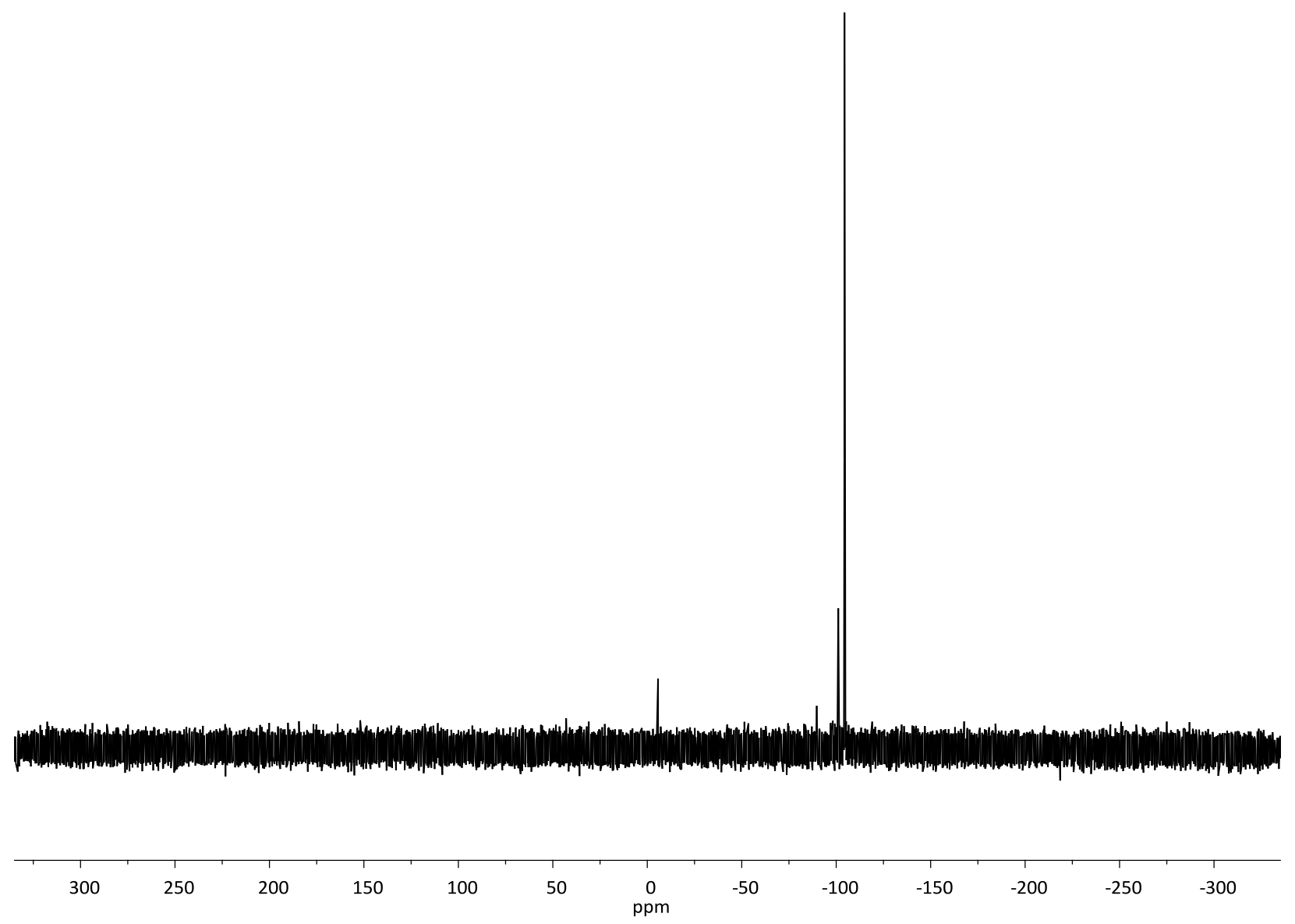

Figure A1.18: ${ }^{119} \mathrm{Sn}$ NMR $\left(\mathrm{C}_{6} \mathrm{D}_{6}\right)$ of 4 . 


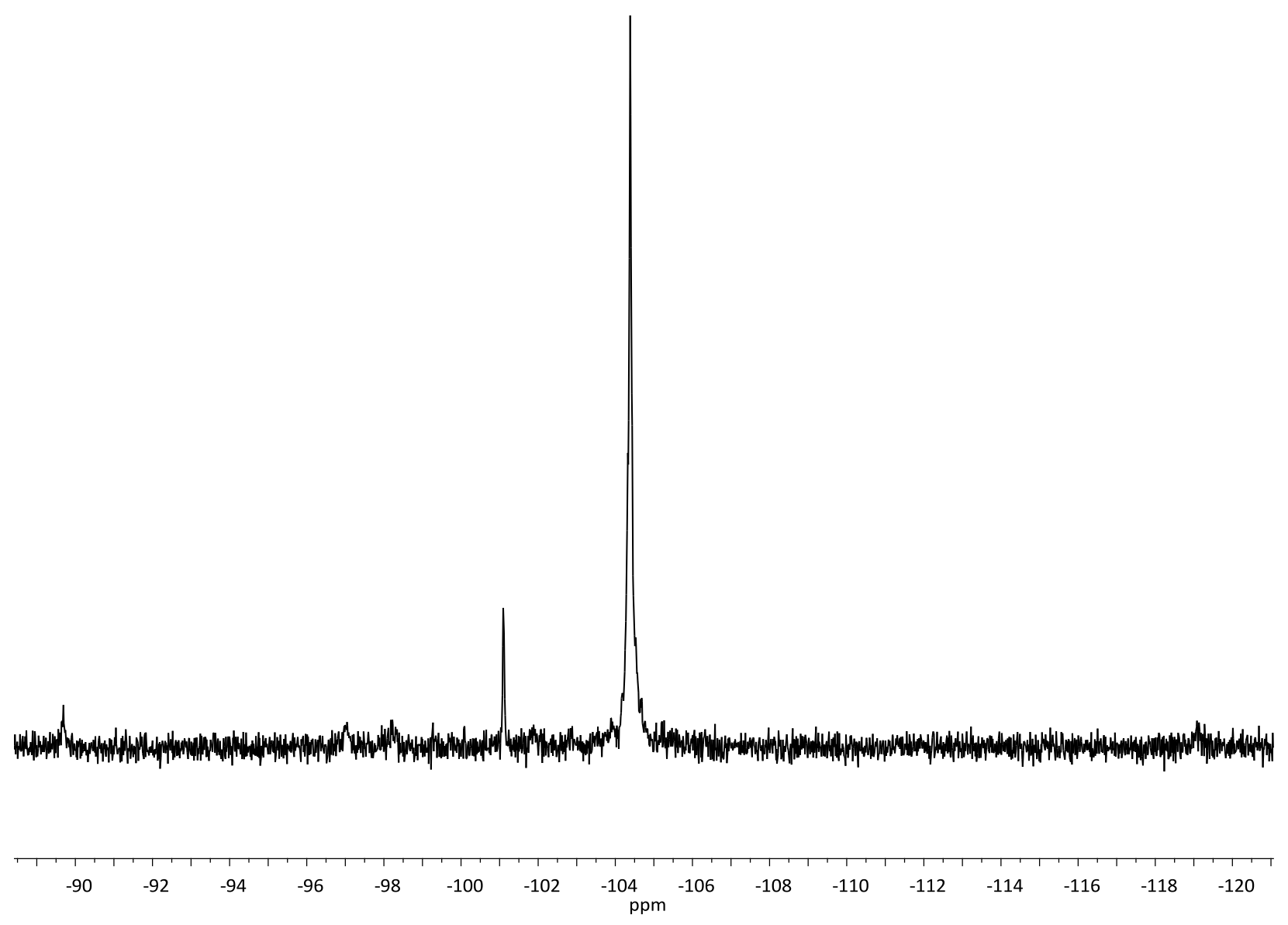

Figure A1.19: Polymer region of ${ }^{119} \mathrm{Sn}$ NMR $\left(\mathrm{C}_{6} \mathrm{D}_{6}\right)$ of 4 . 


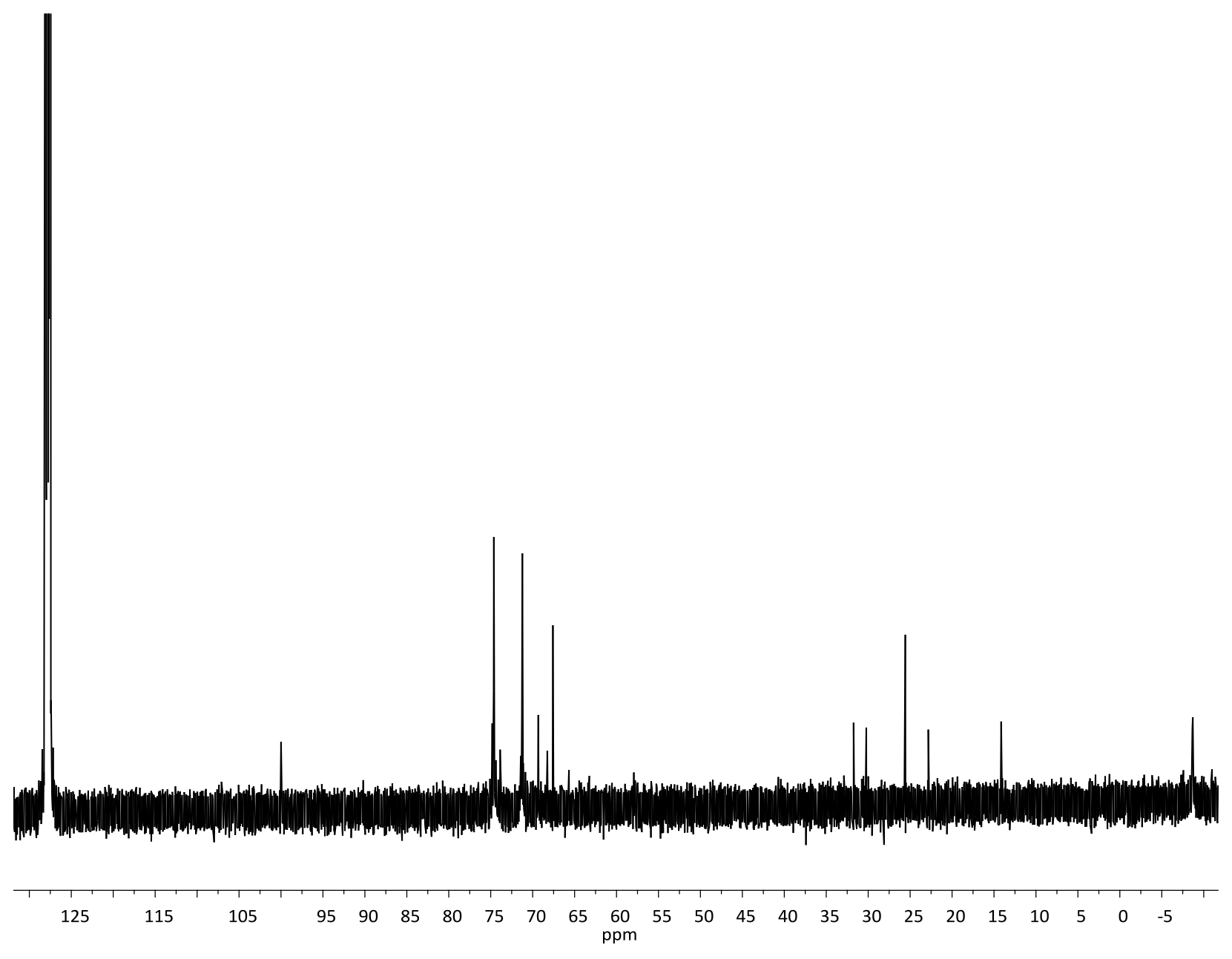

Figure A1.20: ${ }^{13} \mathrm{C}$ NMR $\left(\mathrm{C}_{6} \mathrm{D}_{6}\right)$ of 4 . 


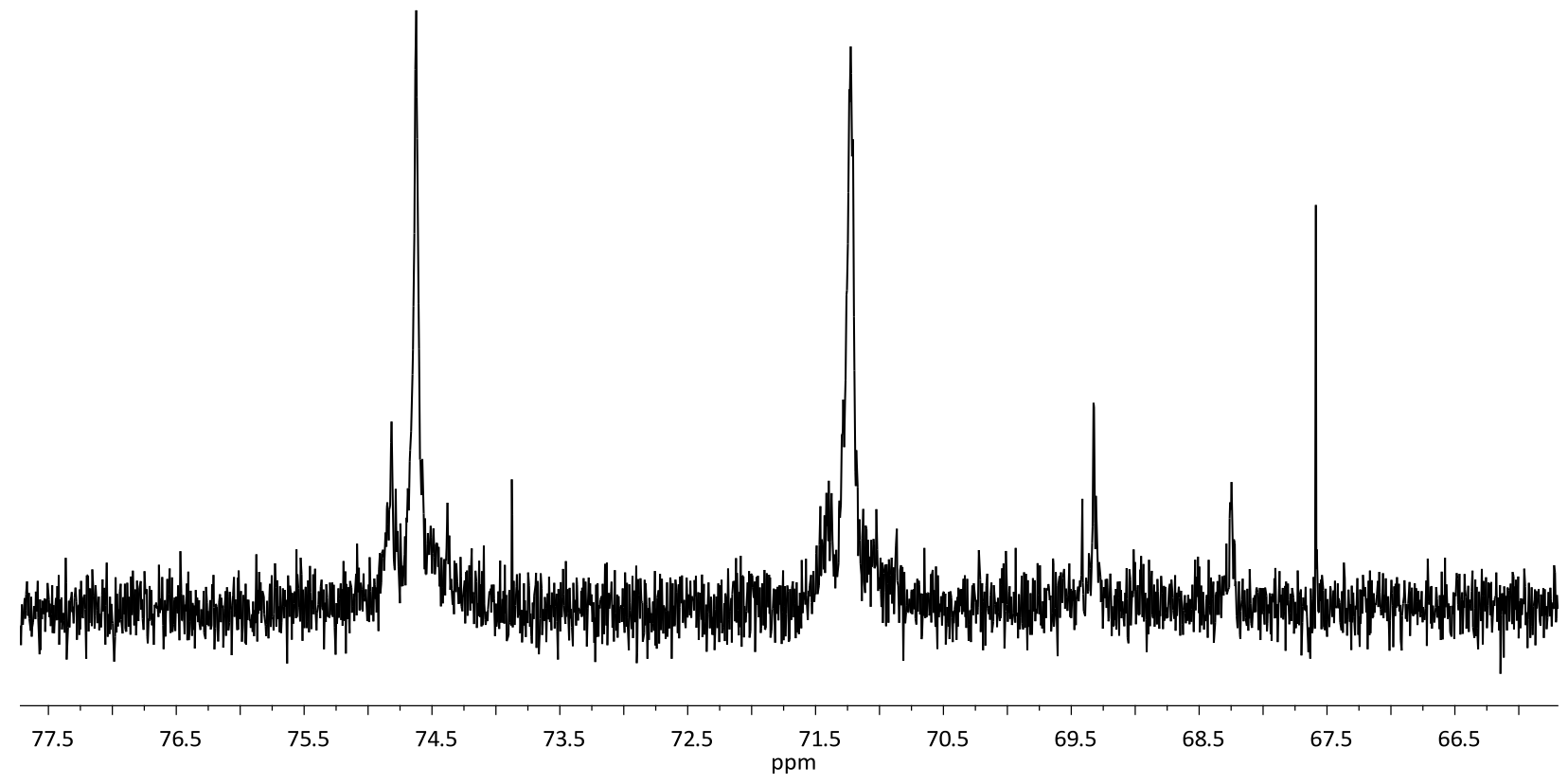

Figure A1.21: Cyclopentadiene region of ${ }^{13} \mathrm{C} N M R\left(\mathrm{C}_{6} \mathrm{D}_{6}\right)$ of 4 . 

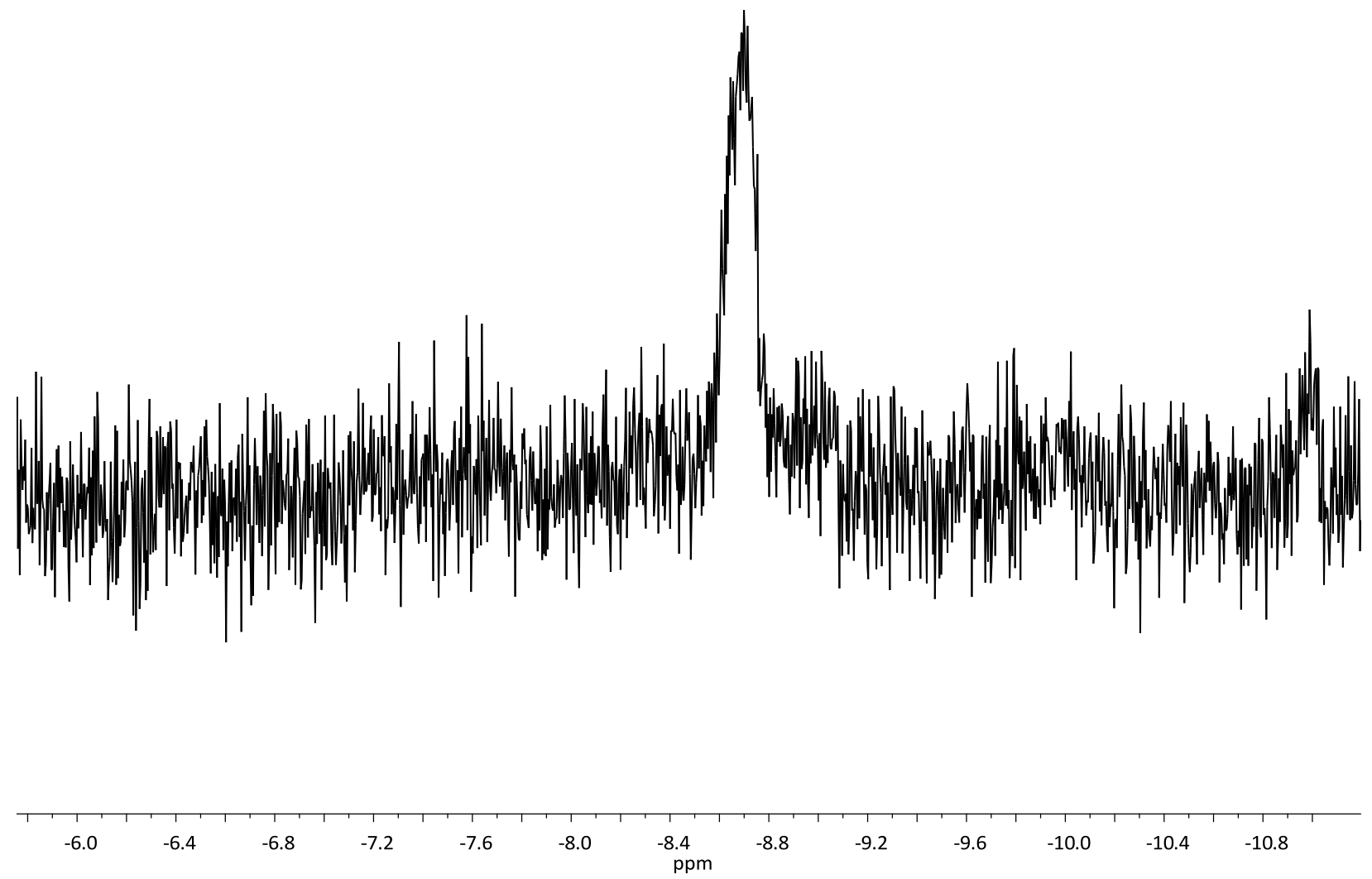

Figure A1.22: Methyl region of ${ }^{13} \mathrm{C} N M R\left(C_{6} D_{6}\right)$ of 4 . 


\section{Appendix 1.6: 4 prepared through ROP}

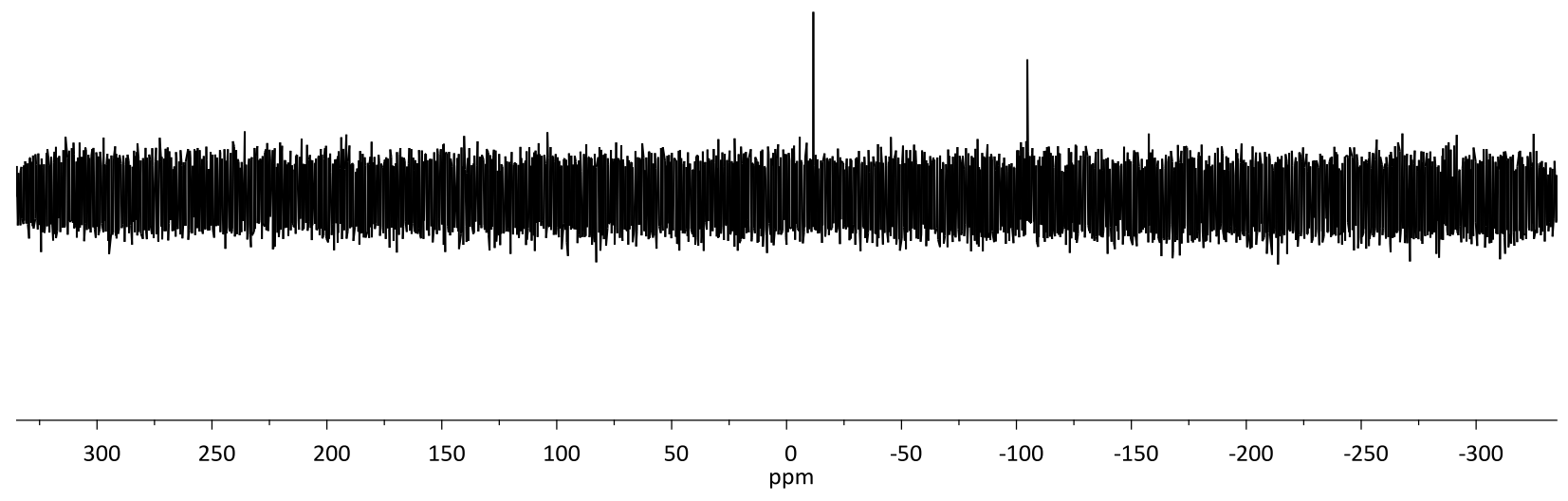

Figure A1.23: ${ }^{119} \mathrm{Sn}$ NMR $\left(\mathrm{C}_{6} \mathrm{D}_{6}\right)$ of 4 prepared through ROP. 
Appendix 1.7: 5a

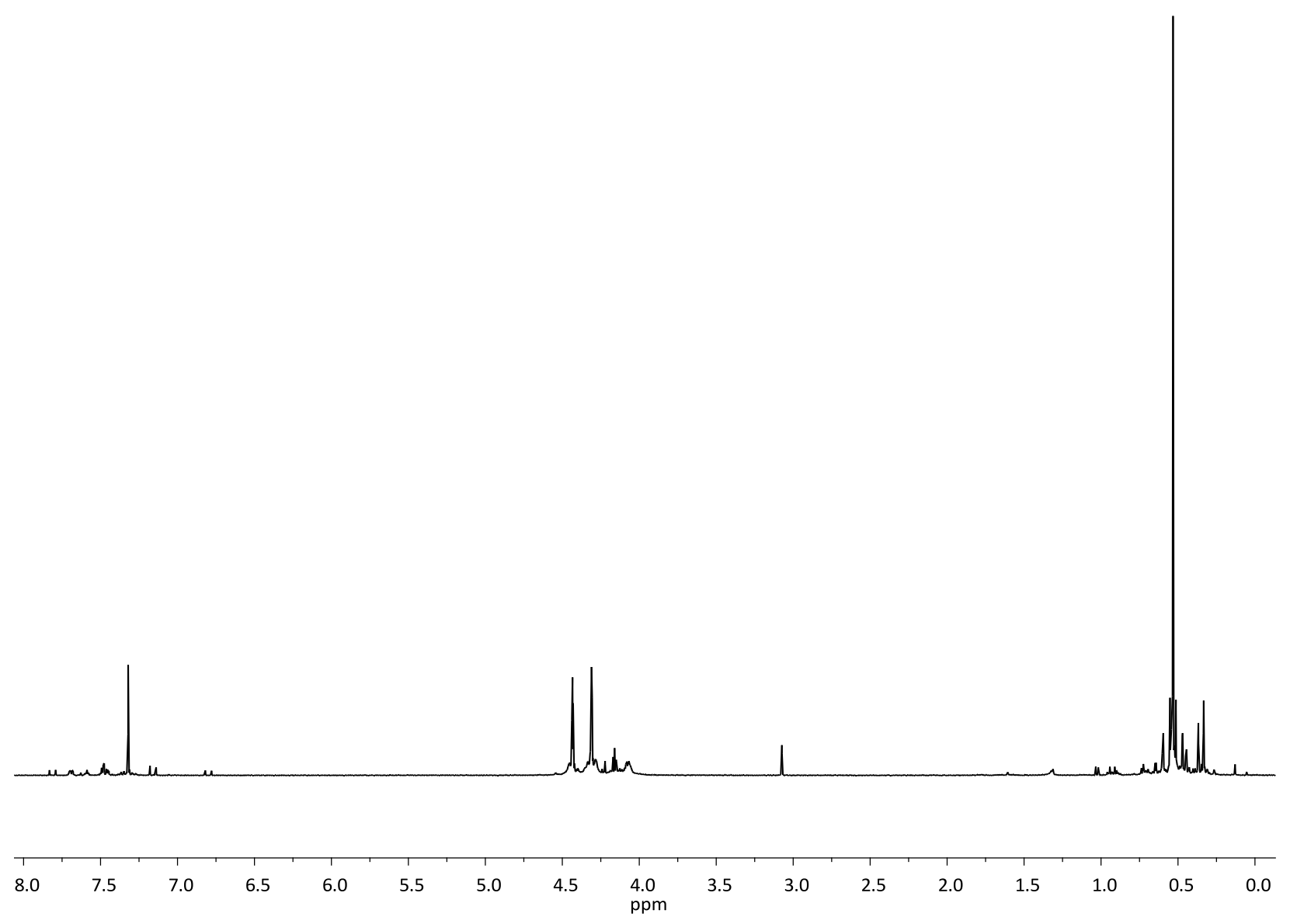

Figure A1.24: ${ }^{1} \mathrm{H}$ NMR $\left(\mathrm{C}_{6} \mathrm{D}_{6}\right)$ of $\mathbf{5 a}$. 

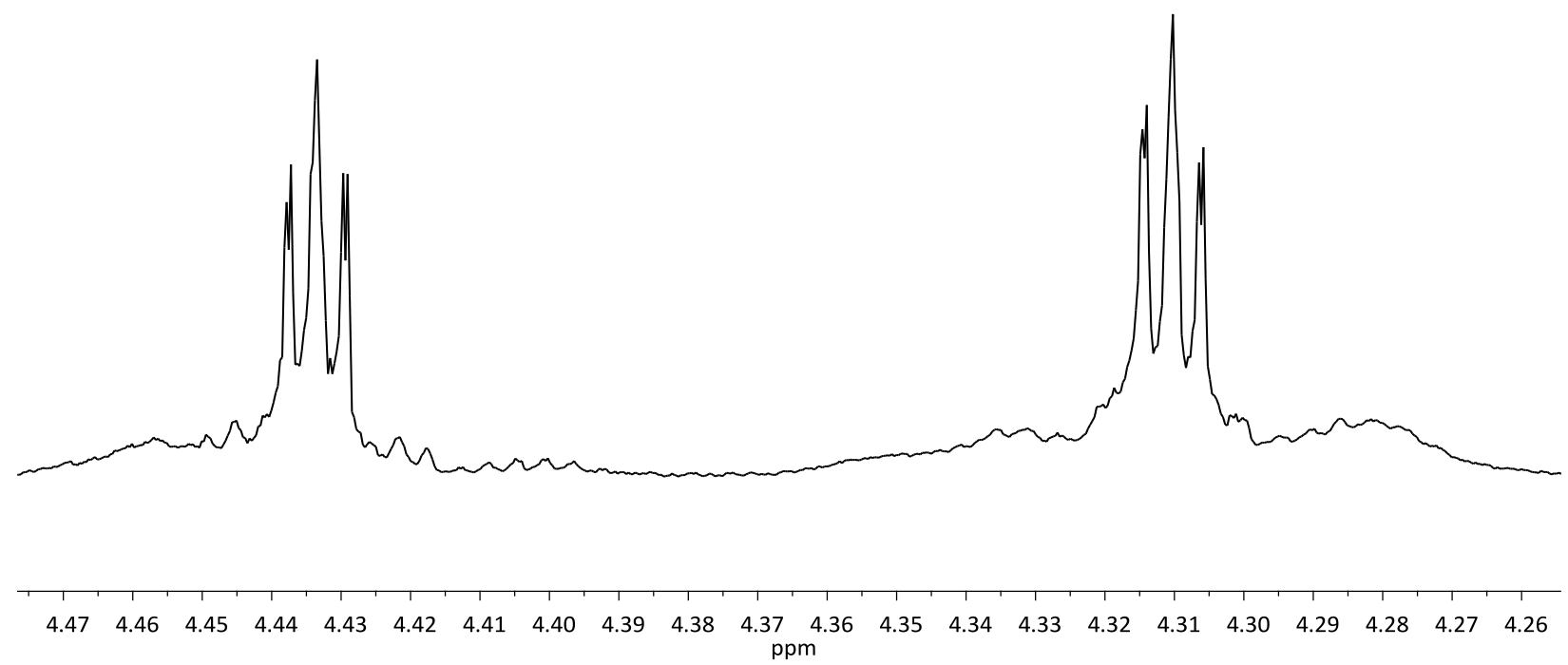

Figure A1.25: Cyclopentadiene region of ${ }^{1} \mathrm{H} N M R\left(\mathrm{C}_{6} \mathrm{D}_{6}\right)$ of $\mathbf{5 a}$. 


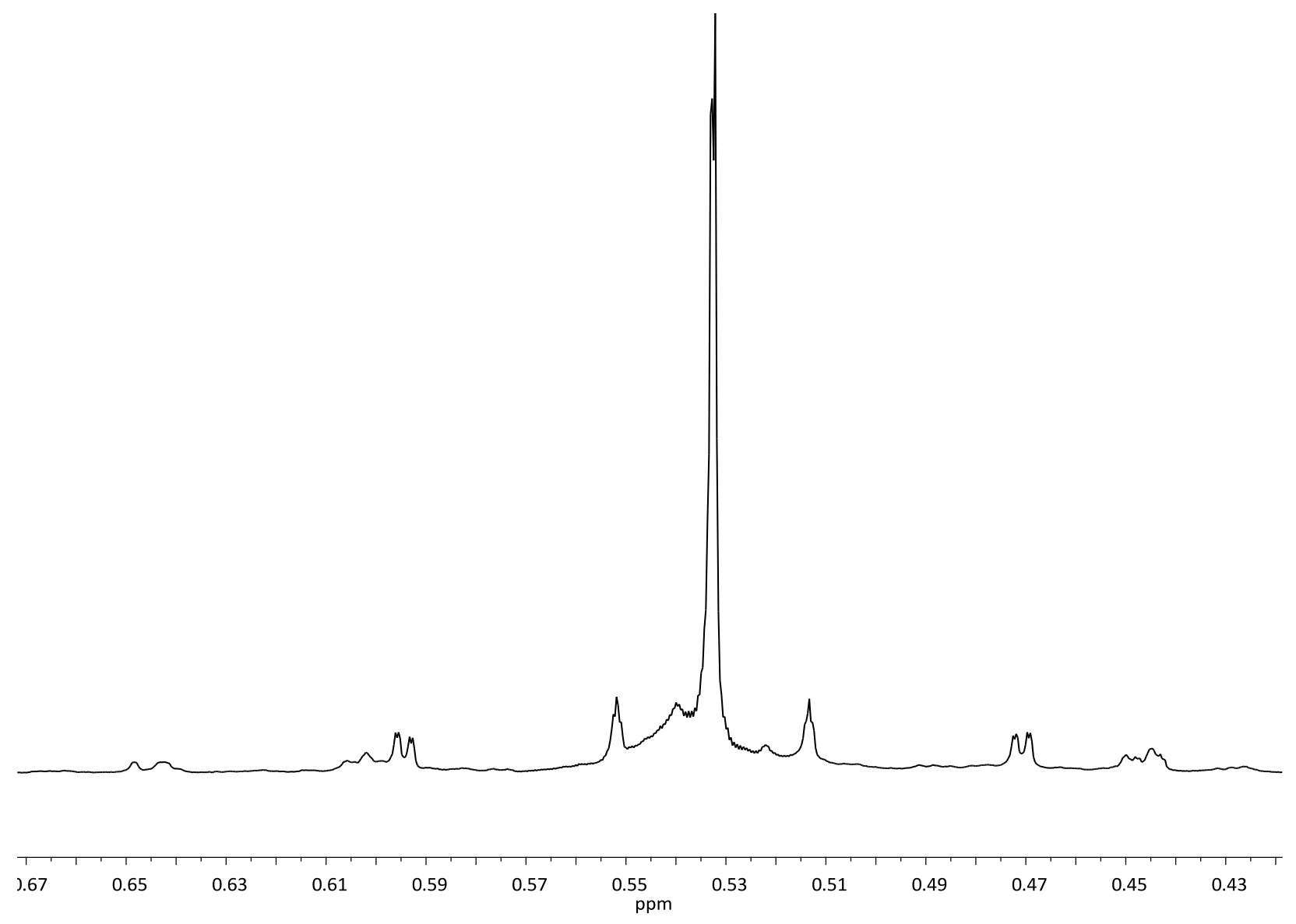

Figure A1.26: Methyl region of ${ }^{1} \mathrm{H}$ NMR $\left(\mathrm{C}_{6} \mathrm{D}_{6}\right)$ of 5a. 


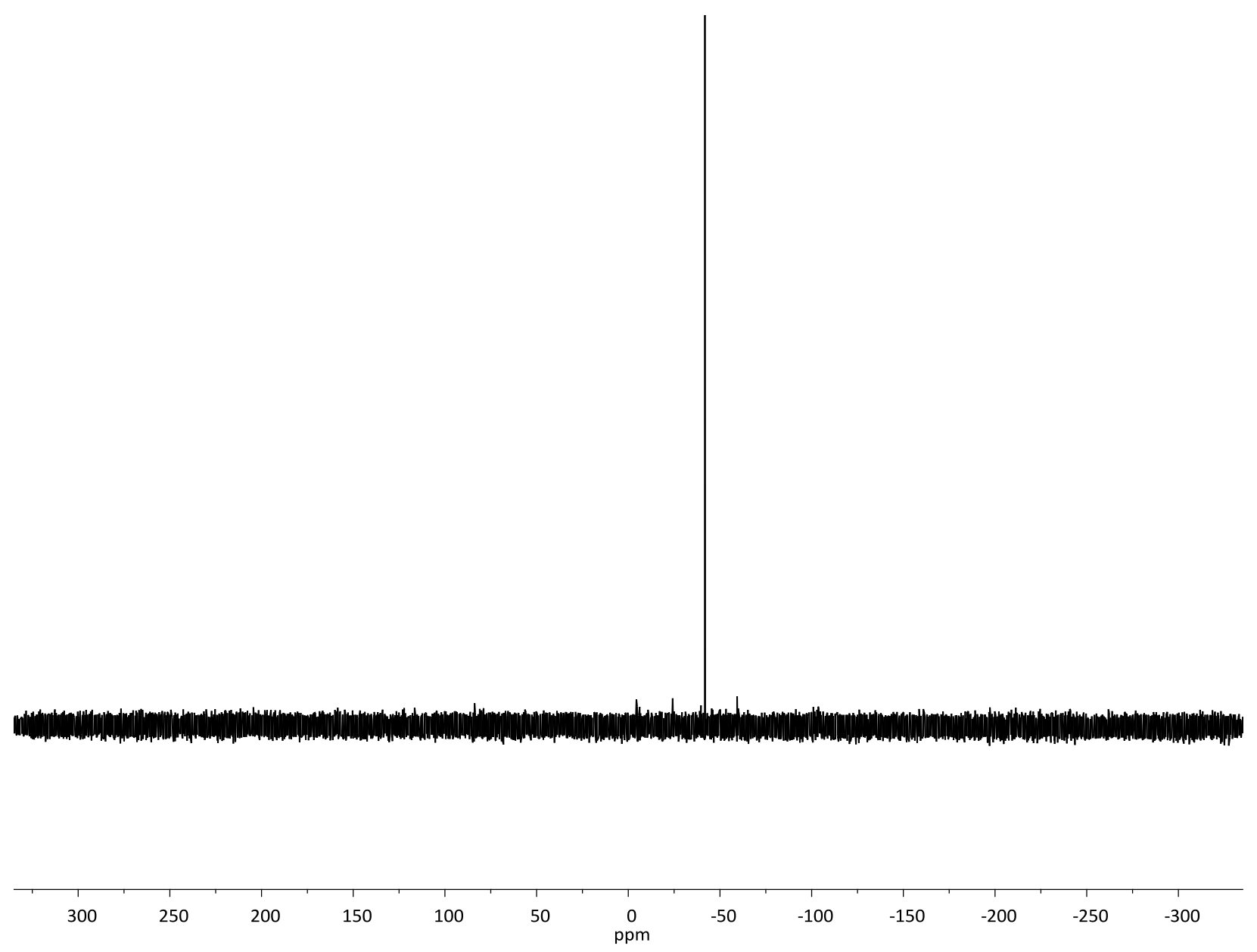

Figure A1.27: ${ }^{119} \mathrm{Sn}$ NMR $\left(\mathrm{C}_{6} \mathrm{D}_{6}\right)$ of $\mathbf{5 a}$. 


\section{Appendix 1.8: 11}

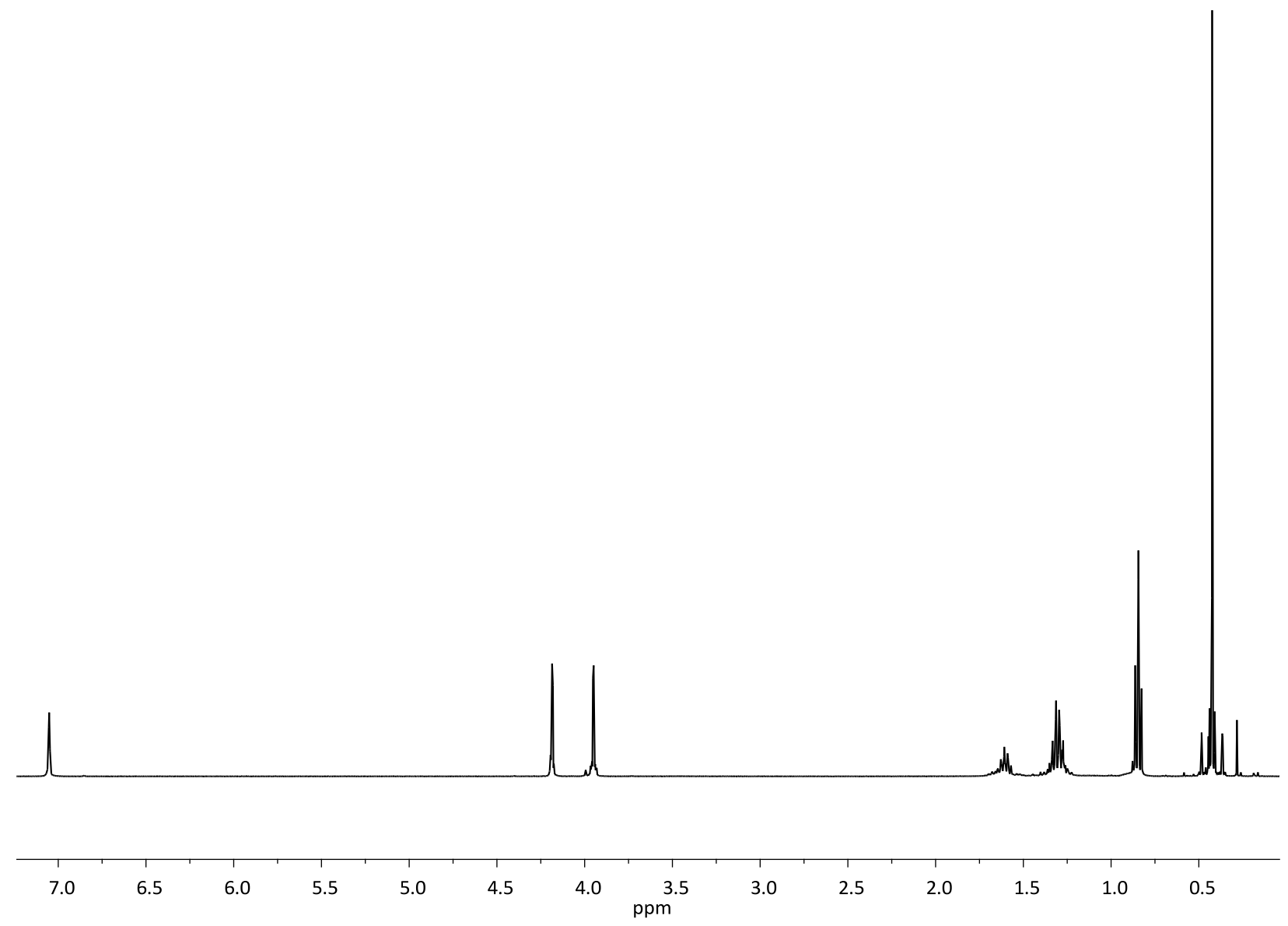

Figure A1.28: ${ }^{1} \mathrm{H}$ NMR $\left(\mathrm{C}_{6} \mathrm{D}_{6}\right)$ of 11. 


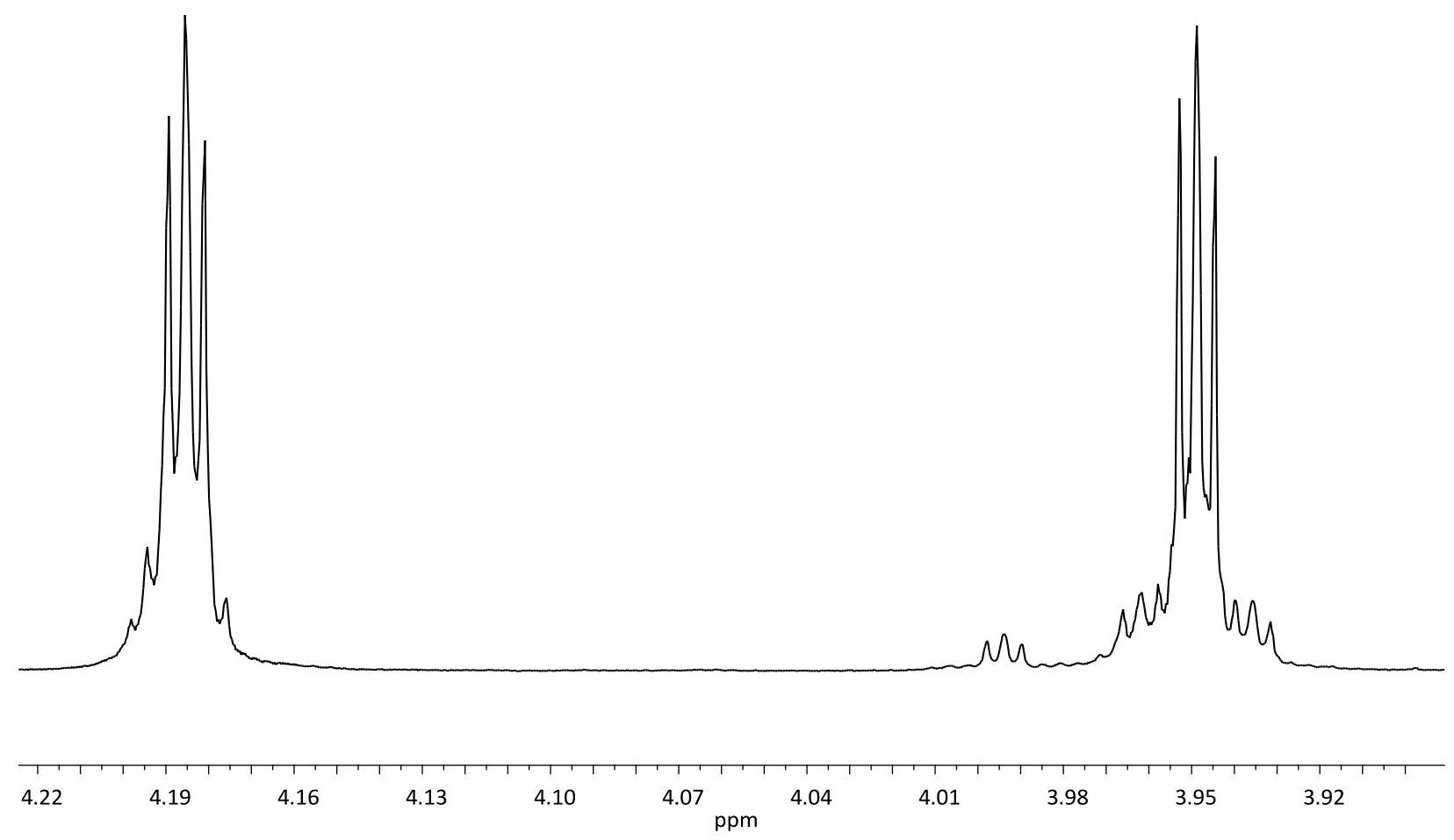

Figure A1.29: Cyclopentadiene region of ${ }^{1} \mathrm{H} N M R\left(\mathrm{C}_{6} \mathrm{D}_{6}\right)$ of $\mathbf{1 1}$. 


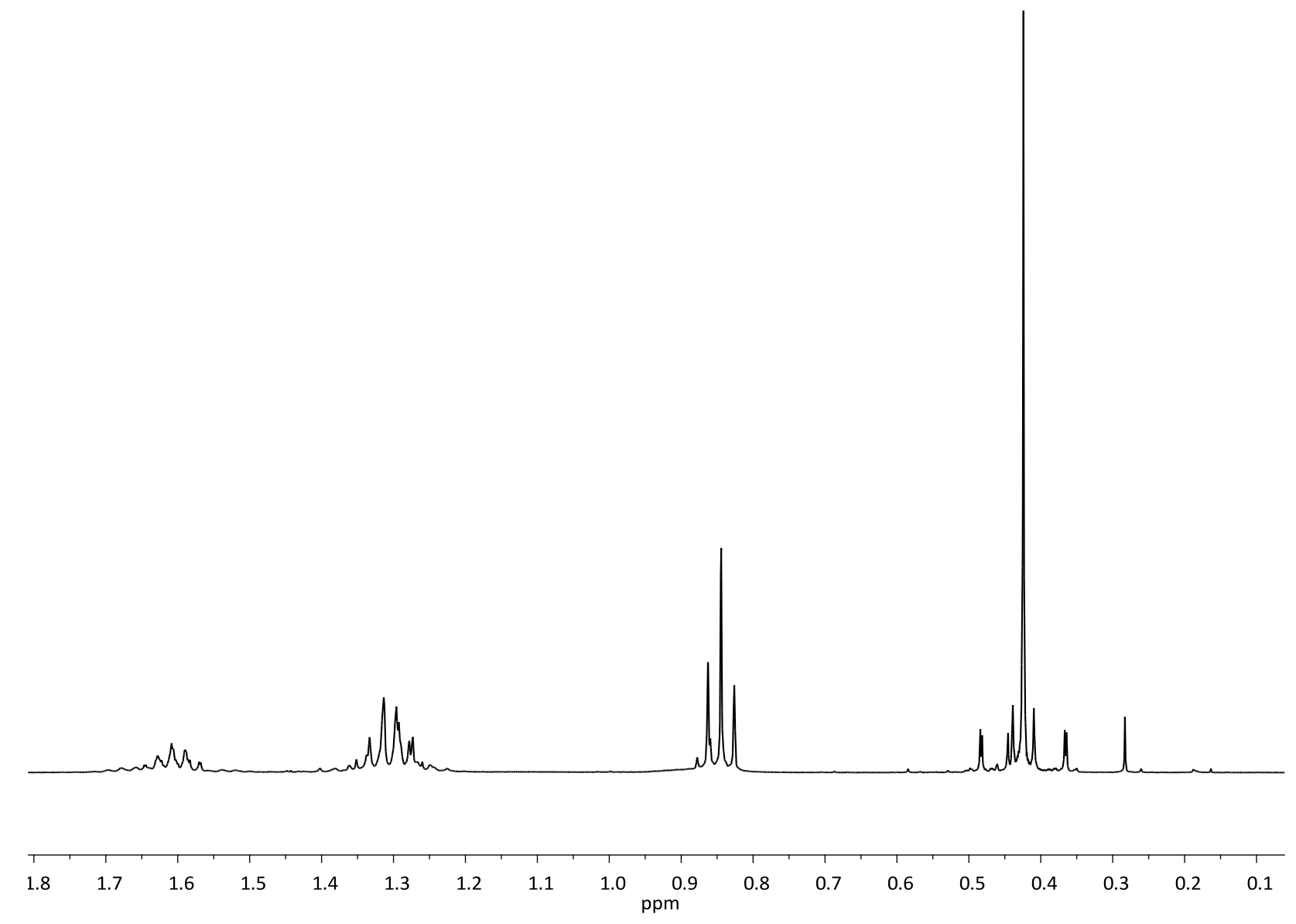

Figure A1.30: Methyl and $n$-butyl region of ${ }^{1} \mathrm{H}$ NMR $\left(\mathrm{C}_{6} \mathrm{D}_{6}\right)$ of 11. 


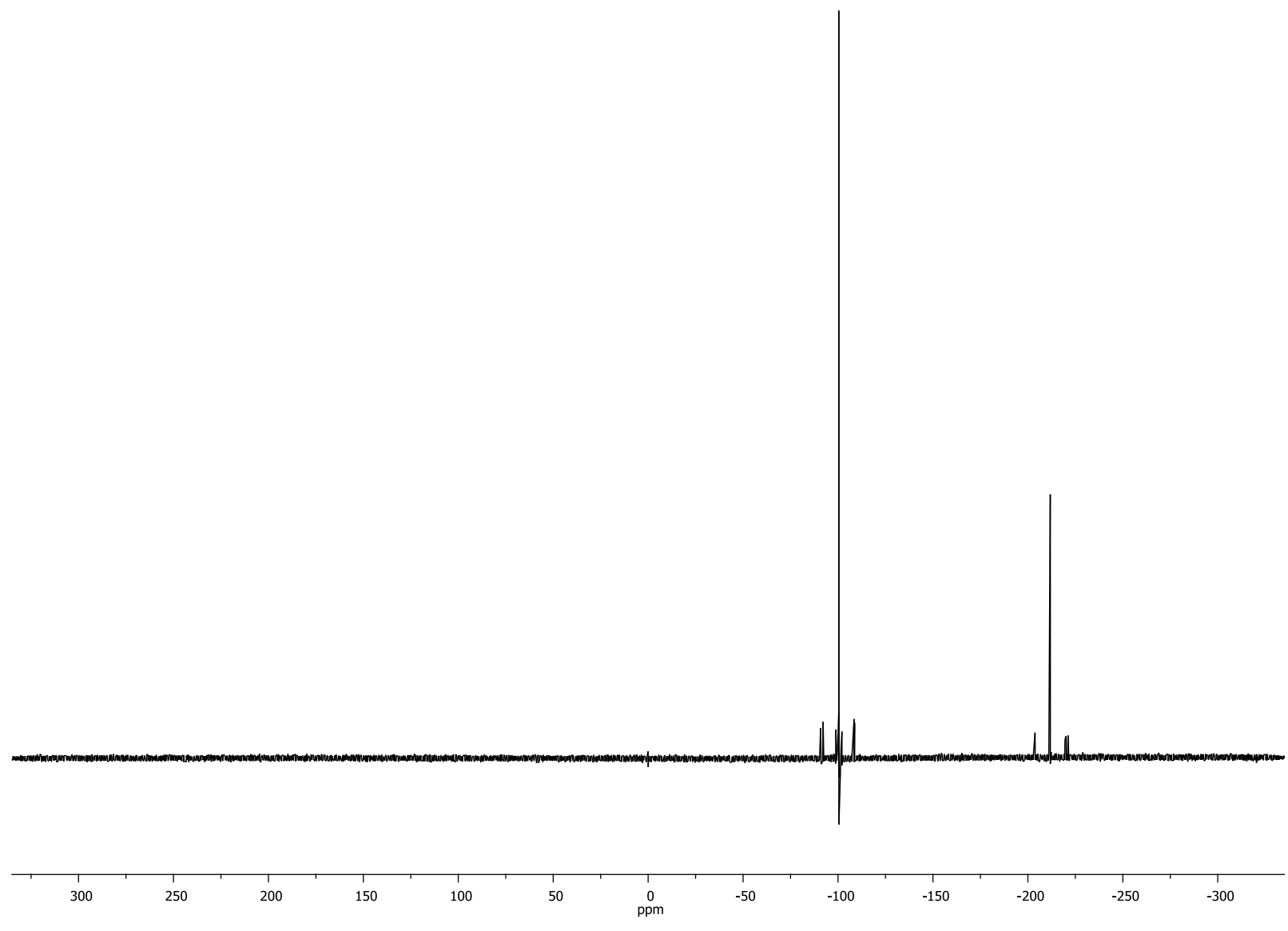

Figure A1.31: ${ }^{119} \mathrm{Sn}$ NMR of $11\left(\mathrm{C}_{6} \mathrm{D}_{6}\right)$ of 11. 


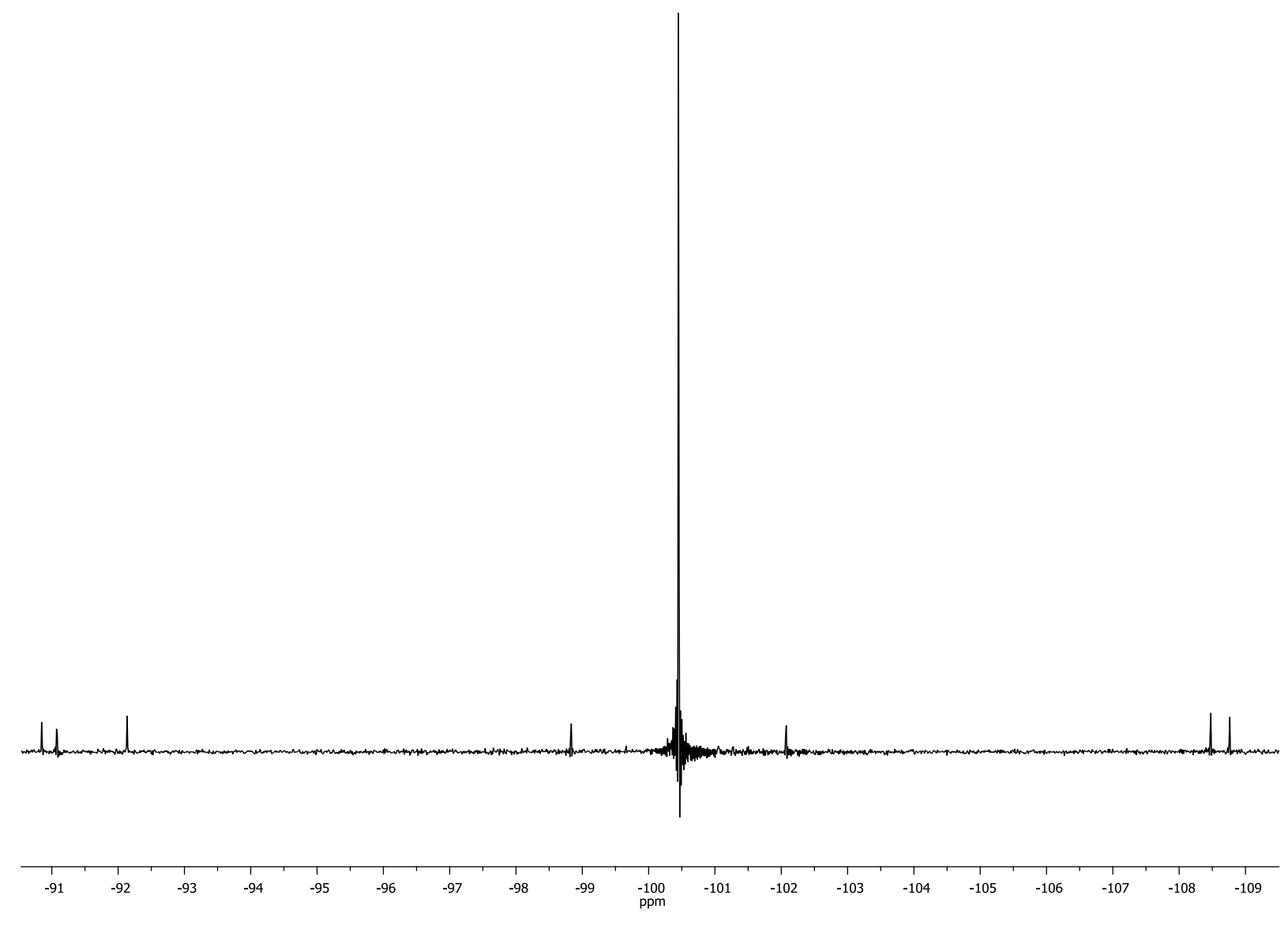

Figure A1.32: Dimethyl stannane region of ${ }^{119} \mathrm{Sn}$ NMR $\left(\mathrm{C}_{6} \mathrm{D}_{6}\right)$ of $\mathbf{1 1}$. 


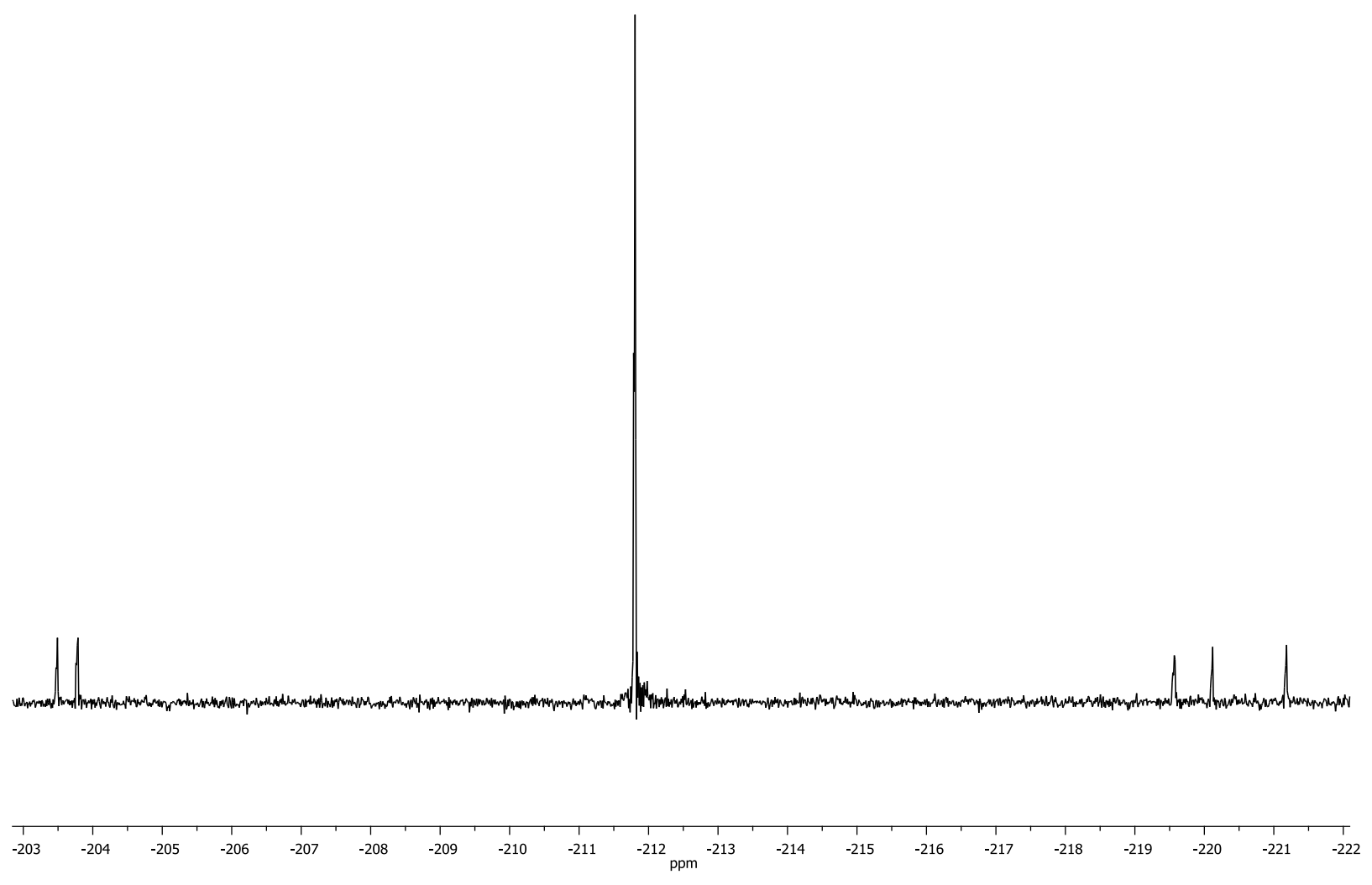

Figure A1.33: Di(n-butyl) stannane region of ${ }^{119} \mathrm{Sn}$ NMR $\left(\mathrm{C}_{6} \mathrm{D}_{6}\right)$ of 11. 


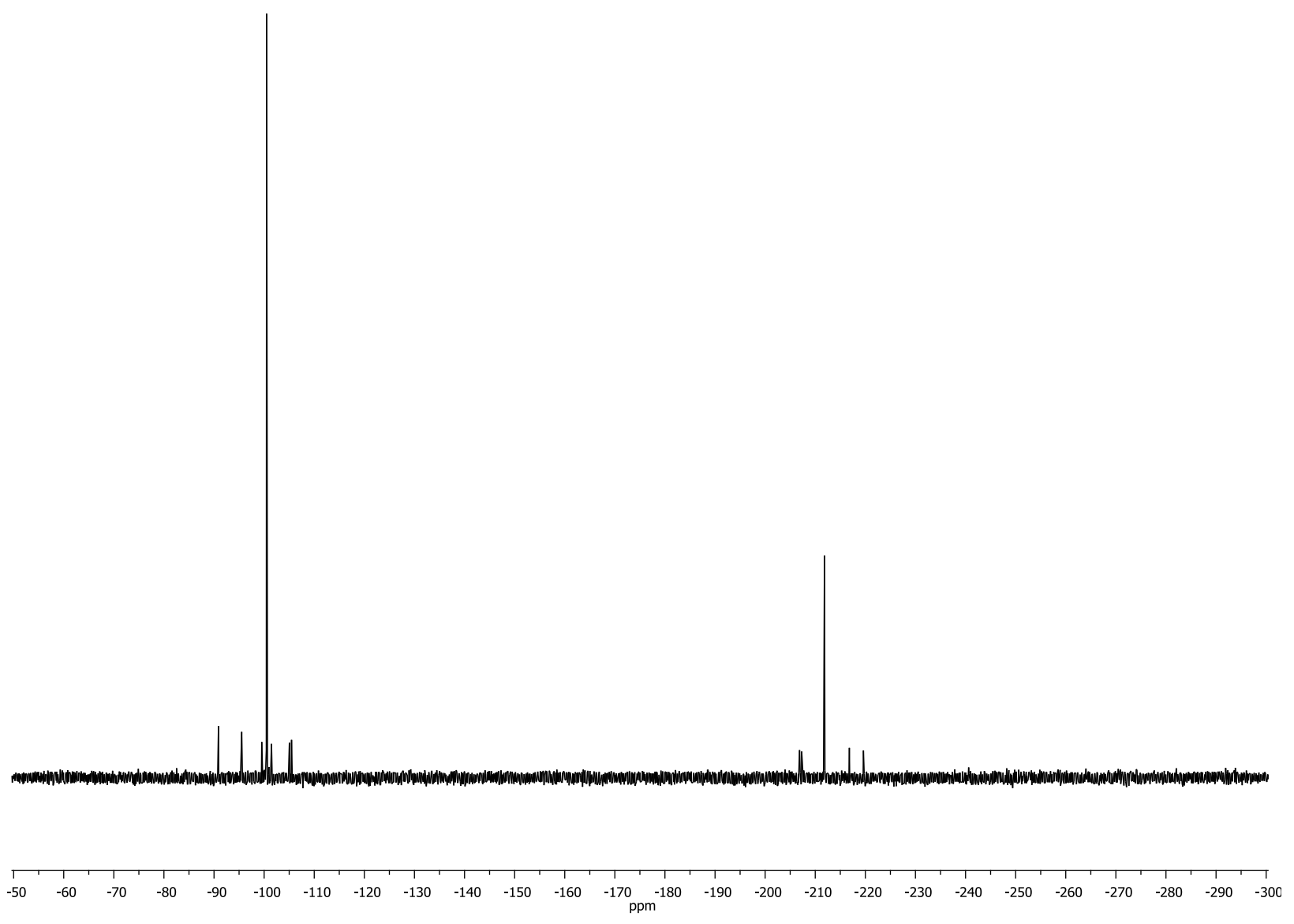

Figure A1.34: ${ }^{117} \mathrm{Sn}$ NMR $\left(\mathrm{C}_{6} \mathrm{D}_{6}\right)$ of 11 run. 


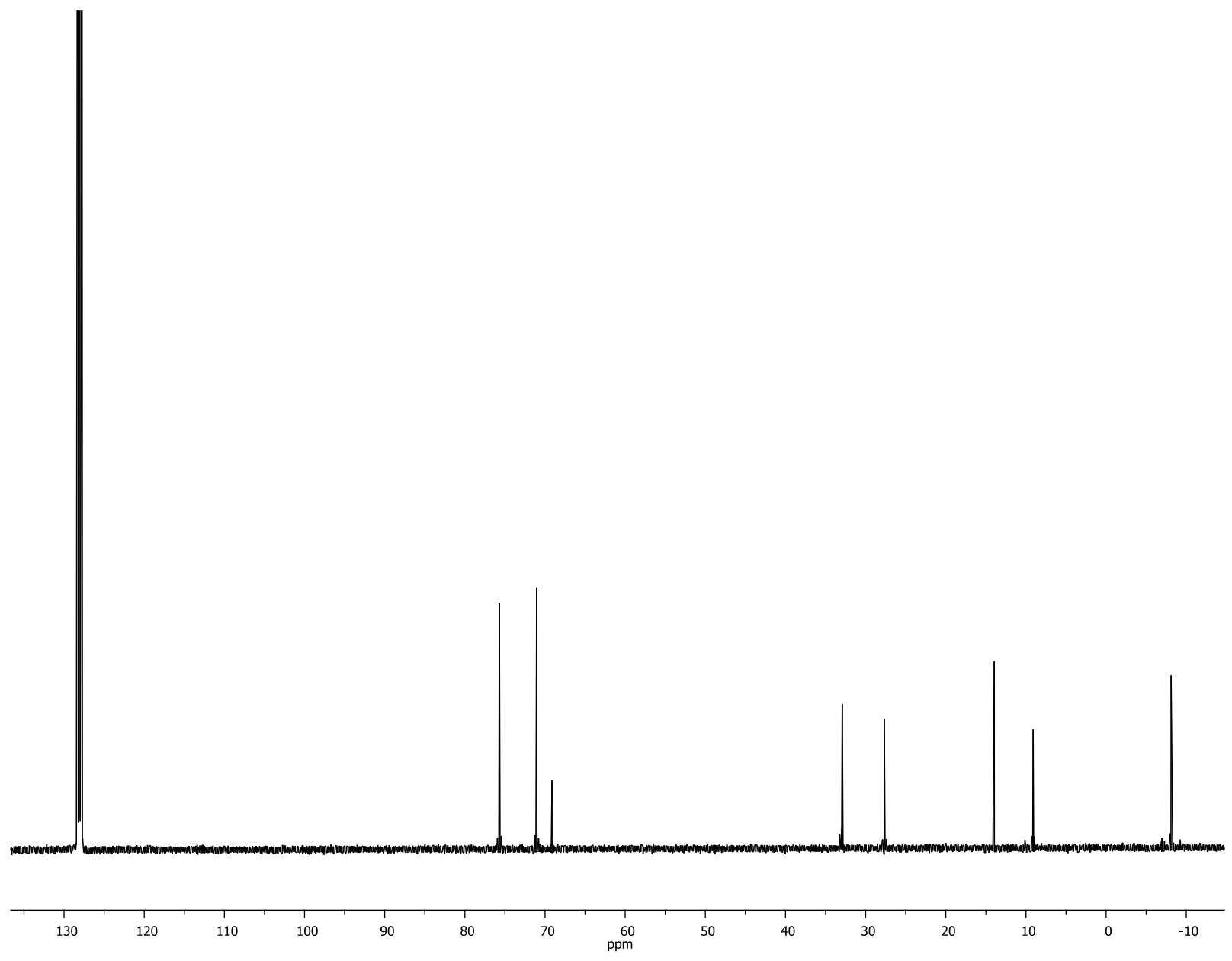

Figure A1.35: ${ }^{13} \mathrm{C}$ NMR $\left(\mathrm{C}_{6} \mathrm{D}_{6}\right)$ of $\mathbf{1 1}$. 


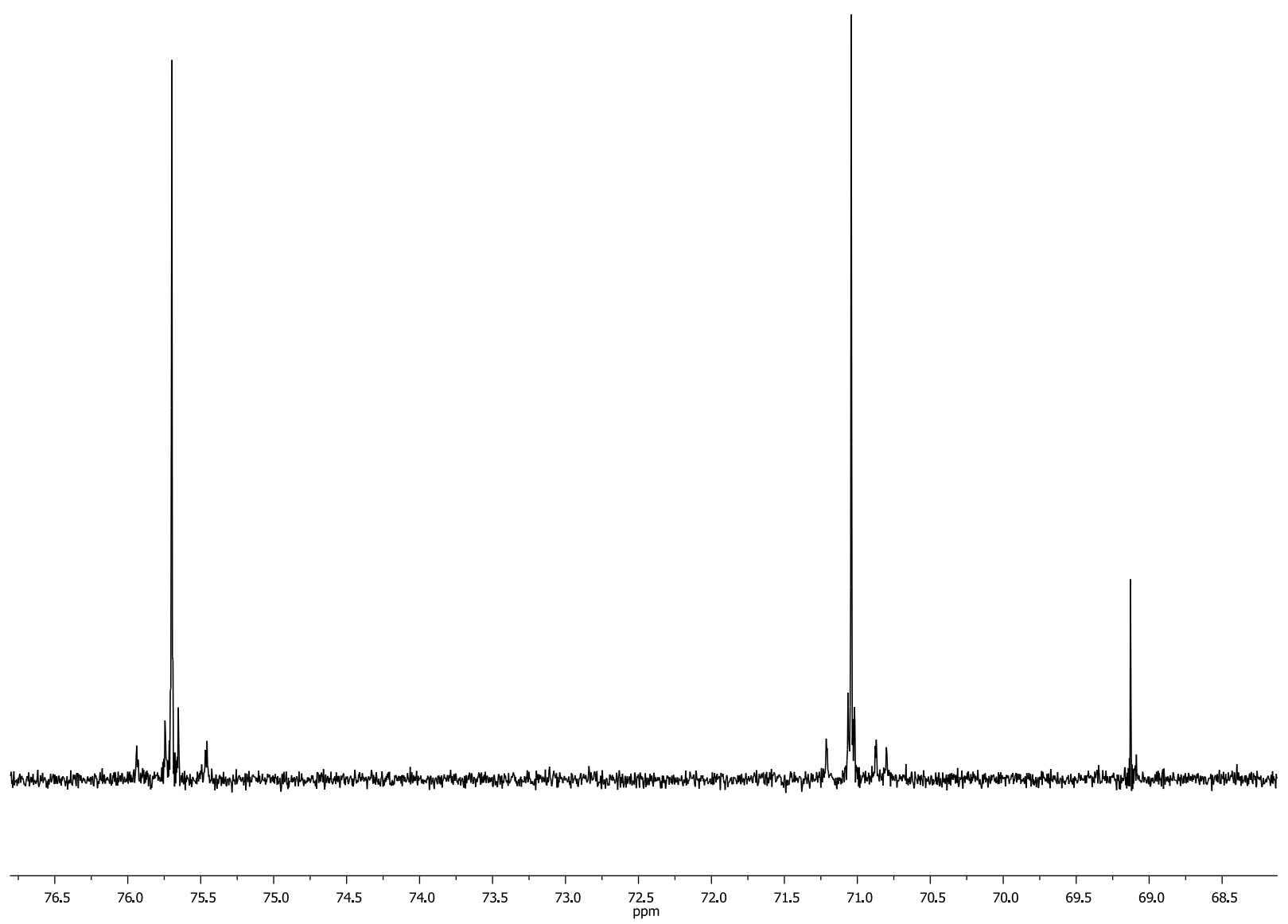

Figure A1.35: Cyclopentadiene region of ${ }^{13} \mathrm{C} N \mathrm{NMR}\left(\mathrm{C}_{6} \mathrm{D}_{6}\right)$ of $\mathbf{1 1}$. 


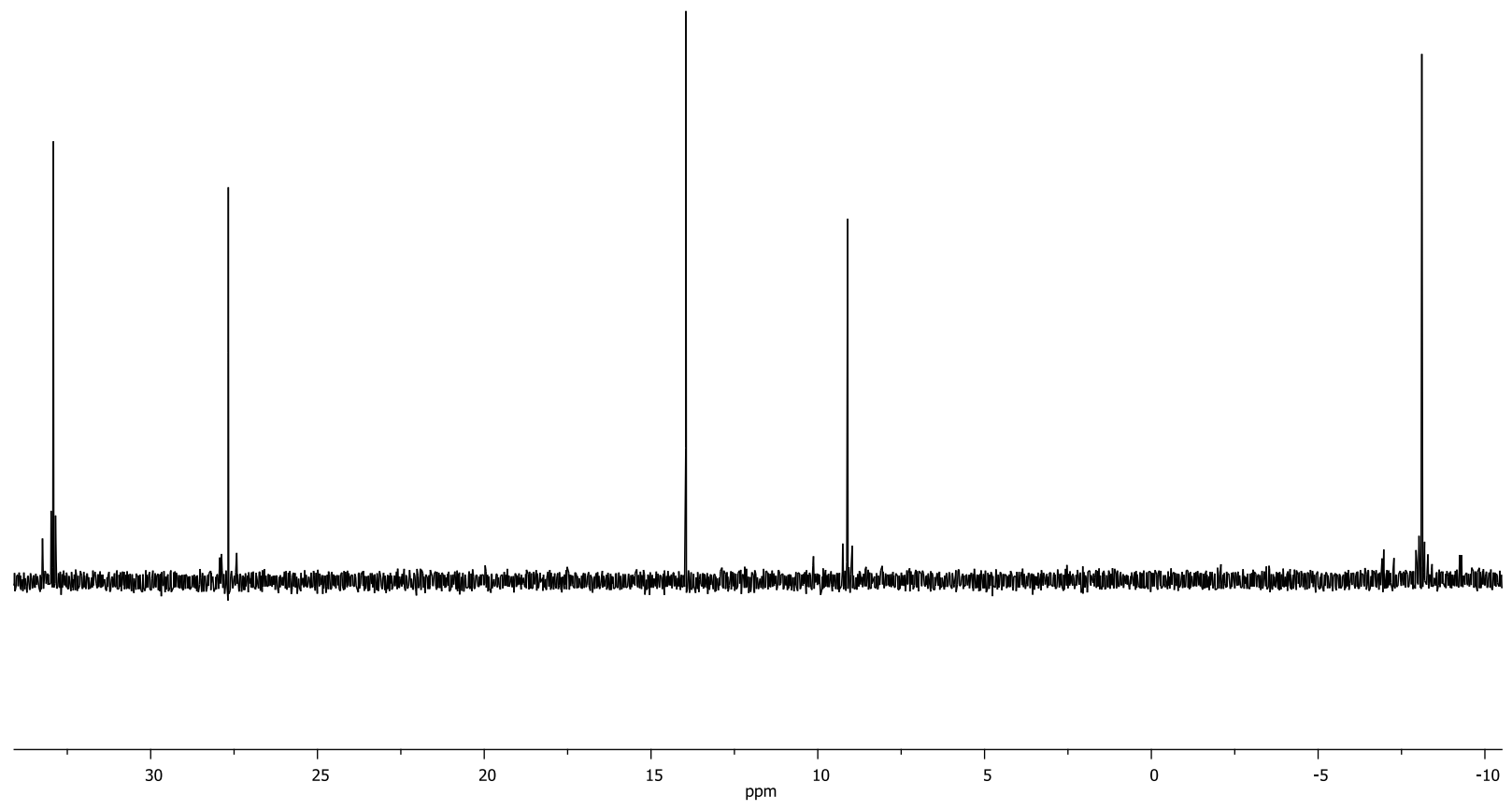

Figure A1.37: Methyl and $n$-butyl region of ${ }^{13} \mathrm{C}$ NMR $\left(\mathrm{C}_{6} \mathrm{D}_{6}\right)$ of $\mathbf{1 1}$. 


\section{Appendix 2: Mass spectrometry}

Table A2.1: Relative abundance for DART-TOF of $\mathbf{1 1}$ at different temperatures (Figures A2.1A2.3) and Skimmer Potentials (Figures A2.4-A2.6).

\begin{tabular}{|c|c|c|c|c|c|c|c|}
\hline$T / C$ & $E / \mathbf{V}$ & $\mathbf{m} / \mathbf{z}$ & $\overline{R A}(\%)$ & $\mathrm{T} / \mathrm{C}$ & $E / \mathbf{V}$ & $\mathbf{m} / \mathbf{z}$ & RA(\%) \\
\hline \multirow[t]{5}{*}{100} & 20 & 498.9 & 100 & 200 & 40 & 498.9 & 88.1 \\
\hline & & 698.9 & N/A & & & 698.9 & 95.6 \\
\hline & & 713.9 & 5.2 & & & 713.9 & 100 \\
\hline & & 1212.8 & 0.1 & & & 1212.8 & 11.1 \\
\hline & & 1428.9 & N/A & & & 1428.9 & 2.0 \\
\hline \multirow[t]{5}{*}{200} & 20 & 498.9 & 100 & 200 & 60 & 498.9 & 75.3 \\
\hline & & 698.9 & 36.7 & & & 698.9 & 1 \\
\hline & & 713.9 & 72.6 & & & 713.9 & 82.5 \\
\hline & & 1212.8 & 10.2 & & & 1212.8 & 3.1 \\
\hline & & 1428.9 & 1.0 & & & 1428.9 & 0.8 \\
\hline \multirow[t]{6}{*}{300} & 20 & 498.9 & 38.2 & 200 & 80 & 498.9 & 46.8 \\
\hline & & 698.9 & 1 & & & 698.9 & 100 \\
\hline & & 713.9 & 94.7 & & & 713.9 & 41.1 \\
\hline & & 1212.8 & 3.8 & & & 1212.8 & 0.5 \\
\hline & & 1428.9 & 3.1 & & & 1428.9 & 0.2 \\
\hline & & 1428.9 & 0.5 & & & & \\
\hline
\end{tabular}




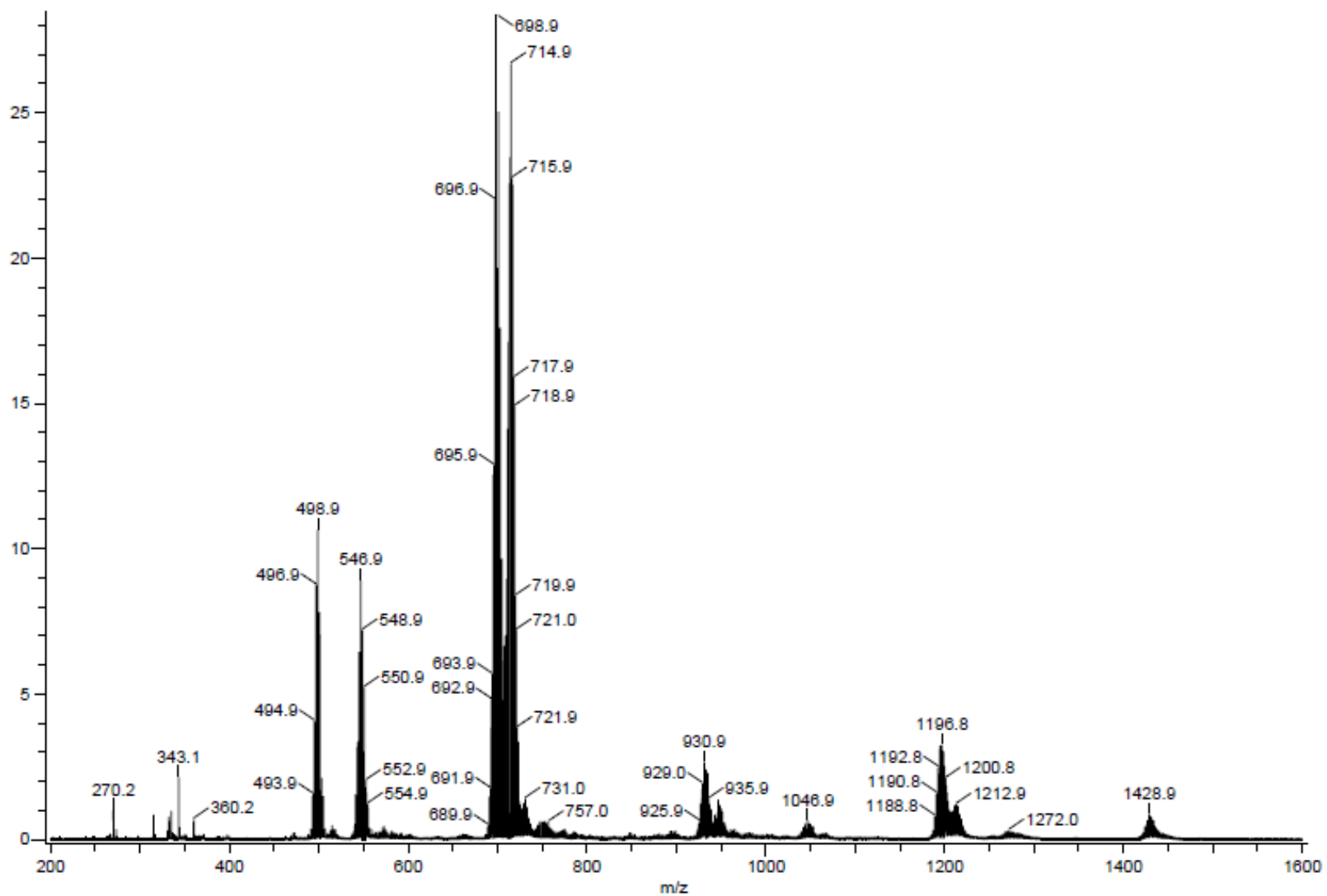

Figure S2.1: DART-TOF of 11 at $300^{\circ} \mathrm{C}, 20 \mathrm{~V}$ 


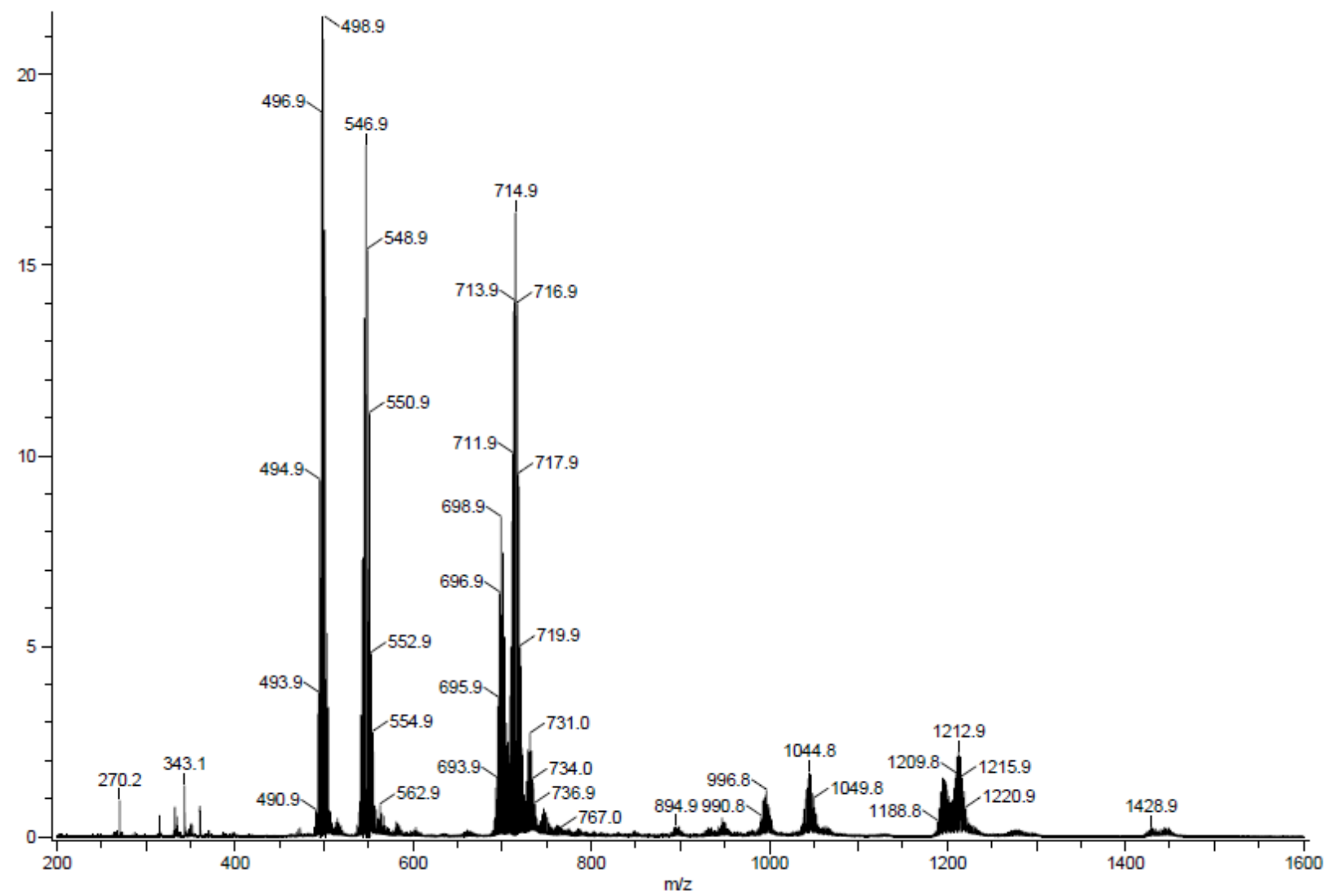

Figure A2.2: DART-MS-TOF of 11 at $200^{\circ} \mathrm{C}, 20 \mathrm{~V}$. 


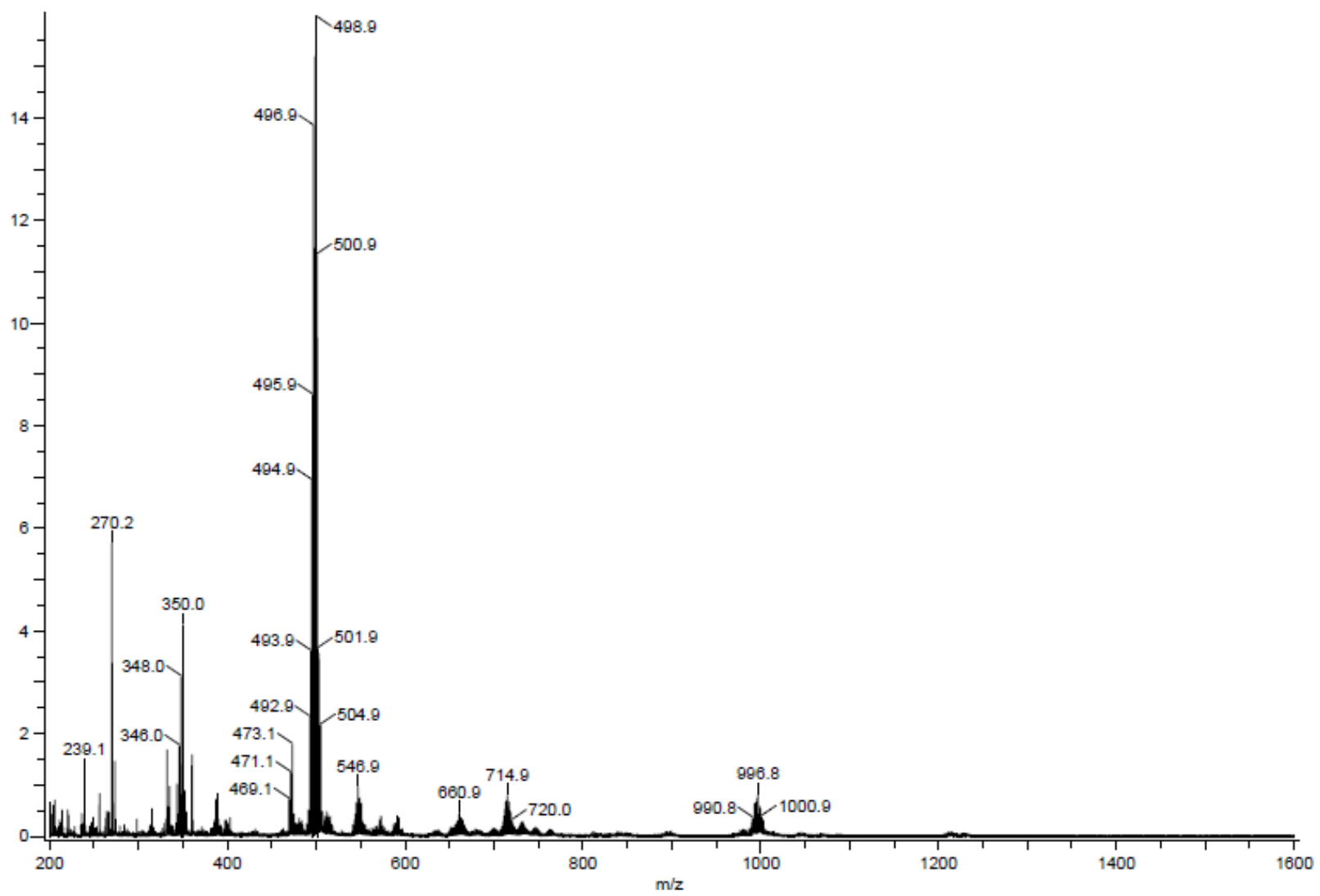

Figure A2.3: DART-MS-TOF of $\mathbf{1 1}$ at $100^{\circ} \mathrm{C}, 20 \mathrm{~V}$. 


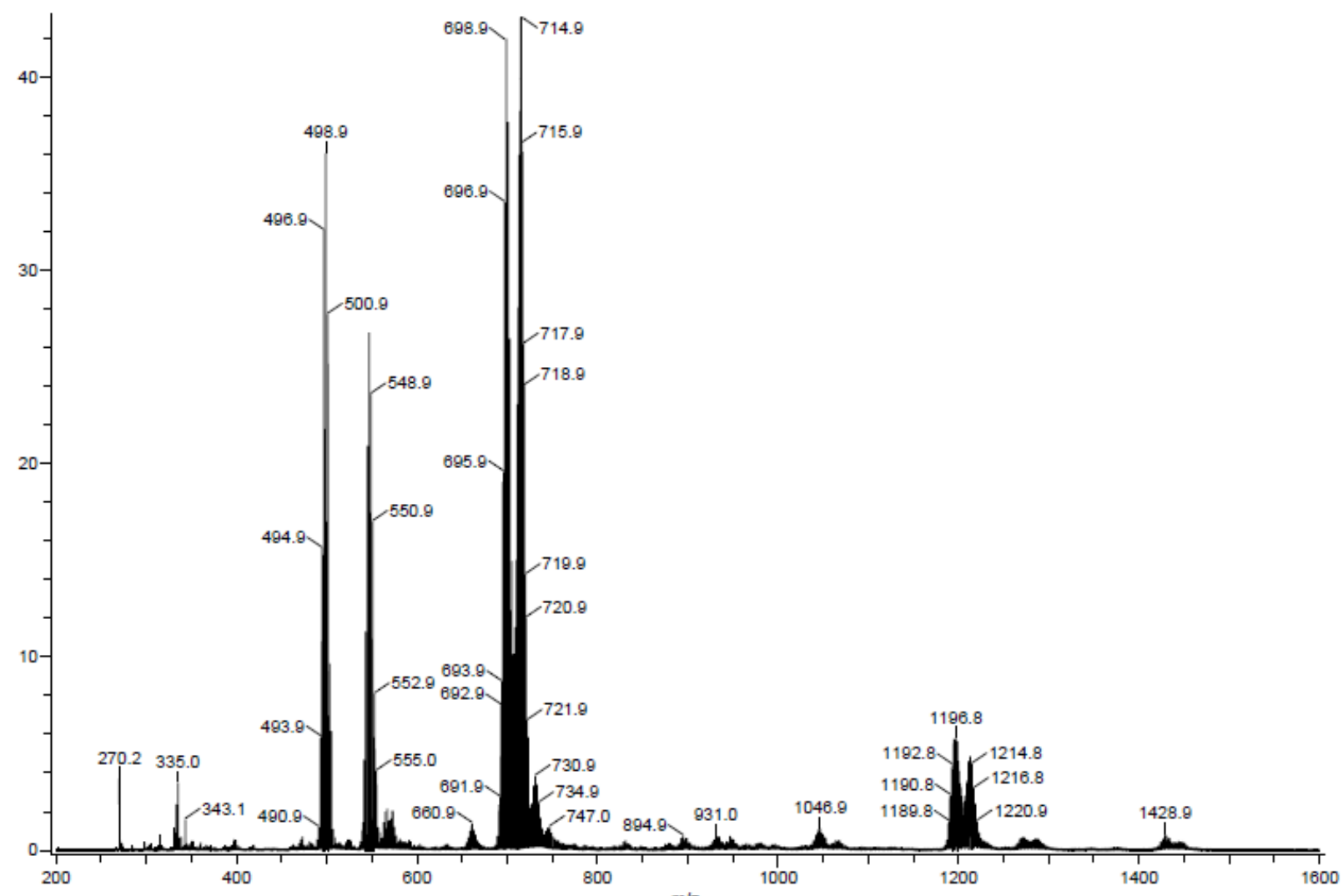

Figure A2.4: DART-MS-TOF of 11 at $200^{\circ} \mathrm{C}, 40 \mathrm{~V}$ 


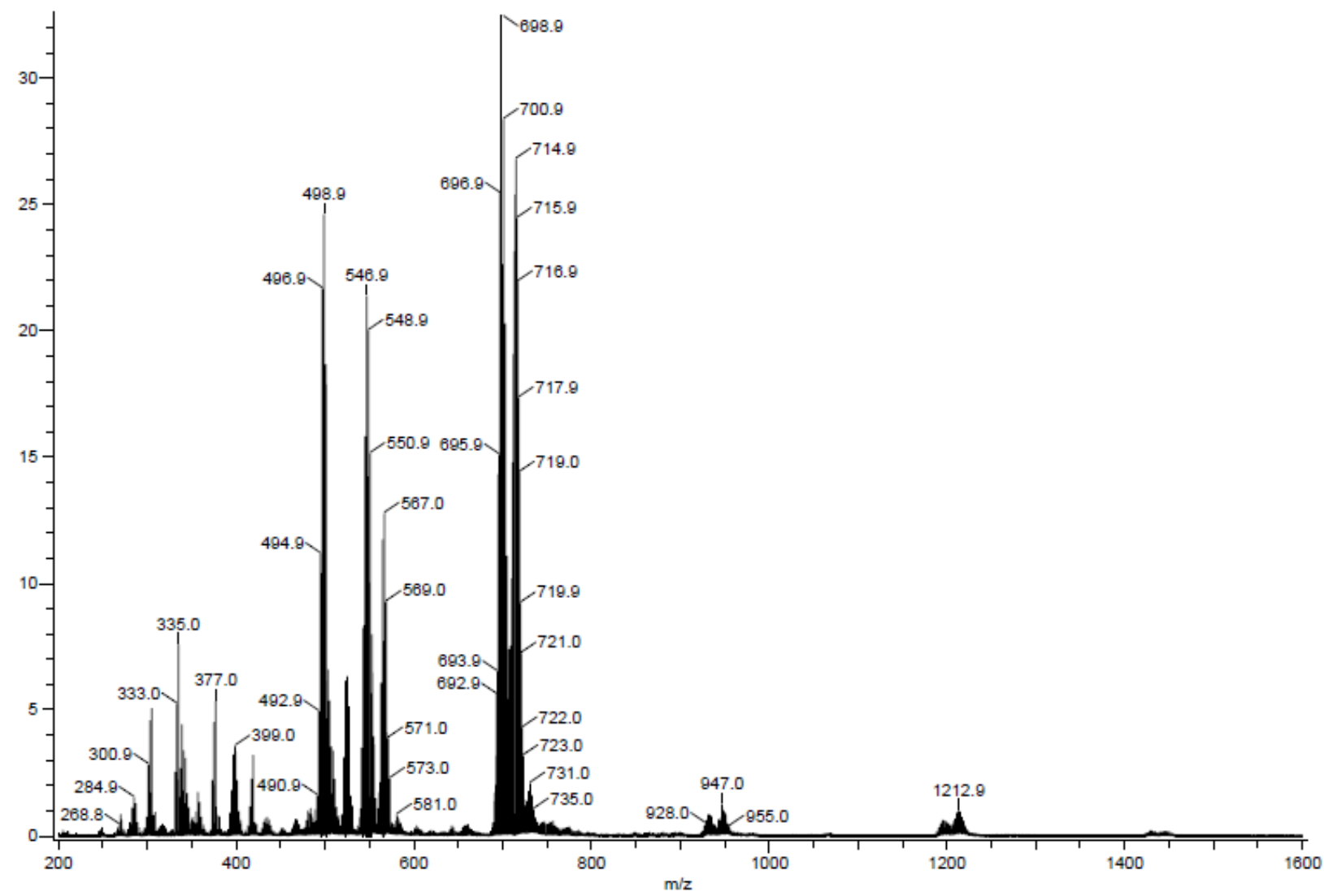

Figure A2.5: DART-MS-TOF of $\mathbf{1 1}$ at $200^{\circ} \mathrm{C}, 60 \mathrm{~V}$. 


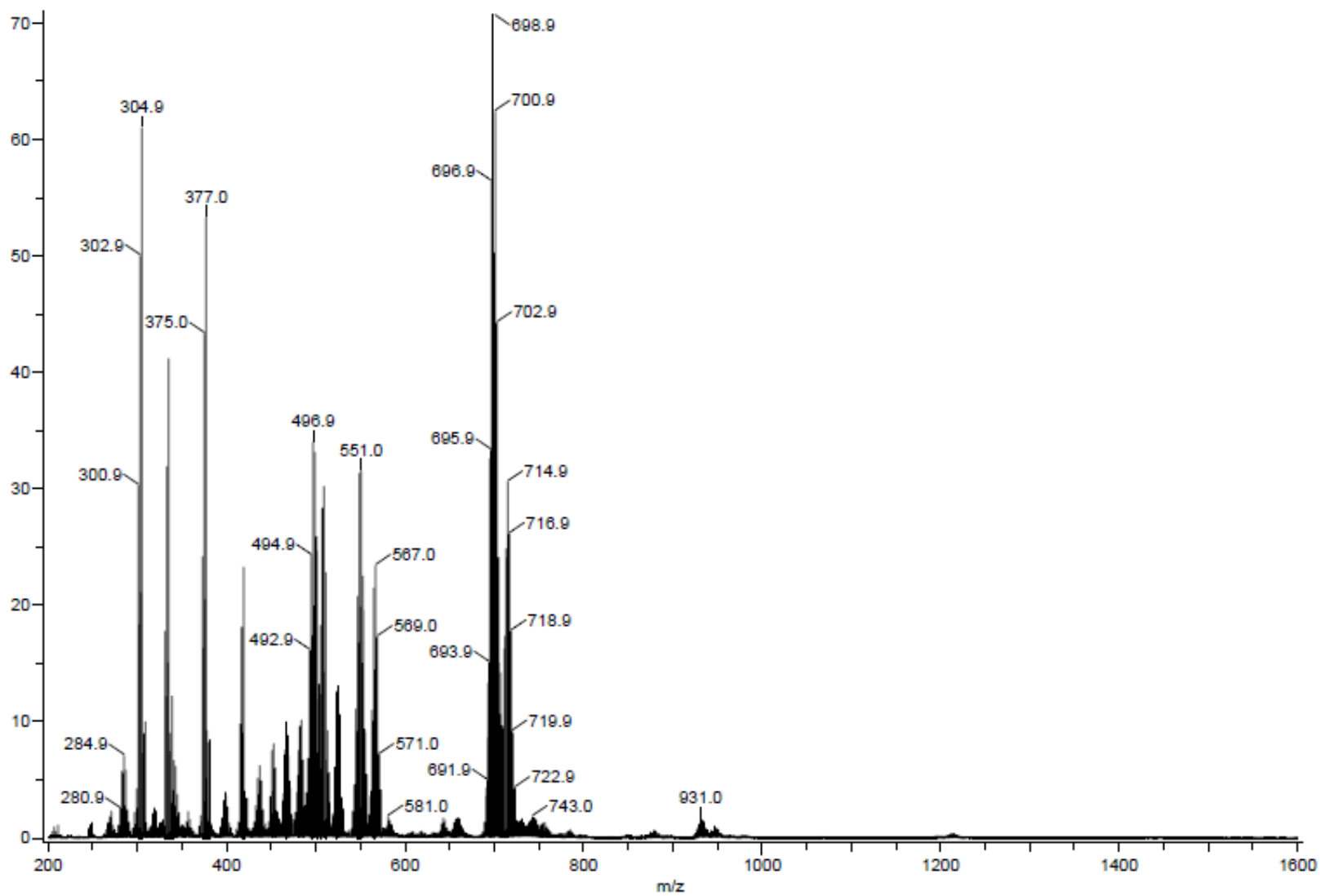

Figure A2.6: DART-MS-TOF of 11 at $200^{\circ} \mathrm{C}, 80 \mathrm{~V}$. 


\section{Appendix 3: Cyclic voltammetry}

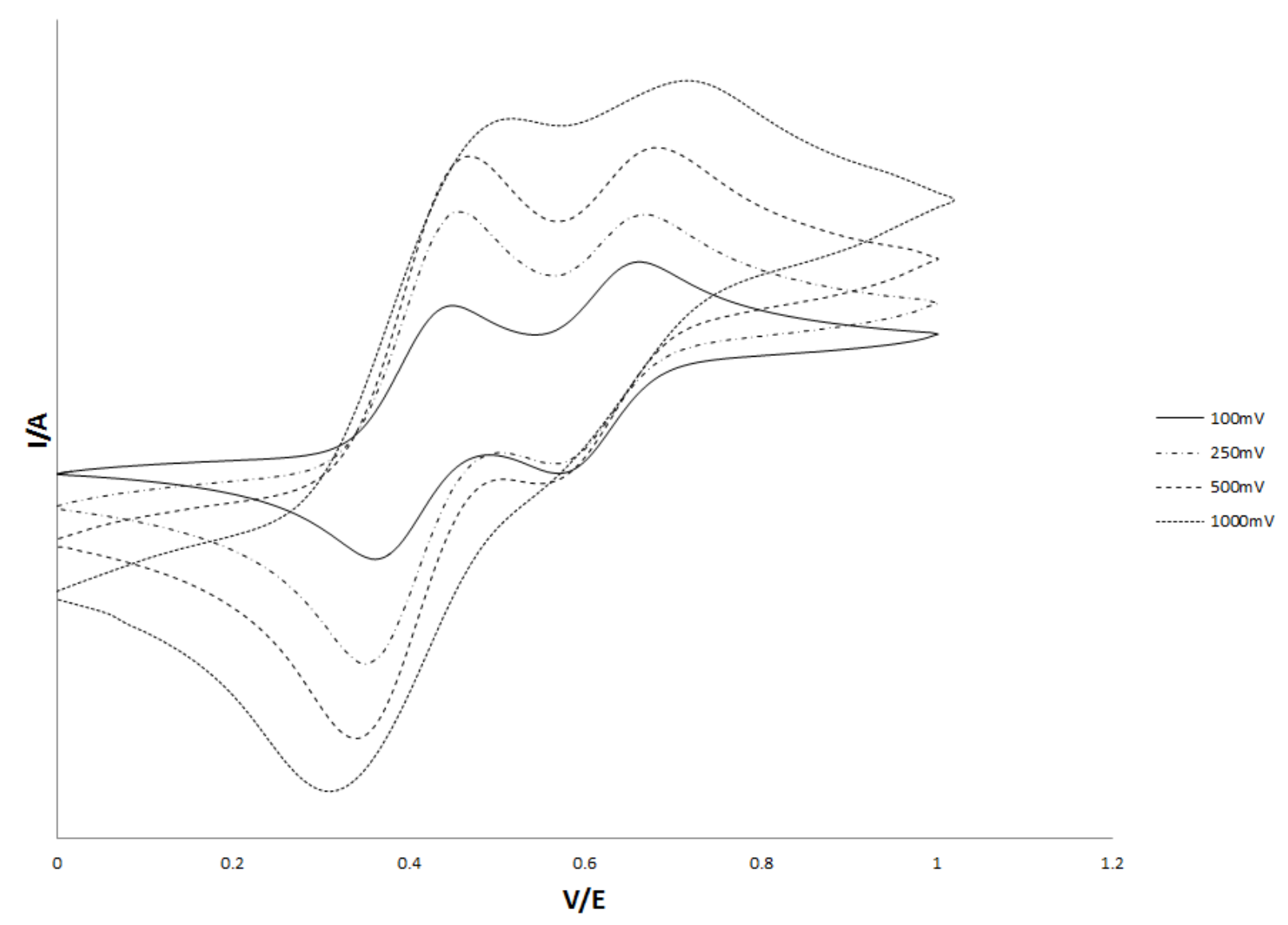

Figure A3.1: Cyclic Voltammetry of compound $\mathbf{1 1}$ at $100 \mathrm{mV}, 250 \mathrm{mV}, 500 \mathrm{mV}$, and $1000 \mathrm{mV}$ scan speeds. 


\section{Appendix 4: Sn NMR simulator program for calculating isotopic intensities}

Instructions: program must be run in python. Programed in python 2.7.

Copy and save this in a text file with the extension .py. in command line load to directory that the file is in and run command "python xxx.py" where xxx is the name of the file.

Values are input into lines 1319-1323

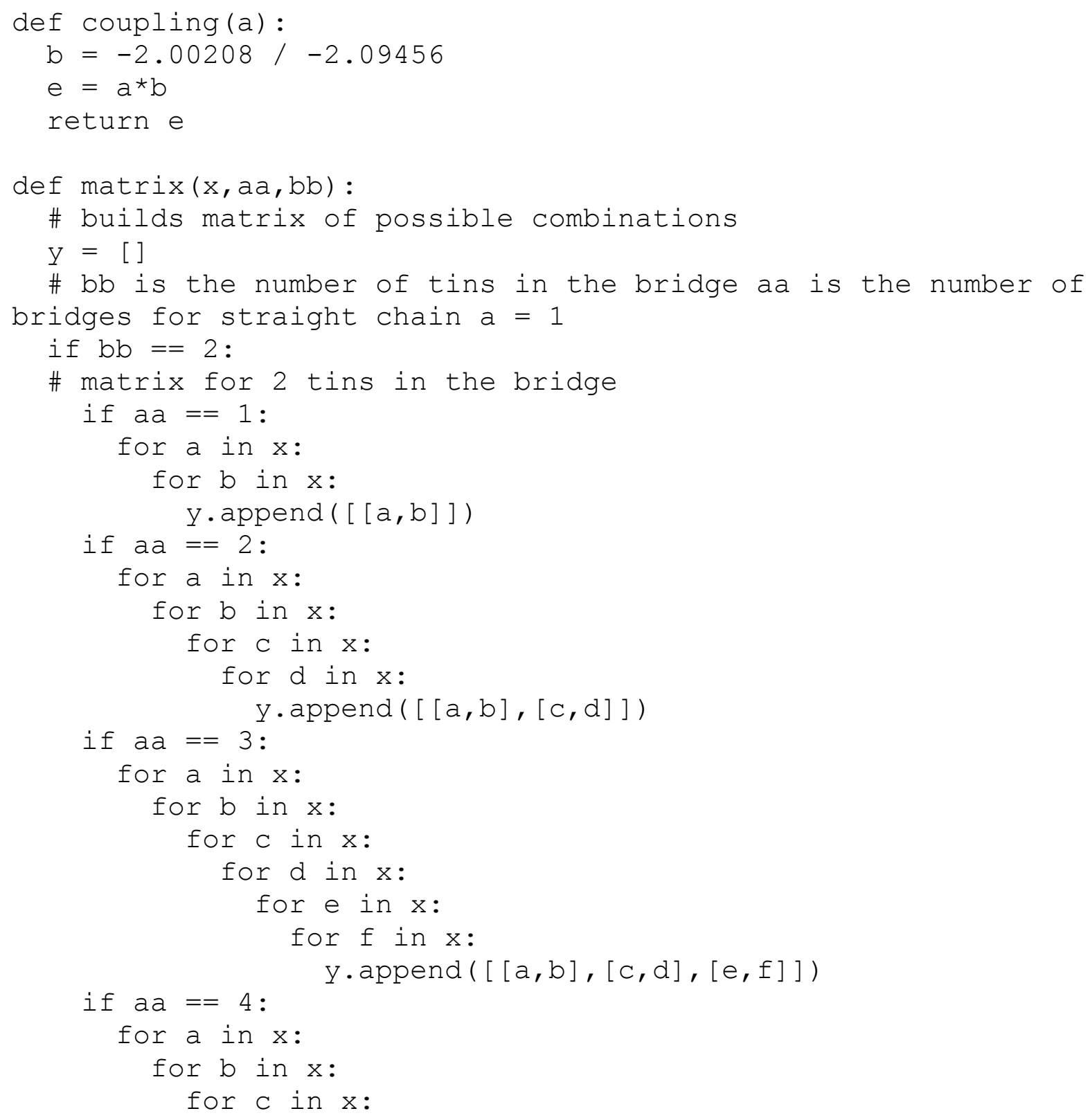




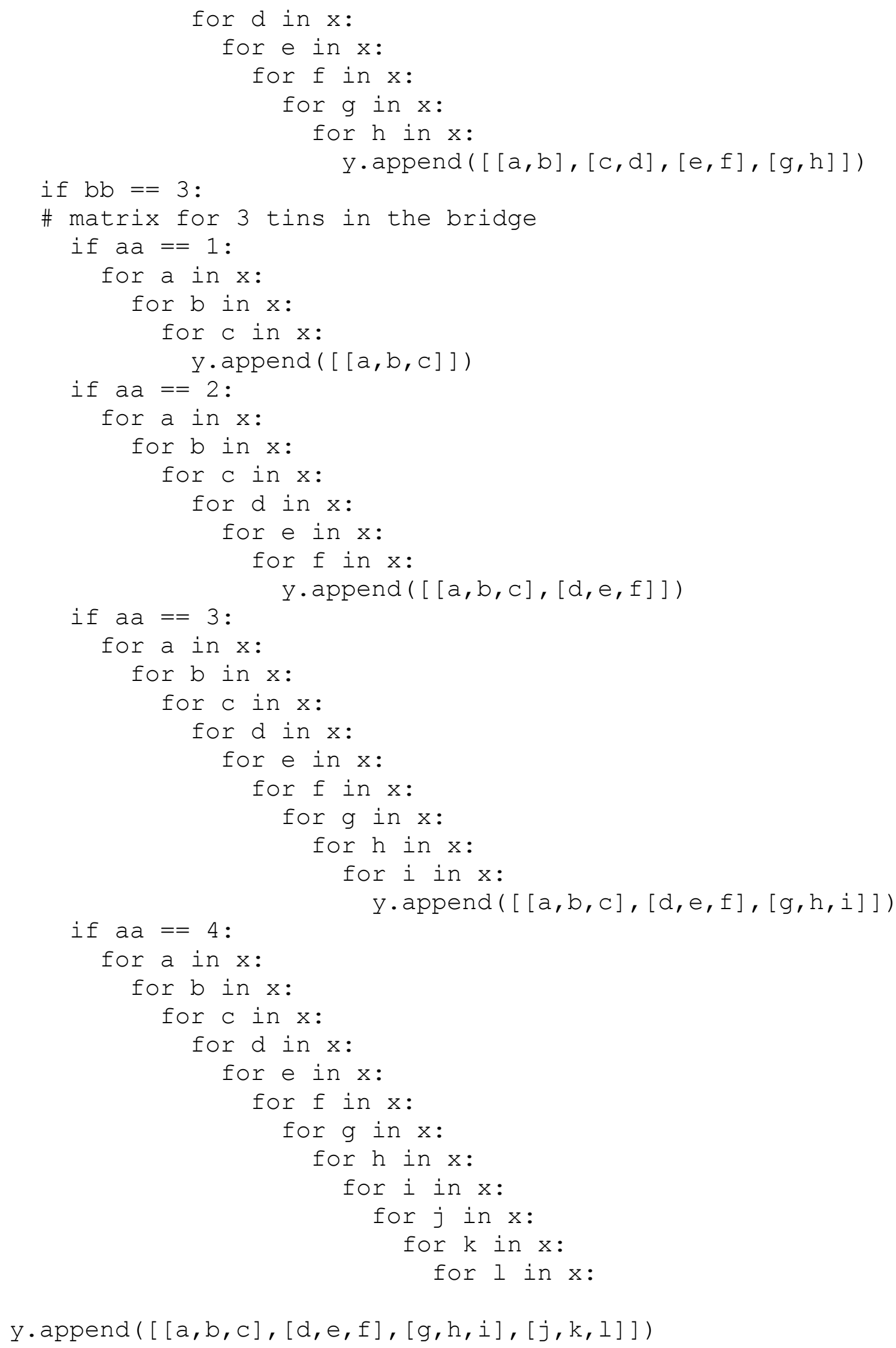




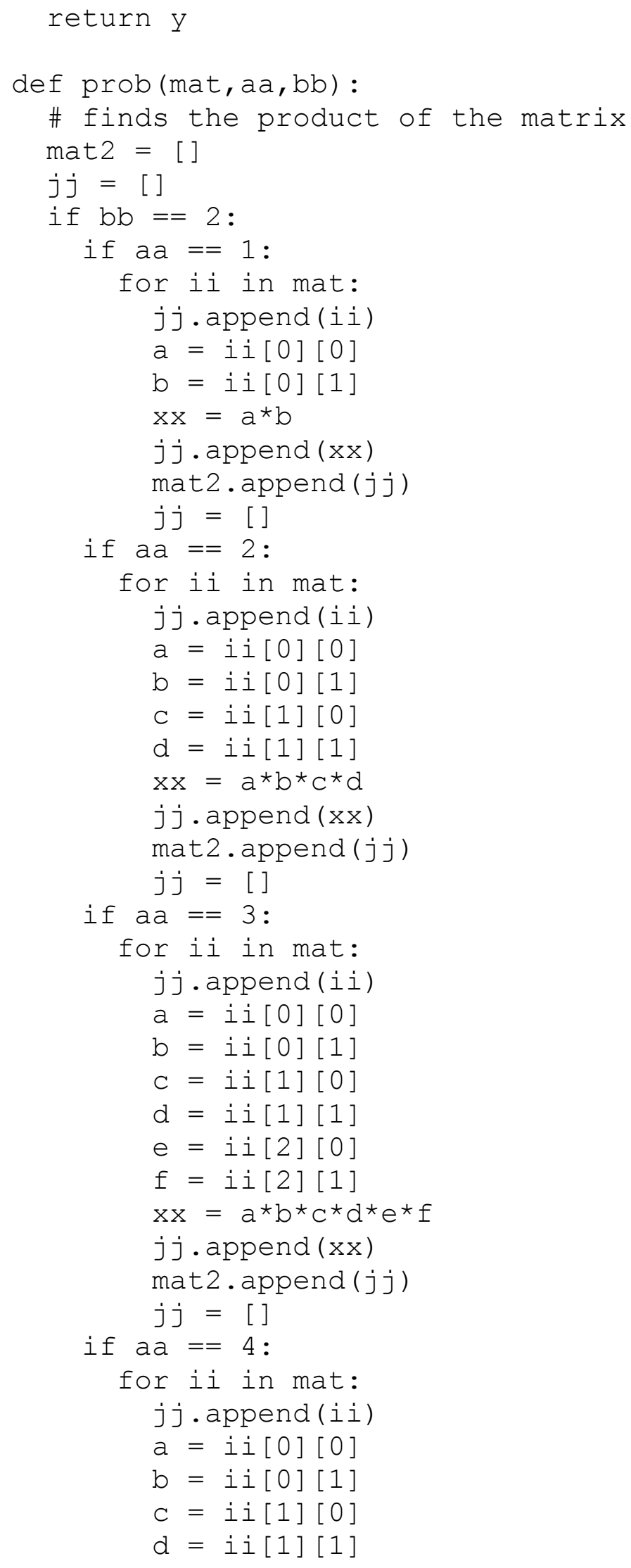




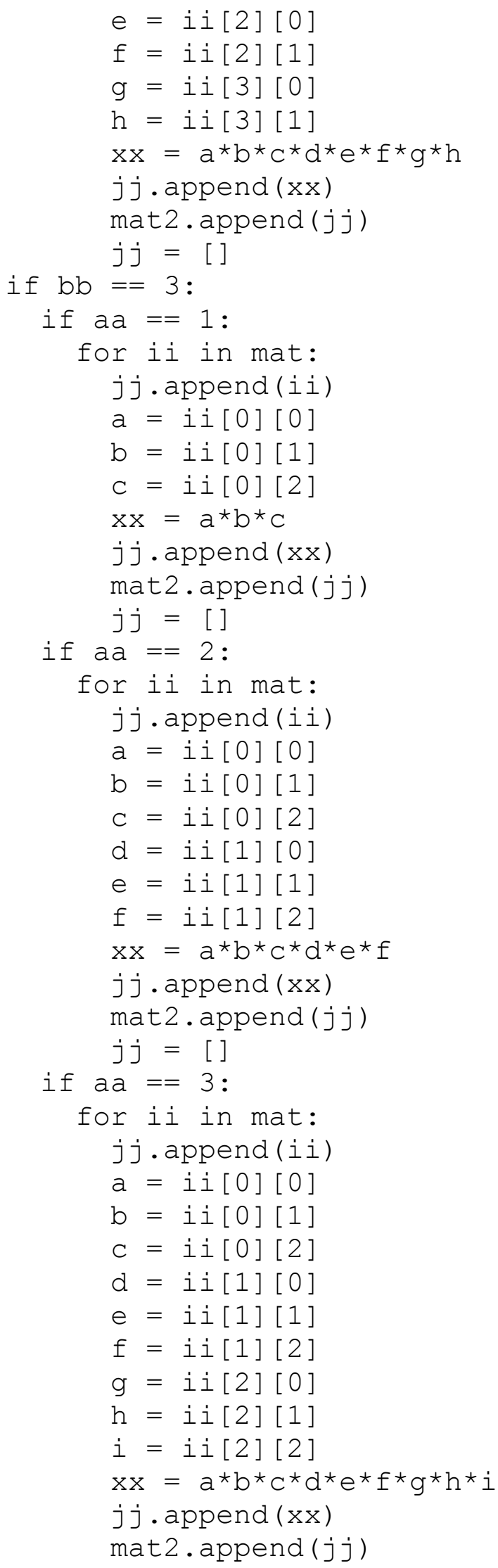




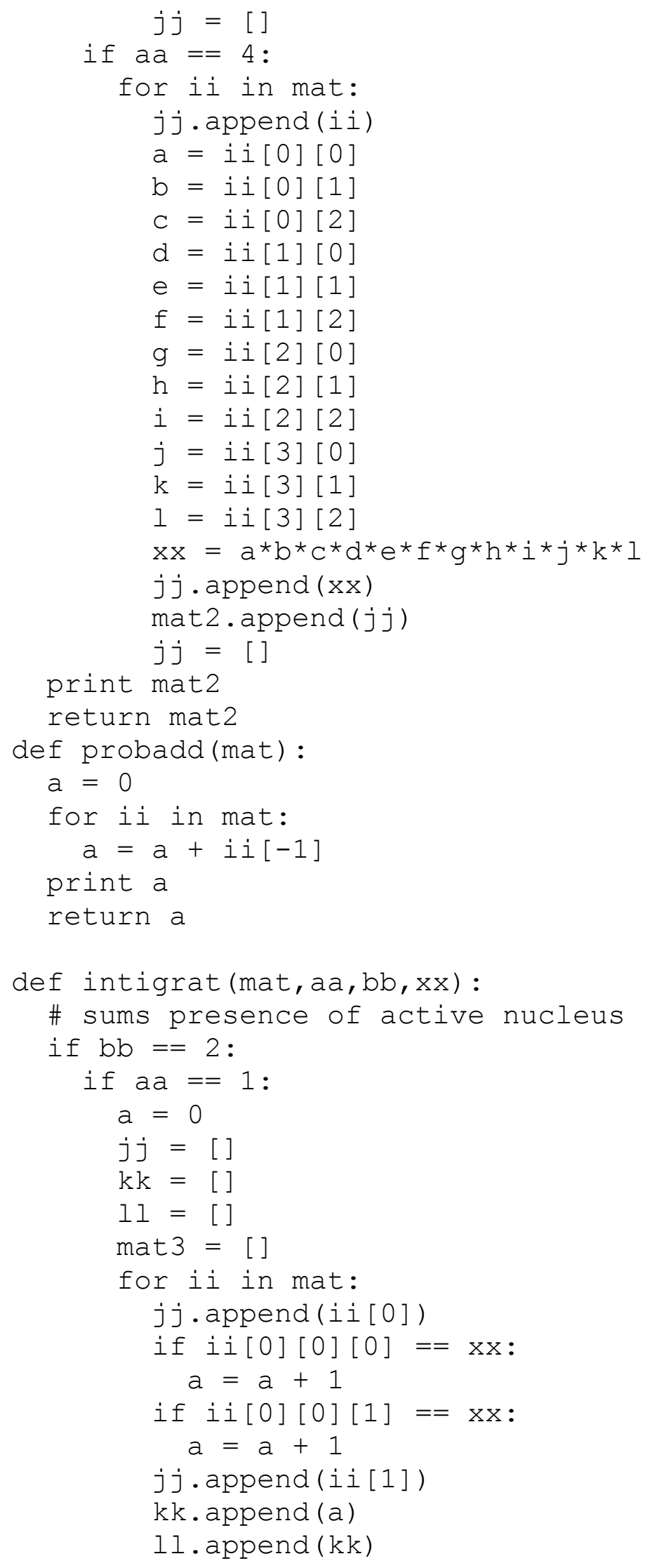




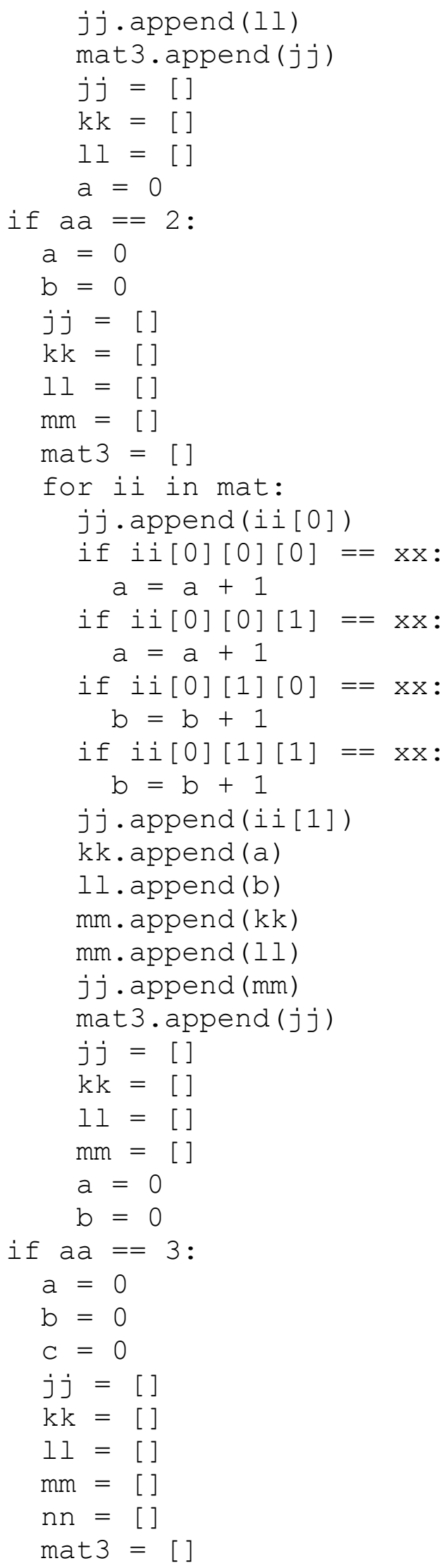




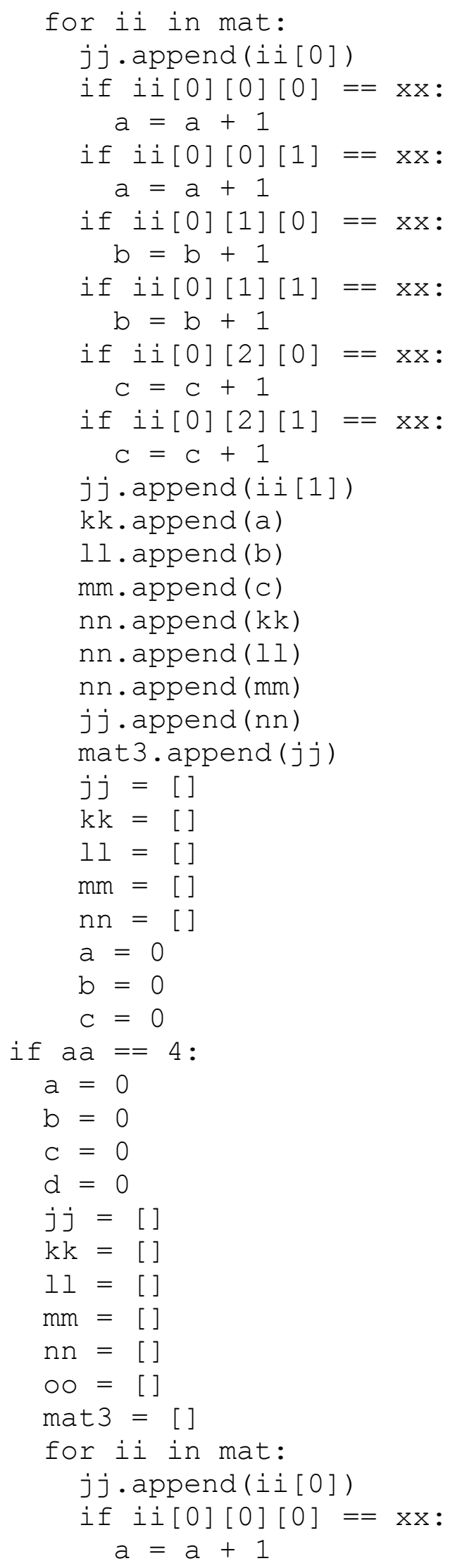




$$
\begin{aligned}
& \text { if ii[0][0][1] }==x x \text { : } \\
& a=a+1 \\
& \text { if ii[0][1][0] }==x x \text { : } \\
& \mathrm{b}=\mathrm{b}+1 \\
& \text { if ii[0][1][1] }==x x \text { : } \\
& \mathrm{b}=\mathrm{b}+1 \\
& \text { if ii[0][2][0] }==x x \text { : } \\
& \mathrm{C}=\mathrm{C}+1 \\
& \text { if ii[0][2][1] }==x x \text { : } \\
& \mathrm{C}=\mathrm{C}+1 \\
& \text { if ii[0][3][0] }==x x \text { : } \\
& d=d+1 \\
& \text { if ii[0][3][1] }==x x \text { : } \\
& \mathrm{d}=\mathrm{d}+1 \\
& \text { jj.append (ii [1]) } \\
& \mathrm{kk} \text {. append (a) } \\
& \text { ll. append (b) } \\
& \text { mm. append (c) } \\
& \text { nn. append (d) } \\
& \text { oo. append (kk) } \\
& \text { o. append (ll) } \\
& \text { o. append (mm) } \\
& \text { o . append ( } \mathrm{nn} \text { ) } \\
& \text { jj.append (oo) } \\
& \text { mat3.append }(j j) \\
& j j=[] \\
& \mathrm{kk}=[] \\
& 11=[] \\
& \mathrm{mm}=[] \\
& \mathrm{nn}=[] \\
& \text { o }=[] \\
& a=0 \\
& \mathrm{~b}=0 \\
& \mathrm{c}=0 \\
& \mathrm{~d}=0 \\
& \text { if } \mathrm{bb}==3 \text { : } \\
& \text { if } \mathrm{aa}==1 \text { : } \\
& a=0 \\
& \mathrm{~b}=0 \\
& j j=[] \\
& \mathrm{kk}=[] \\
& l 1=[] \\
& \operatorname{mat} 3=[] \\
& \text { for ii in mat: } \\
& \text { jj.append (ii[0]) } \\
& \text { if ii[0][0][0] }==x x \text { : } \\
& a=a+1
\end{aligned}
$$




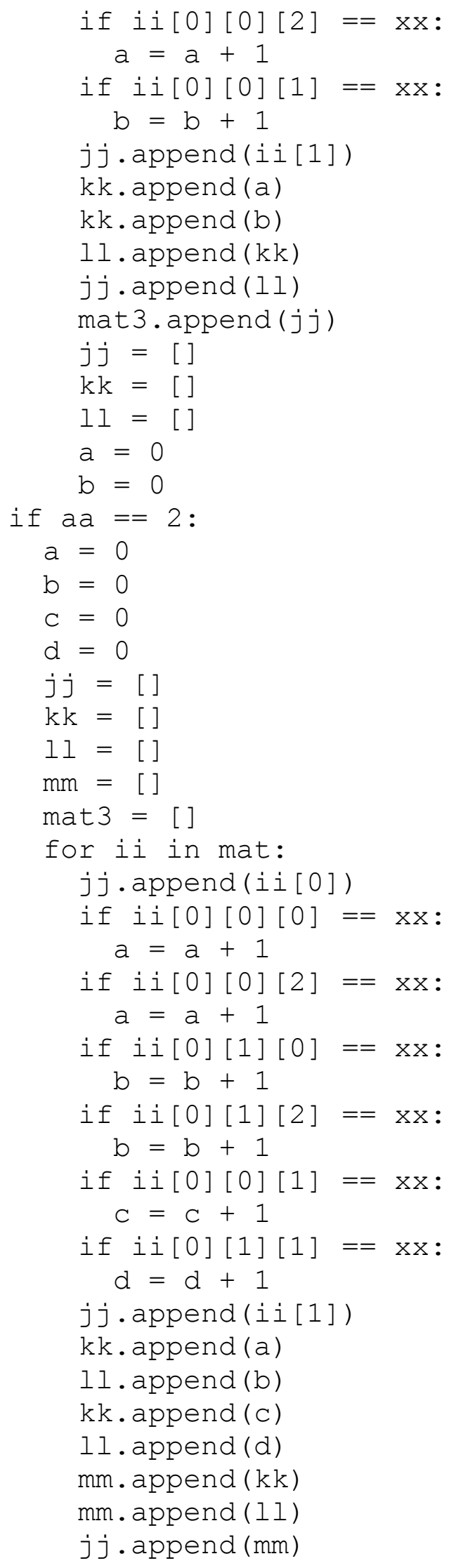




$$
\begin{aligned}
& \text { mat3. append }(j j) \\
& j j=[] \\
& \mathrm{kk}=[] \\
& l 1=[] \\
& \mathrm{mm}=[] \\
& \mathrm{a}=0 \\
& \mathrm{~b}=0 \\
& c=0 \\
& \mathrm{~d}=0 \\
& \text { if } \mathrm{a} a==3 \text { : } \\
& a=0 \\
& \mathrm{~b}=0 \\
& \mathrm{c}=0 \\
& \mathrm{~d}=0 \\
& e=0 \\
& \mathrm{f}=0 \\
& j j=[] \\
& \mathrm{kk}=[] \\
& l 1=[] \\
& \mathrm{mm}=[] \\
& \mathrm{nn}=[] \\
& \text { mat3 = [ ] } \\
& \text { for ii in mat: } \\
& \text { jj.append (ii[0]) } \\
& \text { if ii[0][0][0] }==x x \text { : } \\
& a=a+1 \\
& \text { if ii[0][0][2] }==x x \text { : } \\
& a=a+1 \\
& \text { if ii[0][1][0] }==x x \text { : } \\
& \mathrm{b}=\mathrm{b}+1 \\
& \text { if ii[0][1][2] == } x x \text { : } \\
& \mathrm{b}=\mathrm{b}+1 \\
& \text { if ii[0][2][0] }==x x \text { : } \\
& \mathrm{C}=\mathrm{C}+1 \\
& \text { if ii[0][2][2] }==x x \text { : } \\
& \mathrm{C}=\mathrm{C}+1 \\
& \text { if ii[0][0][1] }==x x \text { : } \\
& d=d+1 \\
& \text { if ii[0][1][1] == } x x \text { : } \\
& e=e+1 \\
& \text { if ii[0][2][1] }==x x \text { : } \\
& f=f+1 \\
& \text { jj.append (ii [1]) } \\
& \text { kk. append (a) } \\
& \text { ll. append (b) } \\
& \text { mm. append (c) } \\
& \mathrm{kk} \text {. append }(\mathrm{d})
\end{aligned}
$$




$$
\begin{aligned}
& 11 . \text { append }(e) \\
& \mathrm{mm} \text {. append (f) } \\
& \mathrm{nn} \text {. append (kk) } \\
& \text { nn. append (ll) } \\
& \mathrm{nn} \text {. append (mm) } \\
& j j \cdot \text { append }(n n) \\
& \text { mat3. append }(j j) \\
& j j=[] \\
& \mathrm{kk}=[] \\
& 11=[] \\
& \mathrm{mm}=[] \\
& \mathrm{nn}=[] \\
& a=0 \\
& \mathrm{~b}=0 \\
& c=0 \\
& \mathrm{~d}=0 \\
& e=0 \\
& \mathrm{f}=0 \\
& \text { if } \mathrm{a} a=4 \text { : } \\
& a=0 \\
& \mathrm{~b}=0 \\
& c=0 \\
& \mathrm{~d}=0 \\
& \mathrm{e}=0 \\
& \mathrm{f}=0 \\
& g=0 \\
& \mathrm{~h}=0 \\
& j j=[] \\
& \mathrm{kk}=[] \\
& l 1=[] \\
& \mathrm{mm}=[] \\
& \mathrm{nn}=[] \\
& \text { o }=[] \\
& \text { mat3 }=\text { [] } \\
& \text { for ii in mat: } \\
& \text { jj.append (ii[0]) } \\
& \text { if ii[0][0][0] }==x x \text { : } \\
& a=a+1 \\
& \text { if ii[0][0][2] }==x x \text { : } \\
& a=a+1 \\
& \text { if ii[0][1][0] = } x x \text { : } \\
& \mathrm{b}=\mathrm{b}+1 \\
& \text { if ii[0][1][2] }==x x \text { : } \\
& \mathrm{b}=\mathrm{b}+1 \\
& \text { if ii[0][2][0] = } x x \text { : } \\
& \mathrm{C}=\mathrm{C}+1 \\
& \text { if ii[0][2][2] }==x x \text { : }
\end{aligned}
$$




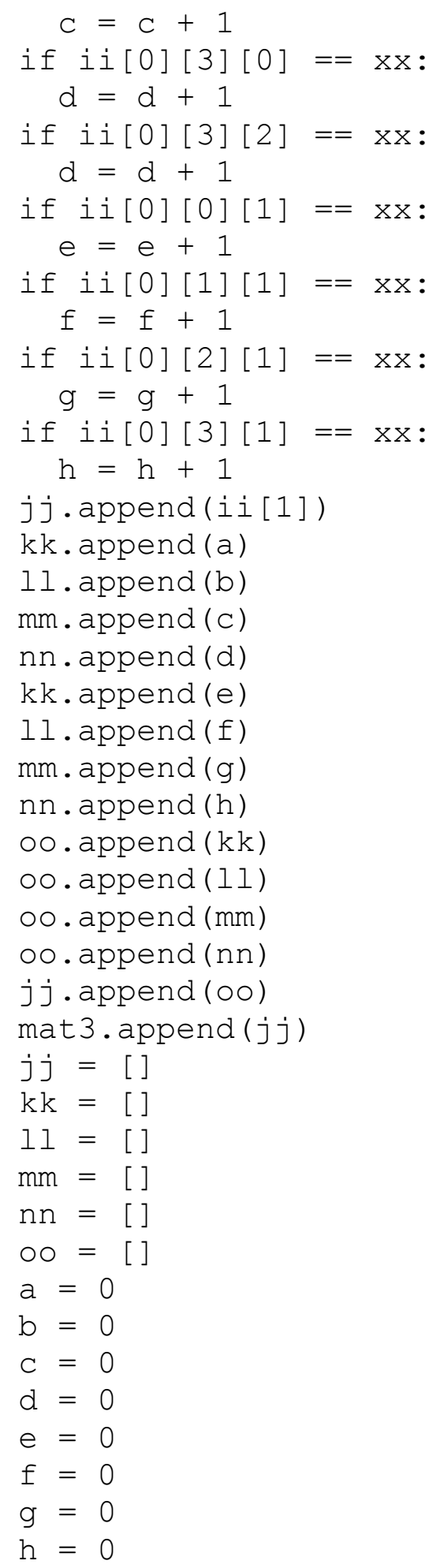




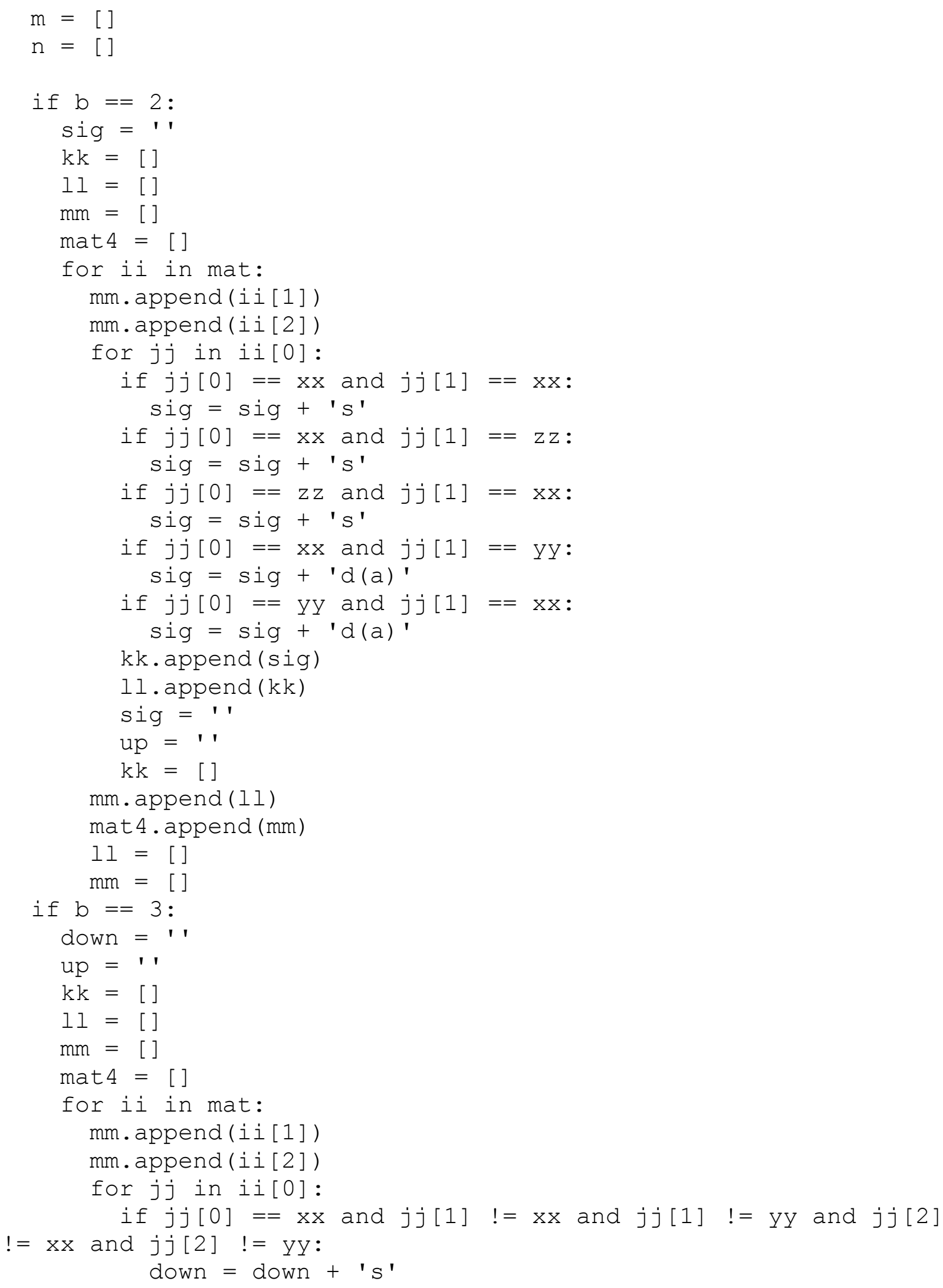




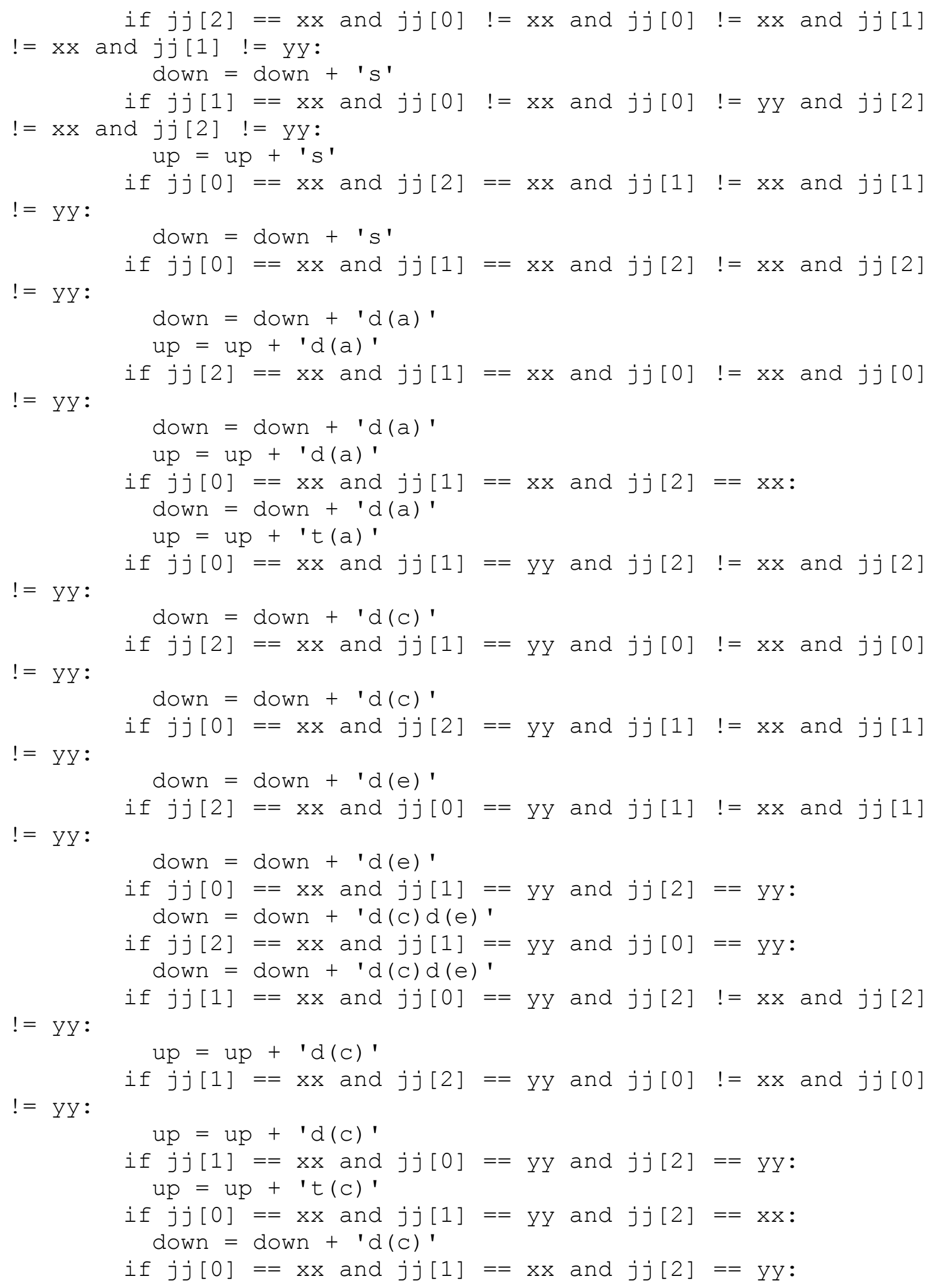




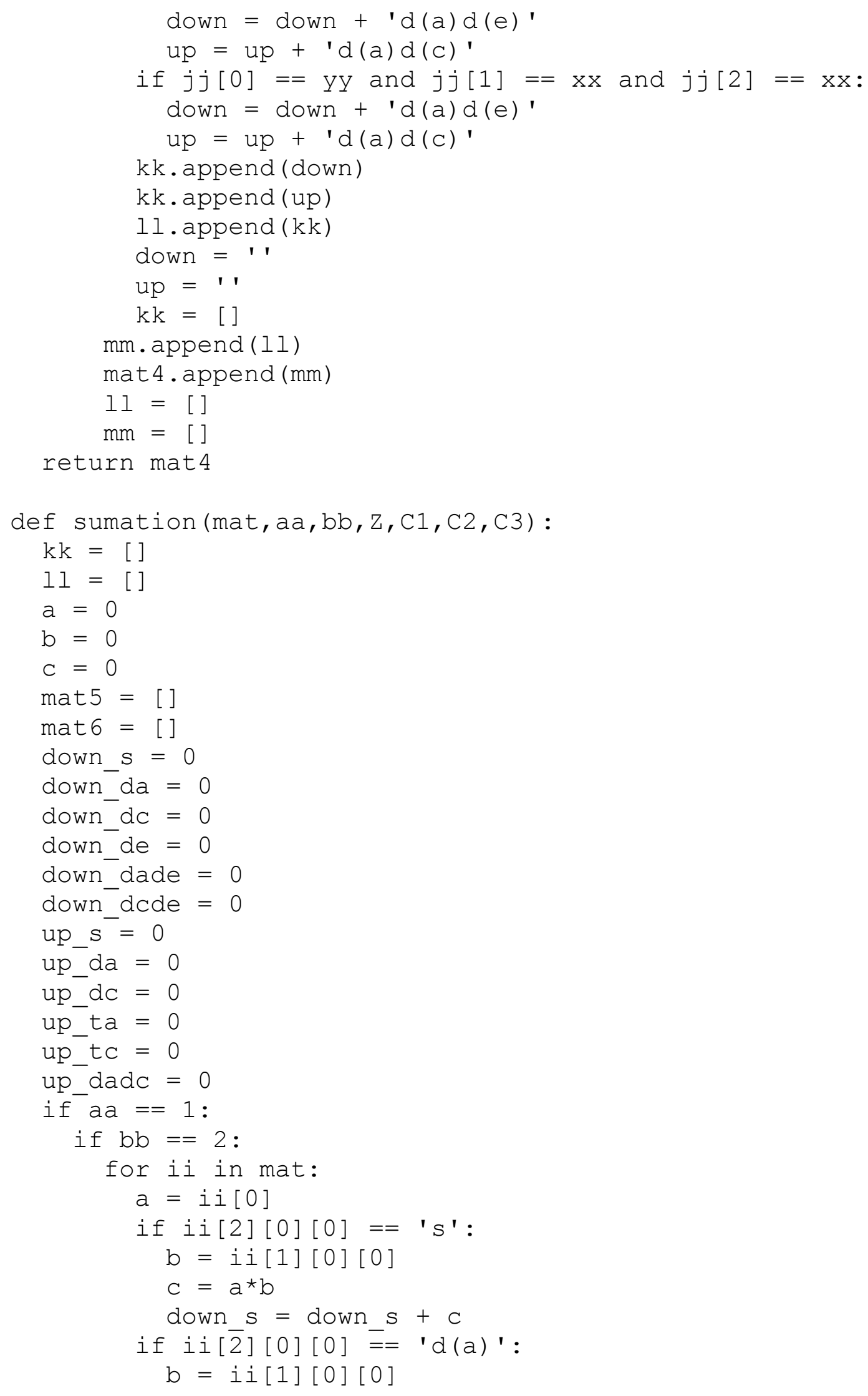




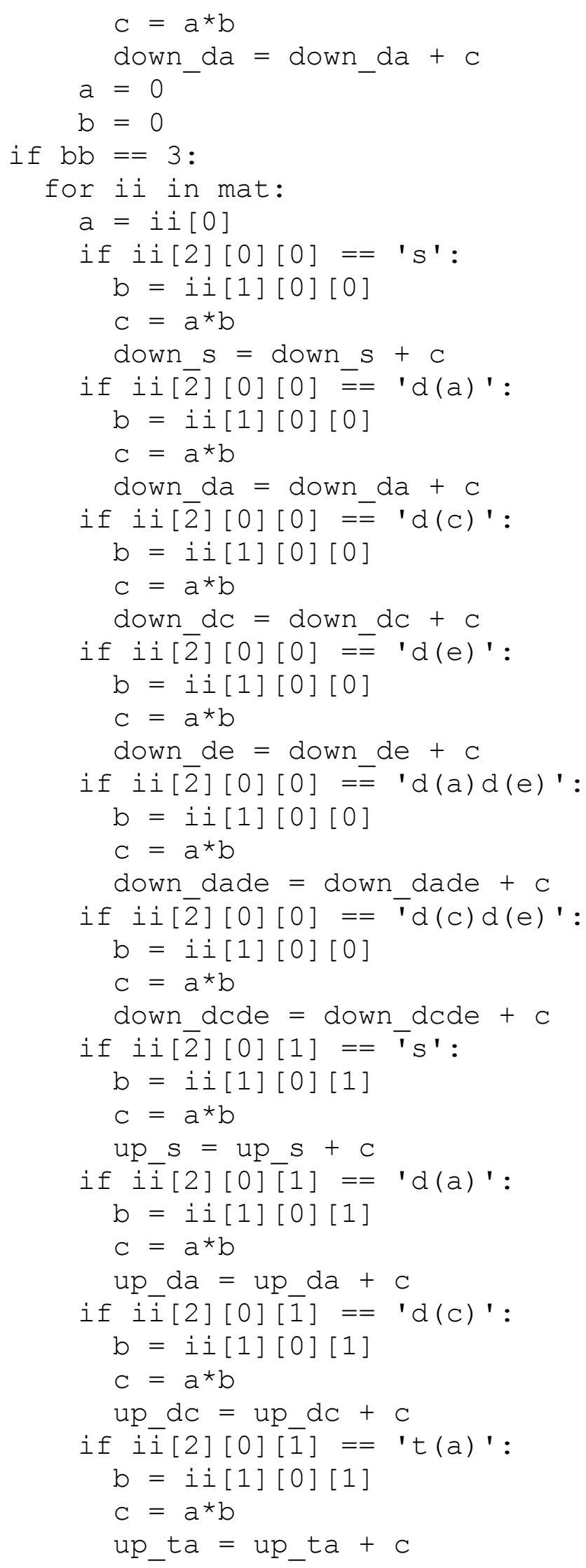




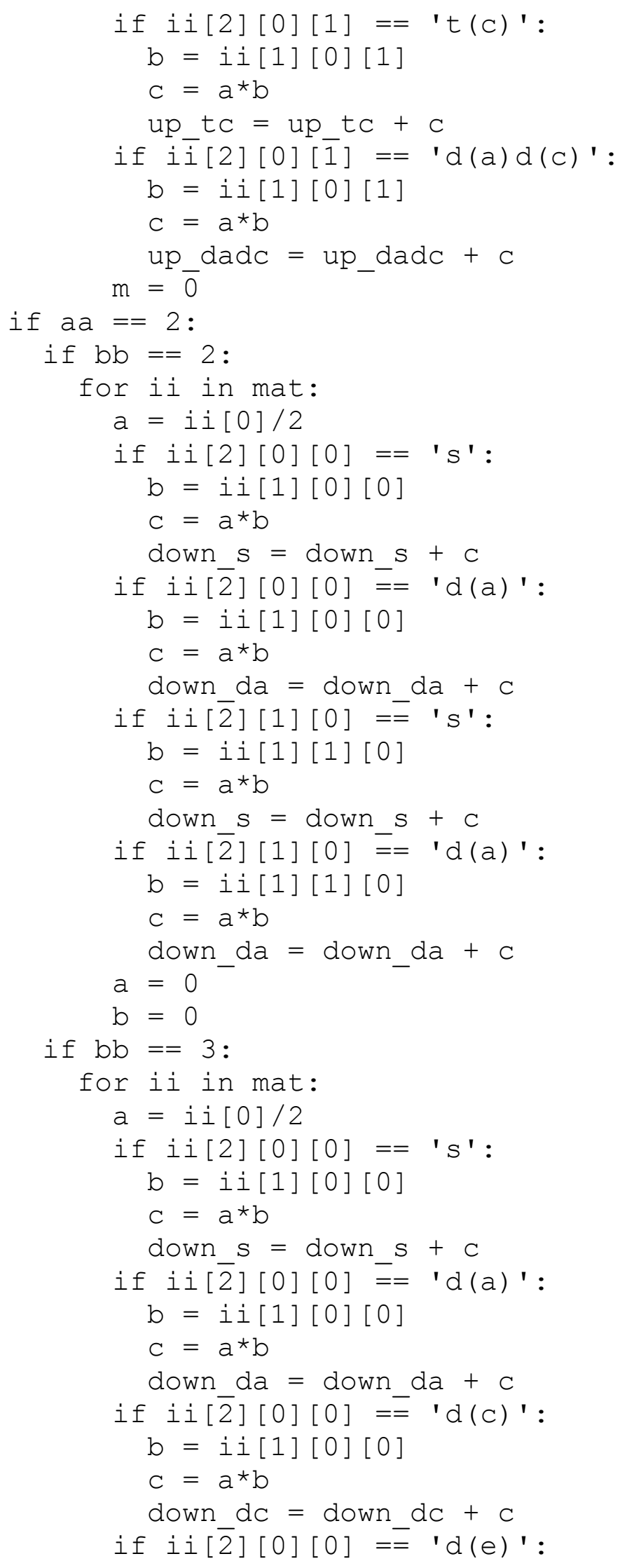




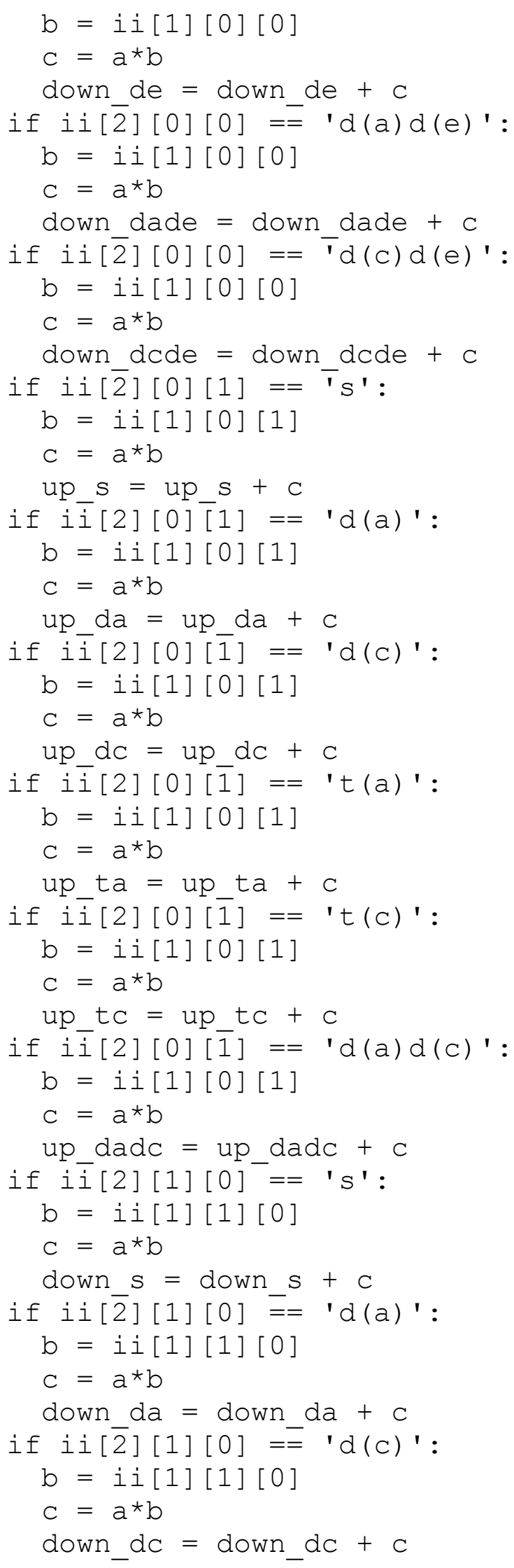




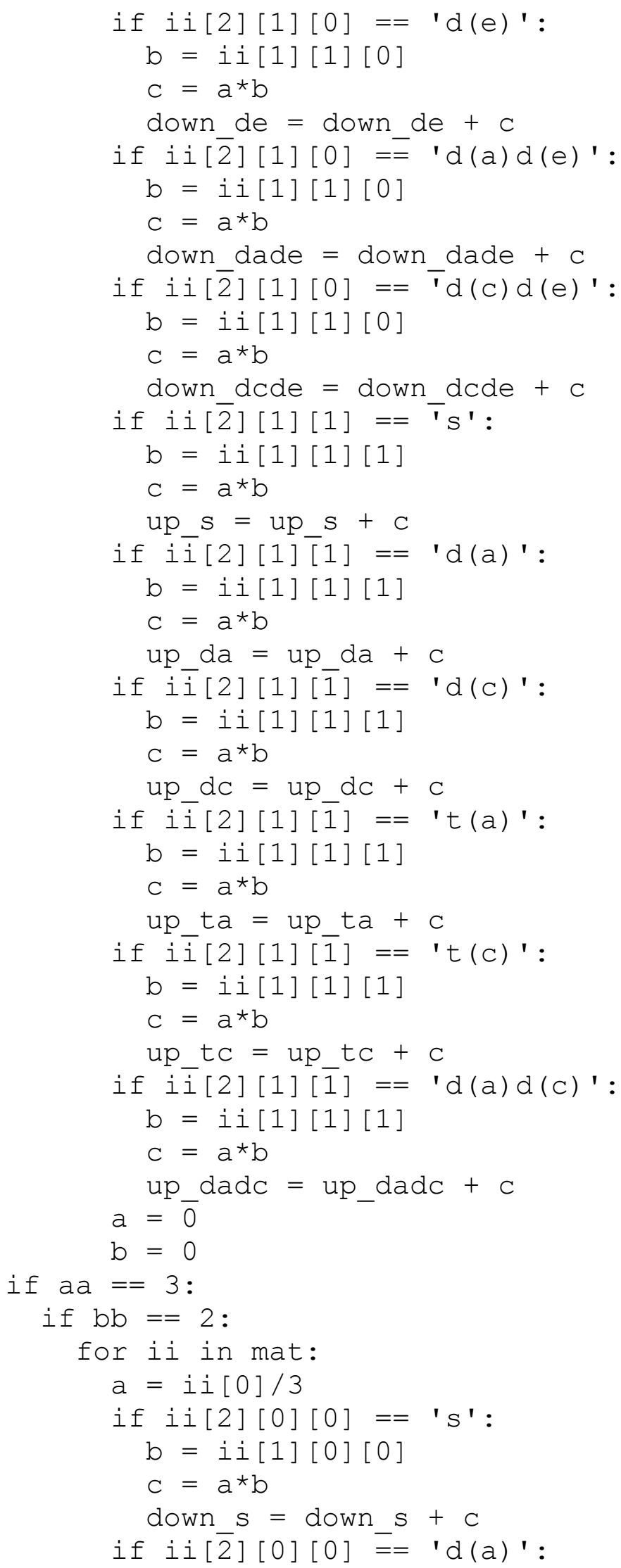




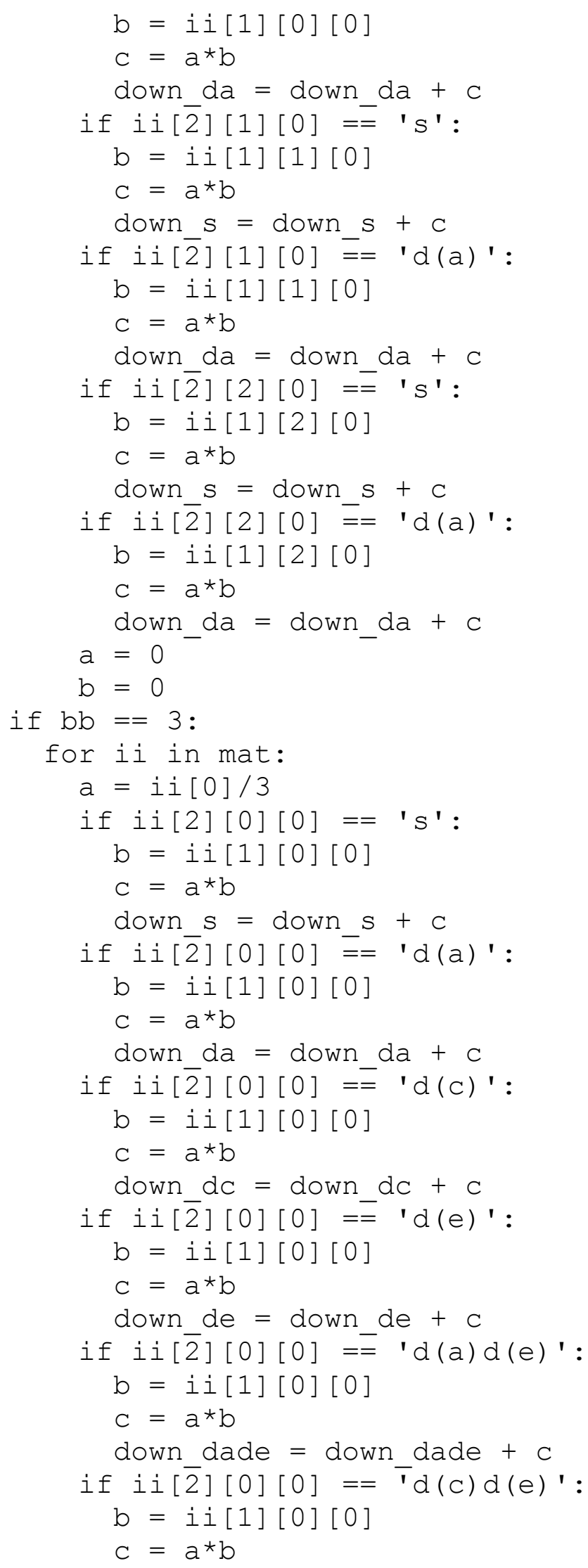




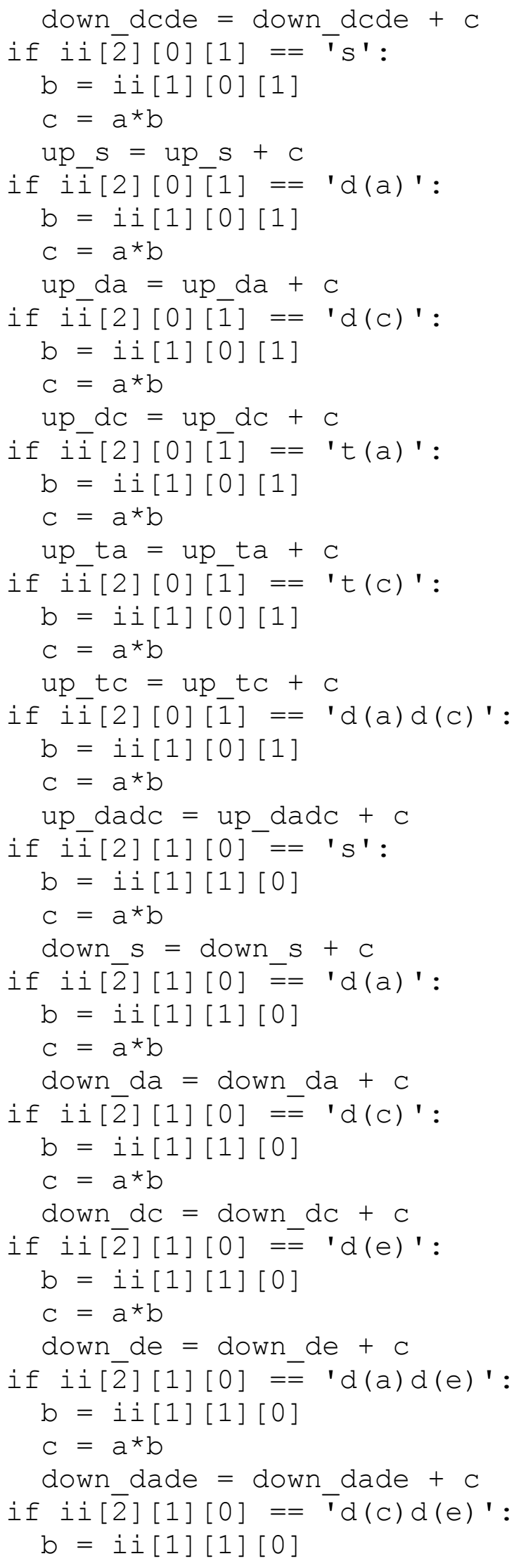




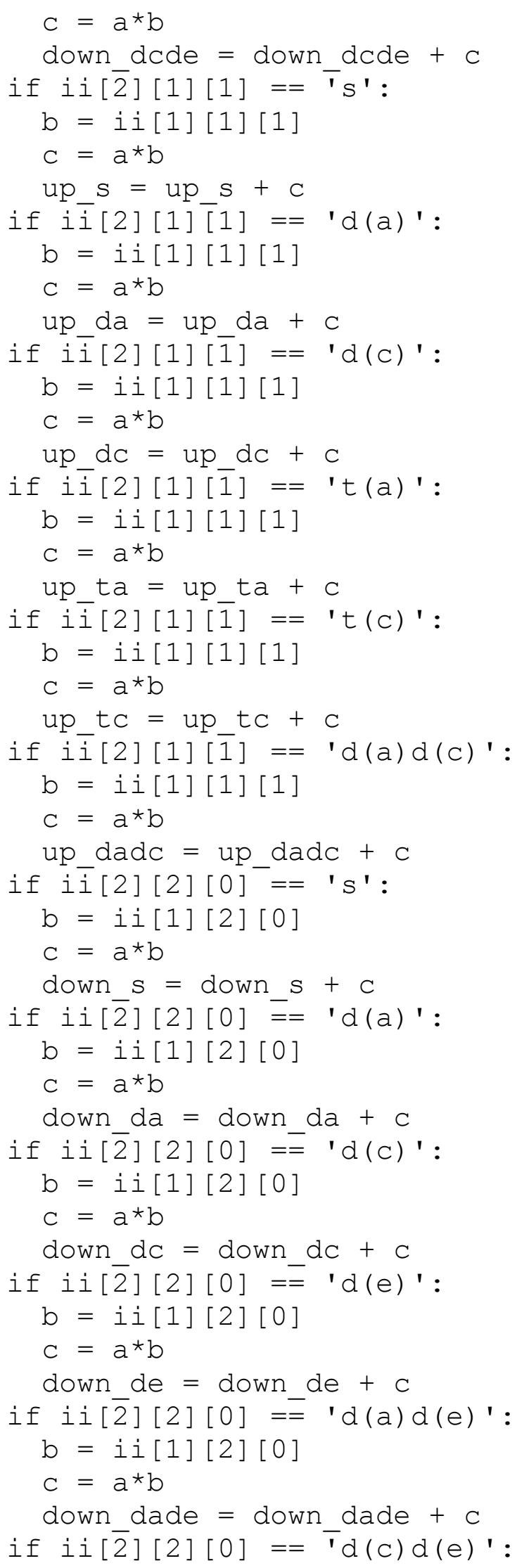




$$
\begin{aligned}
& \mathrm{b}=\mathrm{i} i[1][2][0] \\
& \mathrm{c}=\mathrm{a} * \mathrm{~b} \\
& \text { down dcde }=\text { down dcde }+\mathrm{c} \\
& \text { if ii[2][2][1] == ' } \mathrm{S} \text { ': } \\
& \mathrm{b}=\mathrm{i} i[1][2][1] \\
& c=a * b \\
& u p \_s=u p \_s+c \\
& \text { if } i \bar{i}[2][2][1]==' d(a) ' \text { : } \\
& \mathrm{b}=\mathrm{i} i[1][2][1] \\
& c=a * b \\
& u p \_d a=u p \_d a+c
\end{aligned}
$$

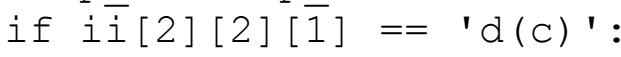

$$
\begin{aligned}
& \mathrm{b}=\mathrm{i} i[1][2][1] \\
& \mathrm{c}=\mathrm{a} * \mathrm{~b} \\
& u p d c=u p d c+c \\
& \text { if } i \bar{i}[2][2][\overline{1}]==' t(a) \text { ' : } \\
& \mathrm{b}=\mathrm{ii[1][2][1]} \\
& c=a * b \\
& \text { up ta }=\text { up ta }+c
\end{aligned}
$$

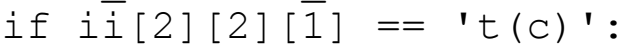

$$
\begin{aligned}
& \mathrm{b}=\mathrm{ii[1][2][1]} \\
& \mathrm{c}=\mathrm{a} * \mathrm{~b} \\
& u p \_t c=u p \_t c+c \\
& \text { if } i \bar{i}[2][2][\overline{1}]==' d(a) d(c)^{\prime} \text { : } \\
& \mathrm{b}=\mathrm{i} i[1][2][1] \\
& c=a^{*} b \\
& u p \_d a d c=u p \_d a d c+c \\
& \mathrm{a}=\overline{0} \\
& \mathrm{~b}=0 \\
& \text { if } \mathrm{aa}==4 \text { : } \\
& \text { if } \mathrm{bb}==2 \text { : } \\
& \text { for ii in mat: } \\
& a=i i[0] / 4 \\
& \text { if ii[2][0][0] ==' ' } \mathrm{s} \text { ': } \\
& \mathrm{b}=\mathrm{i} i[1][0][0] \\
& \mathrm{c}=\mathrm{a} * \mathrm{~b} \\
& \text { down } \mathrm{s}=\text { down } \mathrm{s}+\mathrm{c} \\
& \text { if } i \text { i[ } \overline{2}][0][0]=={ }^{\prime} d(a) ' \text { : } \\
& \mathrm{b}=\mathrm{ii[1][0][0]} \\
& \mathrm{c}=\mathrm{a} * \mathrm{~b} \\
& \text { down_da }=\text { down_da }+\mathrm{c} \\
& \text { if ii[z][1][0] }=\overline{=} \text { ' } \mathrm{s} \text { ' : } \\
& \mathrm{b}=\mathrm{ii[1][1][0]} \\
& \mathrm{c}=\mathrm{a} * \mathrm{~b} \\
& \text { down } s=\text { down_s }+c \\
& \text { if ii[2][1][0] } \overline{=}={ }^{\prime} \mathrm{d}(\mathrm{a}) \mathrm{C}^{\prime} \text { : } \\
& \mathrm{b}=\mathrm{ii}[1][1][0]
\end{aligned}
$$




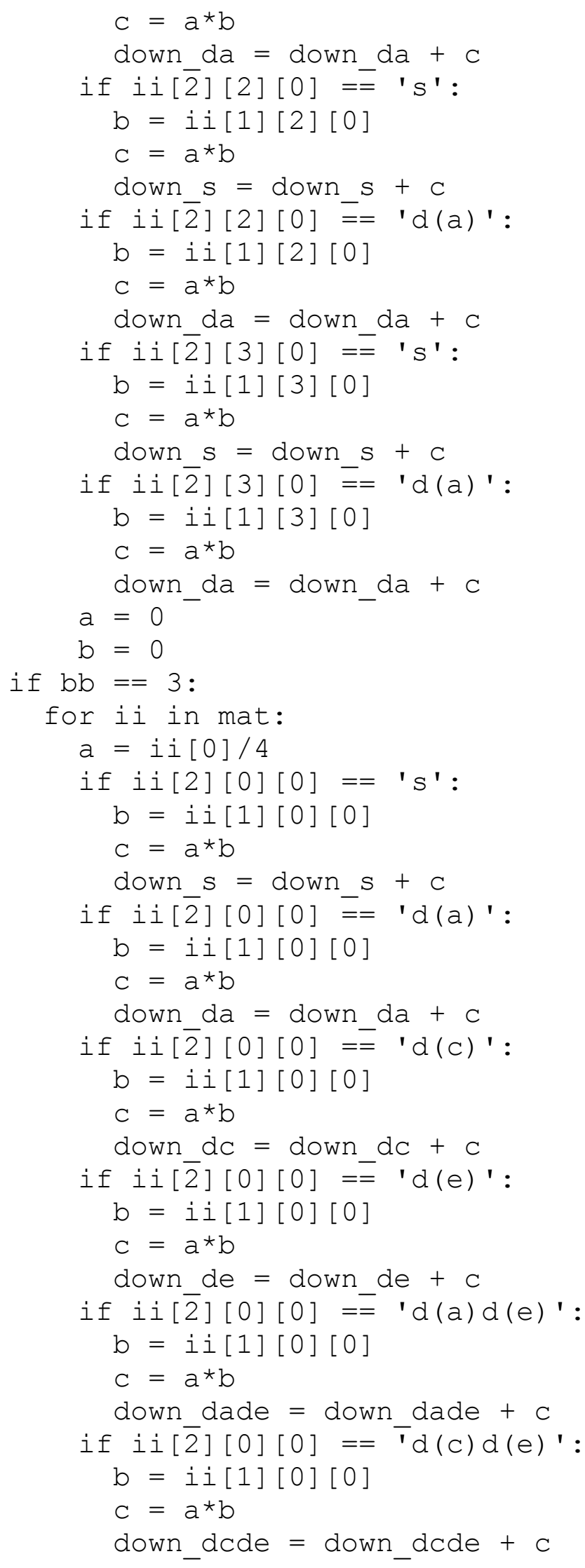




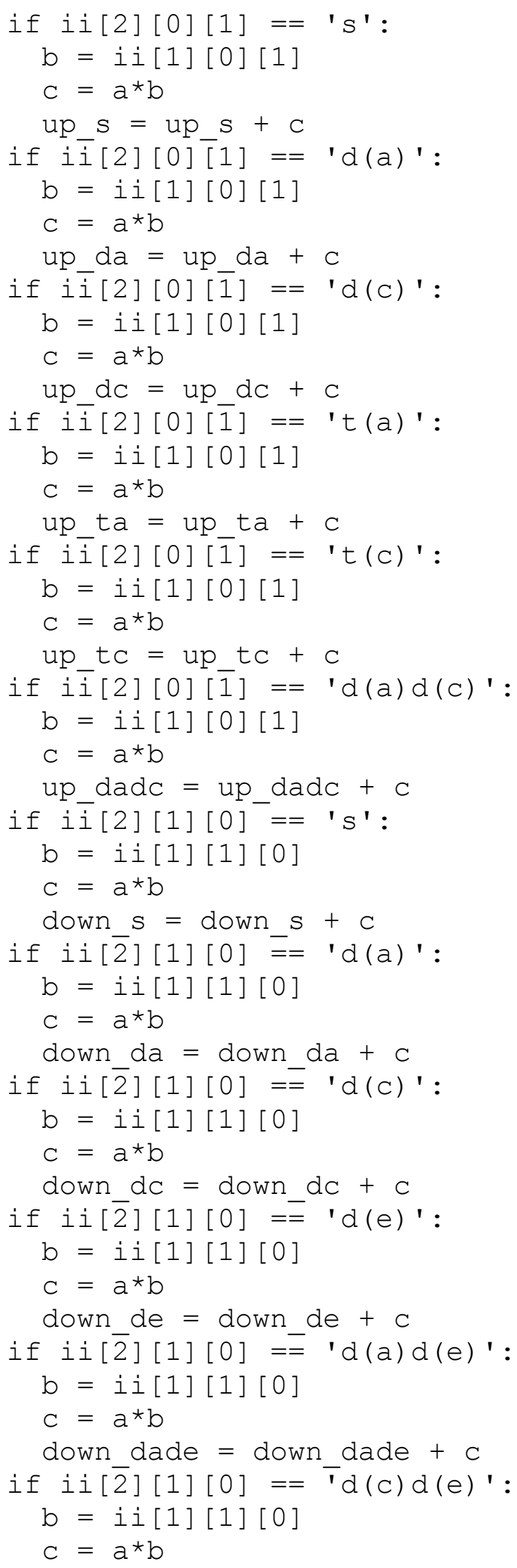




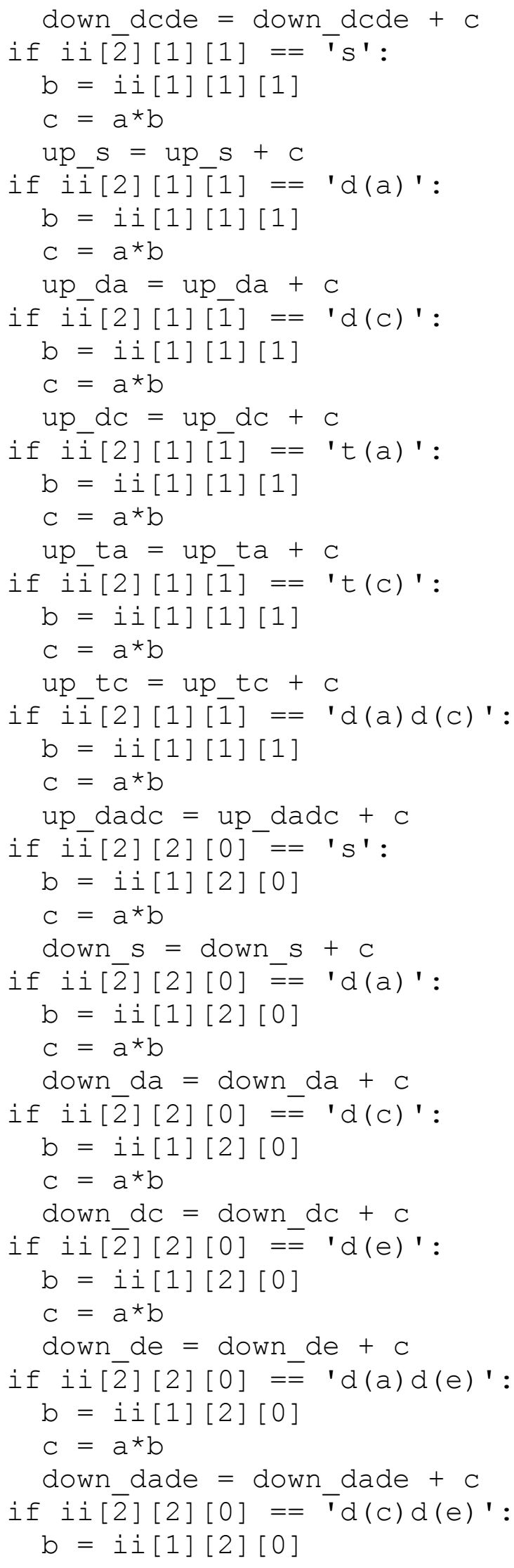




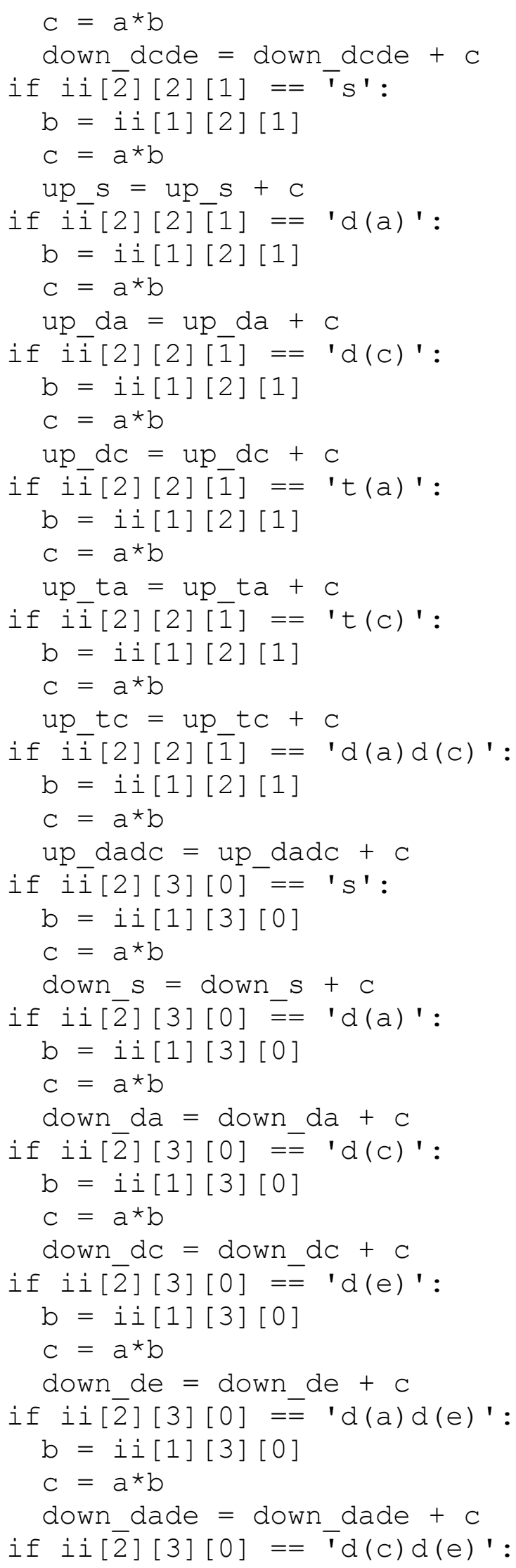




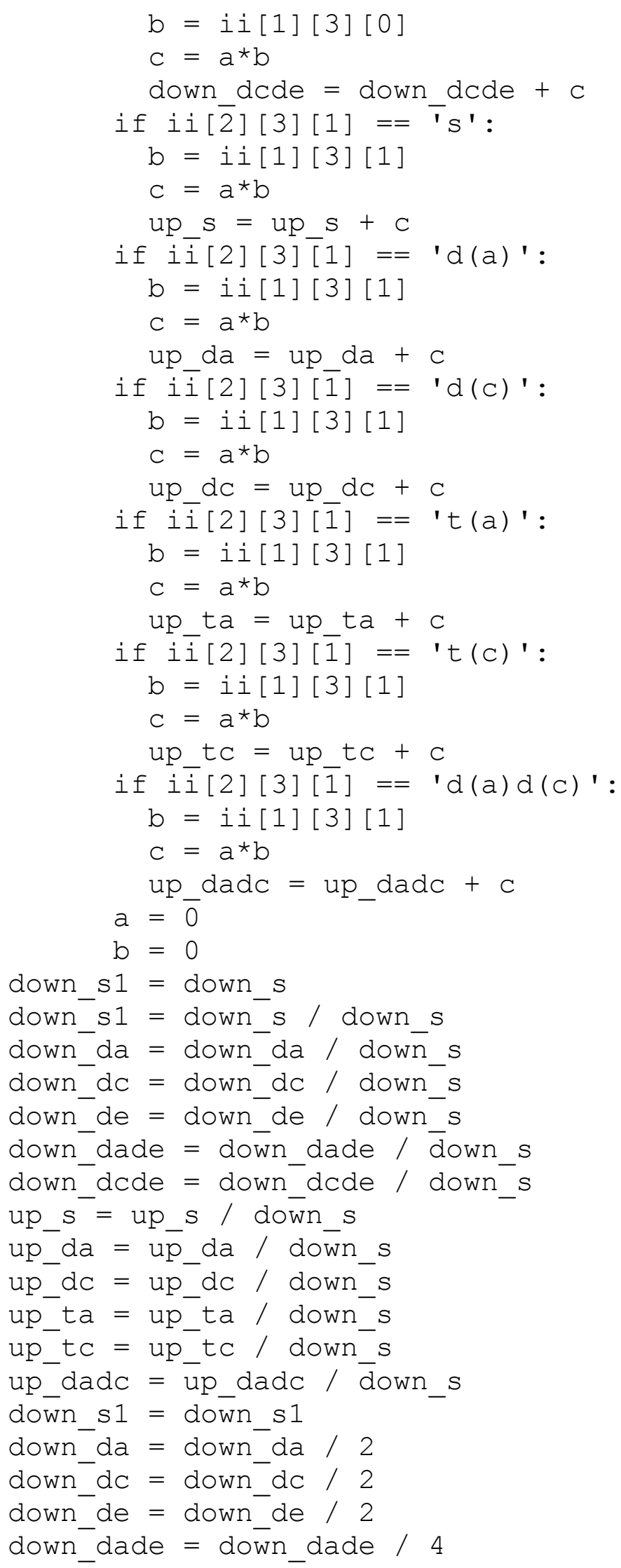




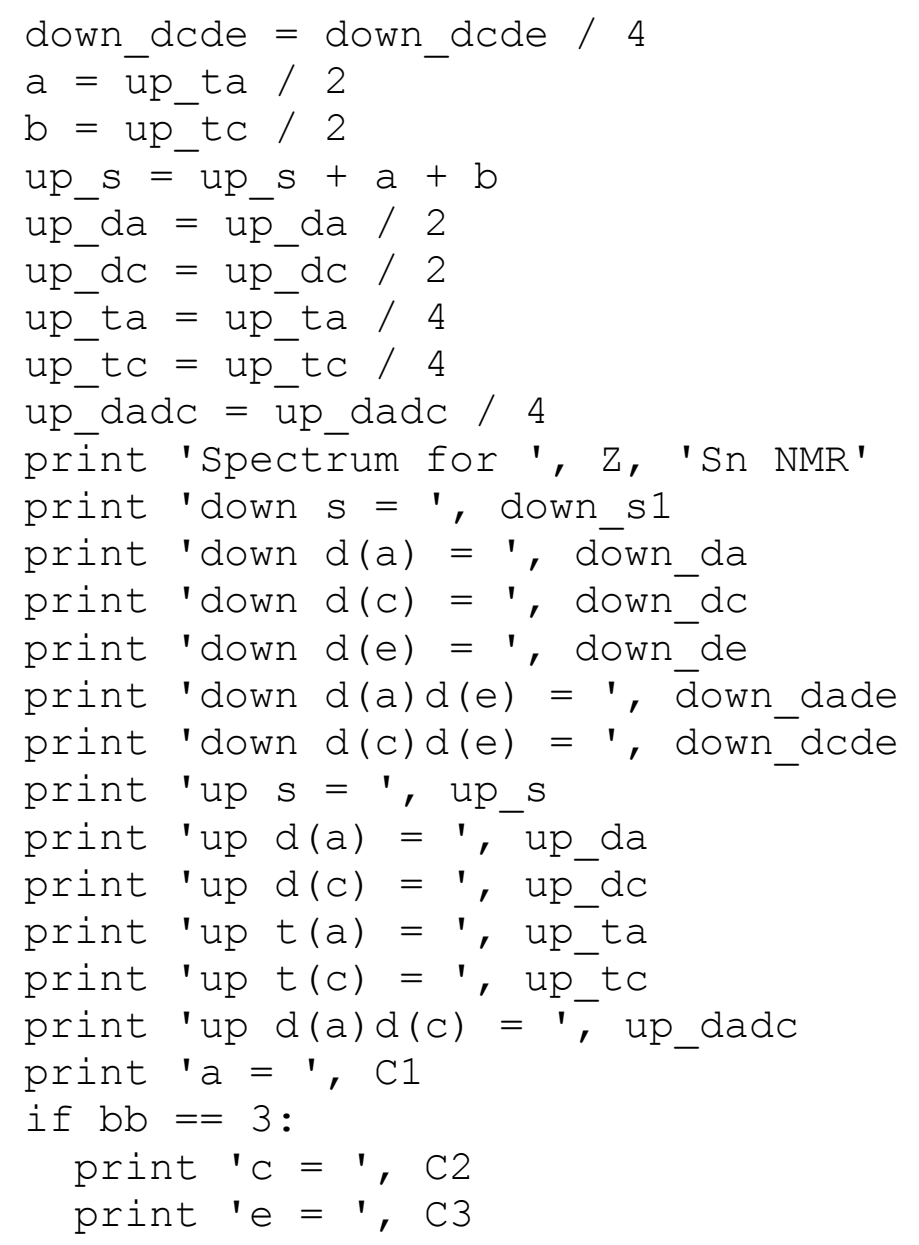




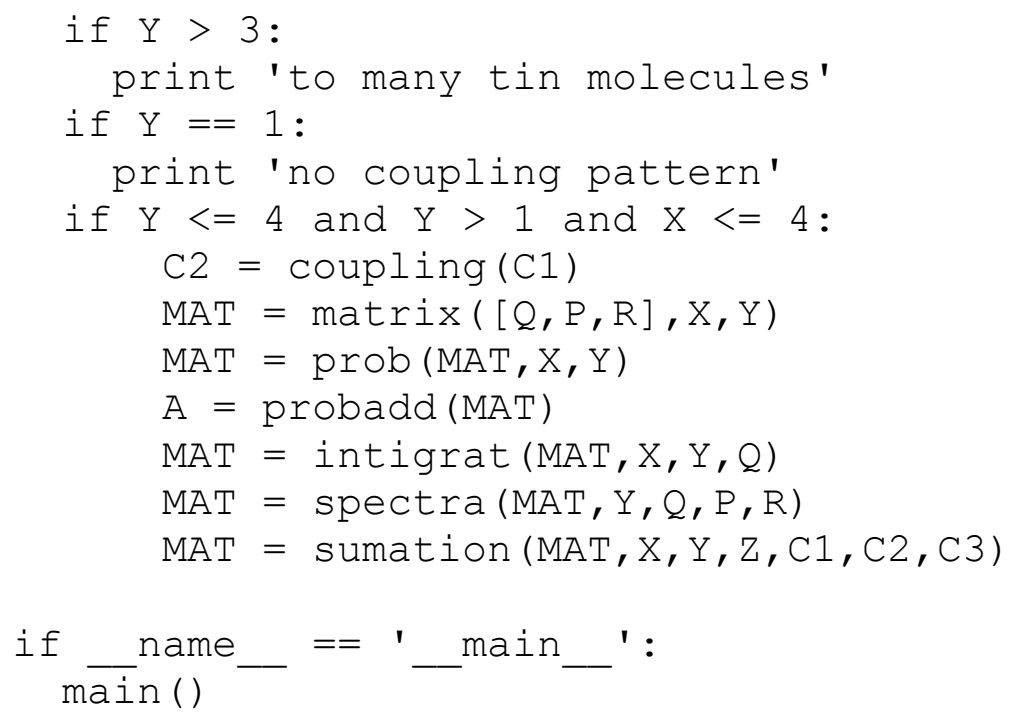


Appendix 5: DFT .mol2 files for optimized structures

Table A5.1: Total Energies LSDA/SDD

\begin{tabular}{lll}
\hline Compound & Optimized Energy & Zero Point Energy \\
& (a.u.) & (a.u.) \\
\hline $4 \mathrm{a}$ & -1182.25541824 & -118225541822 \\
$4 \mathrm{~b}$ & -1855.62932036 & -1855.62932036 \\
$5 \mathrm{a}$ & -673.35512007 & -673.35512007 \\
$9 \mathrm{~b}$ & -990.74034313 & -990.74034314 \\
11 & -1981.51367409 & -1981.51367410 \\
11 (mono cation) & -1981.28185554 & -1981.28185530 \\
$12 \mathrm{a}$ & -1384.62175373 & -1384.62175372 \\
$12 \mathrm{~b}$ & -1752.64314207 & -1752.64314207 \\
$12 \mathrm{c}$ & -2120.66623312 & -2120.66623312 \\
$12 \mathrm{~d}$ & -2755.45948976 & -2755.45948975 \\
13 & -1099.41100877 & -1099.41100877 \\
14 & -1308.91976962 & -1308.91976962
\end{tabular}

\section{A5.1: Compound 4a .mol2}

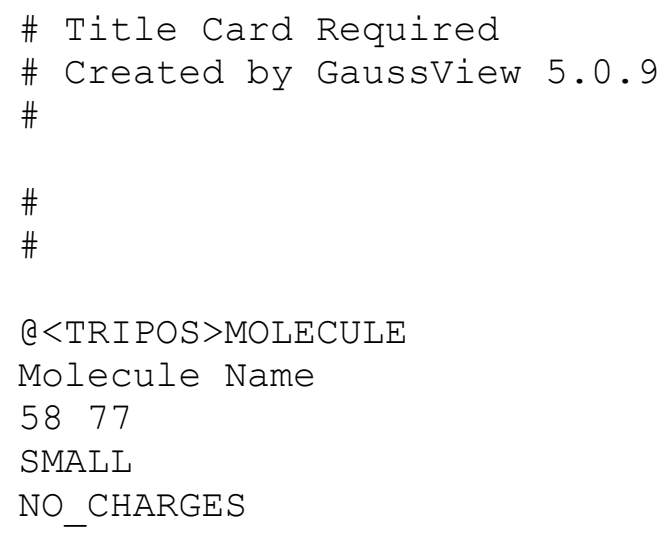




\begin{tabular}{|c|c|c|c|}
\hline 5 H5 & -3.8956 & -2.3538 & $0.0224 \mathrm{H}$ \\
\hline $6 \mathrm{H} 6$ & -7.2090 & 0.2068 & $-1.3627 \mathrm{H}$ \\
\hline C7 & -6.5958 & -0.4314 & $0.7193 \mathrm{C}$ \\
\hline H8 & -7.3284 & 0.0684 & $1.3549 \mathrm{H}$ \\
\hline C9 & -5.5071 & -1.2618 & $1.1711 \mathrm{C}$ \\
\hline $10 \mathrm{H} 10$ & -5.2738 & -1.5054 & $2.2095 \mathrm{H}$ \\
\hline $11 \mathrm{C} 11$ & -4.7754 & -1.7064 & $0.0116 \mathrm{C}$ \\
\hline $12 \mathrm{H} 12$ & -3.3229 & 1.3616 & $-2.0145 \mathrm{H}$ \\
\hline $13 \mathrm{C} 13$ & -3.5870 & 1.4991 & $-0.9631 \mathrm{C}$ \\
\hline 14 C14 & -2.8793 & 0.9267 & $0.1650 \mathrm{C}$ \\
\hline 15 H15 & -5.4509 & 2.7790 & $-1.0863 \mathrm{H}$ \\
\hline $6 \mathrm{C} 16$ & -3.6026 & 1.3328 & $1.3540 \mathrm{C}$ \\
\hline $17 \mathrm{H} 17$ & -3.3516 & 1.0494 & $2.3791 \mathrm{H}$ \\
\hline $18 \mathrm{C} 18$ & -4.7293 & 2.1442 & $0.9621 \mathrm{C}$ \\
\hline 19 H19 & -5.4683 & 2.5853 & $1.6331 \mathrm{H}$ \\
\hline $20 \mathrm{C} 20$ & -4.7195 & 2.2471 & $-0.4756 C$ \\
\hline $21 \mathrm{Fe} 21$ & 4.7843 & -0.3433 & $-0.2067 \mathrm{Fe}$ \\
\hline 22 H22 & 3.1163 & -0.9477 & $-2.3758 \mathrm{H}$ \\
\hline $23 \mathrm{C} 23$ & 3.4361 & -1.2736 & $-1.3829 \mathrm{C}$ \\
\hline $24 \mathrm{C} 24$ & 2.8215 & -0.8851 & $-0.1288 \mathrm{C}$ \\
\hline 25 H25 & 5.2287 & -2.5770 & $-1.8471 \mathrm{H}$ \\
\hline $26 \mathrm{C} 26$ & 3.5945 & -1.5177 & $0.9217 \mathrm{C}$ \\
\hline 27 H27 & 3.4195 & -1.4074 & $1.9947 \mathrm{H}$ \\
\hline $28 \mathrm{C} 28$ & 4.6576 & -2.2870 & $0.3233 \mathrm{C}$ \\
\hline 29 H29 & 5.4138 & -2.8643 & $0.8579 \mathrm{H}$ \\
\hline $30 \mathrm{C} 30$ & 4.5596 & -2.1354 & $-1.1067 \mathrm{C}$ \\
\hline 31 H31 & 5.1266 & 1.5408 & $-2.2750 \mathrm{H}$ \\
\hline 32 C32 & 5.4359 & 1.2498 & $-1.2692 \mathrm{C}$ \\
\hline 33 C33 & 6.5268 & 0.3660 & $-0.9403 \mathrm{C}$ \\
\hline 34 Н34 & 3.9635 & 2.3463 & $0.0500 \mathrm{H}$ \\
\hline 35 H35 & 7.1821 & -0.1369 & $-1.6532 \mathrm{H}$ \\
\hline $36 \mathrm{C} 36$ & 6.5839 & 0.2436 & $0.4953 \mathrm{C}$ \\
\hline 37 H37 & 7.2903 & -0.3677 & $1.0590 \mathrm{H}$ \\
\hline 38 C38 & 5.5278 & 1.0515 & $1.0538 \mathrm{C}$ \\
\hline 39 H39 & 5.2984 & 1.1622 & $2.1156 \mathrm{H}$ \\
\hline $40 C 40$ & 4.8216 & 1.6759 & $-0.0367 \mathrm{C}$ \\
\hline $41 \operatorname{Sn} 41$ & -1.2996 & -0.5114 & $0.0702 \mathrm{Sn}$ \\
\hline $42 \operatorname{sn} 42$ & 1.3119 & 0.6092 & $0.1430 \mathrm{Sn}$ \\
\hline $43 C 43$ & -1.6914 & -1.8460 & $1.7415 \mathrm{C}$ \\
\hline 44 H 44 & -2.7246 & -1.6541 & $2.0875 \mathrm{H}$ \\
\hline 45 H45 & -0.9898 & -1.6753 & $2.5755 \mathrm{H}$ \\
\hline 46 H4 6 & -1.6061 & -2.8992 & $1.4191 \mathrm{H}$ \\
\hline $47 \quad C 47$ & -1.5995 & -1.5563 & $-1.8108 \mathrm{C}$ \\
\hline 48 H48 & -1.2775 & -0.9302 & $-2.6616 \mathrm{H}$ \\
\hline 49 H49 & -2.6756 & -1.7842 & $-1.9228 \mathrm{H}$ \\
\hline 50 H50 & -1.0216 & -2.4971 & $-1.8271 \mathrm{H}$ \\
\hline 51 C51 & 1.6475 & 2.0180 & $-1.4802 \mathrm{C}$ \\
\hline 52 H52 & 0.8490 & 1.9679 & $-2.2397 \mathrm{H}$ \\
\hline 53 H53 & 2.6167 & 1.7632 & $-1.9488 \mathrm{H}$ \\
\hline 54 H54 & 1.6956 & 3.0499 & $-1.0878 \mathrm{H}$ \\
\hline 55 C55 & 1.8044 & 1.5272 & $2.0475 \mathrm{C}$ \\
\hline 56 H56 & 1.3393 & 2.5246 & $2.1346 \mathrm{H}$ \\
\hline
\end{tabular}




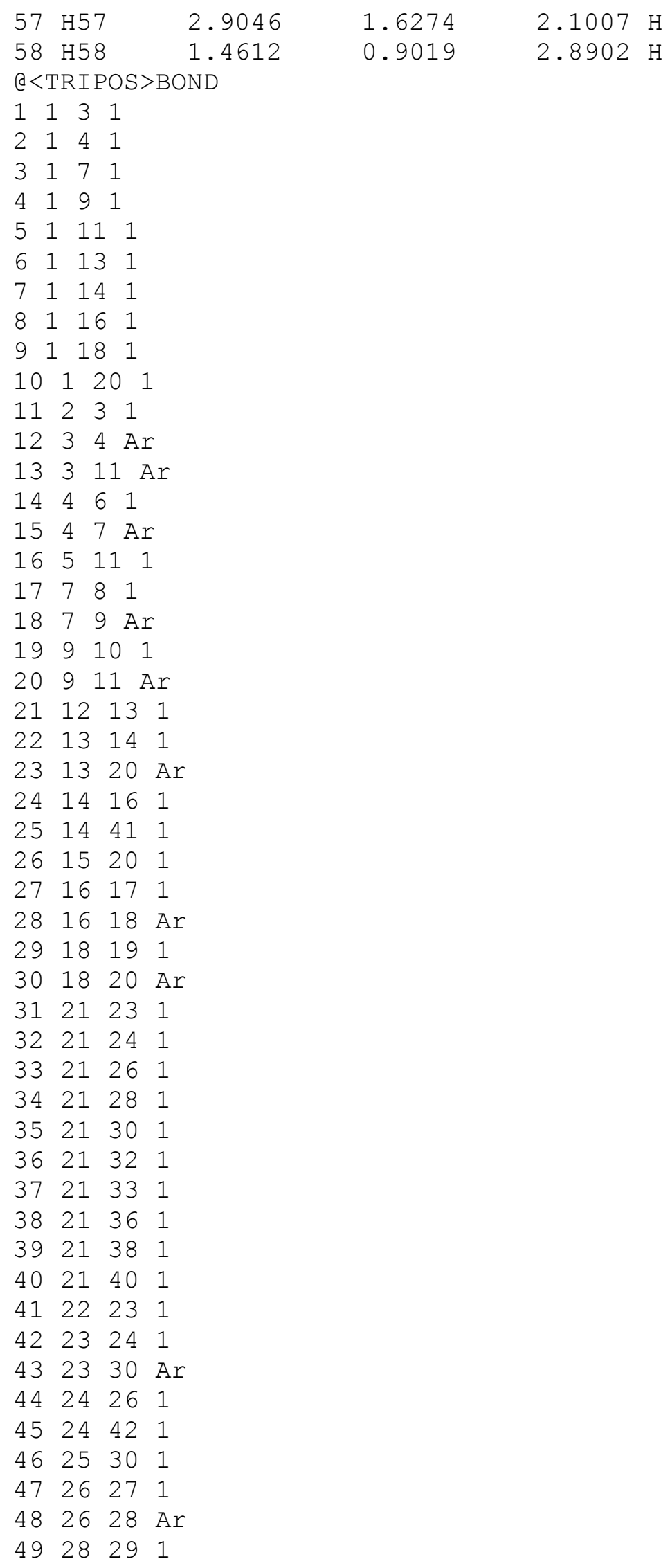


$\begin{array}{llll}50 & 28 & 30 & \text { Ar }\end{array}$

$\begin{array}{llll}51 & 31 & 32 & 1\end{array}$

523233 Ar

533240 Ar

$\begin{array}{llll}54 & 33 & 35 & 1\end{array}$

$5533 \quad 36$ Ar

$\begin{array}{llll}56 & 34 & 40 & 1\end{array}$

$\begin{array}{llll}57 & 36 & 37 & 1\end{array}$

583638 Ar

$\begin{array}{llll}59 & 38 & 39 & 1\end{array}$

603840 Ar

$\begin{array}{llll}61 & 41 & 42 & 1\end{array}$

$\begin{array}{llll}62 & 41 & 43 & 1\end{array}$

$\begin{array}{llll}63 & 41 & 47 & 1\end{array}$

$\begin{array}{llll}64 & 42 & 51 & 1\end{array}$

$\begin{array}{llll}65 & 42 & 55 & 1\end{array}$

$\begin{array}{llll}66 & 43 & 44 & 1\end{array}$

$\begin{array}{llll}67 & 43 & 45 & 1\end{array}$

$\begin{array}{llll}68 & 43 & 46 & 1\end{array}$

$\begin{array}{llll}69 & 47 & 48 & 1\end{array}$

$\begin{array}{llll}70 & 47 & 49 & 1\end{array}$

$\begin{array}{llll}71 & 47 & 50 & 1\end{array}$

$\begin{array}{llll}72 & 51 & 52 & 1\end{array}$

$\begin{array}{llll}73 & 51 & 53 & 1\end{array}$

$\begin{array}{llll}74 & 51 & 54 & 1\end{array}$

$\begin{array}{llll}75 & 55 & 56 & 1\end{array}$

$\begin{array}{llll}76 & 55 & 57 & 1\end{array}$

$\begin{array}{llll}77 & 55 & 58 & 1\end{array}$

\section{A5.2: Compound 4b .mol2}

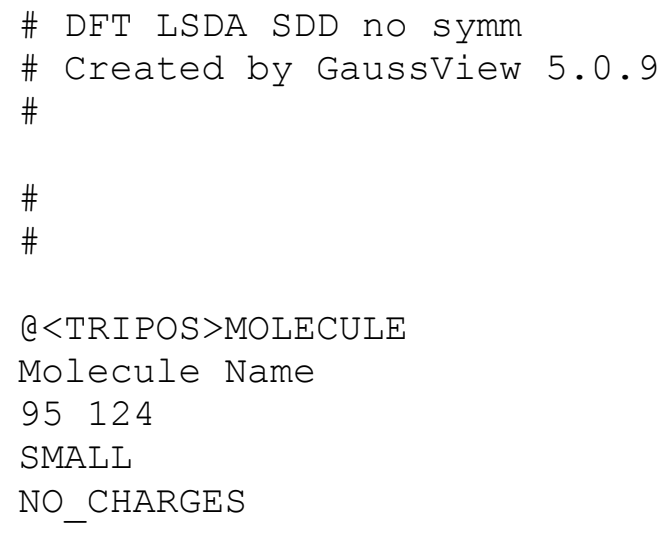




\begin{tabular}{|c|c|c|c|}
\hline $5 \mathrm{H} 5$ & -3.7182 & -2.6473 & $0.7931 \mathrm{H}$ \\
\hline $6 \mathrm{H} 6$ & -6.9873 & -0.6734 & $-1.4079 \mathrm{H}$ \\
\hline C7 & -6.4837 & -0.6874 & $0.7980 \mathrm{C}$ \\
\hline 8 H8 & -7.2570 & -0.0507 & $1.2305 \mathrm{H}$ \\
\hline C9 & -5.4115 & -1.3286 & $1.5191 \mathrm{C}$ \\
\hline $10 \mathrm{H} 10$ & -5.2336 & -1.2647 & $2.5945 \mathrm{H}$ \\
\hline $11 \mathrm{C} 11$ & -4.6098 & -2.0569 & $0.5682 \mathrm{C}$ \\
\hline $12 \mathrm{H} 12$ & -2.9569 & 0.3332 & $-2.0672 \mathrm{H}$ \\
\hline $13 \mathrm{C} 13$ & -3.3440 & 0.7642 & $-1.1406 \mathrm{C}$ \\
\hline 14 C14 & -2.7705 & 0.5821 & $0.1782 \mathrm{C}$ \\
\hline 15 H15 & -5.1810 & 1.8824 & $-1.8485 \mathrm{H}$ \\
\hline $6 \mathrm{C} 16$ & -3.6261 & 1.3009 & $1.1021 \mathrm{C}$ \\
\hline $17 \mathrm{H} 17$ & -3.4952 & 1.3453 & $2.1861 \mathrm{H}$ \\
\hline $18 \mathrm{C} 18$ & -4.7020 & 1.9148 & $0.3631 \mathrm{C}$ \\
\hline 19 H19 & -5.5145 & 2.5095 & $0.7840 \mathrm{H}$ \\
\hline $20 \mathrm{C} 20$ & -4.5270 & 1.5817 & $-1.0283 \mathrm{C}$ \\
\hline $21 \mathrm{Fe} 21$ & 4.2589 & 0.5054 & $-1.7161 \mathrm{Fe}$ \\
\hline 22 H22 & 1.7908 & 0.6888 & $-3.0285 \mathrm{H}$ \\
\hline $23 \mathrm{C} 23$ & 2.4843 & 0.0040 & $-2.5341 C$ \\
\hline $24 \mathrm{C} 24$ & 2.4934 & -0.3125 & $-1.1197 \mathrm{C}$ \\
\hline 25 H25 & 3.8167 & -0.6620 & $-4.2407 \mathrm{H}$ \\
\hline $26 \mathrm{C} 26$ & 3.6020 & -1.2233 & $-0.9088 \mathrm{C}$ \\
\hline 27 H27 & 3.9106 & -1.6340 & $0.0567 \mathrm{H}$ \\
\hline $28 \mathrm{C} 28$ & 4.2521 & -1.4691 & $-2.1717 \mathrm{C}$ \\
\hline 29 H29 & 5.1219 & -2.1098 & $-2.3370 \mathrm{H}$ \\
\hline $30 \mathrm{C} 30$ & 3.5634 & -0.7035 & $-3.1794 C$ \\
\hline 31 H31 & 5.7666 & 1.7761 & $-3.7077 \mathrm{H}$ \\
\hline 32 C32 & 5.5260 & 1.7738 & $-2.6417 \mathrm{C}$ \\
\hline 33 C33 & 6.2262 & 1.0199 & $-1.6210 \mathrm{C}$ \\
\hline 34 Н34 & 3.7267 & 3.1459 & $-2.5397 \mathrm{H}$ \\
\hline 35 C35 & 5.5440 & 1.2884 & $-0.3699 \mathrm{C}$ \\
\hline 36 H36 & 5.8003 & 0.8517 & $0.5993 \mathrm{H}$ \\
\hline 37 C37 & 4.4540 & 2.1982 & $-0.6175 \mathrm{C}$ \\
\hline 38 H38 & 3.7536 & 2.5861 & $0.1262 \mathrm{H}$ \\
\hline 39 C39 & 4.4387 & 2.4957 & $-2.0274 \mathrm{C}$ \\
\hline $40 \operatorname{Sn} 40$ & -1.1648 & -0.7317 & $0.6983 \mathrm{Sn}$ \\
\hline $41 \operatorname{Sn} 41$ & 1.3259 & 0.6120 & $0.4154 \mathrm{Sn}$ \\
\hline $42 C 42$ & -1.6226 & -1.4062 & $2.7108 \mathrm{C}$ \\
\hline 43 H43 & -2.7093 & -1.6045 & $2.7681 \mathrm{H}$ \\
\hline 44 H 44 & -1.3597 & -0.6348 & $3.4554 \mathrm{H}$ \\
\hline 45 H45 & -1.0698 & -2.3315 & $2.9497 \mathrm{H}$ \\
\hline $46 C 46$ & -1.2991 & -2.3823 & $-0.7085 \mathrm{C}$ \\
\hline 47 H47 & -2.2579 & -2.2933 & $-1.2533 \mathrm{H}$ \\
\hline 48 H48 & -1.2756 & -3.3501 & $-0.1758 \mathrm{H}$ \\
\hline 49 H49 & -0.4624 & -2.3540 & $-1.4280 \mathrm{H}$ \\
\hline $50 \mathrm{C} 50$ & 1.0007 & 2.6594 & $-0.2389 \mathrm{C}$ \\
\hline 51 H51 & 1.3059 & 3.3720 & $0.5487 \mathrm{H}$ \\
\hline $52 \mathrm{H} 52$ & -0.0634 & 2.8306 & $-0.4777 \mathrm{H}$ \\
\hline 53 H53 & 1.6151 & 2.8356 & $-1.1417 \mathrm{H}$ \\
\hline $54 \quad C 54$ & 2.6127 & 0.5599 & $2.1644 \mathrm{C}$ \\
\hline 55 H55 & 2.6192 & -0.4470 & $2.6173 \mathrm{H}$ \\
\hline 56 H56 & 2.2786 & 1.2882 & $2.9238 \mathrm{H}$ \\
\hline
\end{tabular}




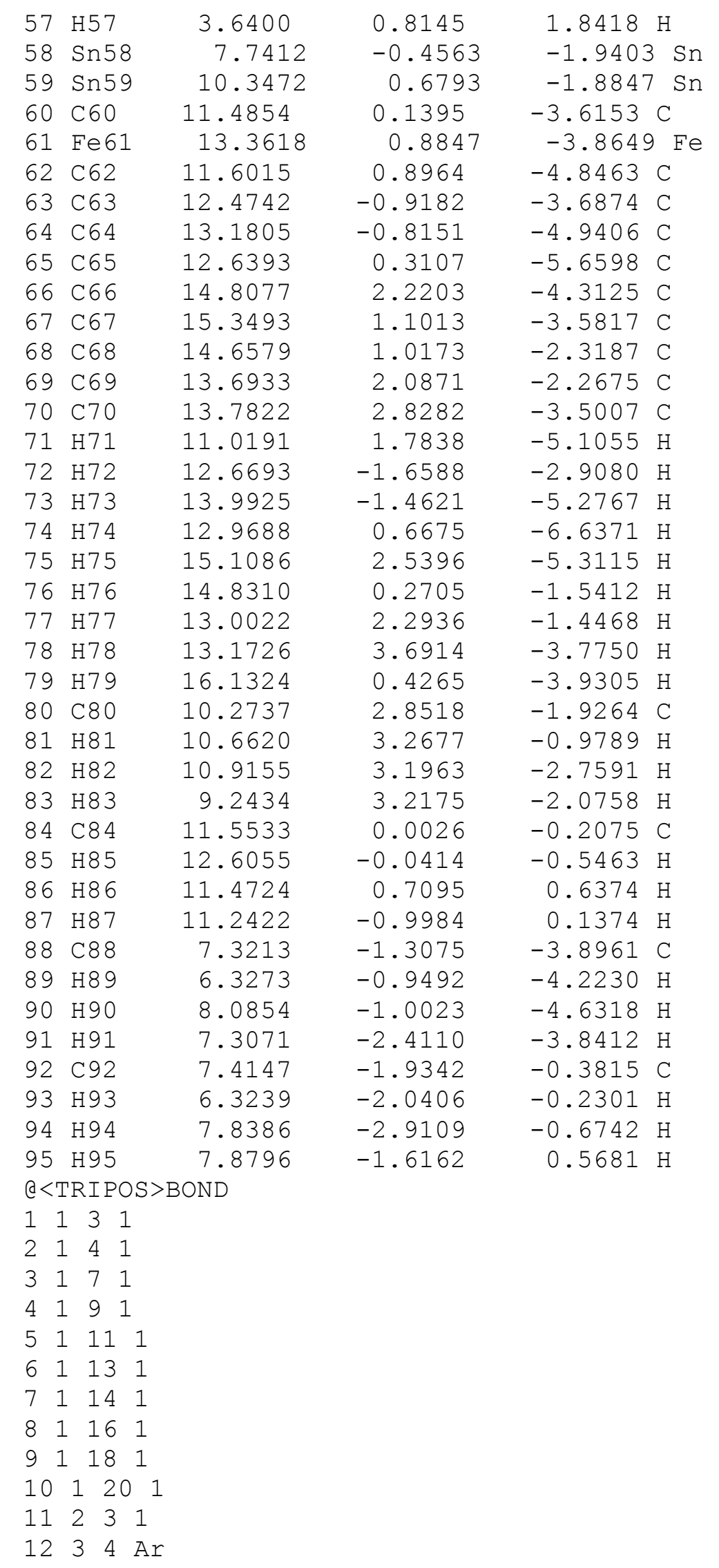


$13311 \mathrm{Ar}$

$\begin{array}{llll}14 & 4 & 6 & 1\end{array}$

1547 Ar

$\begin{array}{llll}16 & 5 & 11 & 1\end{array}$

$\begin{array}{llll}17 & 7 & 8 & 1\end{array}$

1879 Ar

$\begin{array}{llll}19 & 9 & 10 & 1\end{array}$

20911 Ar

$\begin{array}{llll}21 & 12 & 13 & 1\end{array}$

$\begin{array}{llll}22 & 13 & 14 & 1\end{array}$

231320 Ar

$\begin{array}{llll}24 & 14 & 16 & 1\end{array}$

$\begin{array}{llll}25 & 14 & 40 & 1\end{array}$

$\begin{array}{llll}26 & 15 & 20 & 1\end{array}$

$\begin{array}{llll}27 & 16 & 17 & 1\end{array}$

281618 Ar

$\begin{array}{llll}29 & 18 & 19 & 1\end{array}$

301820 Ar

$\begin{array}{llll}31 & 21 & 23 & 1\end{array}$

$\begin{array}{llll}32 & 21 & 24 & 1\end{array}$

$\begin{array}{llll}33 & 21 & 26 & 1\end{array}$

$\begin{array}{llll}34 & 21 & 28 & 1\end{array}$

$\begin{array}{llll}35 & 21 & 30 & 1\end{array}$

$\begin{array}{llll}36 & 21 & 32 & 1\end{array}$

$\begin{array}{llll}37 & 21 & 33 & 1\end{array}$

$\begin{array}{llll}38 & 21 & 35 & 1\end{array}$

$\begin{array}{llll}39 & 21 & 37 & 1\end{array}$

$\begin{array}{llll}40 & 21 & 39 & 1\end{array}$

$\begin{array}{llll}41 & 22 & 23 & 1\end{array}$

$\begin{array}{llll}42 & 23 & 24 & 1\end{array}$

$4323 \quad 30$ Ar

$\begin{array}{llll}44 & 24 & 26 & 1\end{array}$

$\begin{array}{llll}45 & 24 & 41 & 1\end{array}$

$\begin{array}{llll}46 & 25 & 30 & 1\end{array}$

$\begin{array}{llll}47 & 26 & 27 & 1\end{array}$

$48 \quad 26 \quad 28$ Ar

$\begin{array}{llll}49 & 28 & 29 & 1\end{array}$

$\begin{array}{llll}50 & 28 & 30 & \text { Ar }\end{array}$

$\begin{array}{llll}51 & 31 & 32 & 1\end{array}$

$\begin{array}{llll}52 & 32 & 33 & 1\end{array}$

$\begin{array}{llll}53 & 32 & 39 & \text { Ar }\end{array}$

$\begin{array}{llll}54 & 33 & 35 & 1\end{array}$

$\begin{array}{llll}55 & 33 & 58 & 1\end{array}$

$\begin{array}{llll}56 & 34 & 39 & 1\end{array}$

$\begin{array}{llll}57 & 35 & 36 & 1\end{array}$

$\begin{array}{llll}58 & 35 & 37 & \text { Ar }\end{array}$

$\begin{array}{llll}59 & 37 & 38 & 1\end{array}$

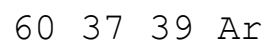

$\begin{array}{llll}61 & 40 & 41 & 1\end{array}$

$\begin{array}{llll}62 & 40 & 42 & 1\end{array}$

$\begin{array}{llll}63 & 40 & 46 & 1\end{array}$

$\begin{array}{llll}64 & 41 & 50 & 1\end{array}$ 


$$
\begin{array}{llll}
65 & 41 & 54 & 1 \\
66 & 42 & 43 & 1 \\
67 & 42 & 44 & 1 \\
68 & 42 & 45 & 1 \\
69 & 46 & 47 & 1 \\
70 & 46 & 48 & 1 \\
71 & 46 & 49 & 1 \\
72 & 50 & 51 & 1 \\
73 & 50 & 52 & 1 \\
74 & 50 & 53 & 1 \\
75 & 54 & 55 & 1 \\
76 & 54 & 56 & 1 \\
77 & 54 & 57 & 1 \\
78 & 58 & 59 & 1 \\
79 & 58 & 88 & 1 \\
80 & 58 & 92 & 1 \\
81 & 59 & 60 & 1 \\
82 & 59 & 80 & 1 \\
83 & 59 & 84 & 1 \\
84 & 60 & 61 & 1 \\
85 & 60 & 62 & 1 \\
86 & 60 & 63 & 1 \\
87 & 61 & 62 & 1 \\
88 & 61 & 63 & 1 \\
89 & 61 & 64 & 1 \\
90 & 61 & 65 & 1 \\
91 & 61 & 66 & 1 \\
92 & 61 & 67 & 1 \\
93 & 61 & 68 & 1 \\
94 & 61 & 69 & 1 \\
95 & 61 & 70 & 1 \\
96 & 62 & 65 & \text {Ar } \\
97 & 62 & 71 & 1 \\
98 & 63 & 64 & \text {Ar } \\
99 & 63 & 72 & 1 \\
100 & 64 & 65 & \text { Ar } \\
101 & 64 & 73 & 1 \\
102 & 65 & 74 & 1 \\
103 & 66 & 67 & \text {Ar } \\
104 & 66 & 70 & \text {Ar } \\
105 & 66 & 75 & 1 \\
106 & 67 & 68 & \text {Ar } \\
107 & 67 & 79 & 1 \\
108 & 68 & 69 & \text {Ar } \\
109 & 68 & 76 & 1 \\
110 & 69 & 70 & \text {Ar } \\
111 & 69 & 77 & 1 \\
112 & 70 & 78 & 1 \\
113 & 80 & 81 & 1 \\
114 & 80 & 82 & 1 \\
115 & 80 & 83 & 1 \\
116 & 84 & 85 & 1
\end{array}
$$


$\begin{array}{llll}117 & 84 & 86 & 1\end{array}$

$\begin{array}{llll}118 & 84 & 87 & 1\end{array}$

$\begin{array}{llll}119 & 88 & 89 & 1\end{array}$

$\begin{array}{llll}120 & 88 & 90 & 1\end{array}$

$\begin{array}{llll}121 & 88 & 91 & 1\end{array}$

$\begin{array}{llll}122 & 92 & 93 & 1\end{array}$

$\begin{array}{llll}123 & 92 & 94 & 1\end{array}$

$124 \quad 92951$

\section{A5.3: Compound 5a .mol2}

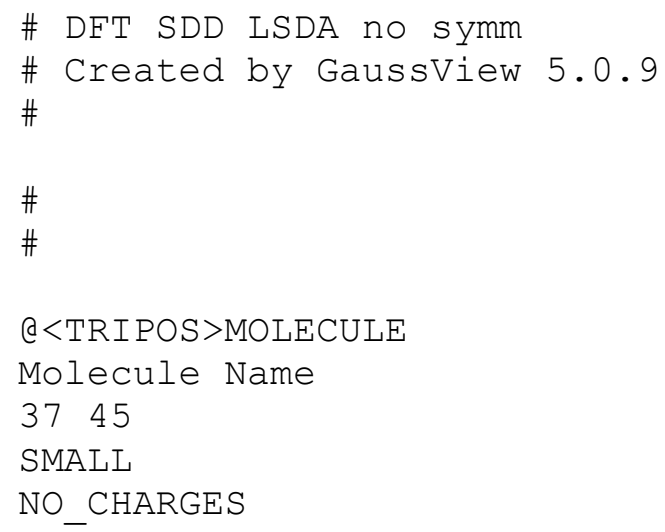

$\begin{array}{llccrl}1 & \text { Fe1 } & 0.0026 & 0.0200 & -0.0066 \mathrm{Fe} \\ 2 & \mathrm{C} 2 & -1.6263 & 1.0081 & -0.7527 \mathrm{C} \\ 3 \mathrm{C} 3 & -1.6165 & 0.9996 & 0.6967 \mathrm{C} \\ 4 & \mathrm{H} 4 & -1.5873 & -0.7338 & -2.2049 \mathrm{H} \\ 5 & \mathrm{C} 5 & -1.5983 & -0.3676 & 1.1587 \mathrm{C} \\ 6 & \mathrm{H} 6 & -1.5788 & -0.6953 & 2.1995 \mathrm{H} \\ 7 & \mathrm{C} 7 & -1.5882 & -1.2233 & -0.0006 \mathrm{C} \\ 8 & \mathrm{H} 8 & -1.5605 & -2.3142 & 0.0055 \mathrm{H} \\ 9 & \mathrm{C} 9 & -1.6006 & -0.3793 & -1.1713 \mathrm{C} \\ 10 & \mathrm{H} 10 & 1.5733 & 1.9212 & 1.3424 \mathrm{H} \\ 11 & \mathrm{C} 11 & 1.5966 & 1.0296 & 0.7108 \mathrm{C} \\ 12 & \mathrm{C} 12 & 1.6311 & 1.0200 & -0.7380 \mathrm{C} \\ 13 & \mathrm{H} 13 & 1.5559 & -0.6468 & 2.2342 \mathrm{H} \\ 14 & \mathrm{C} 14 & 1.6301 & -0.3728 & -1.1392 \mathrm{C} \\ 15 & \mathrm{H} 15 & 1.6386 & -0.7392 & -2.1688 \mathrm{H} \\ 16 & \mathrm{C} 16 & 1.6086 & -1.2024 & 0.0414 \mathrm{C} \\ 17 & \mathrm{H} 17 & 1.5945 & -2.2934 & 0.0610 \mathrm{H} \\ 18 & \mathrm{C} 18 & 1.5885 & -0.3321 & 1.1898 \mathrm{C} \\ 19 & \mathrm{H} 19 & -1.6150 & 1.8840 & 1.3388 \mathrm{H} \\ 20 & \text { Sn20 } & 1.4191 & 2.7151 & -2.0516 \mathrm{Sn} \\ 21 & \text { Sn21 } & -1.4162 & 2.7422 & -2.0142 \mathrm{Sn} \\ 22 & \text { C22 } & -2.3644 & 2.3182 & -3.9198 \mathrm{C} \\ 23 & \text { H23 } & -3.4414 & 2.1292 & -3.7643 \mathrm{H}\end{array}$




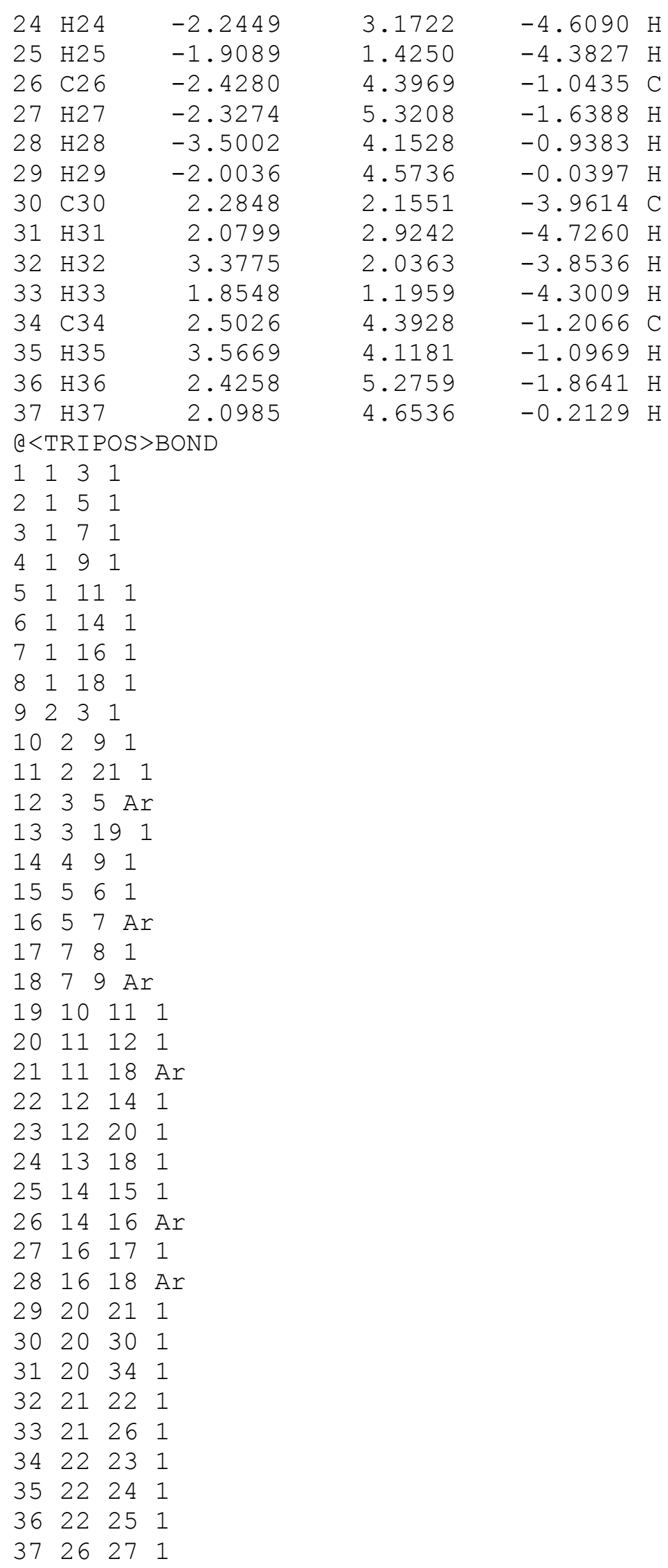


$\begin{array}{llll}38 & 26 & 28 & 1 \\ 39 & 26 & 29 & 1 \\ 40 & 30 & 31 & 1 \\ 41 & 30 & 32 & 1 \\ 42 & 30 & 33 & 1 \\ 43 & 34 & 35 & 1 \\ 44 & 34 & 36 & 1 \\ 45 & 34 & 37 & 1\end{array}$

A5.4: Compound 9b .mol2

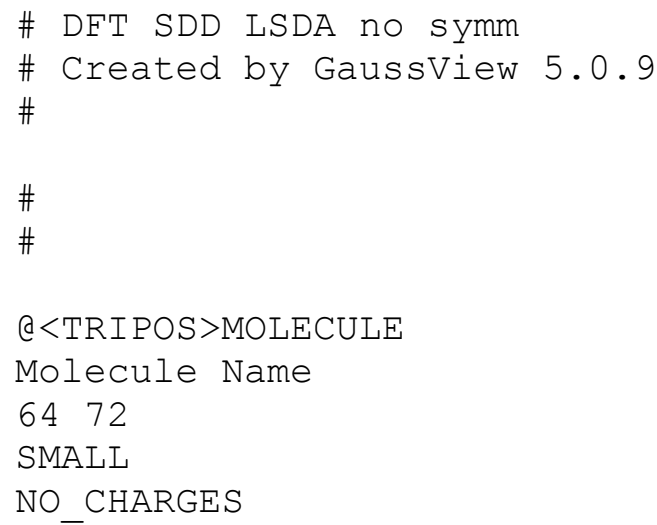




\begin{tabular}{|c|c|c|c|}
\hline 26 H26 & 3.9115 & 2.6137 & -3.9841 \\
\hline $27 \quad C 27$ & 2.7675 & 4.0922 & 0.1137 \\
\hline 28 H28 & 3.7570 & 3.9550 & 0.5868 \\
\hline 29 H29 & 2.6688 & 5.1436 & -0.2073 \\
\hline 30 H30 & 1.9800 & 3.8742 & 0.8583 \\
\hline 31 C31 & 0.3012 & 0.5863 & -3.8651 \\
\hline 32 H32 & -0.6090 & 0.4385 & -4.4818 \\
\hline 33 H33 & 0.3898 & -0.2834 & -3.1818 \\
\hline 34 C34 & -0.9749 & 3.8650 & -3.8755 \\
\hline 35 H35 & -0.1647 & 4.3190 & -4.4800 \\
\hline 36 Н36 & -1.4236 & 4.6683 & -3.2596 \\
\hline $37 \quad c 37$ & -3.3176 & 0.9612 & -0.1749 \\
\hline 38 H38 & -3.5841 & 0.5671 & 0.8219 \\
\hline 39 H39 & -3.9670 & 1.8223 & -0.4097 \\
\hline $40 \mathrm{H} 40$ & -3.4832 & 0.1706 & -0.9272 \\
\hline 41 C41 & -0.9022 & 3.0061 & 1.4191 \\
\hline $42 \mathrm{H} 42$ & -1.1834 & 4.0256 & 1.1041 \\
\hline $43 \mathrm{H} 43$ & -1.5041 & 2.7256 & 2.3022 \\
\hline 44 H4 4 & 0.1672 & 3.0038 & 1.7016 \\
\hline $45 \quad C 45$ & 1.5376 & 0.7220 & -4.7531 \\
\hline 46 H4 6 & 2.4602 & 0.7090 & -4.1291 \\
\hline 47 H 47 & 1.6210 & -0.1574 & -5.4297 \\
\hline $48 \quad C 48$ & -2.0261 & 3.2210 & -4.7768 \\
\hline 49 H 49 & -2.8378 & 2.7904 & -4.1541 \\
\hline 50 H50 & -1.5747 & 2.3668 & -5.3290 \\
\hline 51 C51 & 1.5620 & 1.9879 & -5.6021 \\
\hline 52 H52 & 0.5968 & 2.0890 & -6.1443 \\
\hline 53 H53 & 1.6271 & 2.8719 & -4.9279 \\
\hline $54 \quad C 54$ & 2.7255 & 2.0101 & -6.5813 \\
\hline 55 H55 & 2.6704 & 1.1547 & -7.2810 \\
\hline 56 H56 & 2.7474 & 2.9384 & -7.1800 \\
\hline 57 H57 & 3.6923 & 1.9343 & -6.0448 \\
\hline $58 C 58$ & -2.6212 & 4.1915 & -5.7981 \\
\hline 59 H59 & -3.4570 & 3.6944 & -6.3306 \\
\hline $60 \mathrm{H} 60$ & -3.0604 & 5.0581 & -5.2624 \\
\hline 61 C61 & -1.5916 & 4.6775 & -6.8105 \\
\hline 62 H62 & -2.0457 & 5.3316 & -7.5764 \\
\hline 63 H63 & -0.7824 & 5.2506 & -6.3201 \\
\hline 64 H64 & -1.1223 & 3.8195 & -7.3314 \\
\hline \multicolumn{4}{|c|}{ a $<$ TRIPOS $>$ BOND } \\
\hline \multicolumn{4}{|c|}{$\begin{array}{llll}1 & 1 & 3 & 1\end{array}$} \\
\hline $\begin{array}{llll}1 & 1 & 3 & 1 \\
2 & 1 & 5 & 1\end{array}$ & & & \\
\hline $\begin{array}{llll}3 & 1 & 7 & 1\end{array}$ & & & \\
\hline \multicolumn{4}{|c|}{$\begin{array}{llll}4 & 1 & 9 & 1\end{array}$} \\
\hline \multicolumn{4}{|c|}{$\begin{array}{llll}5 & 1 & 11 & 1\end{array}$} \\
\hline \multicolumn{4}{|c|}{$\begin{array}{llll}6 & 1 & 14 & 1\end{array}$} \\
\hline \multicolumn{4}{|c|}{$\begin{array}{llll}7 & 1 & 16 & 1\end{array}$} \\
\hline \multicolumn{4}{|c|}{$\begin{array}{lllll}8 & 1 & 18 & 1\end{array}$} \\
\hline \multicolumn{4}{|c|}{9231} \\
\hline \multicolumn{4}{|c|}{10291} \\
\hline \multicolumn{4}{|c|}{$\begin{array}{llll}11 & 2 & 21 & 1\end{array}$} \\
\hline 1235 & & & \\
\hline
\end{tabular}


$\begin{array}{llll}13 & 3 & 19 & 1\end{array}$

$\begin{array}{llll}14 & 4 & 9 & 1\end{array}$

$\begin{array}{llll}15 & 5 & 6 & 1\end{array}$

$1657 \mathrm{Ar}$

$\begin{array}{llll}17 & 7 & 8 & 1\end{array}$

1879 Ar

$\begin{array}{llll}19 & 10 & 11 & 1\end{array}$

$\begin{array}{llll}20 & 11 & 12 & 1\end{array}$

211118 Ar

$\begin{array}{llll}22 & 12 & 14 & 1\end{array}$

$\begin{array}{llll}23 & 12 & 20 & 1\end{array}$

$\begin{array}{llll}24 & 13 & 18 & 1\end{array}$

$\begin{array}{llll}25 & 14 & 15 & 1\end{array}$

$2614 \quad 16$ Ar

$\begin{array}{llll}27 & 16 & 17 & 1\end{array}$

281618 Ar

$\begin{array}{llll}29 & 20 & 22 & 1\end{array}$

$\begin{array}{llll}30 & 20 & 23 & 1\end{array}$

$\begin{array}{llll}31 & 20 & 27 & 1\end{array}$

$\begin{array}{llll}32 & 21 & 22 & 1\end{array}$

$\begin{array}{llll}33 & 21 & 37 & 1\end{array}$

$\begin{array}{llll}34 & 21 & 41 & 1\end{array}$

$\begin{array}{llll}35 & 22 & 31 & 1\end{array}$

$\begin{array}{llll}36 & 22 & 34 & 1\end{array}$

$\begin{array}{llll}37 & 23 & 24 & 1\end{array}$

$\begin{array}{llll}38 & 23 & 25 & 1\end{array}$

$\begin{array}{llll}39 & 23 & 26 & 1\end{array}$

$\begin{array}{llll}40 & 27 & 28 & 1\end{array}$

$\begin{array}{llll}41 & 27 & 29 & 1\end{array}$

$\begin{array}{llll}42 & 27 & 30 & 1\end{array}$

$\begin{array}{llll}43 & 31 & 32 & 1\end{array}$

$\begin{array}{llll}44 & 31 & 33 & 1\end{array}$

$\begin{array}{llll}45 & 31 & 45 & 1\end{array}$

$\begin{array}{llll}46 & 34 & 35 & 1\end{array}$

$\begin{array}{llll}47 & 34 & 36 & 1\end{array}$

$\begin{array}{llll}48 & 34 & 48 & 1\end{array}$

$\begin{array}{llll}49 & 37 & 38 & 1\end{array}$

$\begin{array}{llll}50 & 37 & 39 & 1\end{array}$

$\begin{array}{llll}51 & 37 & 40 & 1\end{array}$

$\begin{array}{llll}52 & 41 & 42 & 1\end{array}$

$\begin{array}{llll}53 & 41 & 43 & 1\end{array}$

$\begin{array}{llll}54 & 41 & 44 & 1\end{array}$

$\begin{array}{llll}55 & 45 & 46 & 1\end{array}$

$\begin{array}{llll}56 & 45 & 47 & 1\end{array}$

$\begin{array}{llll}57 & 45 & 51 & 1\end{array}$

$\begin{array}{llll}58 & 48 & 49 & 1\end{array}$

$\begin{array}{llll}59 & 48 & 50 & 1\end{array}$

$\begin{array}{llll}60 & 48 & 58 & 1\end{array}$

$\begin{array}{llll}61 & 51 & 52 & 1\end{array}$

$\begin{array}{llll}62 & 51 & 53 & 1\end{array}$

$\begin{array}{llll}63 & 51 & 54 & 1\end{array}$

$\begin{array}{llll}64 & 54 & 55 & 1\end{array}$ 
$\begin{array}{llll}65 & 54 & 56 & 1\end{array}$

$\begin{array}{llll}66 & 54 & 57 & 1\end{array}$

$\begin{array}{llll}67 & 58 & 59 & 1\end{array}$

$\begin{array}{llll}68 & 58 & 60 & 1\end{array}$

$\begin{array}{llll}69 & 58 & 61 & 1\end{array}$

$\begin{array}{llll}70 & 61 & 62 & 1\end{array}$

$\begin{array}{llll}71 & 61 & 63 & 1\end{array}$

$\begin{array}{llll}72 & 61 & 64 & 1\end{array}$

\section{A5.5: Compound 11 .mol2}

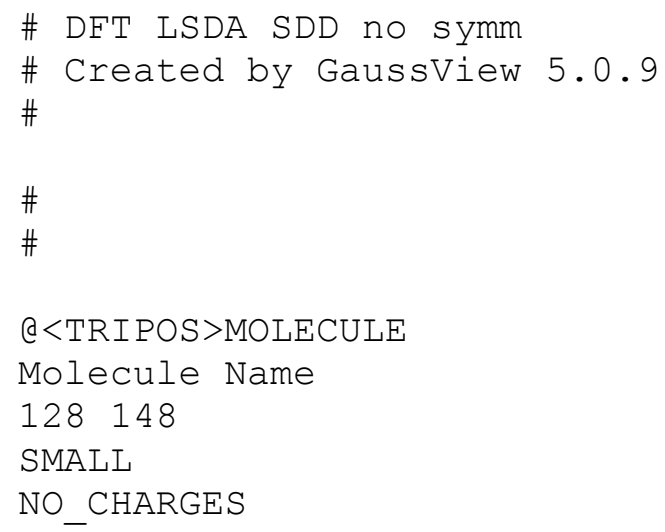




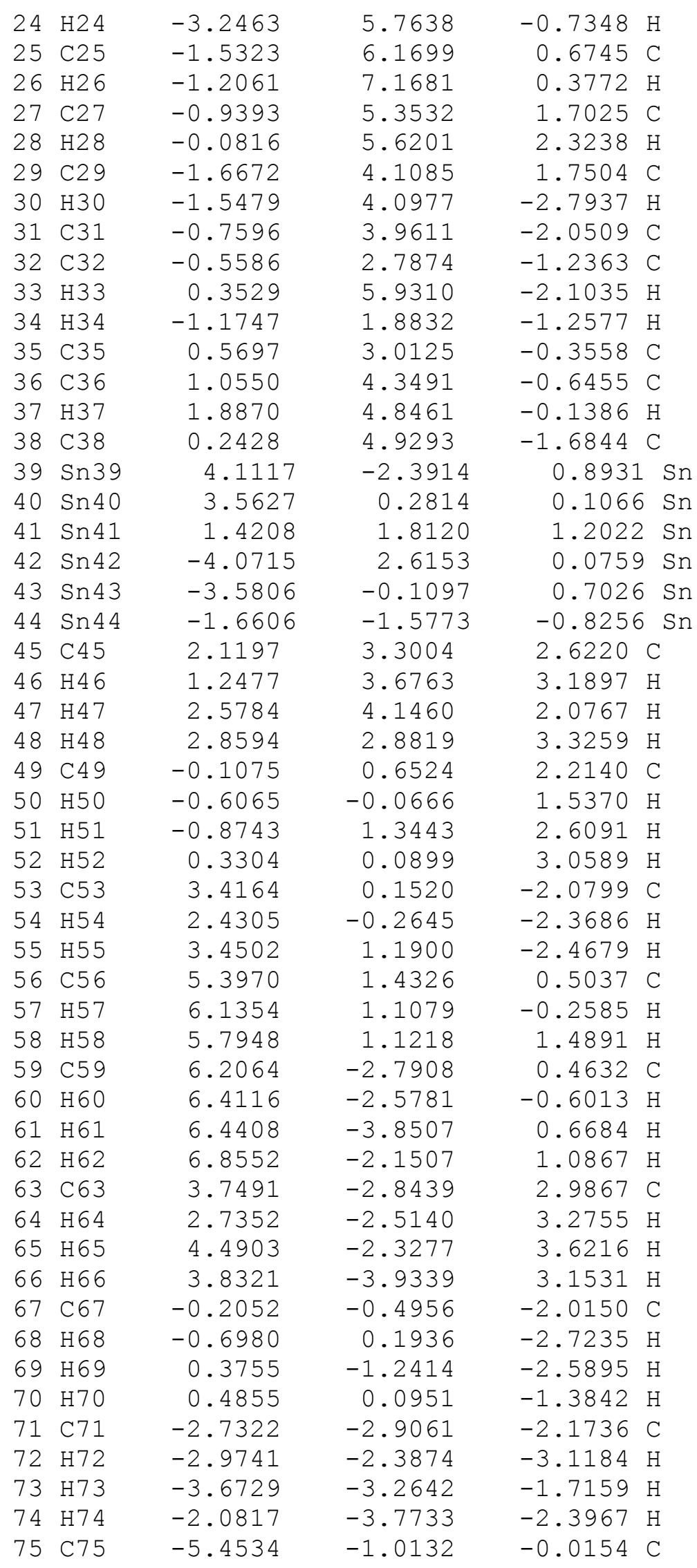




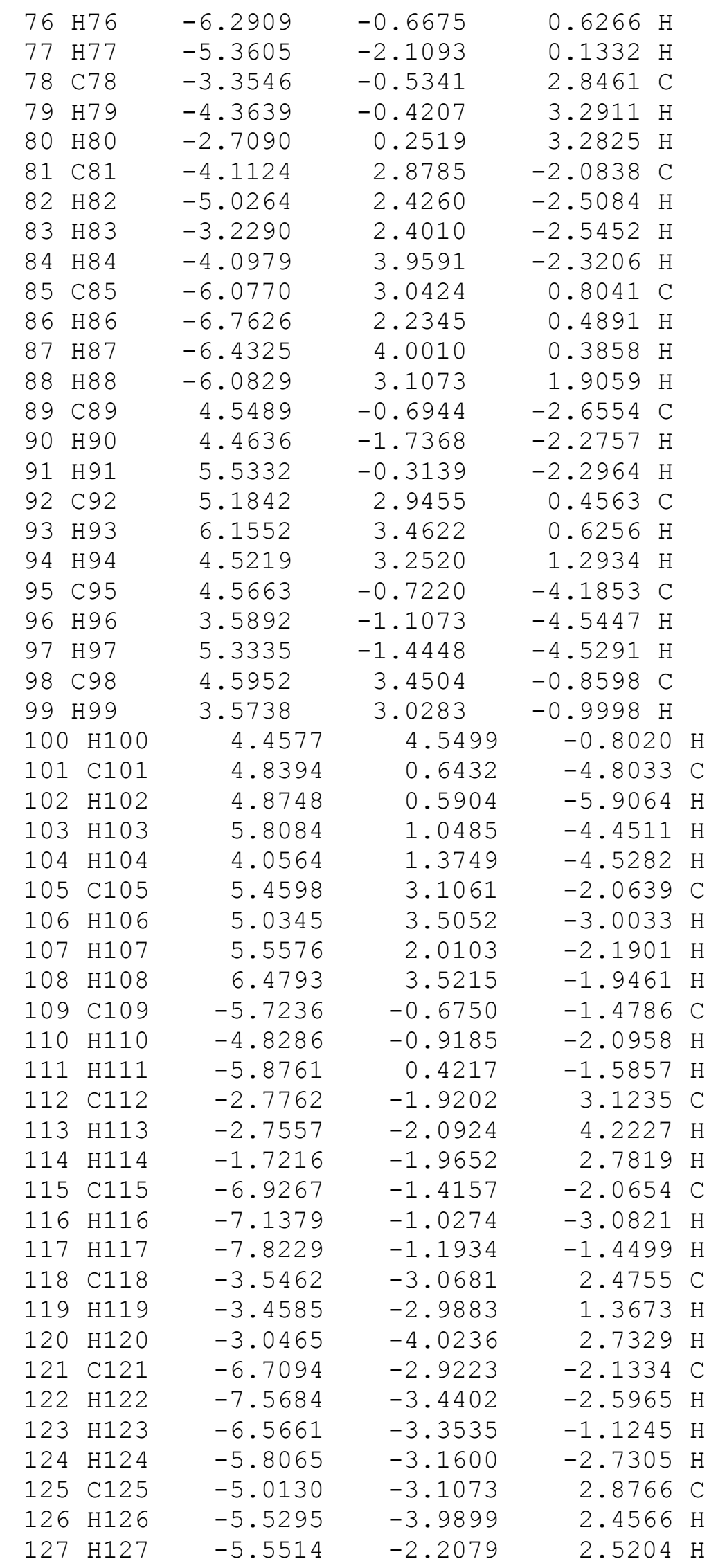




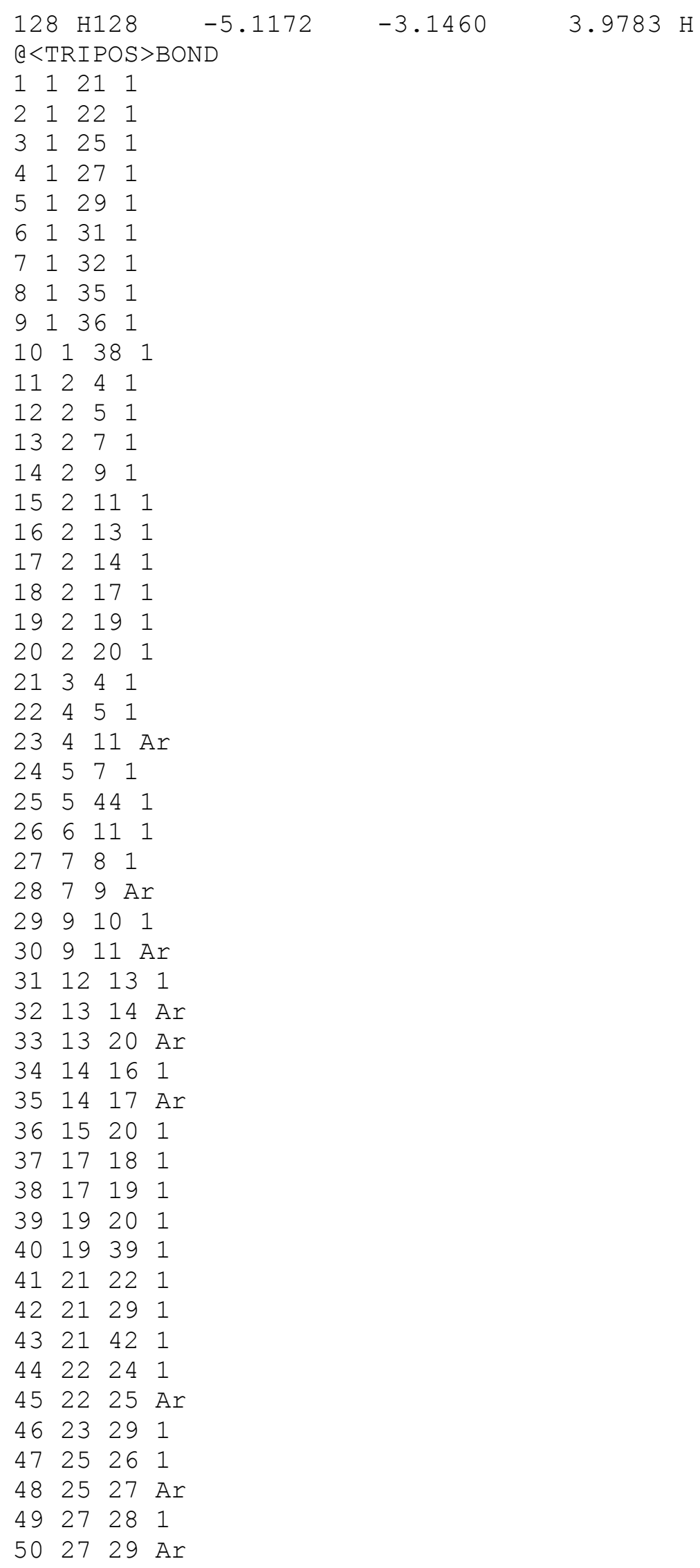


$\begin{array}{llll}51 & 30 & 31 & 1\end{array}$

$\begin{array}{llll}52 & 31 & 32 & \text { Ar }\end{array}$

$\begin{array}{llll}53 & 31 & 38 & \text { Ar }\end{array}$

$\begin{array}{llll}54 & 32 & 34 & 1\end{array}$

$\begin{array}{llll}55 & 32 & 35 & 1\end{array}$

$\begin{array}{llll}56 & 33 & 38 & 1\end{array}$

$\begin{array}{llll}57 & 35 & 36 & 1\end{array}$

$\begin{array}{llll}58 & 35 & 41 & 1\end{array}$

$\begin{array}{llll}59 & 36 & 37 & 1\end{array}$

603638 Ar

$\begin{array}{llll}61 & 39 & 40 & 1\end{array}$

$\begin{array}{llll}62 & 39 & 59 & 1\end{array}$

$\begin{array}{llll}63 & 39 & 63 & 1\end{array}$

$\begin{array}{llll}64 & 40 & 41 & 1\end{array}$

$\begin{array}{llll}65 & 40 & 53 & 1\end{array}$

$\begin{array}{llll}66 & 40 & 56 & 1\end{array}$

$\begin{array}{llll}67 & 41 & 45 & 1\end{array}$

$\begin{array}{llll}68 & 41 & 49 & 1\end{array}$

$\begin{array}{llll}69 & 42 & 43 & 1\end{array}$

$\begin{array}{llll}70 & 42 & 81 & 1\end{array}$

$\begin{array}{llll}71 & 42 & 85 & 1\end{array}$

$\begin{array}{llll}72 & 43 & 44 & 1\end{array}$

$\begin{array}{llll}73 & 43 & 75 & 1\end{array}$

$\begin{array}{llll}74 & 43 & 78 & 1\end{array}$

$\begin{array}{llll}75 & 44 & 67 & 1\end{array}$

$\begin{array}{llll}76 & 44 & 71 & 1\end{array}$

$\begin{array}{llll}77 & 45 & 46 & 1\end{array}$

$\begin{array}{llll}78 & 45 & 47 & 1\end{array}$

$\begin{array}{llll}79 & 45 & 48 & 1\end{array}$

$\begin{array}{llll}80 & 49 & 50 & 1\end{array}$

$\begin{array}{llll}81 & 49 & 51 & 1\end{array}$

$\begin{array}{llll}82 & 49 & 52 & 1\end{array}$

$\begin{array}{llll}83 & 53 & 54 & 1\end{array}$

$\begin{array}{llll}84 & 53 & 55 & 1\end{array}$

$\begin{array}{llll}85 & 53 & 89 & 1\end{array}$

$\begin{array}{llll}86 & 56 & 57 & 1\end{array}$

$\begin{array}{llll}87 & 56 & 58 & 1\end{array}$

$\begin{array}{llll}88 & 56 & 92 & 1\end{array}$

$\begin{array}{llll}89 & 59 & 60 & 1\end{array}$

$\begin{array}{llll}90 & 59 & 61 & 1\end{array}$

$\begin{array}{llll}91 & 59 & 62 & 1\end{array}$

$\begin{array}{llll}92 & 63 & 64 & 1\end{array}$

$\begin{array}{llll}93 & 63 & 65 & 1\end{array}$

$\begin{array}{llll}94 & 63 & 66 & 1\end{array}$

$\begin{array}{llll}95 & 67 & 68 & 1\end{array}$

$\begin{array}{llll}96 & 67 & 69 & 1\end{array}$

$\begin{array}{llll}97 & 67 & 70 & 1\end{array}$

$\begin{array}{llll}98 & 71 & 72 & 1\end{array}$

$\begin{array}{llll}99 & 71 & 73 & 1\end{array}$

$\begin{array}{llll}100 & 71 & 74 & 1\end{array}$

$\begin{array}{llll}101 & 75 & 76 & 1\end{array}$

$\begin{array}{llll}102 & 75 & 77 & 1\end{array}$ 
$\begin{array}{llll}103 & 75 & 109 & 1\end{array}$

$\begin{array}{llll}104 & 78 & 79 & 1\end{array}$

$\begin{array}{llll}105 & 78 & 80 & 1\end{array}$

$\begin{array}{llll}106 & 78 & 112 & 1\end{array}$

$\begin{array}{llll}107 & 81 & 82 & 1\end{array}$

$\begin{array}{lllll}108 & 81 & 83 & 1\end{array}$

$\begin{array}{llll}109 & 81 & 84 & 1\end{array}$

$\begin{array}{llll}110 & 85 & 86 & 1\end{array}$

$\begin{array}{llll}111 & 85 & 87 & 1\end{array}$

$\begin{array}{llll}112 & 85 & 88 & 1\end{array}$

$\begin{array}{llll}113 & 89 & 90 & 1\end{array}$

$\begin{array}{llll}114 & 89 & 91 & 1\end{array}$

$\begin{array}{llll}115 & 89 & 95 & 1\end{array}$

$\begin{array}{llll}116 & 92 & 93 & 1\end{array}$

$\begin{array}{llll}117 & 92 & 94 & 1\end{array}$

$\begin{array}{llll}118 & 92 & 98 & 1\end{array}$

$\begin{array}{llll}119 & 95 & 96 & 1\end{array}$

$\begin{array}{llll}120 & 95 & 97 & 1\end{array}$

$\begin{array}{llll}121 & 95 & 101 & 1\end{array}$

$\begin{array}{llll}122 & 98 & 99 & 1\end{array}$

$\begin{array}{llll}123 & 98 & 100 & 1\end{array}$

$\begin{array}{llll}124 & 98 & 105 & 1\end{array}$

$\begin{array}{llll}125 & 101 & 102 & 1\end{array}$

$\begin{array}{llll}126 & 101 & 103 & 1\end{array}$

$\begin{array}{llll}127 & 101 & 104 & 1\end{array}$

$\begin{array}{llll}128 & 105 & 106 & 1\end{array}$

$\begin{array}{llll}129 & 105 & 107 & 1\end{array}$

$\begin{array}{llll}130 & 105 & 108 & 1\end{array}$

$\begin{array}{llll}131 & 109 & 110 & 1\end{array}$

1321091111

$\begin{array}{llll}133 & 109 & 115 & 1\end{array}$

$\begin{array}{llll}134 & 112 & 113 & 1\end{array}$

$\begin{array}{llll}135 & 112 & 114 & 1\end{array}$

$\begin{array}{llll}136 & 112 & 118 & 1\end{array}$

$\begin{array}{llll}137 & 115 & 116 & 1\end{array}$

$\begin{array}{llll}138 & 115 & 117 & 1\end{array}$

$\begin{array}{llll}139 & 115 & 121 & 1\end{array}$

$\begin{array}{lllll}140 & 118 & 119 & 1\end{array}$

$\begin{array}{llll}141 & 118 & 120 & 1\end{array}$

$\begin{array}{llll}142 & 118 & 125 & 1\end{array}$

$\begin{array}{llll}143 & 121 & 122 & 1\end{array}$

$\begin{array}{llll}144 & 121 & 123 & 1\end{array}$

$\begin{array}{llll}145 & 121 & 124 & 1\end{array}$

$\begin{array}{llll}146 & 125 & 126 & 1\end{array}$

$\begin{array}{llll}147 & 125 & 127 & 1\end{array}$

$\begin{array}{llll}148 & 125 & 128 & 1\end{array}$

\section{A5.6: Compound 11 (mono cation) .mol2}

\# DFT LSDA SDD no symm 


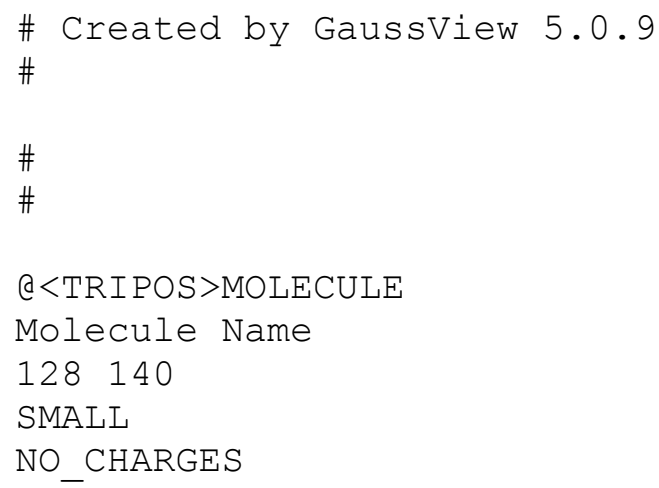




\begin{tabular}{|c|c|c|c|c|c|}
\hline 39 & $\operatorname{sn} 39$ & -3.9149 & -2.6020 & -0.792 & $0 \mathrm{Sr}$ \\
\hline 40 & $\operatorname{Sn} 40$ & -3.6062 & 0.1028 & 0.0215 & \\
\hline 41 & $\operatorname{Sn} 41$ & -1.6040 & 1.7498 & -1.181 & \\
\hline 42 & $\operatorname{Sn} 42$ & 3.9710 & 2.8060 & -0.020 & \\
\hline 43 & $\operatorname{Sn} 43$ & 3.6704 & 0.0796 & -0.762 & \\
\hline 44 & $\operatorname{Sn} 44$ & 1.8883 & -1.4595 & $0.881 \xi$ & \\
\hline 45 & C4 5 & -2.3715 & 3.1694 & -2.6277 & $\mathrm{C}$ \\
\hline 46 & H4 6 & -1.5218 & 3.5967 & -3.1926 & $\mathrm{H}$ \\
\hline 47 & H4 7 & -2.8985 & 3.9876 & -2.1035 & $\mathrm{H}$ \\
\hline 48 & H4 8 & -3.0707 & 2.6974 & -3.3386 & $\mathrm{H}$ \\
\hline 49 & C49 & 0.0497 & 0.6742 & -2.0852 & C \\
\hline 50 & H5O & 0.6599 & 0.1563 & -1.3189 & $\mathrm{H}$ \\
\hline 51 & H51 & 0.7015 & 1.3895 & -2.6209 & $\mathrm{H}$ \\
\hline 52 & H52 & -0.3160 & -0.0694 & -2.8166 & $\mathrm{H}$ \\
\hline 53 & C53 & -3.3994 & 0.0067 & 2.1996 & C \\
\hline 54 & H5 4 & -2.3689 & -0.2794 & 2.4927 & $\mathrm{H}$ \\
\hline 55 & H55 & -3.5652 & 1.0368 & 2.5747 & $\mathrm{H}$ \\
\hline 56 & C5 6 & -5.5103 & 1.1164 & -0.3913 & $\mathrm{C}$ \\
\hline 57 & H5 7 & -6.2140 & 0.7873 & 0.4005 & $\mathrm{H}$ \\
\hline 58 & H5 8 & -5.9052 & 0.7368 & -1.3530 & $\mathrm{H}$ \\
\hline 59 & C59 & -5.9552 & -3.1800 & -0.3319 & C \\
\hline 60 & H60 & -6.1646 & -2.9819 & 0.7344 & $\mathrm{H}$ \\
\hline 61 & H61 & -6.0994 & -4.2567 & -0.5311 & $\mathrm{H}$ \\
\hline 62 & H62 & -6.6675 & -2.6041 & -0.9480 & $\mathrm{H}$ \\
\hline 63 & C63 & -3.4401 & -3.1139 & -2.8432 & $\mathrm{C}$ \\
\hline 64 & H64 & -2.4378 & -2.7395 & -3.1182 & $\mathrm{H}$ \\
\hline 65 & H65 & -4.1837 & -2.6776 & -3.5322 & $\mathrm{H}$ \\
\hline 66 & H6 6 & -3.4581 & -4.2134 & -2.9601 & $\mathrm{H}$ \\
\hline 67 & C67 & 0.2931 & -0.4905 & 1.9935 & C \\
\hline 68 & H68 & 0.6819 & 0.3144 & 2.6417 & $\mathrm{H}$ \\
\hline 69 & H69 & -0.1713 & -1.2581 & 2.6407 & $\mathrm{H}$ \\
\hline 70 & $\mathrm{H} 7 \mathrm{O}$ & -0.4773 & -0.0657 & 1.3221 & $\mathrm{H}$ \\
\hline 71 & C71 & 3.0586 & -2.6175 & 2.2914 & C \\
\hline 72 & H72 & 3.3447 & -1.9945 & 3.1571 & $\mathrm{H}$ \\
\hline 73 & H73 & 3.9815 & -3.0025 & 1.8205 & $\mathrm{H}$ \\
\hline 74 & H7 4 & 2.4532 & -3.4696 & 2.6543 & $\mathrm{H}$ \\
\hline 75 & C75 & 5.5850 & -0.7458 & -0.0921 & C \\
\hline 76 & H7 6 & 6.3848 & -0.4064 & -0.7827 & $\mathrm{H}$ \\
\hline 77 & H77 & 5.5187 & -1.8487 & -0.1963 & $\mathrm{H}$ \\
\hline 78 & C78 & 3.3536 & -0.2918 & -2.8996 & C \\
\hline 79 & H79 & 4.3430 & -0.1446 & -3.3774 & $\mathrm{H}$ \\
\hline 80 & H8O & 2.6757 & 0.4898 & -3.2925 & $\mathrm{H}$ \\
\hline 81 & C81 & 3.9052 & 3.0275 & 2.1382 & C \\
\hline 82 & H82 & 4.7588 & 2.4957 & 2.5952 & $\mathrm{H}$ \\
\hline 83 & H83 & 2.9681 & 2.6119 & 2.5514 & $\mathrm{H}$ \\
\hline 84 & H8 4 & 3.9705 & 4.0985 & 2.4066 & $\mathrm{H}$ \\
\hline 85 & C85 & 5.9281 & 3.4362 & -0.7134 & $\mathrm{C}$ \\
\hline 86 & H8 6 & 6.6935 & 2.7121 & -0.3812 & $\mathrm{H}$ \\
\hline 87 & H87 & 6.1690 & 4.4284 & -0.2922 & $\mathrm{H}$ \\
\hline 88 & H8 8 & 5.9508 & 3.5008 & -1.8147 & $\mathrm{H}$ \\
\hline 89 & C89 & -4.4260 & -0.9637 & 2.7830 & $\mathrm{C}$ \\
\hline 90 & H9O & -4.1835 & -2.0022 & 2.4657 & $\mathrm{H}$ \\
\hline
\end{tabular}




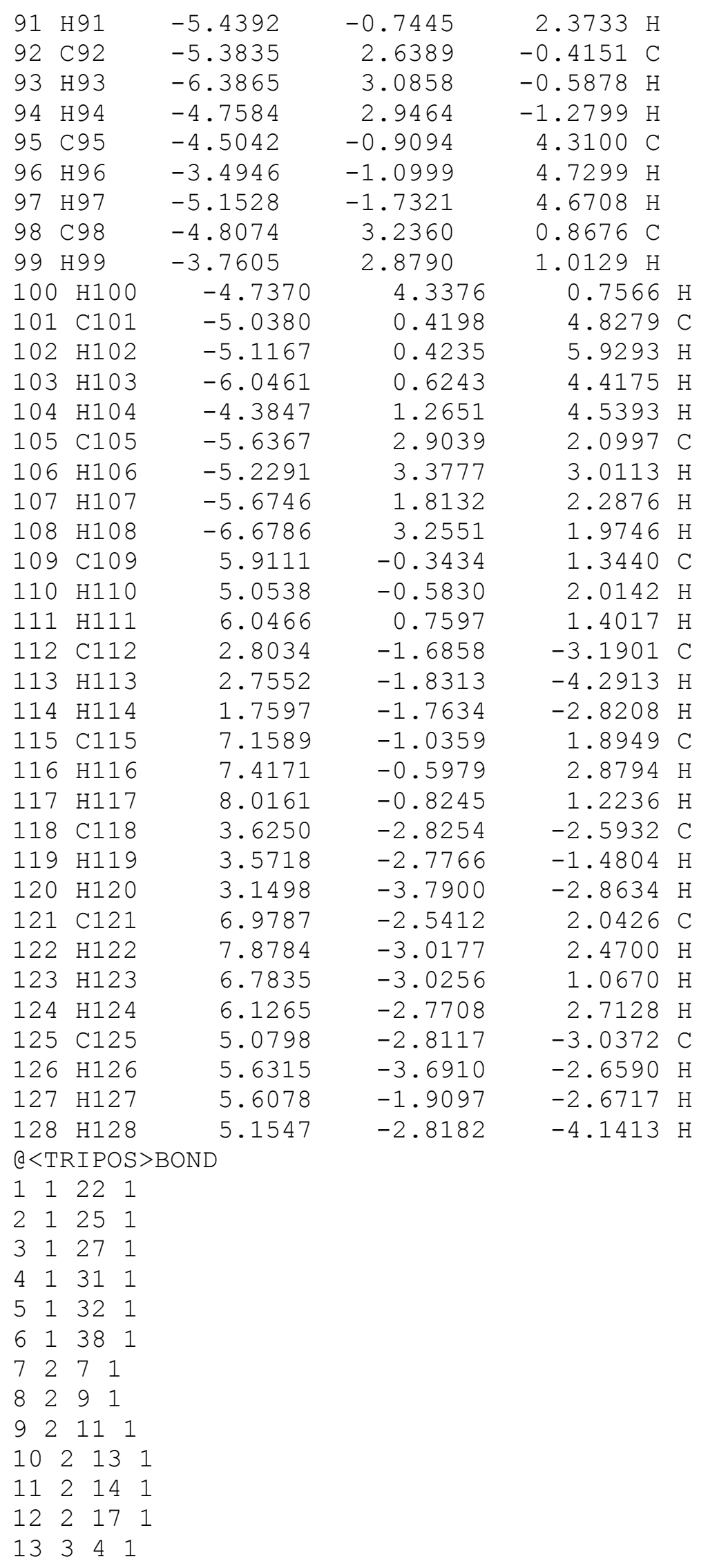


$1445 \mathrm{Ar}$

15411 Ar

1657 Ar

$\begin{array}{llll}17 & 5 & 44 & 1\end{array}$

$\begin{array}{llll}18 & 6 & 11 & 1\end{array}$

$\begin{array}{llll}19 & 7 & 8 & 1\end{array}$

2079 Ar

$\begin{array}{llll}21 & 9 & 10 & 1\end{array}$

22911 Ar

$\begin{array}{llll}23 & 12 & 13 & 1\end{array}$

241314 Ar

251320 Ar

$\begin{array}{llll}26 & 14 & 16 & 1\end{array}$

$27 \quad 14 \quad 17$ Ar

$\begin{array}{llll}28 & 15 & 20 & 1\end{array}$

$\begin{array}{llll}29 & 17 & 18 & 1\end{array}$

301719 Ar

311920 Ar

$\begin{array}{llll}32 & 19 & 39 & 1\end{array}$

$\begin{array}{llll}33 & 21 & 22 & 1\end{array}$

342129 Ar

$\begin{array}{llll}35 & 21 & 42 & 1\end{array}$

$\begin{array}{llll}36 & 22 & 24 & 1\end{array}$

$\begin{array}{llll}37 & 22 & 25 & \text { Ar }\end{array}$

$\begin{array}{llll}38 & 23 & 29 & 1\end{array}$

$\begin{array}{llll}39 & 25 & 26 & 1\end{array}$

402527 Ar

$\begin{array}{llll}41 & 27 & 28 & 1\end{array}$

422729 Ar

$\begin{array}{llll}43 & 30 & 31 & 1\end{array}$

443132 Ar

453138 Ar

$\begin{array}{llll}46 & 32 & 34 & 1\end{array}$

$47 \quad 32 \quad 35$ Ar

$\begin{array}{llll}48 & 33 & 38 & 1\end{array}$

$4935 \quad 36$ Ar

$\begin{array}{llll}50 & 35 & 41 & 1\end{array}$

$\begin{array}{llll}51 & 36 & 37 & 1\end{array}$

523638 Ar

$\begin{array}{llll}53 & 39 & 40 & 1\end{array}$

$\begin{array}{llll}54 & 39 & 59 & 1\end{array}$

$\begin{array}{llll}55 & 39 & 63 & 1\end{array}$

$\begin{array}{llll}56 & 40 & 41 & 1\end{array}$

$\begin{array}{llll}57 & 40 & 53 & 1\end{array}$

$\begin{array}{llll}58 & 40 & 56 & 1\end{array}$

$\begin{array}{llll}59 & 41 & 45 & 1\end{array}$

$\begin{array}{llll}60 & 41 & 49 & 1\end{array}$

$\begin{array}{llll}61 & 42 & 43 & 1\end{array}$

$\begin{array}{llll}62 & 42 & 81 & 1\end{array}$

$\begin{array}{llll}63 & 42 & 85 & 1\end{array}$

$\begin{array}{llll}64 & 43 & 44 & 1\end{array}$

$\begin{array}{llll}65 & 43 & 75 & 1\end{array}$ 


$$
\begin{array}{llll}
66 & 43 & 78 & 1 \\
67 & 44 & 67 & 1 \\
68 & 44 & 71 & 1 \\
69 & 45 & 46 & 1 \\
70 & 45 & 47 & 1 \\
71 & 45 & 48 & 1 \\
72 & 49 & 50 & 1 \\
73 & 49 & 51 & 1 \\
74 & 49 & 52 & 1 \\
75 & 53 & 54 & 1 \\
76 & 53 & 55 & 1 \\
77 & 53 & 89 & 1 \\
78 & 56 & 57 & 1 \\
79 & 56 & 58 & 1 \\
80 & 56 & 92 & 1 \\
81 & 59 & 60 & 1 \\
82 & 59 & 61 & 1 \\
83 & 59 & 62 & 1 \\
84 & 63 & 64 & 1 \\
85 & 63 & 65 & 1 \\
86 & 63 & 66 & 1 \\
87 & 67 & 68 & 1 \\
88 & 67 & 69 & 1 \\
89 & 67 & 70 & 1 \\
90 & 71 & 72 & 1 \\
91 & 71 & 73 & 1 \\
92 & 71 & 74 & 1 \\
93 & 75 & 76 & 1 \\
94 & 75 & 77 & 1 \\
95 & 75 & 109 & 1 \\
96 & 78 & 79 & 1 \\
97 & 78 & 80 & 1 \\
98 & 78 & 112 & 1 \\
99 & 81 & 82 & 1 \\
100 & 81 & 83 & 1 \\
101 & 81 & 84 & 1 \\
102 & 85 & 86 & 1 \\
103 & 85 & 87 & 1 \\
104 & 85 & 88 & 1 \\
105 & 89 & 90 & 1 \\
106 & 89 & 91 & 1 \\
107 & 89 & 95 & 1 \\
108 & 92 & 93 & 1 \\
109 & 92 & 94 & 1 \\
110 & 92 & 98 & 1 \\
111 & 95 & 96 & 1 \\
112 & 95 & 97 & 1 \\
113 & 95 & 101 & 1 \\
114 & 98 & 99 & 1 \\
115 & 98 & 100 & 1 \\
116 & 98 & 105 & 1 \\
117 & 101 & 102 & 1 \\
& & & \\
71 & \\
71
\end{array}
$$




$\begin{array}{llll}118 & 101 & 103 & 1 \\ 119 & 101 & 104 & 1 \\ 120 & 105 & 106 & 1 \\ 121 & 105 & 107 & 1 \\ 122 & 105 & 108 & 1 \\ 123 & 109 & 110 & 1 \\ 124 & 109 & 111 & 1 \\ 125 & 109 & 115 & 1 \\ 126 & 112 & 113 & 1 \\ 127 & 112 & 114 & 1 \\ 128 & 112 & 118 & 1 \\ 129 & 115 & 116 & 1 \\ 130 & 115 & 117 & 1 \\ 131 & 115 & 121 & 1 \\ 132 & 118 & 119 & 1 \\ 133 & 118 & 120 & 1 \\ 134 & 118 & 125 & 1 \\ 135 & 121 & 122 & 1 \\ 136 & 121 & 123 & 1 \\ 137 & 121 & 124 & 1 \\ 138 & 125 & 126 & 1 \\ 139 & 125 & 127 & 1 \\ 140 & 125 & 128 & 1\end{array}$

A5.7: Compound 12a .mol2

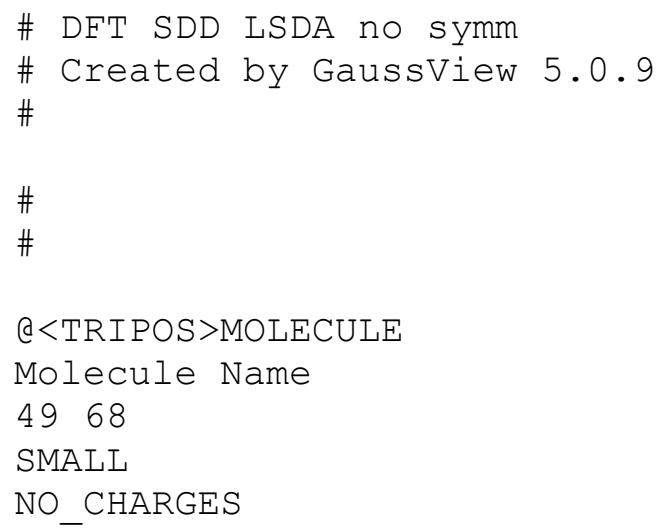




\begin{tabular}{|c|c|c|c|}
\hline $10 \mathrm{H} 10$ & 1.7321 & 4.0250 & $-1.0051 \mathrm{H}$ \\
\hline $11 \mathrm{C} 11$ & 1.9902 & 2.8460 & $0.9096 \mathrm{C}$ \\
\hline $12 \mathrm{H} 12$ & -1.0913 & 1.3066 & $2.7648 \mathrm{H}$ \\
\hline $13 \mathrm{C} 13$ & -1.2717 & 1.9157 & $1.8757 \mathrm{C}$ \\
\hline $14 \mathrm{C} 14$ & -0.9235 & 1.5425 & $0.5206 \mathrm{C}$ \\
\hline $15 \mathrm{H} 15$ & -2.1893 & 3.7970 & $2.7352 \mathrm{H}$ \\
\hline $16 \mathrm{C} 16$ & -1.2990 & 2.6559 & $-0.3240 \mathrm{C}$ \\
\hline $17 \mathrm{H} 17$ & -1.1551 & 2.7080 & $-1.4059 \mathrm{H}$ \\
\hline $18 \mathrm{C} 18$ & -1.8650 & 3.6956 & $0.4977 \mathrm{C}$ \\
\hline 19 H19 & -2.2251 & 4.6653 & $0.1501 \mathrm{H}$ \\
\hline $0 \quad \mathrm{C} 20$ & -1.8483 & 3.2358 & $1.8637 \mathrm{C}$ \\
\hline Fe21 & -0.5149 & -3.1910 & $-1.1277 \mathrm{Fe}$ \\
\hline 2 H22 & -1.3061 & -1.0750 & $-2.7875 \mathrm{H}$ \\
\hline $23 \quad 23$ & -1.5691 & -1.6596 & $-1.9026 \mathrm{C}$ \\
\hline $24 \quad C 24$ & -1.1608 & -1.3625 & $-0.5463 \mathrm{C}$ \\
\hline $25 \mathrm{H} 25$ & -2.7918 & -3.3515 & $-2.7749 \mathrm{H}$ \\
\hline $26 \mathrm{C} 26$ & -1.7122 & -2.4078 & $0.2893 \mathrm{C}$ \\
\hline $27 \mathrm{H} 27$ & -1.5694 & -2.4970 & $1.3689 \mathrm{H}$ \\
\hline $28 \quad c 28$ & -2.4442 & -3.3314 & $-0.5384 \mathrm{C}$ \\
\hline 9 H29 & -2.9568 & -4.2328 & $-0.1986 \mathrm{H}$ \\
\hline $30 \mathrm{C} 30$ & -2.3555 & -2.8669 & $-1.8999 \mathrm{C}$ \\
\hline 31 H31 & 2.1103 & -2.2170 & $-0.8104 \mathrm{H}$ \\
\hline $32 \quad$ C32 & 1.5026 & -3.0928 & $-1.0492 \mathrm{C}$ \\
\hline 33 C33 & 1.0584 & -3.4726 & $-2.3667 \mathrm{C}$ \\
\hline 34 Н34 & 1.1400 & -4.0424 & $0.9727 \mathrm{H}$ \\
\hline 35 H35 & 1.2685 & -2.9355 & $-3.2933 \mathrm{H}$ \\
\hline $36 \mathrm{c} 36$ & 0.2779 & -4.6783 & $-2.2429 \mathrm{C}$ \\
\hline 37 H37 & -0.2129 & -5.2113 & $-3.0587 \mathrm{H}$ \\
\hline 38 C38 & 0.2377 & -5.0420 & $-0.8478 \mathrm{C}$ \\
\hline 39 H39 & -0.2875 & -5.8992 & $-0.4239 \mathrm{H}$ \\
\hline $10 \quad C 40$ & 0.9942 & -4.0605 & $-0.1091 \mathrm{C}$ \\
\hline $41 \quad \mathrm{C} 41$ & 1.1601 & 0.4138 & $-1.4129 \mathrm{C}$ \\
\hline $42 \mathrm{H} 42$ & 2.2080 & 0.1510 & $-1.1720 \mathrm{H}$ \\
\hline $43 \mathrm{H} 43$ & 1.1270 & 1.4969 & $-1.6342 \mathrm{H}$ \\
\hline 44 H44 & 0.8767 & -0.1514 & $-2.3202 \mathrm{H}$ \\
\hline $45 \quad C 45$ & 0.8964 & -0.6274 & $1.5519 \mathrm{C}$ \\
\hline 46 H4 6 & 1.5532 & 0.1611 & $1.9639 \mathrm{H}$ \\
\hline 47 H4 7 & 1.5056 & -1.5197 & $1.3184 \mathrm{H}$ \\
\hline 48 H4 8 & 0.1723 & -0.9109 & $2.3397 \mathrm{H}$ \\
\hline 19 Si 49 & -0.0033 & -0.0057 & $0.0176 \mathrm{Si}$ \\
\hline \multicolumn{4}{|c|}{$\mathrm{a}<\mathrm{TRIPOS}>\mathrm{BOND}$} \\
\hline \multicolumn{4}{|l|}{$\begin{array}{lll}1 & 1 & 3\end{array}$} \\
\hline \multicolumn{4}{|l|}{$\begin{array}{llll}2 & 1 & 4 & 1\end{array}$} \\
\hline \multicolumn{4}{|l|}{$\begin{array}{llll}3 & 1 & 7 & 1\end{array}$} \\
\hline \multicolumn{4}{|l|}{$\begin{array}{llll}4 & 1 & 9 & 1\end{array}$} \\
\hline \multicolumn{4}{|l|}{$\begin{array}{llll}5 & 1 & 11 & 1\end{array}$} \\
\hline \multicolumn{4}{|l|}{$\begin{array}{llll}6 & 1 & 13 & 1\end{array}$} \\
\hline \multicolumn{4}{|l|}{$\begin{array}{llll}7 & 1 & 14 & 1\end{array}$} \\
\hline \multicolumn{4}{|l|}{$\begin{array}{lllll}8 & 1 & 16 & 1\end{array}$} \\
\hline \multicolumn{4}{|l|}{$\begin{array}{llll}9 & 1 & 18 & 1\end{array}$} \\
\hline \multicolumn{4}{|c|}{$\begin{array}{llll}10 & 1 & 20 & 1\end{array}$} \\
\hline 231 & & & \\
\hline
\end{tabular}




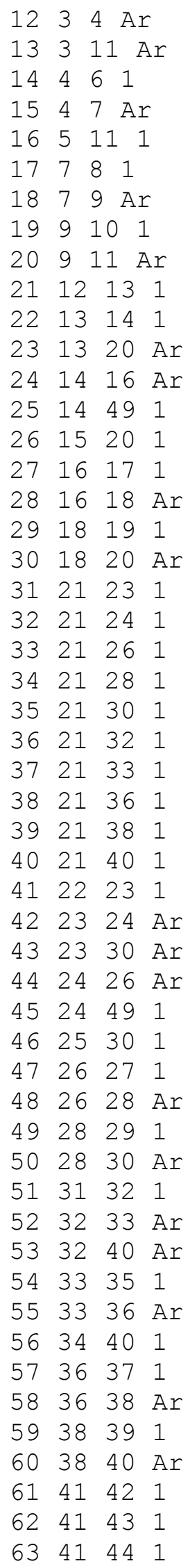




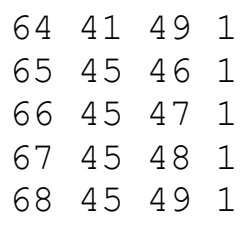

A5.8: Compound 12b .mol2

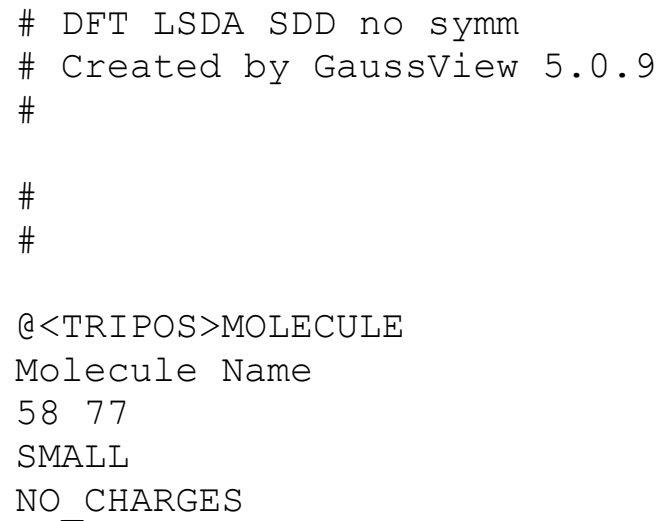




\begin{tabular}{|c|c|c|c|c|c|}
\hline 28 & C28 & 3.9631 & -2.2837 & 0.4404 & C \\
\hline 29 & H29 & 4.6389 & -2.9359 & 0.9961 & $\mathrm{H}$ \\
\hline 30 & C30 & 3.8664 & -2.1856 & -0.9948 & $\mathrm{C}$ \\
\hline 31 & H31 & 4.8169 & 1.3908 & -2.2939 & $\mathrm{H}$ \\
\hline 32 & C32 & 5.1407 & 1.0822 & -1.2983 & $\mathrm{C}$ \\
\hline 33 & C33 & 6.1295 & 0.0752 & -1.0017 & $\mathrm{C}$ \\
\hline 34 & H34 & 3.8797 & 2.3712 & 0.0698 & $\mathrm{H}$ \\
\hline 35 & H35 & 6.6870 & -0.5117 & -1.7334 & $\mathrm{H}$ \\
\hline 36 & C36 & 6.2363 & -0.0360 & 0.4320 & $\mathrm{C}$ \\
\hline 37 & H37 & 6.8884 & -0.7222 & 0.9747 & $\mathrm{H}$ \\
\hline 38 & C38 & 5.3137 & 0.9027 & 1.0219 & $\mathrm{C}$ \\
\hline 39 & H39 & 5.1448 & 1.0520 & 2.0897 & $\mathrm{H}$ \\
\hline 40 & $\mathrm{C} 40$ & 4.6403 & 1.5958 & -0.0478 & C \\
\hline 41 & $\mathrm{C} 41$ & -1.1117 & -1.5821 & 1.5277 & C \\
\hline 42 & H4 2 & -2.0927 & -2.0918 & 1.5720 & $\mathrm{H}$ \\
\hline 43 & H4 3 & -0.9681 & -1.0390 & 2.4810 & $\mathrm{H}$ \\
\hline 44 & H4 4 & -0.3157 & -2.3455 & 1.4506 & $\mathrm{H}$ \\
\hline 45 & C45 & -1.1408 & -1.2696 & -1.6002 & C \\
\hline 46 & H 46 & -1.1646 & -0.5330 & -2.4260 & $\mathrm{H}$ \\
\hline 47 & $\mathrm{H} 47$ & -2.0502 & -1.8947 & -1.6780 & $\mathrm{H}$ \\
\hline 48 & $\mathrm{H} 48$ & -0.2533 & -1.9140 & -1.7461 & $\mathrm{H}$ \\
\hline 49 & C49 & 1.2040 & 1.8230 & -1.4116 & $\mathrm{C}$ \\
\hline 50 & H5O & 0.9851 & 1.2521 & -2.3341 & $\mathrm{H}$ \\
\hline 51 & H51 & 2.2269 & 2.2348 & -1.5019 & $\mathrm{H}$ \\
\hline 52 & H52 & 0.4866 & 2.6619 & -1.3546 & $\mathrm{H}$ \\
\hline 53 & C53 & 1.3466 & 1.6138 & 1.7255 & C \\
\hline 54 & H5 4 & 0.6022 & 2.4186 & 1.8653 & $\mathrm{H}$ \\
\hline 55 & H55 & 2.3590 & 2.0597 & 1.7553 & $\mathrm{H}$ \\
\hline 56 & H5 6 & 1.2574 & 0.9178 & 2.5809 & $\mathrm{H}$ \\
\hline 57 & Si 57 & 1.0628 & 0.6991 & 0.0991 & $\mathrm{Si}$ \\
\hline 58 & Si 58 & -1.0383 & -0.3864 & 0.0678 & $\mathrm{Si}$ \\
\hline \multicolumn{6}{|c|}{ a $<$ TRIPOS $>$ BOND } \\
\hline \\
\hline \multicolumn{2}{|c|}{$\begin{array}{llll}1 & 1 & 3 & 1 \\
2 & 1 & 4 & 1\end{array}$} & & & & \\
\hline \multicolumn{6}{|c|}{$\begin{array}{llll}3 & 1 & 7 & 1\end{array}$} \\
\hline \multicolumn{6}{|c|}{$\begin{array}{llll}4 & 1 & 9 & 1\end{array}$} \\
\hline \multicolumn{6}{|c|}{$\begin{array}{llll}5 & 1 & 11 & 1\end{array}$} \\
\hline \multicolumn{6}{|c|}{$\begin{array}{llll}6 & 1 & 13 & 1\end{array}$} \\
\hline \multicolumn{6}{|c|}{$\begin{array}{llll}7 & 1 & 14 & 1\end{array}$} \\
\hline \multicolumn{6}{|c|}{$\begin{array}{lllll}8 & 1 & 16 & 1\end{array}$} \\
\hline \multicolumn{6}{|c|}{$\begin{array}{llll}9 & 1 & 18 & 1\end{array}$} \\
\hline \multicolumn{6}{|c|}{$\begin{array}{llll}10 & 1 & 20 & 1\end{array}$} \\
\hline \multicolumn{6}{|c|}{11231} \\
\hline \multicolumn{6}{|c|}{$1234 \mathrm{Ar}$} \\
\hline \multicolumn{6}{|c|}{13311 Ar } \\
\hline \multicolumn{6}{|c|}{14461} \\
\hline \multicolumn{6}{|c|}{1547 Ar } \\
\hline \multicolumn{6}{|c|}{$\begin{array}{llll}16 & 5 & 11 & 1\end{array}$} \\
\hline \multicolumn{6}{|c|}{17781} \\
\hline \multicolumn{6}{|c|}{$1879 \mathrm{Ar}$} \\
\hline \multicolumn{6}{|c|}{$\begin{array}{llll}19 & 9 & 10 & 1\end{array}$} \\
\hline 20 & 911 & & & & \\
\hline
\end{tabular}


$\begin{array}{llll}21 & 12 & 13 & 1\end{array}$

$\begin{array}{llll}22 & 13 & 14 & 1\end{array}$

231320 Ar

$\begin{array}{llll}24 & 14 & 16 & 1\end{array}$

$\begin{array}{llll}25 & 14 & 58 & 1\end{array}$

$\begin{array}{llll}26 & 15 & 20 & 1\end{array}$

$\begin{array}{llll}27 & 16 & 17 & 1\end{array}$

$2816 \quad 18$ Ar

$\begin{array}{llll}29 & 18 & 19 & 1\end{array}$

301820 Ar

$\begin{array}{llll}31 & 21 & 23 & 1\end{array}$

$\begin{array}{llll}32 & 21 & 24 & 1\end{array}$

$\begin{array}{llll}33 & 21 & 26 & 1\end{array}$

$\begin{array}{llll}34 & 21 & 28 & 1\end{array}$

$\begin{array}{llll}35 & 21 & 30 & 1\end{array}$

$\begin{array}{llll}36 & 21 & 32 & 1\end{array}$

$\begin{array}{llll}37 & 21 & 33 & 1\end{array}$

$\begin{array}{llll}38 & 21 & 36 & 1\end{array}$

$\begin{array}{llll}39 & 21 & 38 & 1\end{array}$

$\begin{array}{llll}40 & 21 & 40 & 1\end{array}$

$\begin{array}{llll}41 & 22 & 23 & 1\end{array}$

$\begin{array}{llll}42 & 23 & 24 & 1\end{array}$

$4323 \quad 30 \mathrm{Ar}$

$\begin{array}{llll}44 & 24 & 26 & 1\end{array}$

$\begin{array}{llll}45 & 24 & 57 & 1\end{array}$

$\begin{array}{llll}46 & 25 & 30 & 1\end{array}$

$\begin{array}{llll}47 & 26 & 27 & 1\end{array}$

482628 Ar

$\begin{array}{llll}49 & 28 & 29 & 1\end{array}$

$\begin{array}{llll}50 & 28 \quad 30 & \text { Ar }\end{array}$

$\begin{array}{llll}51 & 31 & 32 & 1\end{array}$

523233 Ar

$53 \quad 3240$ Ar

$\begin{array}{llll}54 & 33 & 35 & 1\end{array}$

$5533 \quad 36$ Ar

$\begin{array}{llll}56 & 34 & 40 & 1\end{array}$

$\begin{array}{llll}57 & 36 & 37 & 1\end{array}$

583638 Ar

$\begin{array}{llll}59 & 38 & 39 & 1\end{array}$

603840 Ar

$\begin{array}{llll}61 & 41 & 42 & 1\end{array}$

$\begin{array}{llll}62 & 41 & 43 & 1\end{array}$

$\begin{array}{llll}63 & 41 & 44 & 1\end{array}$

$\begin{array}{llll}64 & 41 & 58 & 1\end{array}$

$\begin{array}{llll}65 & 45 & 46 & 1\end{array}$

$\begin{array}{llll}66 & 45 & 47 & 1\end{array}$

$\begin{array}{llll}67 & 45 & 48 & 1\end{array}$

$\begin{array}{llll}68 & 45 & 58 & 1\end{array}$

$\begin{array}{llll}69 & 49 & 50 & 1\end{array}$

$\begin{array}{llll}70 & 49 & 51 & 1\end{array}$

$\begin{array}{llll}71 & 49 & 52 & 1\end{array}$

$\begin{array}{llll}72 & 49 & 57 & 1\end{array}$ 
$\begin{array}{llll}73 & 53 & 54 & 1\end{array}$

$\begin{array}{llll}74 & 53 & 55 & 1\end{array}$

$\begin{array}{llll}75 & 53 & 56 & 1\end{array}$

$\begin{array}{llll}76 & 53 & 57 & 1\end{array}$

$\begin{array}{llll}77 & 57 & 58 & 1\end{array}$

\section{A5.9: Compound 12c .mol2}

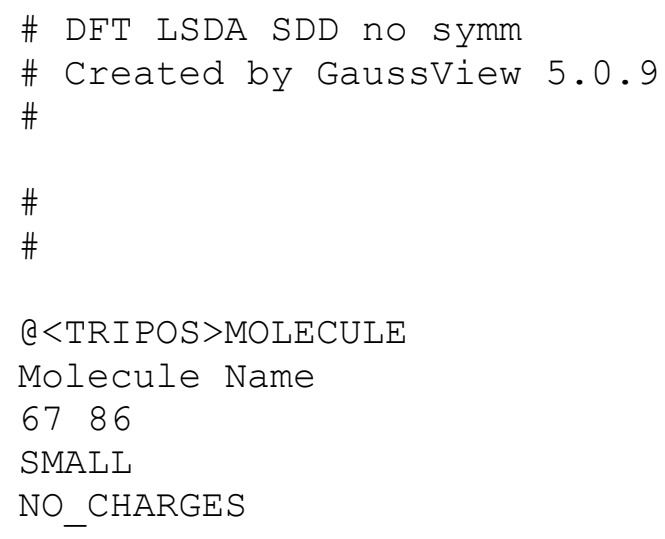




\begin{tabular}{|c|c|c|c|c|c|}
\hline 28 & $\mathrm{C} 28$ & 7.6023 & 2.5935 & -1.3019 & $\mathrm{C}$ \\
\hline 29 & H2 9 & 8.3615 & 2.7243 & -2.0748 & $\mathrm{H}$ \\
\hline 30 & C30 & 7.4965 & 3.3479 & -0.0779 & C \\
\hline 31 & H31 & 7.9379 & 1.1060 & 3.0956 & $\mathrm{H}$ \\
\hline 32 & C32 & 8.2936 & 0.7355 & 2.1326 & $\mathrm{C}$ \\
\hline 33 & C33 & 9.4168 & 1.2494 & 1.3885 & C \\
\hline 34 & H34 & 6.8399 & -0.9330 & 1.6603 & $\mathrm{H}$ \\
\hline 35 & H35 & 10.0610 & 2.0772 & 1.6891 & $\mathrm{H}$ \\
\hline 36 & C36 & 9.5257 & 0.4928 & 0.1658 & C \\
\hline 37 & H37 & 10.2675 & 0.6461 & -0.6195 & $\mathrm{H}$ \\
\hline 38 & C38 & 8.4692 & -0.4890 & 0.1536 & C \\
\hline 39 & H39 & 8.2711 & -1.2088 & -0.6424 & $\mathrm{H}$ \\
\hline 40 & C40 & 7.7108 & -0.3406 & 1.3707 & C \\
\hline 41 & C41 & 0.3694 & -0.1889 & 1.8246 & C \\
\hline 42 & $\mathrm{H} 42$ & -0.5878 & -0.7064 & 2.0290 & $\mathrm{H}$ \\
\hline 43 & H4 3 & 0.4290 & 0.6951 & 2.4872 & $\mathrm{H}$ \\
\hline 44 & H4 4 & 1.1988 & -0.8694 & 2.0941 & $\mathrm{H}$ \\
\hline 45 & C4 5 & 0.5343 & -1.1508 & -1.1584 & C \\
\hline 46 & H4 6 & 0.5887 & -0.8047 & -2.2081 & $\mathrm{H}$ \\
\hline 47 & H4 7 & -0.3677 & -1.7825 & -1.0524 & $\mathrm{H}$ \\
\hline 48 & H4 8 & 1.4284 & -1.7729 & -0.9642 & $\mathrm{H}$ \\
\hline 49 & C49 & 4.2196 & 0.6815 & 2.3106 & C \\
\hline 50 & H5O & 4.1278 & 1.7100 & 2.7088 & $\mathrm{H}$ \\
\hline 51 & H51 & 5.1305 & 0.2266 & 2.7441 & $\mathrm{H}$ \\
\hline 52 & H52 & 3.3383 & 0.1088 & 2.6568 & $\mathrm{H}$ \\
\hline 53 & C53 & 4.4892 & -1.0165 & -0.3117 & C \\
\hline 54 & H5 4 & 3.7071 & -1.6957 & 0.0778 & $\mathrm{H}$ \\
\hline 55 & H55 & 5.4804 & -1.4431 & -0.0657 & $\mathrm{H}$ \\
\hline 56 & H5 6 & 4.3930 & -0.9891 & -1.4135 & $\mathrm{H}$ \\
\hline 57 & C5 5 & 2.4627 & 1.9627 & -2.2770 & C \\
\hline 58 & H5 8 & 3.3325 & 2.5974 & -2.5308 & $\mathrm{H}$ \\
\hline 59 & H59 & 1.5487 & 2.4497 & -2.6671 & $\mathrm{H}$ \\
\hline 60 & $\mathrm{H} 60$ & 2.5833 & 0.9929 & -2.7954 & $\mathrm{H}$ \\
\hline 61 & $\mathrm{C} 61$ & 2.0566 & 3.3784 & 0.4726 & C \\
\hline 62 & H62 & 2.8467 & 4.1038 & 0.2023 & $\mathrm{H}$ \\
\hline 63 & H63 & 2.0654 & 3.2560 & 1.5722 & $\mathrm{H}$ \\
\hline 64 & H64 & 1.0762 & 3.8040 & 0.1849 & $\mathrm{H}$ \\
\hline 65 & Si 65 & 0.4702 & 0.3314 & 0.0107 & $\mathrm{Si}$ \\
\hline 66 & Si 66 & 2.3342 & 1.7182 & -0.4012 & $\mathrm{Si}$ \\
\hline 67 & Si 67 & 4.3021 & 0.7164 & 0.4230 & $\mathrm{Si}$ \\
\hline \multicolumn{6}{|c|}{ a $<$ TRIPOS $>$ BOND } \\
\hline 1 & 131 & & & & \\
\hline 2 & 141 & & & & \\
\hline 3 & 171 & & & & \\
\hline 4 & 191 & & & & \\
\hline 5 & $1 \quad 111$ & & & & \\
\hline 6 & $1 \quad 131$ & & & & \\
\hline 7 & 1141 & & & & \\
\hline 8 & 1161 & & & & \\
\hline & 1181 & & & & \\
\hline & 120 & & & & \\
\hline 11 & 231 & & & & \\
\hline
\end{tabular}


1234 Ar

13311 Ar

14461

$\begin{array}{llll}15 & 4 & \mathrm{Ar}\end{array}$

$\begin{array}{llll}16 & 5 & 11 & 1\end{array}$

$\begin{array}{llll}17 & 7 & 8 & 1\end{array}$

1879 Ar

$\begin{array}{llll}19 & 9 & 10 & 1\end{array}$

20911 Ar

$\begin{array}{llll}21 & 12 & 13 & 1\end{array}$

$\begin{array}{llll}22 & 13 & 14 & 1\end{array}$

231320 Ar

$\begin{array}{llll}24 & 14 & 16 & 1\end{array}$

$\begin{array}{llll}25 & 14 & 65 & 1\end{array}$

$\begin{array}{llll}26 & 15 & 20 & 1\end{array}$

$\begin{array}{llll}27 & 16 & 17 & 1\end{array}$

281618 Ar

$\begin{array}{llll}29 & 18 & 19 & 1\end{array}$

301820 Ar

$\begin{array}{llll}31 & 21 & 23 & 1\end{array}$

$\begin{array}{llll}32 & 21 & 24 & 1\end{array}$

$\begin{array}{llll}33 & 21 & 26 & 1\end{array}$

$\begin{array}{llll}34 & 21 & 28 & 1\end{array}$

$\begin{array}{llll}35 & 21 & 30 & 1\end{array}$

$\begin{array}{llll}36 & 21 & 32 & 1\end{array}$

$\begin{array}{llll}37 & 21 & 33 & 1\end{array}$

$\begin{array}{llll}38 & 21 & 36 & 1\end{array}$

$\begin{array}{llll}39 & 21 & 38 & 1\end{array}$

$\begin{array}{llll}40 & 21 & 40 & 1\end{array}$

$\begin{array}{llll}41 & 22 & 23 & 1\end{array}$

$\begin{array}{llll}42 & 23 & 24 & 1\end{array}$

432330 Ar

$\begin{array}{llll}44 & 24 & 26 & 1\end{array}$

$\begin{array}{llll}45 & 24 & 67 & 1\end{array}$

$\begin{array}{llll}46 & 25 & 30 & 1\end{array}$

$\begin{array}{llll}47 & 26 & 27 & 1\end{array}$

482628 Ar

$\begin{array}{llll}49 & 28 & 29 & 1\end{array}$

$\begin{array}{llll}50 & 28 & 30 & \text { Ar }\end{array}$

$\begin{array}{llll}51 & 31 & 32 & 1\end{array}$

523233 Ar

$53 \quad 3240$ Ar

$\begin{array}{llll}54 & 33 & 35 & 1\end{array}$

553336 Ar

$\begin{array}{llll}56 & 34 & 40 & 1\end{array}$

$\begin{array}{llll}57 & 36 & 37 & 1\end{array}$

583638 Ar

$\begin{array}{llll}59 & 38 & 39 & 1\end{array}$

$\begin{array}{llll}60 & 38 \quad 40 & \text { Ar }\end{array}$

$\begin{array}{llll}61 & 41 & 42 & 1\end{array}$

$\begin{array}{llll}62 & 41 & 43 & 1\end{array}$

$\begin{array}{llll}63 & 41 & 44 & 1\end{array}$ 
$\begin{array}{llll}64 & 41 & 65 & 1\end{array}$

$\begin{array}{llll}65 & 45 & 46 & 1\end{array}$

$\begin{array}{llll}66 & 45 & 47 & 1\end{array}$

$\begin{array}{llll}67 & 45 & 48 & 1\end{array}$

$\begin{array}{llll}68 & 45 & 65 & 1\end{array}$

$\begin{array}{llll}69 & 49 & 50 & 1\end{array}$

$\begin{array}{llll}70 & 49 & 51 & 1\end{array}$

$\begin{array}{llll}71 & 49 & 52 & 1\end{array}$

$\begin{array}{llll}72 & 49 & 67 & 1\end{array}$

$\begin{array}{llll}73 & 53 & 54 & 1\end{array}$

$\begin{array}{llll}74 & 53 & 55 & 1\end{array}$

$\begin{array}{llll}75 & 53 & 56 & 1\end{array}$

$\begin{array}{llll}76 & 53 & 67 & 1\end{array}$

$\begin{array}{llll}77 & 57 & 58 & 1\end{array}$

$\begin{array}{llll}78 & 57 & 59 & 1\end{array}$

$\begin{array}{llll}79 & 57 & 60 & 1\end{array}$

$\begin{array}{llll}80 & 57 & 66 & 1\end{array}$

$\begin{array}{llll}81 & 61 & 62 & 1\end{array}$

$\begin{array}{llll}82 & 61 & 63 & 1\end{array}$

$\begin{array}{llll}83 & 61 & 64 & 1\end{array}$

$\begin{array}{llll}84 & 61 & 66 & 1\end{array}$

$\begin{array}{llll}85 & 65 & 66 & 1\end{array}$

$\begin{array}{llll}86 & 66 & 67 & 1\end{array}$

\section{A5.10: Compound 12d .mol2}

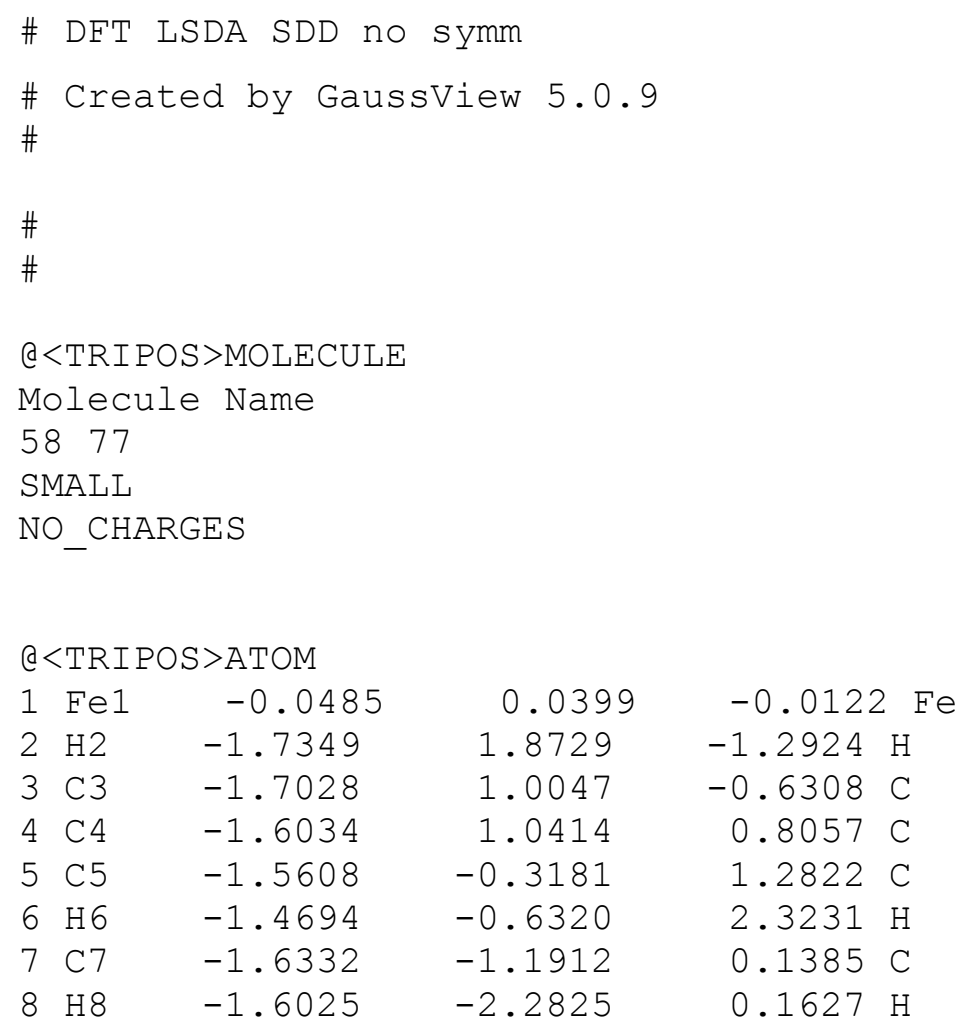




\begin{tabular}{|c|c|c|c|}
\hline C9 & -1.7205 & -0.3797 & $-1.0589 \mathrm{C}$ \\
\hline $10 \mathrm{H} 10$ & 1.6234 & 1.9580 & $1.1818 \mathrm{H}$ \\
\hline 11 C11 & 1.5972 & 1.0592 & $0.5638 \mathrm{C}$ \\
\hline $12 \mathrm{C} 12$ & 1.4932 & 1.0218 & $-0.8738 C$ \\
\hline $13 \mathrm{H} 13$ & 1.7035 & -0.6099 & $2.0874 \mathrm{H}$ \\
\hline $14 \mathrm{H} 14$ & 1.4248 & 1.8858 & $-1.5366 \mathrm{H}$ \\
\hline $15 \mathrm{C} 15$ & 1.4737 & -0.3606 & $-1.2823 \mathrm{C}$ \\
\hline $16 \mathrm{H} 16$ & 1.3819 & -0.7250 & $-2.3078 \mathrm{H}$ \\
\hline 17 C17 & 1.5616 & -1.1782 & $-0.0980 \mathrm{C}$ \\
\hline 18 H18 & 1.5526 & -2.2689 & $-0.0707 \mathrm{H}$ \\
\hline 19 C19 & 1.6390 & -0.3003 & $1.0433 \mathrm{C}$ \\
\hline $20 \mathrm{H} 20$ & -1.5519 & 1.9403 & $1.4219 \mathrm{H}$ \\
\hline $21 \mathrm{Si} 21$ & -1.7383 & -0.9970 & $-2.8137 \mathrm{Si}$ \\
\hline 22 H22 & -1.0345 & -0.0106 & $-3.7127 \mathrm{H}$ \\
\hline 23 H23 & -1.0140 & -2.3176 & $-2.8985 \mathrm{H}$ \\
\hline 24 Si24 & -3.9299 & -1.2981 & $-3.6160 \mathrm{Si}$ \\
\hline 25 H25 & -4.6609 & -2.2841 & $-2.7411 \mathrm{H}$ \\
\hline $26 \mathrm{H} 26$ & -4.6771 & 0.0094 & $-3.5461 \mathrm{H}$ \\
\hline 27 Si27 & -3.9862 & -2.0759 & $-5.8276 \mathrm{Si}$ \\
\hline 28 H28 & -3.2700 & -3.3986 & $-5.9210 \mathrm{H}$ \\
\hline 29 H29 & -3.2636 & -1.1065 & $-6.7272 \mathrm{H}$ \\
\hline 30 si30 & -6.1886 & -2.3353 & $-6.5888 \mathrm{Si}$ \\
\hline 31 H31 & -6.9124 & -3.3013 & $-5.6864 \mathrm{H}$ \\
\hline 32 H32 & -6.8998 & -1.0099 & $-6.4904 \mathrm{H}$ \\
\hline $33 \mathrm{si33}$ & -6.2747 & -3.1065 & $-8.8020 \mathrm{Si}$ \\
\hline 34 H34 & -5.5922 & -4.4480 & $-8.8787 \mathrm{H}$ \\
\hline 35 H35 & -5.5016 & -2.1519 & $-9.6755 \mathrm{H}$ \\
\hline $36 \mathrm{si36}$ & -8.4886 & -3.2785 & $-9.5807 \mathrm{Si}$ \\
\hline 37 H37 & -9.2235 & -4.2662 & $-8.7085 \mathrm{H}$ \\
\hline 38 H38 & -9.1423 & -1.9277 & $-9.4211 \mathrm{H}$ \\
\hline 39 C39 & -8.5762 & -3.8193 & $-11.3581 C$ \\
\hline 40 C40 & -8.6320 & -2.9567 & $-12.5212 C$ \\
\hline $41 \mathrm{C} 41$ & -8.6897 & -5.1815 & $-11.8394 \mathrm{C}$ \\
\hline $42 \mathrm{H} 42$ & -8.5928 & -1.8656 & $-12.5031 \mathrm{H}$ \\
\hline $43 C 43$ & -8.7795 & -3.7770 & $-13.6963 \mathrm{C}$ \\
\hline $44 \quad C 44$ & -8.8157 & -5.1544 & $-13.2740 \mathrm{C}$ \\
\hline 45 H45 & -8.7008 & -6.0759 & $-11.2128 \mathrm{H}$ \\
\hline 46 H 46 & -8.8676 & -3.4163 & $-14.7222 \mathrm{H}$ \\
\hline 47 H47 & -8.9362 & -6.0227 & $-13.9235 \mathrm{H}$ \\
\hline 48 H48 & -11.6291 & -3.3390 & $-10.0321 \mathrm{H}$ \\
\hline $49 C 49$ & -11.7603 & -3.6511 & $-11.0704 \mathrm{C}$ \\
\hline 50 C50 & -11.8170 & -2.7785 & $-12.2166 \mathrm{C}$ \\
\hline 51 C51 & -11.8751 & -5.0102 & $-11.5368 C$ \\
\hline $52 \quad C 52$ & -11.9707 & -3.5989 & $-13.3925 \mathrm{C}$ \\
\hline 53 H53 & -11.7404 & -1.6904 & $-12.1976 \mathrm{H}$ \\
\hline 54 H54 & -11.8515 & -5.9054 & $-10.9136 \mathrm{H}$ \\
\hline $55 \mathrm{C} 55$ & -12.0070 & -4.9781 & $-12.9723 \mathrm{C}$ \\
\hline 56 H56 & -12.0336 & -3.2403 & $-14.4210 \mathrm{H}$ \\
\hline 57 H57 & -12.1005 & -5.8454 & $-13.6273 \mathrm{H}$ \\
\hline 58 Fe58 & -10.289 & -4.0903 & $-12.3871 \mathrm{Fe}$ \\
\hline
\end{tabular}


$\begin{array}{llll}2 & 1 & 4 & 1\end{array}$

$\begin{array}{llll}3 & 1 & 5 & 1\end{array}$

$\begin{array}{llll}4 & 1 & 7 & 1\end{array}$

$\begin{array}{llll}5 & 1 & 9 & 1\end{array}$

$\begin{array}{llll}6 & 1 & 11 & 1\end{array}$

$\begin{array}{llll}7 & 1 & 12 & 1\end{array}$

$\begin{array}{llll}8 & 1 & 15 & 1\end{array}$

$\begin{array}{llll}9 & 1 & 17 & 1\end{array}$

$\begin{array}{llll}10 & 1 & 19 & 1\end{array}$

$\begin{array}{llll}11 & 2 & 3 & 1\end{array}$

1234 Ar

$\begin{array}{llll}13 & 3 & 9 & 1\end{array}$

1445 Ar

$\begin{array}{llll}15 & 4 & 20 & 1\end{array}$

$\begin{array}{llll}16 & 5 & 6 & 1\end{array}$

1757 Ar

$\begin{array}{llll}18 & 7 & 8 & 1\end{array}$

$\begin{array}{llll}19 & 7 & 9 & 1\end{array}$

$\begin{array}{llll}20 & 9 & 21 & 1\end{array}$

$\begin{array}{llll}21 & 10 & 11 & 1\end{array}$

221112 Ar

231119 Ar

$\begin{array}{llll}24 & 12 & 14 & 1\end{array}$

251215 Ar

$\begin{array}{llll}26 & 13 & 19 & 1\end{array}$

$\begin{array}{llll}27 & 15 & 16 & 1\end{array}$

281517 Ar

$\begin{array}{llll}29 & 17 & 18 & 1\end{array}$

301719 Ar

$\begin{array}{llll}31 & 21 & 22 & 1\end{array}$

$\begin{array}{llll}32 & 21 & 23 & 1\end{array}$

$\begin{array}{llll}33 & 21 & 24 & 1\end{array}$

$\begin{array}{llll}34 & 24 & 25 & 1\end{array}$

$\begin{array}{llll}35 & 24 & 26 & 1\end{array}$

$\begin{array}{llll}36 & 24 & 27 & 1\end{array}$

$\begin{array}{llll}37 & 27 & 28 & 1\end{array}$

$\begin{array}{llll}38 & 27 & 29 & 1\end{array}$

$\begin{array}{llll}39 & 27 & 30 & 1\end{array}$

$\begin{array}{llll}40 & 30 & 31 & 1\end{array}$

$\begin{array}{llll}41 & 30 & 32 & 1\end{array}$

$\begin{array}{llll}42 & 30 & 33 & 1\end{array}$

$\begin{array}{llll}43 & 33 & 34 & 1\end{array}$

$\begin{array}{llll}44 & 33 & 35 & 1\end{array}$

$\begin{array}{llll}45 & 33 & 36 & 1\end{array}$

$\begin{array}{llll}46 & 36 & 37 & 1\end{array}$

$\begin{array}{llll}47 & 36 & 38 & 1\end{array}$

$\begin{array}{llll}48 & 36 & 39 & 1\end{array}$

$\begin{array}{llll}49 & 39 & 40 & 1\end{array}$

$\begin{array}{llll}50 & 39 & 41 & 1\end{array}$

$\begin{array}{llll}51 & 39 & 58 & 1\end{array}$

$\begin{array}{llll}52 & 40 & 42 & 1\end{array}$

534043 Ar 
$\begin{array}{llll}54 & 40 & 58 & 1\end{array}$

$\begin{array}{llll}55 & 41 & 44 & \mathrm{Ar}\end{array}$

$\begin{array}{llll}56 & 41 & 45 & 1\end{array}$

$\begin{array}{llll}57 & 41 & 58 & 1\end{array}$

$58 \quad 43 \quad 44$ Ar

$\begin{array}{llll}59 & 43 & 46 & 1\end{array}$

$\begin{array}{llll}60 & 43 & 58 & 1\end{array}$

$\begin{array}{llll}61 & 44 & 47 & 1\end{array}$

$\begin{array}{llll}62 & 44 & 58 & 1\end{array}$

$\begin{array}{llll}63 & 48 & 49 & 1\end{array}$

$64 \quad 4950$ Ar

$\begin{array}{llll}65 & 49 & 51 & \text { Ar }\end{array}$

$\begin{array}{llll}66 & 49 & 58 & 1\end{array}$

$\begin{array}{llll}67 & 50 & 52 & \text { Ar }\end{array}$

$\begin{array}{llll}68 & 50 & 53 & 1\end{array}$

$\begin{array}{llll}69 & 50 & 58 & 1\end{array}$

$\begin{array}{llll}70 & 51 & 54 & 1\end{array}$

$\begin{array}{llll}71 & 51 & 55 & \text { Ar }\end{array}$

$\begin{array}{llll}72 & 51 & 58 & 1\end{array}$

$73 \quad 5255$ Ar

$\begin{array}{llll}74 & 52 & 56 & 1\end{array}$

$\begin{array}{llll}75 & 52 & 58 & 1\end{array}$

$\begin{array}{llll}76 & 55 & 57 & 1\end{array}$

$\begin{array}{llll}77 & 55 & 58 & 1\end{array}$

\section{A5.11: Compound 13 .mol2}

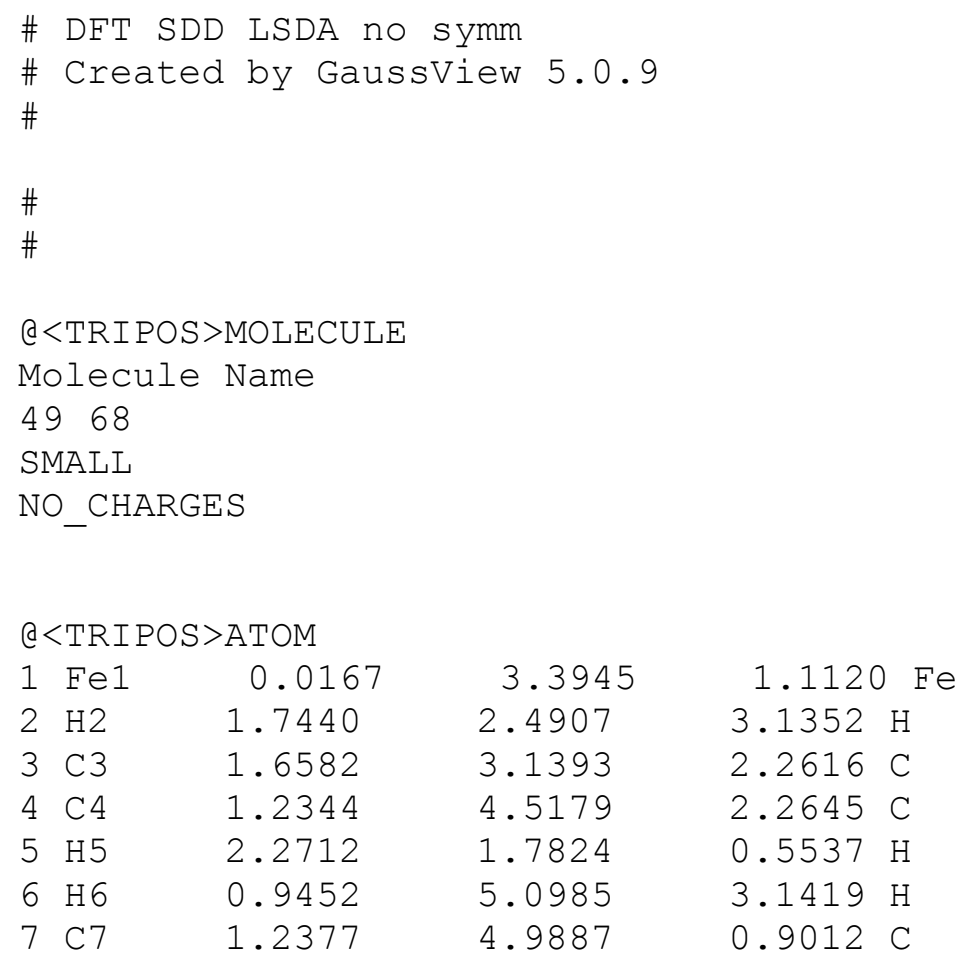




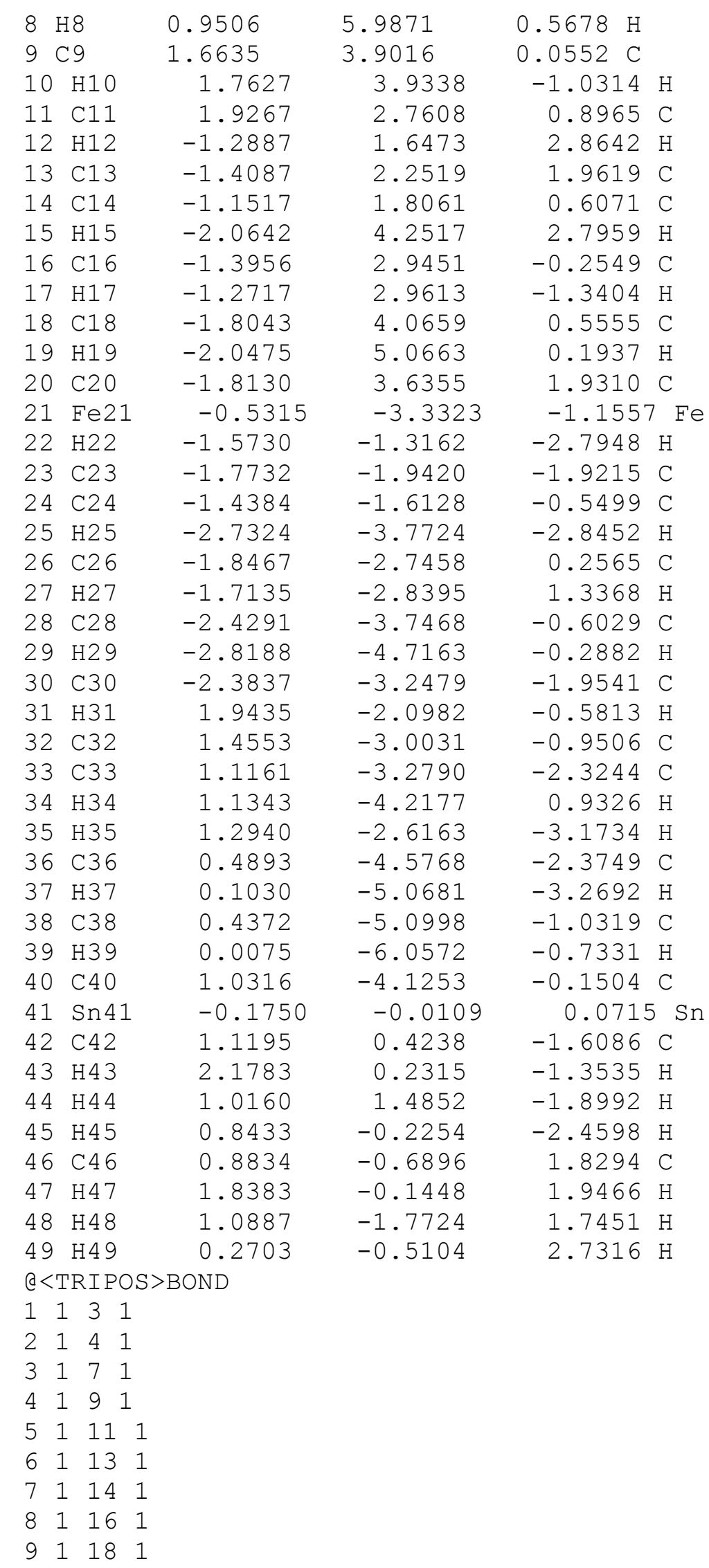


$\begin{array}{llll}10 & 1 & 20 & 1\end{array}$

$\begin{array}{llll}11 & 2 & 3 & 1\end{array}$

1234 Ar

13311 Ar

$\begin{array}{llll}14 & 4 & 6 & 1\end{array}$

$\begin{array}{llll}15 & 4 & \mathrm{Ar}\end{array}$

$\begin{array}{llll}16 & 5 & 11 & 1\end{array}$

$\begin{array}{llll}17 & 7 & 8 & 1\end{array}$

1879 Ar

$\begin{array}{llll}19 & 9 & 10 & 1\end{array}$

20911 Ar

$\begin{array}{llll}21 & 12 & 13 & 1\end{array}$

$\begin{array}{llll}22 & 13 & 14 & 1\end{array}$

231320 Ar

$\begin{array}{llll}24 & 14 & 16 & 1\end{array}$

$\begin{array}{llll}25 & 14 & 41 & 1\end{array}$

$\begin{array}{llll}26 & 15 & 20 & 1\end{array}$

$\begin{array}{llll}27 & 16 & 17 & 1\end{array}$

281618 Ar

$\begin{array}{llll}29 & 18 & 19 & 1\end{array}$

301820 Ar

$\begin{array}{llll}31 & 21 & 23 & 1\end{array}$

$\begin{array}{llll}32 & 21 & 24 & 1\end{array}$

$\begin{array}{llll}33 & 21 & 26 & 1\end{array}$

$\begin{array}{llll}34 & 21 & 28 & 1\end{array}$

$\begin{array}{llll}35 & 21 & 30 & 1\end{array}$

$\begin{array}{llll}36 & 21 & 32 & 1\end{array}$

$\begin{array}{llll}37 & 21 & 33 & 1\end{array}$

$\begin{array}{llll}38 & 21 & 36 & 1\end{array}$

$\begin{array}{llll}39 & 21 & 38 & 1\end{array}$

$\begin{array}{llll}40 & 21 & 40 & 1\end{array}$

$\begin{array}{llll}41 & 22 & 23 & 1\end{array}$

$\begin{array}{llll}42 & 23 & 24 & 1\end{array}$

$4323 \quad 30$ Ar

$\begin{array}{llll}44 & 24 & 26 & 1\end{array}$

$\begin{array}{llll}45 & 24 & 41 & 1\end{array}$

$\begin{array}{llll}46 & 25 & 30 & 1\end{array}$

$\begin{array}{llll}47 & 26 & 27 & 1\end{array}$

$48 \quad 26 \quad 28$ Ar

$\begin{array}{llll}49 & 28 & 29 & 1\end{array}$

$\begin{array}{llll}50 & 28 & 30 & \text { Ar }\end{array}$

$\begin{array}{llll}51 & 31 & 32 & 1\end{array}$

523233 Ar

$53 \quad 3240$ Ar

$\begin{array}{llll}54 & 33 & 35 & 1\end{array}$

$5533 \quad 36$ Ar

$\begin{array}{llll}56 & 34 & 40 & 1\end{array}$

$\begin{array}{llll}57 & 36 & 37 & 1\end{array}$

583638 Ar

$\begin{array}{llll}59 & 38 & 39 & 1\end{array}$

603840 Ar

$\begin{array}{llll}61 & 41 & 42 & 1\end{array}$ 
$\begin{array}{llll}62 & 41 & 46 & 1\end{array}$

$\begin{array}{llll}63 & 42 & 43 & 1\end{array}$

$\begin{array}{llll}64 & 42 & 44 & 1\end{array}$

$\begin{array}{llll}65 & 42 & 45 & 1\end{array}$

$\begin{array}{llll}66 & 46 & 47 & 1\end{array}$

$\begin{array}{llll}67 & 46 & 48 & 1\end{array}$

$\begin{array}{llll}68 & 46 & 49 & 1\end{array}$

\section{A5.11: Compound 13 .mol2}

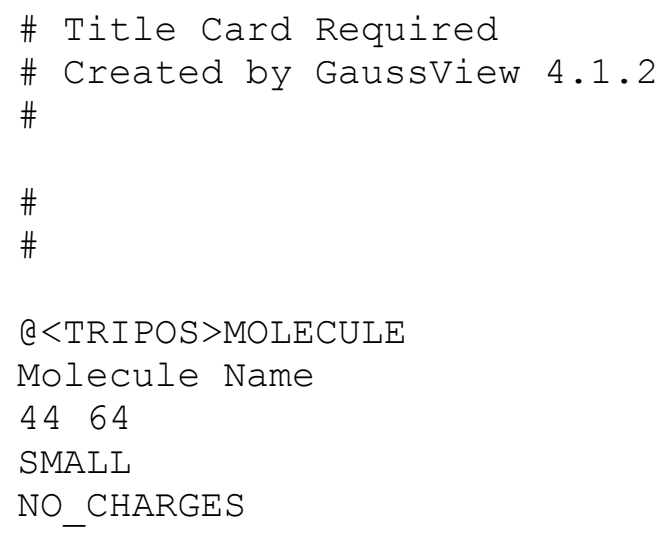




\begin{tabular}{|c|c|c|c|c|}
\hline 26 & $\mathrm{C} 26$ & -2.5574 & 1.5891 & $0.0064 \mathrm{C}$ \\
\hline 27 & $\mathrm{C} 27$ & -3.4191 & 1.5954 & $-1.1600 \mathrm{C}$ \\
\hline 28 & $\mathrm{C} 28$ & -3.4112 & 1.5820 & $1.1786 \mathrm{C}$ \\
\hline 29 & Fe29 & -3.8180 & 0.0001 & $0.0013 \mathrm{Fe}$ \\
\hline 30 & C30 & -4.7845 & 1.6269 & $-0.7069 \mathrm{C}$ \\
\hline 31 & H31 & -3.0704 & 1.5879 & $-2.1937 \mathrm{H}$ \\
\hline 32 & C32 & -4.7796 & 1.6185 & $0.7352 \mathrm{C}$ \\
\hline 33 & H33 & -3.0556 & 1.5624 & $2.2098 \mathrm{H}$ \\
\hline 34 & C34 & -4.7861 & -1.6174 & $-0.7254 \mathrm{C}$ \\
\hline 35 & C35 & -4.7796 & -1.6264 & $0.7167 \mathrm{C}$ \\
\hline 36 & C36 & -3.4106 & -1.5957 & $1.1589 \mathrm{C}$ \\
\hline 37 & C37 & -3.4213 & -1.5815 & $-1.1796 \mathrm{C}$ \\
\hline 38 & H3 8 & -5.6693 & 1.6420 & $-1.3450 \mathrm{H}$ \\
\hline 39 & H39 & -5.6601 & 1.6263 & $1.3794 \mathrm{H}$ \\
\hline 40 & $\mathrm{H} 4 \mathrm{O}$ & -5.6717 & -1.6245 & $-1.3626 \mathrm{H}$ \\
\hline 41 & H 41 & -5.6595 & -1.6415 & $1.3616 \mathrm{H}$ \\
\hline 42 & $\mathrm{H} 42$ & -3.0537 & -1.5889 & $2.1899 \mathrm{H}$ \\
\hline 43 & C43 & -2.5583 & -1.5894 & $-0.0145 \mathrm{C}$ \\
\hline 44 & H4 4 & -3.0737 & -1.5616 & $-2.2136 \mathrm{H}$ \\
\hline \multicolumn{5}{|c|}{$\mathrm{a}<\mathrm{TRIPOS}>\mathrm{BOND}$} \\
\hline 1 & 131 & & & \\
\hline 2 & 141 & & & \\
\hline 3 & 161 & & & \\
\hline 4 & 181 & & & \\
\hline 5 & 191 & & & \\
\hline 6 & $1 \quad 111$ & & & \\
\hline 7 & $1 \quad 121$ & & & \\
\hline 8 & $1 \quad 151$ & & & \\
\hline 9 & $1 \quad 171$ & & & \\
\hline 10 & 118 & & & \\
\hline 11 & 231 & & & \\
\hline 12 & $34 \mathrm{~A}$ & & & \\
\hline 13 & $39 \mathrm{~A}$ & & & \\
\hline 14 & $46 \mathrm{~A}$ & & & \\
\hline 15 & 419 & & & \\
\hline 16 & $\begin{array}{lll}5 & 9 & 1\end{array}$ & & & \\
\hline 17 & $\begin{array}{lll}6 & 7 & 1\end{array}$ & & & \\
\hline 18 & $\begin{array}{lll}6 & 8 & 1\end{array}$ & & & \\
\hline 19 & 891 & & & \\
\hline 20 & 8212 & $r$ & & \\
\hline 21 & 1011 & 1 & & \\
\hline 22 & $11 \quad 12$ & Ar & & \\
\hline 23 & 1118 & Ar & & \\
\hline 24 & 1214 & 1 & & \\
\hline 25 & 1215 & Ar & & \\
\hline 26 & 1318 & 1 & & \\
\hline 27 & 1516 & 1 & & \\
\hline 28 & 1517 & 1 & & \\
\hline 29 & 1718 & 1 & & \\
\hline 30 & 1720 & Ar & & \\
\hline 31 & $20 \quad 22$ & 2 & & \\
\hline . & 2123 & 2 & & \\
\hline
\end{tabular}


$\begin{array}{llll}33 & 22 & 24 & 2\end{array}$

$\begin{array}{llll}34 & 23 & 25 & 2\end{array}$

$3524 \quad 43$ Ar

$\begin{array}{llll}36 & 25 & 26 & \text { Ar }\end{array}$

$\begin{array}{llll}37 & 26 & 27 & 1\end{array}$

$\begin{array}{llll}38 & 26 & 28 & 1\end{array}$

$\begin{array}{llll}39 & 26 & 29 & 1\end{array}$

$\begin{array}{llll}40 & 27 & 29 & 1\end{array}$

412730 Ar

$\begin{array}{llll}42 & 27 & 31 & 1\end{array}$

$\begin{array}{llll}43 & 28 & 29 & 1\end{array}$

$4428 \quad 32$ Ar

$\begin{array}{llll}45 & 28 & 33 & 1\end{array}$

$\begin{array}{llll}46 & 29 & 30 & 1\end{array}$

$\begin{array}{llll}47 & 29 & 32 & 1\end{array}$

$\begin{array}{llll}48 & 29 & 34 & 1\end{array}$

$\begin{array}{llll}49 & 29 & 35 & 1\end{array}$

$\begin{array}{llll}50 & 29 & 36 & 1\end{array}$

$\begin{array}{llll}51 & 29 & 37 & 1\end{array}$

$\begin{array}{llll}52 & 29 & 43 & 1\end{array}$

533032 Ar

$\begin{array}{llll}54 & 30 & 38 & 1\end{array}$

$\begin{array}{llll}55 & 32 & 39 & 1\end{array}$

563435 Ar

$\begin{array}{llll}57 & 34 & 37 & \text { Ar }\end{array}$

$\begin{array}{llll}58 & 34 & 40 & 1\end{array}$

593536 Ar

$\begin{array}{llll}60 & 35 & 41 & 1\end{array}$

$\begin{array}{llll}61 & 36 & 42 & 1\end{array}$

$\begin{array}{llll}62 & 36 & 43 & 1\end{array}$

$\begin{array}{llll}63 & 37 & 43 & 1\end{array}$

$\begin{array}{llll}64 & 37 & 44 & 1\end{array}$ 


\section{References}

(1) Mark, J. E.; Allcock, H. R.; West, R. Inorganic Polymers; 2nd ed.; Oxford University Press: New York, USA, 2005.

(2) Braunstein, P.; Morise, X. Chem. Rev. 2000, 100, 3541.

(3) Trummer, M.; Choffat, F.; Smith, P.; Caseri, W. Macromol. Rapid Commun. 2012, 33, 448 .

(4) Zou, W. K.; Yang, N. L. Polym. Prepr. (Am. Chem. Soc., Div. Polym. Chem.) 1992, 33, 188.

(5) Devylder, N.; Hill, M.; Molloy, K. C.; Price, G. J. Chem. Commun. (Cambridge) 1996, 711 .

(6) Okano, M.; Matsumoto, N.; Arakawa, M.; Tsuruta, T.; Hamano, H. Chem. Commun. 1998, 1799.

(7) Okano, M.; Watanabe, K.; Totsuka, S. Electrochemistry 2003, 71, 257.

(8) Imori, T.; Tilley, T. D. J. Chem. Soc., Chem. Commun. 1993, 1607.

(9) Imori, T.; Lu, V.; Cai, H.; Tilley, T. D. J. Am. Chem. Soc. 1995, 117, 9931.

(10) Lu, V. Y.; Tilley, T. D. Macromolecules 2000, 33, 2403.

(11) Neale, N. R.; Tilley, T. D. J. Am. Chem. Soc. 2002, 124, 3802.

(12) Babcock, J. R.; Sita, L. R. J. Am. Chem. Soc. 1996, 118, 12481.

(13) Trummer, M.; Solenthaler, D.; Smith, P.; Caseri, W. Rsc Advances 2011, 1, 823.

(14) Choffat, F.; Smith, P.; Caseri, W. J. Mater. Chem. 2005, 15, 1789.

(15) Trummer, M.; Choffat, F.; Raemi, M.; Smith, P.; Caseri, A. Phosphorus, Sulfur Silicon Relat. Elem. 2011, 186, 1330.

(16) Choffat, F.; Kaser, S.; Wolfer, P.; Schmid, D.; Mezzenga, R.; Smith, P.; Caseri, W. Macromolecules 2007, 40, 7878.

(17) Khan, A.; Gossage, R. A.; Foucher, D. A. Can. J. Chem. 2010, 88, 1046.

(18) Elschenbroich, C.; Salzer, A. Organometallics: A Concise Introduction; 1st ed.; VCH Verlagsgesellschaft: Weinheim, Germany, 1989.

(19) Holder, S. J.; Jones, R. G.; Benfield, R. E.; Went, M. J. Polymer 1996, 37, 3477. 
(20) Mustafa, A.; Achilleos, M.; Ruiz-Iban, J.; Davies, J.; Benfield, R. E.; Jones, R. G.; Grandjean, D.; Holder, S. J. React. Funct. Polym. 2006, 66, 123.

(21) Thompson, S. M.; Schubert, U. Inorg. Chim. Acta 2003, 350, 329.

(22) Thompson, S. M.; Schubert, U. Inorg. Chim. Acta 2004, 357, 1959.

(23) Woo, H. G.; Park, J. M.; Song, S. J.; Yang, S. Y.; Kim, I. S.; Kim, W. G. Bull. Korean Chem. Soc. 1997, 18, 1291.

(24) Woo, H. G.; Song, S. J.; Kim, B. H. Bull. Korean Chem. Soc. 1998, 19, 1161.

(25) Schittelkopf, K.; Fischer, R. C.; Meyer, S.; Wilfling, P.; Uhlig, F. Appl. Organomet. Chem. 2010, 24, 897.

(26) Drenth, W.; Noltes, J. G.; Bulten, E. J.; Creemers, H. M. J. C. J. Organometal. Chem. 1969, 17, 173.

(27) Sita, L. R.; Terry, K. W.; Shibata, K. J. Am. Chem. Soc. 1995, 117, 8049.

(28) Takeda, K.; Shiraishi, K. Chem. Phys. Lett. 1992, 195, 121.

(29) Liao, L., Ryerson University, 2011.

(30) Adams, S.; Draeger, M. Main Group Met. Chem. 1988, 11, 151.

(31) de Haas, M. P.; Choffat, F.; Caseri, W.; Smith, P.; Warman, J. M. Adv. Mater. 2006, $18,44$.

(32) Choffat, F.; Wolfer, P.; Smith, P.; Caseri, W. Macromol. Mater. Eng. 2010, 295, 210.

(33) Osborne, A. G.; Whiteley, R. H. J. Organomet. Chem. 1975, 101, C27.

(34) Shul'pin, G. B.; Rybinskaya, M. I. Usp. Khim. 1974, 43, 1524.

(35) Braunschweig, H.; Dirk, R.; Muller, M.; Nguyen, P.; Resendes, R.; Gates, D. P.; Manners, I. Angew. Chem. Int. Ed. Engl. 1997, 36, 2338. 5817.

(36) Lund, C. L.; Schachner, J. A.; Quail, J. W.; Muller, J. Organometallics 2006, 25,

(37) Osborne, A. G.; Whiteley, R. H. J. Organomet. Chem. 1980, 193, 345.

(38) Rulkens, R.; Lough, A. J.; Manners, I. Angew. Chem. Int. Ed. Engl. 1996, 35, 1805.

(39) Seyferth, D.; Withers, H. P. Organometallics 1982, 1, 1275. 
(40) Broussier, R.; Darold, A.; Gautheron, B.; Dromzee, Y.; Jeannin, Y. Inorg. Chem. 1990, 29, 1817.

(41) Herberhold, M.; Steffl, U.; Milius, W.; Wrackmeyer, B. Angew. Chem. Int. Ed. Engl. 1996, 35, 1803.

(42) Bishop, J. J.; Davison, A.; Katcher, M. L.; Lichtenb.Dw; Merrill, R. E.; Smart, J. C. J. Organomet. Chem. 1971, 27, 241.

(43) Kuz'mina, L. G.; Struchkov, Y. T.; Lemenovskii, D. A.; Urazovskii, I. F.; Nifant'ev, I. E.; Perevalova, E. G. Koord. Khim. 1983, 9, 1212.

(44) Lesley, M. J. G.; Mock, U.; Norman, N. C.; Orpen, A. G.; Rice, C. R.; Starbuck, J. J. Organomet. Chem. 1999, 582, 116.

(45) Althoff, A.; Jutzi, P.; Lenze, N.; Neumann, B.; Stammler, A.; Stammler, H. G. Organometallics 2003, 22, 2766.

(46) Schachner, J. A.; Lund, C. L.; Burgess, I. J.; Quail, J. W.; Schatte, G.; Mueller, J. Organometallics 2008, 27, 4703.

(47) Watts, W. E. J. Am. Chem. Soc. 1966, 88, 855.

(48) Zechel, D. L.; Foucher, D. A.; Pudelski, J. K.; Yap, G. P. A.; Rheingold, A. L.; Manners, I. J. Chem. Soc., Dalton Trans. 1995, 1893.

(49) Reddy, N. P.; Hayashi, T.; Tanaka, M. Chem. Commun. 1996, 1865.

(50) Clearfield, A.; Simmons, C. J.; Withers, H. P.; Seyferth, D. Inorg. Chim. Acta 1983, 75, 139.

(51) Mizuta, T.; Imamura, Y.; Miyoshi, K.; Yorimitsu, H.; Oshima, K. Organometallics 2005, 24, 990.

(52) Spang, C.; Edelmann, F. T.; Noltemeyer, M.; Roesky, H. W. Chem. Ber. 1989, $122,1247$.

(53) Mueller-Westerhoff, U. T. Angew. Chem. 1986, 98, 700.

(54) Gausset, O.; Delpon-Lacaze, G.; Schurmann, M.; Jurkschat, K. Acta Crystallogr., Sect. C: Cryst. Struct. Commun. 1998, 54, 1425.

(55) Altmann, R.; Gausset, O.; Horn, D.; Jurkschat, K.; Schurmann, M.; Fontani, M.; Zanello, P. Organometallics 2000, 19, 430.

(56) Nguyen, P.; Gomez-Elipe, P.; Manners, I. Chem. Rev. 1999, 99, 1515.

(57) Manners, I. Science 2001, 294, 1664. 
(58) Abd-El-Aziz, A. S.; Manners, I. J. Inorg. Organomet. Polym. Mater. 2005, 15, 157.

(59) Arimoto, F. S.; Haven, A. C. J. Am. Chem. Soc. 1955, 77, 6295.

(60) Miles, D.; Ward, J.; Foucher, D. A. Organometallics 2010, 29, 1057.

(61) Korshak, V. V.; Sosin, S. L.; Alexeeva, V. P. Dok Akad Nauk SSSR 1960, 132, 360.

(62) Rosenberg.H; Neuse, E. W. J. Organomet. Chem. 1966, 6, 76.

(63) Rausch, M. D. J. Org. Chem. 1963, 28, 3337.

(64) Neuse, E. W.; Bednarik, L. Macromolecules 1979, 12, 187.

(65) Yamamoto, T.; Sanechika, K.; Yamamoto, A.; Katada, M.; Motoyama, I.; Sano, H. Inorg. Chim. Acta 1983, 73, 75.

(66) Hirao, T.; Kurashina, M.; Aramaki, K.; Nishihara, H. J. Chem. Soc., Dalton Trans. 1996, 2929.

(67) Roling, P. V.; Rausch, M. D. J. Org. Chem. 1972, 37, 729.

(68) Park, P.; Lough, A. J.; Foucher, D. A. Macromolecules 2002, 35, 3810.

(69) Miles, D.; Ward, J.; Foucher, D. A. Macromolecules 2009, 42, 9199.

(70) Itazaki, M.; Ueda, K.; Nakazawa, H. Angew. Chem., Int. Ed. 2009, 48, 3313.

(71) Pittman, C. U.; Patterson.W. J.; McManus, S. P. J. Polym. Sci., Part A: Polym. Chem. 1971, 9, 3187.

(72) Patterson.W. J.; McManus, S. P.; Pittman, C. U. J. Polym. Sci., Part A: Polym. Chem. 1974, 12, 837.

(73) Brandt, P. F.; Rauchfuss, T. B. J. Am. Chem. Soc. 1992, 114, 1926.

(74) Foucher, D. A.; Tang, B. Z.; Manners, I. J. Am. Chem. Soc. 1992, 114, 6246.

(75) Ni, Y. Z.; Rulkens, R.; Pudelski, J. K.; Manners, I. Macromol. Rapid Commun. $1995,16,637$.

(76) Reddy, N. P.; Yamashita, H.; Tanaka, M. J. Chem. Soc., Chem. Commun. 1995, 2263.

(77) Ni, Y. Z.; Rulkens, R.; Manners, I. J. Am. Chem. Soc. 1996, 118, 4102. 
(78) Tanabe, M.; Vandermeulen, G. W. M.; Chan, W. Y.; Cyr, P. W.; Vanderark, L.; Rider, D. A.; Manners, I. Nat. Mater. 2006, 5, 467.

(79) Chan, W. Y.; Lough, A. J.; Manners, I. Chem.--Eur. J. 2007, 13, 8867.

(80) Chan, W. Y.; Lough, A. J.; Manners, I. Organometallics 2007, 26, 1217.

(81) Tanabe, M.; Manners, I. J. Am. Chem. Soc. 2004, 126, 11434.

(82) Jakle, F.; Berenbaum, A.; Lough, A. J.; Manners, I. Chem.--Eur. J. 2000, 6, 2762.

(83) Schachner, J. A.; Tockner, S.; Lund, C. L.; Quail, J. W.; Rehahn, M.; Mueller, J. Organometallics 2007, 26, 4658. 1794.

(84) Bagh, B.; Gilroy, J. B.; Staubitz, A.; Mueller, J. J. Am. Chem. Soc. 2010, 132,

(85) Foucher, D. A.; Manners, I. Makromol. Chem., Rapid Commun. 1993, 14, 63.

(86) Foucher, D. A.; Honeyman, C. H.; Nelson, J. M.; Tang, B. Z.; Manners, I. Angew. Chem. Int. Ed. Engl. 1993, 32, 1709.

(87) Rulkens, R.; Gates, D. P.; Balaishis, D.; Pudelski, J. K.; McIntosh, D. F.; Lough, A. J.; Manners, I. J. Am. Chem. Soc. 1997, 119, 10976.

(88) Foucher, D. A.; Ziembinski, R.; Tang, B. Z.; Macdonald, P. M.; Massey, J.; Jaeger, C. R.; Vancso, G. J.; Manners, I. Macromolecules 1993, $26,2878$.

(89) Zechel, D. L.; Hultzsch, K. C.; Rulkens, R.; Balaishis, D.; Ni, Y. Z.; Pudelski, J. K.; Lough, A. J.; Manners, I. Organometallics 1996, 15, 1972.

(90) Bourke, S. C.; Jakle, F.; Vejzovic, E.; Lam, K. C.; Rheingold, A. L.; Lough, A. J.; Manners, I. Chem.--Eur. J. 2003, 9, 3042.

(91) Braunschweig, H.; Adams, C. J.; Kupfer, T.; Manners, I.; Richardson, R. M.; Whittell, G. R. Angew. Chem., Int. Ed. 2008, 47, 3826.

(92) Buretea, M. A.; Tilley, T. D. Organometallics 1997, 16, 1507.

(93) Nelson, J. M.; Rengel, H.; Manners, I. J. Am. Chem. Soc. 1993, 115, 7035.

(94) Mochida, K.; Shibayama, N.; Goto, M. Chem. Lett. 1998, 339.

(95) Dementev, V. V.; Cervanteslee, F.; Parkanyi, L.; Sharma, H.; Pannell, K. H.; Nguyen, M. T.; Diaz, A. Organometallics 1993, 12, 1983.

(96) Paquet, C.; Cyr, P. W.; Kumacheva, E.; Manners, I. Chem. Mater. 2004, 16, 5205.

(97) Paquet, C.; Cyr, P. W.; Kumacheva, E.; Manners, I. Chem. Commun. 2004, 234. 
(98) Benkeser, R. A.; Goggin, D.; Schroll, G. J. Am. Chem. Soc. 1954, 76, 4025.

(99) Rausch, M.; Vogel, M.; Rosenberg, H. J. Org. Chem. 1957, 22, 900.

(100) Seyferth, D.; Hofmann, H. P.; Helling, J. F.; Burton, R. Inorg. Chem. 1962, 1, 227.

(101) Pellegrini, J. P., Jr.; Spilners, I. J.; Gulf Research and Development Co. . 1967, p $4 \mathrm{pp}$.

(102) Rosenberg, H.; United States Dept. of the Air Force . 1969, p 5 pp.

(103) Dodo, T.; Suzuki, H.; Takiguch.T Bull. Chem. Soc. Jpn. 1970, 43, 288.

(104) Kohler, F. H.; Geike, W. A.; Hertkorn, N. J. Organomet. Chem. 1987, 334, 359.

(105) Kabouche, Z.; Dinh, N. H. J. Organomet. Chem. 1989, 375, 191.

(106) Herberhold, M.; Milius, W.; Steffl, U.; Vitzithum, K.; Wrackmeyer, B.; Herber, R. H.; Fontani, M.; Zanello, P. Eur. J. Inorg. Chem. 1999, 145.

(107) Lenze, N.; Neumann, B.; Salmon, A.; Stammler, A.; Stammler, H. G.; Jutzi, P. J. Organomet. Chem. 2001, 619, 74.

(108) Wu, Y. J.; Ding, L.; Zhou, Z. X.; Du, C. X.; Wang, W. L. J. Organomet. Chem. 1998, 564, 233.

(109) Poehlker, C.; Schellenberg, I.; Poettgen, R.; Dehnen, S. Chem. Commun. 2010, $46,2605$.

(110) Wright, M. E. Organometallics 1990, 9, 853.

(111) Liu, C. M.; Lou, S. J.; Liang, Y. M. Synth. Commun. 1998, 28, 2271.

(112) Guillaneux, D.; Kagan, H. B. J. Org. Chem. 1995, 60, 2502.

(113) Butler, I. R.; Wilkes, S. B.; McDonald, S. J.; Hobson, L. J.; Taralp, A.; Wilde, C. P. Polyhedron 1993, 12, 129.

(114) Zhang, W. B.; Yoneda, Y.; Kida, T.; Nakatsuji, Y.; Ikeda, I. Tetrahedron: Asymmetry 1998, 9, 3371 .

(115) Wright, M. E.; Sigman, M. S. Macromolecules 1992, 25, 6055.

(116) Jakle, F.; Rulkens, R.; Zech, G.; Foucher, D. A.; Lough, A. J.; Manners, I. Chem.-Eur. J. 1998, 4, 2117. $54,57$.

(117) Herberhold, M.; Steffl, U.; Wrackmeyer, B. Z. Naturforsch., B: Chem. Sci. 1999, 
(118) Herberhold, M.; Steffl, U.; Milius, W.; Wrackmeyer, B. J. Organomet. Chem. 1997, 533, 109. 1027.

(119) Herberhold, M.; Steffl, U.; Milius, W.; Wrackmeyer, B. Chem.--Eur. J. 1998, 4,

(120) Herberhold, M.; Steffl, U.; Milius, W.; Wrackmeyer, B. Z. Anorg. Allg. Chem. 1998, $624,386$. 2359.

(121) Berenbaum, A.; Jakle, F.; Lough, A. J.; Manners, I. Organometallics 2002, 21,

(122) Sharma, H. K.; Cervantes-Lee, F.; Mahmoud, J. S.; Pannell, K. H. Organometallics 1999, 18, 399.

(123) Vogel, U.; Lough, A. J.; Manners, I. Angew. Chem., Int. Ed. 2004, 43, 3321.

(124) Kuate, A. C. T.; Daniliuc, C. G.; Jones, P. G.; Tamm, M. Eur. J. Inorg. Chem. 2012, 1727.

(125) Jakle, F.; Rulkens, R.; Zech, G.; Massey, J. A.; Manners, I. J. Am. Chem. Soc. 2000, 122, 4231.

(126) Baumgartner, T.; Jakle, F.; Rulkens, R.; Zech, G.; Lough, A. J.; Manners, I. J. Am. Chem. Soc. 2002, 124, 10062.

(127) Bagh, B.; Breit, N. C.; Dey, S.; Gilroy, J. B.; Schatte, G.; Harms, K.; Mueller, J. Chem.--Eur. J. 2012, 18, 9722.

(128) Petersen, R.; Foucher, D. A.; Tang, B. Z.; Lough, A.; Raju, N. P.; Greedan, J. E.; Manners, I. Chem. Mater. 1995, 7, 2045.

(129) Bagh, B.; Breit, N. C.; Harms, K.; Schatte, G.; Burgess, I. J.; Braunschweig, H.; Mueller, J. Inorg. Chem. 2012, 51, 11155.

(130) Chan, W. Y.; Lough, A. J.; Manners, I. Angew. Chem., Int. Ed. 2007, 46, 9069.

(131) Bera, H.; Braunschweig, H.; Oechsner, A.; Seeler, F.; Sigritz, R. J. Organomet. Chem. 2010, 695, 2609.

(132) Sato, M.; Anano, H. J. Organomet. Chem. 1998, 555, 167.

(133) Dong, T. Y.; Hwang, M. Y.; Wen, Y. S.; Hwang, W. S. J. Organomet. Chem. 1990, 391, 377 .

(134) Tarraga, A.; Oton, F.; Espinosa, A.; Velasco, M. D.; Molina, P.; Evans, D. J. Chem. Commun. 2004, 458. 
(135) Oton, F.; Espinosa, A.; Tarraga, A.; de Arellano, C. R.; Molina, P. Chem.--Eur. J. 2007, 13, 5742 .

(136) Robin, M. B.; Day, P. Advan. Inorg. Chem. Radiochem. 1967, 10, 247.

(137) Gao, H.; Wei, X.; Liu, X.; Yan, T. J. Phys. Chem. B 2010, 114, 4056.

(138) Cody, R. B.; Laramee, J. A.; Durst, H. D. Anal. Chem. 2005, 77, 2297.

(139) Rausch, M. D.; Ciappene.Dj J. Organomet. Chem. 1967, 10, 127. 